\title{
Decolonizing Trauma Studies: Trauma and Postcolonialism
}

\author{
Edited by
}

Sonya Andermahr

Printed Edition of the Special Issue Published in Humanities 
Sonya Andermahr (Ed.)

\section{Decolonizing Trauma Studies: \\ Trauma and Postcolonialism}


This book is a reprint of the Special Issue that appeared in the online, open access journal, Humanities (ISSN 2076-0787) from 2015 - 2016 (available at:

http://www.mdpi.com/journal/humanities/special_issues/TraumaPostcolonialism).

\section{Guest Editor}

Sonya Andermahr

University of Northampton

UK

Editorial Office

MDPI AG

Klybeckstrasse 64

Basel, Switzerland

\section{Publisher}

Shu-Kun Lin

Managing Editor

Jie $\mathrm{Gu}$

\section{Edition 2016}

MDPI • Basel $\bullet$ Beijing $・$ Wuhan $・$ Barcelona

ISBN 978-3-03842-195-5 (Hbk)

ISBN 978-3-03842-196-2 (PDF)

(C) 2016 by the authors; licensee MDPI, Basel, Switzerland. All articles in this volume are Open Access distributed under the Creative Commons Attribution license (CC BY), which allows users to download, copy and build upon published articles even for commercial purposes, as long as the author and publisher are properly credited, which ensures maximum dissemination and a wider impact of our publications. However, the dissemination and distribution of physical copies of this book as a whole is restricted to MDPI, Basel, Switzerland. 


\section{Table of Contents}

List of Contributors V

About the Guest Editor. VII

\section{Sonya Andermahr}

"Decolonizing Trauma Studies: Trauma and Postcolonialism"-Introduction

Reprinted from: Humanities 2015, 4(4), 500-505

http://www.mdpi.com/2076-0787/4/4/500 1

\section{Irene Visser}

Decolonizing Trauma Theory: Retrospect and Prospects

Reprinted from: Humanities 2015, 4(2), 250-265

http://www.mdpi.com/2076-0787/4/2/250

\section{Hamish Dalley}

The Question of "Solidarity" in Postcolonial Trauma Fiction: Beyond the

Recognition Principle

Reprinted from: Humanities 2015, 4(3), 369-392

http://www.mdpi.com/2076-0787/4/3/369

\section{Beatriz Pérez Zapata}

Decolonizing Trauma: A Study of Multidirectional Memory in Zadie Smith's “The Embassy of Cambodia"

Reprinted from: Humanities 2015, 4(4), 523-534

http://www.mdpi.com/2076-0787/4/4/523

\section{Silvia Pellicer-Ortín}

A Journey across Multidirectional Connections: Linda Grant's The Cast Iron Shore

Reprinted from: Humanities 2015, 4(4), 535-553

http://www.mdpi.com/2076-0787/4/4/535

\section{Justine Seran}

Australian Aboriginal Memoir and Memory: A Stolen Generations Trauma Narrative

Reprinted from: Humanities 2015, 4(4), 661-675

http://www.mdpi.com/2076-0787/4/4/661 


\section{Dolores Herrero}

Oranges and Sunshine: The Story of a Traumatic Encounter

Reprinted from: Humanities 2015, 4(4), 714-725

http://www.mdpi.com/2076-0787/4/4/714 .96

\section{Jocelyn Martin}

Manilaner's Holocaust Meets Manileños' Colonisation: Cross-Traumatic Affiliations and Postcolonial Considerations in Trauma Studies

Reprinted from: Humanities 2015, 4(4), 818-833

http://www.mdpi.com/2076-0787/4/4/818 108

\section{Silvia Martínez-Falquina}

Postcolonial Trauma Theory in the Contact Zone: The Strategic Representation of Grief in Edwidge Danticat's Claire of the Sea Light

Reprinted from: Humanities 2015, 4(4), 834-860

http://www.mdpi.com/2076-0787/4/4/834

\section{Dovile Budryte}

Decolonization of Trauma and Memory Politics: Insights from Eastern Europe

Reprinted from: Humanities 2016, 5(1), 7

http://www.mdpi.com/2076-0787/5/1/7

\section{Natalie Clark}

Shock and Awe: Trauma as the New Colonial Frontier

Reprinted from: Humanities 2016, 5(1), 14

http://www.mdpi.com/2076-0787/5/1/14

\section{Stef Craps, Bryan Cheyette, Alan Gibbs, Sonya Andermahr and Larissa Allwork}

Decolonizing Trauma Studies Round-Table Discussion

Reprinted from: Humanities 2015, 4(4), 905-923

http://www.mdpi.com/2076-0787/4/4/905 


\section{List of Contributors}

Larissa Allwork: School of History, University of Leicester, University Road, Leicester, LE1 7RH, UK.

Sonya Andermahr: School of the Arts, University of Northampton, NN2 6JD, UK; English Division, The School of The Arts, The University of Northampton, Avenue Campus, St. George's Avenue, Northampton NN2 6JD, UK.

Dovile Budryte: School of Liberal Arts, Georgia Gwinnett College, 1000 University Center Lane, Lawrenceville, GA 30043, USA.

Bryan Cheyette: Department of English Literature, University of Reading, Whiteknights, Reading RG6 6AA, UK.

Natalie Clark: School of Social Work, 2080 West Mall, The University of British Columbia, Vancouver, BC V6T 1T2, Canada.

Stef Craps: Department of Literary Studies, Ghent University, Blandijnberg 2, 9000 Gent, Belgium.

Hamish Dalley: Department of English, Daemen College, 4380 Main Street, Amherst, NY 14226, USA.

Alan Gibbs: School of English, O'Rahilly Building, University College Cork, Cork, Ireland.

Dolores Herrero: Department of English and German Philology, Faculty of Arts, University of Zaragoza, Campus Universitario, 50009 Zaragoza, Spain.

Jocelyn Martin: Department of English, School of Humanities, Ateneo de Manila University, Katipunan Avenue, Loyola Heights, 1108 Quezon City, Philippines.

Silvia Martínez-Falquina: Departamento de Filología Inglesa y Alemana, Facultad de Filosofía y Letras, University of Zaragoza, Calle Pedro Cerbuna 12, 50009 Zaragoza, Spain.

Silvia Pellicer-Ortín: Department of English and German Philology, University of Zaragoza, Calle Pedro Cerbuna, 12. 50009 Zaragoza, Spain.

Justine Seran: English Literature Department, The University of Edinburgh, 50 George Square, Edinburgh EH8 9JU, UK.

Irene Visser: Department of English Language and Culture, Faculty of Arts, University of Groningen, Oude Kijk in 't Jatstraat 26, 9712 EK Groningen, The Netherlands.

Beatriz Pérez Zapata: Department of English and German Philology, University of Zaragoza, Calle Pedro Cerbuna 12, 50012 Zaragoza, Spain. 



\section{About the Guest Editor}

Sonya Andermahr is Reader in English at the University of Northampton, U.K. She has written widely on contemporary women's writing in Britain and the United States. Her publications include Jeanette Winterson (Palgrave 2009), Trauma Narratives and Herstory (with Silvia Pellicer-Ortín; Palgrave Macmillan, 2013), Angela Carter: New Critical Readings (with Lawrence Phillips; Continuum, 2012), and A Glossary of Feminist Theory (with Terry Lovell and Carol Wolkowitz; Edward Arnold, 2000). She is currently completing a book on narratives of maternal loss in contemporary women's writing and guest editing a special issue on Brigid Brophy for Contemporary Women's Writing. 



\title{
"Decolonizing Trauma Studies: Trauma and Postcolonialism"-Introduction
}

\author{
Sonya Andermahr
}

Reprinted from Humanities. Cite as: Andermahr, S. "Decolonizing Trauma Studies: Trauma and Postcolonialism"--Introduction. Humanities 2015, 4, 500-505.

This Special Issue aims to explore the complex and contested relationship between trauma studies and postcolonial criticism, focusing on the ongoing project to create a decolonized trauma theory that attends to and accounts for the suffering of minority groups and non-Western cultures, broadly defined as cultures beyond Western Europe and North America. The issue builds on the insights of, inter alia, Stef Craps's book, Postcolonial Witnessing [1], and responds to his challenge to interrogate and move beyond a Eurocentric trauma paradigm. Authors were invited to submit papers on the theorization and representation of any aspect of postcolonial, non-Western and/or minority cultural trauma with a focus predominately, but not exclusively, on literature.

The field of trauma studies emerged in the early 1990s as an attempt to construct an ethical response to forms of human suffering and their cultural and artistic representation. Born out of the confluence between deconstructive and psychoanalytic criticism and the study of Holocaust literature, from its outset trauma theory's mission was to bear witness to traumatic histories in such a way as to attend to the suffering of the other. Indeed, in a famous formulation, Caruth went so far as to suggest that 'trauma itself may provide the very link between cultures' ([2], p. 11). Yet, while trauma theory has undoubtedly yielded numerous insights into the relationship between psychic suffering and cultural representation, postcolonial critics have been arguing for some time that trauma theory has not fulfilled its promise of cross-cultural ethical engagement. Rather than forging relationships of empathy and solidarity with non-Western others, a narrowly Western canon of trauma literature has in effect emerged, one which privileges the suffering of white Europeans, and neglects the specificity of non-Western and minority cultural traumas. In 2003, for example, Jill Bennett and Roseanne Kennedy called for a transformation of trauma studies from a Eurocentric discipline to one capable of engaging with 'the multicultural and diasporic nature of contemporary culture' ([3], p. 5), and in 2008 a number of influential critiques by Gert Beulens and Stef Craps [4], Michael Rothberg [5], and Roger Luckhurst [6] added to the voices calling for a radical re-routing of the field.

A decade on from Bennett and Kennedy's path-breaking work, Stef Craps's Postcolonial Witnessing sums up the postcolonial case against trauma theory. The book mounts a summative critique of the Eurocentric bias of trauma theory and sets out the challenges to be met in constructing a thoroughly decolonized trauma studies. Craps argues forcibly that despite its laudable ethical origins, which sought to foster cross-cultural solidarity, trauma theory has largely failed to recognise the sufferings of non-Western others. For him the founding texts of trauma theory fail on at least four counts: 
they marginalise or ignore traumatic experiences of non-Western or minority cultures, they tend to take for granted the universal validity of definitions of trauma and recovery that have developed out of the history of Western modernity, they often favour or even prescribe a modernist aesthetic of fragmentation and aporia as uniquely suited to the task of bearing witness to trauma, and they generally disregard the connections between metropolitan and non-Western or minority traumas. ([1], p. 2).

One of the major stumbling blocks to a truly globalized discipline, according to Craps, is the fact that trauma theory "continues to adhere to the traditional event-based model of trauma, according to which trauma results from a single, extraordinary, catastrophic event" ([1], p. 31). In numerous accounts, trauma is defined as "a frightening event outside of ordinary experience" ([7], p. 172) but, as Craps argues, this paradigmatic model of trauma does not necessarily work for non-Western and/or minority group trauma (nor even for groups and individuals within Western societies). In particular, the experience of racism does not fit either of the "classical" forms of trauma: "Unlike structural trauma, racism is historically specific; yet, unlike historical trauma, it is not related to a particular event, with a before and an after. Understanding racism as a historical trauma, which can be worked through, would be to obscure the fact that it continues to cause damage in the present" ([1], p. 32). Therefore, racially based forms of trauma historically rooted in the global systems of slavery and colonialism pose a significant challenge to the Eurocentric model of trauma as a single overwhelming event.

Drawing on the pioneering work of Frantz Fanon, and more recent theories of "insidious trauma" [8] and "postcolonial syndrome" [9] among others, Craps develops a supplementary model of trauma, which addresses the normative, quotidian, and persistent nature of racialized trauma. If the ethical aspirations of the field are to be realized, he concludes, there is an urgent need to decolonize trauma studies by recognizing the globalized contexts of traumatic events, the specific forms traumatic suffering takes, and the myriad ways in which it is represented in literary works. Eschewing neither psychoanalysis nor deconstruction, this model seeks to "take account of the specific social and historical contexts in which trauma narratives are produced and received, and be open and attentive to the diverse strategies of representation and resistance that these contexts invite or necessitate" ([1], p. 5). Such a decolonized trauma theory would, firstly, redress the marginalization of non-Western and minority traumas; secondly, it would challenge the supposed universal validity of Western definitions of trauma; thirdly, provide alternatives to dominant trauma aesthetics; and lastly, address the underexplored relationship between so-called First and Third World traumas.

Work in comparative literature and memory studies has contributed significantly to the process of decolonizing trauma theory, particularly in this last respect. For example, the work of Michael Rothberg on 'multidirectional memory' provides an indispensable conceptual model for this kind of cross-cultural analysis. In his essay, "From Gaza to Warsaw", Rothberg asks the salient question: "What happens when different histories of extreme violence confront each other in the public sphere?' ([10], p. 523). His work is concerned with challenging the hierarchical and/or exclusivist approach to chronicling collective traumas - "either mine or yours"- and he is at pains to point out how, "Collective memories of seemingly distinct histories — such as those of slavery, 
the Holocaust, and colonialism - are not so easily separable.” ([10], p. 524). In his earlier book, Multidirectional Memory, Rothberg developed the concept at length:

Against the framework that understands collective memory as competitive memory - as a zero-sum struggle over scarce resources-I suggest that we consider memory as multidirectional: as subject to ongoing negotiation, cross-referencing, and borrowing; as productive and not private. [...] This interaction of different historical memories illustrates the productive, intercultural dynamic that I call multidirectional memory ([11], p. 3).

In particular, he suggests the usefulness of the term for thinking about how minority subjects in the present come to terms with and think about their and our collective histories. In recent years, moreover, there have been a number of publications such as The Future of Trauma Theory [12] and Contemporary Approaches in Literary Trauma Theory [13] which seek to move beyond the dominant Eurocentric model of trauma theory, to explore the underexplored link between trauma and postcolonialism, and to suggest new avenues of research.

This Special Issue aims to contribute to such a reshaping of the field. Its authors responded to the challenge to rethink trauma studies from a postcolonial and globalized perspective with gusto and ambition. They represent an international field of scholars working on a wide range of writers and artists from numerous postcolonial contexts. Of particular note is Irene Visser's essay "Decolonizing Trauma Theory: Retrospects and Prospects", which develops her work on the ongoing dialogue between trauma theory and postcolonialism, and sets out what she sees as the achievements and continuing challenges of the decolonizing project. In her view, an interrogation of Western secular modes of thought and a greater openness towards non-Western belief systems and indigenous healing rituals is required if trauma theory is to achieve its goal of inclusiveness. Dolores Herrero, another critic who has advocated a more socially nuanced and culturally-specific approach to trauma, also contributes to this Special Issue in an essay exploring the trauma of the 'Stolen Generations' through its representation in Jim Loach's film Oranges and Sunshine (2010).

In addition to the individual essays, this Special Issue includes the transcript of a round-table discussion that took place at the "Decolonizing Trauma Studies" Symposium held at the University of Northampton on 15 May 2015, which featured contributions from the Symposium's three Keynote speakers: Professor Stef Craps from the University of Ghent), Professor Bryan Cheyette (University of Reading), and Dr Alan Gibbs (University College Cork) [14]. The speakers were asked to address five key questions facing contemporary trauma studies: (1) does trauma studies suffer from psychological universalism and what is the relationship between individual and collective traumas when we are discussing non-Western and minority cultural groups? (2) Are there signs that trauma studies is becoming less Eurocentric? (3) What are the implications and challenges of a decolonized trauma theory for our understanding of our own disciplines and their relations to others? (4) What are the implications for pedagogy particularly thinking around the ethics of detachment and identification? (5) How do you see the field of trauma studies developing in the future? 
In his contribution to the discussion, Alan Gibbs spoke engagingly about the increasingly compelling challenges, coming from a variety of voices, to the dominant model of trauma as it is encoded in the American Psychological Association's definition of PTSD [15]. Gibbs underlined the point that not only is this model problematic in a postcolonial context but that it frequently fails to account for the range of traumas experienced by Western subjects within Western societies themselves. As he argues in his book Contemporary American Trauma Narratives, the dominant trauma paradigm does not even adequately reflect or explain contemporary American contexts [16]. However, Gibbs is optimistic that the field of trauma studies is showing signs of moving in a new direction; in particular, he identifies a greater awareness of 'the variety of manifestations of trauma' and a greater "sensitivity to localized variations in causes and symptomatology and treatment and the representation of trauma" [17]. In addressing the issue of the relationship between so-called Western and non-Western cultural traumas, Bryan Cheyette challenges the long-standing binary opposition between "the West and Rest". He calls into question the oft-made assumption that the Holocaust is an exclusively European cultural trauma and argues, like Rothberg, for a more complex examination of the overlapping histories of anti-semitism and colonialism, including an exploration of the colonial precedents for the genocidal practices associated with the Holocaust. Cheyette also argued for the decolonization not just of trauma theory, but of all disciplinary subjects and all forms of cultural enquiry including postcolonial studies itself.

In answering the central question about future directions of field, Stef Craps made the point that while work to date has done much to challenge the "inappropriateness and the injustice of applying western frameworks to a colonial or postcolonial situation" [18], scholars have been less concerned with producing a concrete alternative. For him, more work needs to be done on the practical development of alternatives to the dominant trauma discourse. As he comments, this requires "specialized knowledge of other cultures and languages, of the different media and forms of expression they use, and of local beliefs about suffering and healing" [18]. His view is echoed by the editors of another recent study of postcolonial trauma fiction, who argue that theory needs to be enriched by a knowledge of social context, combining "the psychological and the cultural, in an interdisciplinary approach that draws on psychoanalysis, sociology, philosophy, and history in the study of the aesthetic representation of trauma" ([19], p. xiv). In other words, while trauma theory has undergone a transformation in the light of postcolonial critique, the challenge now is to apply these insights in our practice. This might in turn necessitate a shift in power from the (Western) metropolitan centers of academe to more localized sites of knowledge. The fact that this Special Issue includes contributors from non-Western locales is a sign that this work is at least underway. In his concluding remarks to the round-table discussion, Professor Craps refers to Michael Rothberg's acknowledgement, in the preface to The Future of Trauma Theory, that trauma is not always the only or best lens for exploring complex global problems, let alone solving them. Therefore, while we undoubtedly need to "pluralize" and reconceptualise trauma theory, we also have to "recognise the limits of its applicability" [20]. With that caveat in mind, I am hopeful that this Special Issue demonstrates that the theoretical tools developed by trauma studies are capable of expanding our knowledge and understanding of the representation of individual and collective 
suffering of subjects experiencing heterogeneous kinds of trauma in a variety of post-colonial, nonWestern and/or minority cultural contexts.

\section{Conflicts of Interest}

The author declares no conflict of interest.

\section{References and Notes}

1. Stef Craps. Postcolonial Witnessing: Trauma Out of Bounds. Basingstoke: Palgrave Macmillan, 2013.

2. Cathy Caruth. "Trauma and Experience: Introduction." In Trauma: Explorations in Memory. Edited by Cathy Caruth. Baltimore and London: Johns Hopkins University Press, 1995.

3. Jill Bennet, and Rosanne Kennedy. "Introduction." In World Memory: Personal Trajectories in Global Time. Edited by Jill Bennet and Rosanne Kennedy. New York and London: Palgrave Macmillan, 2003, p.5.

4. Stef Craps, and Gert Buelens. "Introduction: Postcolonial Trauma Novels." Studies in the Novel 40 (2008): 1-12.

5. Michael Rothberg. "Decolonizing Trauma Studies: A Response." Studies in the Novel 40 (2008): 224-34.

6. Roger Luckhurst. The Trauma Question. London: Routledge, 2008.

7. Bessel van der Kolk, and Onno van der Hart. "The Intrusive Past: The Flexibility of Memory and the Engraving of Trauma." In Trauma: Explorations in Memory. Edited by Cathy Caruth. Baltimore: Johns Hopkins, 1995.

8. Maria P. P. Root. "Reconstructing the Impact of Trauma on Personality." In Personality and Psychopathology: Feminist Reappraisals. Edited by Laura S. Brown and Mary Ballou. New York: Guilford, 1992.

9. Eduardo Duran, Bonnie Duran, Maria Yellow Horse Brave Heart, and Susan Yellow Horse Davis. "Healing the American Indian Soul Wound." In International Handbook of Multigenerational Legacies of Trauma. Edited by Danielli Yael. New York: Plenum, 1998, pp. 341-54.

10. Michael Rothberg. "From Gaza to Warsaw: Mapping multidirectional memory." Criticism 53 (2011): 523-48.

11. Michael Rothberg. Multidirectional Memory: Remembering the Holocaust in the Age of Decolonization. Stanford: Stanford University Press, 2009.

12. Gert Buelens, Samuel Durrant, and Robert Eaglestone, eds. The Future of Trauma Theory: Contemporary Literature and Cultural Criticism. London: Routledge, 2013.

13. Michelle Balaev, ed. Contemporary Approaches in Literary Trauma Theory. Basingstoke: Palgrave Macmillan, 2014.

14. The "Decolonizing Trauma Studies" Symposium was co-organised by myself and Dr Larissa Allwork and funded by the University of Northampton's School of the Arts Research and Enterprise Fund. 
15. American Psychiatric Association. Diagnostic and Statistic Manual, 4th rev. ed. Washington: APA, 2000.

16. Alan Gibbs. Contemporary American Trauma Narratives. Edinburgh: Edinburgh University Press, 2014.

17. Alan Gibbs. "Decolonizing Trauma Studies Round-Table Discussion." Unpublished manuscript, last modified 18 September 2015. Microsoft Word file.

18. Stef Craps. "Decolonizing Trauma Studies Round Table Discussion." Unpublished manuscript, last modified 18 September 2015. Microsoft Word file.

19. Dolores Herrero, and Sonia Baelo-Allué, eds. "Introduction." In The Splintered Glass: Facets of Trauma in the Post-Colony and Beyond. Amsterdam and New York: Rodopi, 2011, pp. ix-xxvi.

20. Michael Rothberg. "Introduction." In The Future of Trauma Theory: Contemporary Literature and Cultural Criticism. Edited by Gert Beulens, Samuel Durrant and Robert Eaglestone. London: Routledge, 2013, pp. xi-xviii. 


\section{Decolonizing Trauma Theory: Retrospect and Prospects}

\section{Irene Visser}

Abstract: Decolonizing trauma theory has been a major project in postcolonial literary scholarship ever since its first sustained engagements with trauma theory. Since then, trauma theory and postcolonial literary studies have been uneasy bedfellows, and the time has now come to take stock of what remains in postcolonial trauma studies from the original formulations of trauma theory, and see which further steps must be envisaged in order to reach the ideal of a truly decolonized trauma theory today. To this end, this article presents a detailed overview of the short history and the present situation of the trajectory of decolonizing trauma theory for postcolonial studies, clarifying the various re-routings that have so far taken place, and delineating the present state of the project, as well as the need for further developments towards an increased expansion and inclusiveness of the theory. I argue that openness to non-Western belief systems and their rituals and ceremonies in the engagement with trauma is needed in order to achieve the remaining major objectives of the long-standing project of decolonizing trauma theory.

Reprinted from Humanities. Cite as: Visser, I. Decolonizing Trauma Theory: Retrospect and Prospects. Humanities 2015, 4, 250-265.

\section{Introduction}

The call for a decolonized trauma theory may be dated quite precisely to the publication of the special issue of Studies in the Novel (Vol. 40, nrs.1 and 2) of Spring/Summer 2008, whose topic, as presented by editors Buelens and Craps, was the rapprochement between trauma theory and postcolonial literary studies [1]. Before that date, trauma theory as conceptualized in the 1990s by Cathy Caruth, Geoffrey Hartman, Shoshana Felman, and Dori Laub had already garnered much negative critique due to the theory's many controversies, contradictions, and limitations. Roger Luckhurst's The Trauma Question, also published in 2008, presented an overview of the theory's inherent inconsistencies and contradictions, concluding that it had serious limitations for literary studies [2]. While Luckhurst does not focus on the usefulness of trauma theory for postcolonial studies, a major point raised in his book concerns the theory's blind spot to politics, which Luckhurst calls "its shocking failure" to "address atrocity, genocide and war" ([2], p. 213). The depoliticizing and dehistoricizing tendencies of the dominant trauma theory were also deemed major obstacles by most of the contributors of Studies in the Novel (StiN) to the rapprochement that was envisaged by the issue's guest editors Gert Buelens and Stef Craps. In fact, while the editors emphasized possibilities, the contributors saw major obstacles to a fully postcolonial trauma theory, and opened up many pressing questions about the complex relationship between trauma theory and postcolonial literary studies. These were summarized by Michael Rothberg in a detailed and insightful response essay published in the same issue of StiN [3]. Although feeling that the investigative theme of StiN was timely and that it accomplished "much necessary and overdue work", Rothberg's essay concludes that the publication's contributors seriously question whether 
trauma theory as currently conceptualized "provides the best framework for thinking about the legacies of violence in the colonized/postcolonial world" ([3], p. 226). As the contributors argue convincingly, Rothberg concludes that "turn-of-the-millennium trauma studies has remained stuck within Euro-American conceptual and historical frameworks" ([3], p. 225); thus, if we wish to find ways forward, we shall have to turn away from the original formulations of literary trauma theory and develop the tools needed "in the simultaneously intellectual, ethical, and political task of standing against ongoing forms of racial and colonial violence" ([3], p. 232). This, then, delineates the project that Rothberg, in 2008, correctly predicted as necessary and urgent for the time to come, a project which he felt should be named "decolonizing trauma studies" ([3], p. 226).

In retrospect, Rothberg's response essay marks a clear start to the present ongoing discussion about the decolonization of trauma theory for postcolonial cultural and literary studies. The many and pluriform contributions that have added to the discussion since 2008 often address and repeat Rothberg's central arguments, building on the groundwork that his article provides, and thus demonstrate that Rothberg's main considerations have remained astute and relevant. For example, in a special issue of the Journal of Postcolonial Writing (2009), devoted to tracing new directions in postcolonial studies, editors and contributors emphasize the importance of a continued postcolonial critique of historical and political processes as the original sites of trauma for postcolonial communities, as opposed to trends in trauma studies that neglect or elide such processes [4]. In a recent special issue of Postcolonial Text, titled "Situating Postcolonial Trauma Studies" (2014), guest editor Norman Saadi Nikro discusses the complexity of the relationship between Holocaust-centered trauma studies and present-day postcolonial trauma studies, referring explicitly to Rothberg's essay of 2008 and pointing out that Rothberg's concerns have remained important issues in postcolonial scholarship to the present time. Other major publications, too, have returned to Rothberg's concerns, explicitly or implicitly affirming their relevance for present theorization of trauma, and highlighting the ongoing need to decolonize trauma theory for postcolonial literary studies [5-8].

Rothberg's foundational essay, then, is the starting point for my overview of the development in theoretical and critical thinking about the decolonization of postcolonial trauma theory from 2008 to the present. Outlining the changes that have been effectuated already, I delineate and clarify the present situation of the decolonizing project. My retrospective overview opens with the points that Rothberg highlighted as urgent: trauma theory's Eurocentric, event-based conception of trauma; its too-narrow focus on Freudian psychoanalysis; and its deconstructionist approach that closes off other approaches to literary trauma. Discarding or reconfiguring these elements have been crucial steps in the decolonizing project that started in 2008; however, as I will argue, there are further steps to be taken in order to fully accomplish the ideal of a decolonized trauma theory.

\section{Decolonizing Trauma Theory: Initial Steps}

Rothberg established in 2008 that the Eurocentric foundation of trauma theory as originally conceptualized by Cathy Caruth et al., was untenable in postcolonial theory and that it needed a redirection, stating that as long as trauma theory remains "tied to a narrow Eurocentric framework, it distorts the histories it addresses (such as the Holocaust) and threatens to reproduce the very 
Eurocentrism that lies behind those histories" ([3], p. 227). Moreover, as Rothberg observes, the theory's narrow focus casts doubt on Caruth's much-quoted notion that trauma may itself provide the link between cultures ([3], p. 227). Part of the original theory's Eurocentrism is its exclusive focus on the event-based model of trauma, which does not account for the sustained and long processes of the trauma of colonialism. Unlike postcolonial trauma studies, for instance, Holocaust trauma studies engage with a more clearly definable period of history, and a clearer historical sense of victims, perpetrators, and responsibility. Early trauma theory, in Rothberg's words, presupposes "the completed past of a singular event - while colonial and postcolonial traumas persist into the present" ([3], p. 230). Rothberg here refers to early trauma theory's use of the first definition of trauma in the Diagnostic and Statistical Manual of Mental Disorders (DSM-III) of the American Psychiatric Association, which accorded trauma official recognition, and which defined trauma as a serious injury or a threat to the physical integrity of the self in the form of an overwhelming, sudden, and unassimilable experience [9]. The metaphor of trauma often used in trauma theory is that of a sudden, sharp piercing of a membrane, as, for instance, by a sharp object implanted in the psyche, where it remains in its original form, hidden behind the screen of consciousness, but making itself known through a serious of symptoms. The "sudden" or unexpected aspect of trauma is not the prolonged, cumulative hurt of long years of repression that constitutes the trauma of colonialism, with its repeated and cumulative stressor events. Later editions of the DSM (DSM-IV and DSM-IV-Text Revision of 2000; and DSM-V of 2013) have made the definition more inclusive, allowing trauma to occur along a continuum of responses and broadening it to include vicarious trauma, such as that incurred by witnesses or other recipients of traumatic events, as well as removing the emphasis on individual traumatization. However, in cultural trauma theory as developed by Caruth et al., in the early 1990s, the DSM-III was still the norm, and it is to this norm, which resulted in a Eurocentric, event-based, individualistic orientation, that contributors to StiN articulated their resistance. As Rothberg notes, despite the fact that the contributors' critical focus stays appropriately on Caruth's theory of trauma "in its psychoanalytic mode", the implications of their critique are "far-reaching" in calling for the need for a redirection of the theory ([3], p. 226). This redirection would constitute a first, significant step ahead in the project of decolonizing trauma, intended to achieve a more thorough, global, and responsible paradigm. The histories of trauma of the Holocaust, slavery, and colonialism, re-enacted through narrative, must not be considered as contesting for primacy, but rather as non-contesting and co-existing, from a recognition that collectively held traumatic memories resonate profoundly. Rothberg's suggestion is to rethink trauma as "collective, spatial, and material (instead of individual, temporal, and linguistic)", which would break "the hold of the category of trauma as it had been developed by Caruth, Felman, Laub, and others" ([3], p. 228).

Following Rothberg's article of 2008, there has been a widespread recognition among postcolonial scholars of the need for a new model for understanding and interpreting trauma to enable more differentiated and more culturally and historically specific notions. For instance, Craps, in his critique of what he terms "Caruthian theory", argues that if trauma studies are to "have any hope of redeeming its promise of ethical effectiveness", the social and historic relations must be taken into account, and that traumatic histories of subordinate groups should be situated 
against the histories of socially dominant groups ([10], p. 53). At this moment of the history of the project of decolonizing trauma, we may conclude that a consensus among scholars has been reached and that this argument need no longer be made: much postcolonial scholarship has situated trauma in specific historic and societal perspectives in a broad range of national literatures in postcolonial literary studies, and the Eurocentric, event-based model of original trauma theory has now, in 2015, been discarded.

This necessary advance in postcolonial trauma studies has made the theory more comprehensive, and at the same time has also allowed more cultural specificity than Caruth's trauma theory envisaged. By the same token, this rerouting of trauma theory has also opened up movements away from the restrictions of the Freudian foundation of classic trauma theory. This part of decolonizing trauma theory has indeed been a far-reaching reconfiguration of the original theory, which was from the start firmly grounded in Freudian psychoanalysis and poststructuralist deconstruction. Although Rothberg notes that many of the contributors to StiN concur with the "withering critique" that Caruth's Freudian approach had received from various influential critics ([3], pp. 230-31), at the same time, it was incontestably the hegemonic theory's foundation, and it has taken quite some time for postcolonial literary scholarship to reconsider alternatives for this foundation in Freudian psychoanalysis.

To understand the difficulty of the removal of Freudian psychoanalysis from the engagement with postcolonial trauma, we need to point out that a defining part of the strong influence of Caruth's landmark publication Unclaimed Experience (1996) is its promise of a renewed engagement with history, or, as she puts it, to "rethink the possibility of history" ([11], p. 12). Caruth's suggestion, although vaguely worded, is that in the encounter with trauma, history is to be regarded as no longer "straightforwardly referential", that is, no longer based on "simple models of experience and reference" ([11], p. 11). Contrary to what this seems to mean at first glance, Caruth does not envisage a new orientation towards politics in real-life and/or historic contexts, but instead a turning away from such engagement in favor of Freud's notion of the indirect referentiality of history, as expressed particularly in his account of the Jews' collective racial memory of guilt and traumatic secrets in his Moses and Monotheism of 1939; Caruth's much-debated claim was that Freud's thinking could "help us understand our own catastrophic era" ([11], p. 12). While this chapter of Caruth's Unclaimed Experience has been widely quoted, it has also elicited increasingly negative reactions. Luckhurst, for instance, denies the value of Moses and Monotheism for present-day theorization, stating that "largely ungrounded speculations such as this on prehistory were typical of Victorian anthropology" ([2], p. 10); Ruth Leys also forcefully refutes Caruth's readings ([12], p. 282). For a decolonized trauma theory, I would argue it is necessary to discard Caruth's emphasis on a new perspective on history when this is predicated on the dissolution of historical factuality. For instance, the trauma of Māori history as the aftermath of colonialism as depicted in literature by Māori authors such as Witi Ihimaera, Apirana Taylor, and Patricia Grace is not the anti-historical, phylogenetic, and mythic trauma of Freudian theory, but the trauma of concrete historical factuality: of dispossession, of land loss, and of instances of racial discrimination. 


\section{Re-Viewing Melancholia}

Like the contributors of StiN, other theorists and scholars have also distanced themselves from Caruth's Freudian, transgenerational, and psycho-historical model of trauma. A central point of critique, for example, that which is expressed by Dominick LaCapra against Caruth's Freudian theoretical framework, is directed at the notion that melancholia and fragility are defining and unalterable characteristics of the post-traumatic stage, and lead to the lasting effect of weakened communal and individual identities ([13], pp. xi-xiii). LaCapra instead poses "acting out" and "working through" as two interconnected, non-binary modes of coming to terms with traumatic experiences, in which melancholia may be regarded as a form of "acting out", whereas the Freudian concept of "working through" is to be considered "an articulatory practice" that enables the traumatized subject to recall memories of "something that happened to one (or one's people) back then while realizing that one is living here and now with openings to the future" ([13], p. 22). In Caruth's Freudian outlook, as Luckhurst observes, the emphasis is on the affirmation of the crippling effects of trauma; memory is situated "entirely under the sign of post-traumatic melancholia", and "there is a kind of injunction to maintain the post-traumatic condition" ([2], p. 210). For postcolonial literary studies, the implications of this "injunction" are problematic if the aftermath of colonial trauma is by definition expressed only in terms of weakness, victimization, and melancholia, by which themes of social activism, recuperation, and psychic resilience are obscured. Eli Park Sorenson, in his book Postcolonial Studies and the Literary (2010), while positively evaluating Caruth's trauma theory as a "narrative turn" in postcolonial studies, nevertheless also finds the theory inadequate due to its emphasis on melancholia, which results in a crippling self-reflexivity [14]. For a decolonized trauma theory, then, the intersection between postcolonial theory and dominant trauma theory has needed to be reconceived to theorize not only melancholia, weakness, and stasis but also the completely opposite dynamics of life-affirming and activist processes. In his book Postcolonial Witnessing: Trauma Out of Bounds (2012), Craps underscores the notion often expressed after 2008 in postcolonial studies: that literary trauma criticism is still too overly reliant on Caruth's work of the mid-1990s, and again asserts that its hegemony should be overturned [8]. Referring to what Luckhurst terms "the injunction to maintain weakness and melancholia", Craps posits instead the critical commitment in postcolonial studies "to make visible the creative and political" rather than the "pathological and negative" in trauma literature ([8], p. 127). Since 2008, when the contributors to StiN first found that postcolonial trauma fiction assigns meaning to themes of recuperation, redress, and resilience, many other scholars have expressed similar views. We can justifiably conclude that today, in 2015 , it is generally agreed that the postcolonial interrogation of the legacy of Western colonialism cannot maintain the "injunction" to regard malaise and melancholia, with their connotations of submissiveness and inaction, as the inevitable outcome of traumatization. Removing this injunction has been accomplished as a clear and necessary step in the project of decolonizing trauma theory.

What remains undisputed, I wish to stress, is Caruth's notion of the enduring and ultimately unknowable and inexpressible nature of traumatic wounding. Caruth's focus on the impossibility of exact and "ultimate" knowing does not oppose or contradict the notion that narrative is curative, 
and that trauma victims may come to terms with their traumatic experiences. It is the domain of literature to present, re-present, and dramatize trauma in its many manifestations without making claims to precise definitions or complete exactitude. Without negating the lasting, profound impact of trauma, postcolonial trauma narratives often also demonstrate that resilience and growth are possible in the aftermath of traumatic wounding. An example of this positive narrative arc is presented by Toni Morrison's novel Home (2012), the story of Frank and Cee (Ycidra) Money. Home depicts the siblings' traumatic memories of childhood abuse, also drawing into play the wider history of slavery and racist persecution and lynchings, as well as Frank's trauma as a veteran of the Korean war, and his many symptoms of Post-Traumatic Stress Disorder (PTSD). Cee suffers from the traumatic experiences of exploitation and near-death as a victim of illegal experimentation. Despite these ineradicable scars of past and recent wounding, the final pages of Home speak unreservedly of healing, rejuvenation, and personal growth. Its final page presents the image of a green bay tree that is damaged at the core, but at the same time alive and growing:

\section{It looked so strong}

So beautiful.

\section{Hurt right down the middle}

But alive and well. ([15], p. 147)

The image of the beautiful tree symbolizes a sense of closure that is not the erasure or denial of past hurt, but which affirms growth and health to emphasize that recovery, despite traumatic wounding, is possible, and that trauma, although it stands outside precise representation, can be integrated. Morrison's novel is an example of many similar narratives that emphasize renewed life and growth after traumatization, in contradistinction to trauma theory's insistence on melancholia and weakness.

Stepping aside for a moment from the discussion of the project of decolonizing trauma theory, we should note that in her more recent book on trauma, titled Literature in the Ashes of History (2013), Caruth moves away from her initial emphasis on stasis and melancholia as the inevitable condition of trauma victims, and instead now postulates that trauma calls for a turn to life, emphasizing its "imperative to live" ([16], p. xi). We should not take this to mean a departure from Caruth's earlier alignment with Freudian psychoanalysis; on the contrary, Freud continues to inform her new thinking about trauma, but Caruth now foregrounds the language of Freud's life drive, "by which Freud signals a mode of speaking and of writing that bear [sic] witness to the past by turning toward the future" ([16], p. xi). This turn towards life, and subsequently growth, constitutes what Caruth sees as the challenge for the theory of trauma in the 21 st century in which she poses the disappearance of history as a site where "we can recognize the persistence of a language, or a writing, that emerges precisely as the archival resources of meaning and tradition slip away" ([16], p. xi). In its vague and sweeping generalization, this statement nevertheless clearly negates Caruth's previous emphasis on melancholia, which, as I have shown, has been found by many scholars to be unproductive and ultimately untenable, particularly in the engagement with postcolonial literature. Since 2008, an increasing number of postcolonial critics have rejected trauma theory's limited Freudian orientation towards trauma and have argued for an 
expansion and redirection of the theory in order to adequately understand trauma during and after colonization. A major issue that necessitated a resolution has been the controversy about the value of narrative.

\section{Re-Valuing the Function of Narrative}

A crucial concern in the decolonizing project has been the debate about early trauma theory's deconstructionist approach to narrative, in particular its aesthetics of the indeterminacy or impossibility of meaning. This issue has been crucial to literary scholars because it touches on the value of narrative, and it has long been controversial because Caruth's aporetic dictum opposes notions of the therapeutic and recuperative value of narrative that are prioritized in other theories of trauma. Early trauma theory's deconstructionist notions of the impossibility of truthfulness or accuracy in narrative were initially presented as inherent in the theory's ethical orientation, which demanded an empathetic connectivity in the reception of trauma narratives. This other-directed response must follow from the recognition that trauma cannot be fully verbalized or understood, as expressed in Caruth's oft-quoted statement that "the most direct seeing of a violent event may occur as an absolute inability to know it" ([11], pp. 91-92). As I observe above, it seems an unproblematic notion that due to the limitations of human expression the exact and ultimate meaning of a traumatic experience can neither be fully understood nor perfectly narrated in language, but Caruth's theory goes beyond this notion, posing instead that verbal expression of trauma constitutes an affront to understanding, or, even, an act of betrayal of the traumatic memory. From the mid-1990s onwards, this orthodoxy of the "unsayability" of trauma as the only, or prescribed, ethical position in the reception of trauma had an opposing, but very influential counterpart, associated with the work of psychiatrist Judith Herman (in particular, her book Trauma and Recovery). Herman views narrative as an empowering and effective therapeutic method in the treatment of trauma victims. Narratives of trauma, as an "organized, detailed, verbal account, oriented in time and historical content", contribute to healing and recovery ([17], p. 177).

These opposing views about the value of trauma narrative, termed "the flat contradiction in trauma theory" by Luckhurst ([2], p. 82), have long been problematic to literary scholars wishing to use the theory in their critical praxis. Following Caruth's formulation, trauma narrative must be regarded as leading to increased indeterminacy, denying the possibility of resolution and recovery, whereas in Herman's view, trauma narrative is therapeutic, enabling psychic integration and eventual resolution of trauma. For many years, Caruth's aporetic stance remained a core element in trauma theory and was adhered to by some postcolonial scholars as well, although it inevitably proved inadequate to a full reading of postcolonial trauma. For example, Susan Y. Najita's Decolonizing Cultures in the Pacific initially underwrites Caruth's rejection of narratives of recovery, which Najita terms the "fetishized narrative of complete recuperation" ([18], p. 63). However, despite this initial denial, Najita's readings of postcolonial trauma fiction lead her to conclude that the dominant theory's notion of aporia is too limiting a perspective, and that, in fact, dominant themes in literary texts are of recovery and redress, often through political activism [18]. The theme of recuperation through activist resistance is found in much postcolonial trauma 
criticism, and these findings oppose the orthodoxy of Caruth's passivist melancholia as well as trauma theory's denial of the value of narrative.

While it has taken quite some time for the strong emphasis on the denial of the therapeutic value of traumatic narrativization to fully disappear in postcolonial thinking about trauma, Caruth's original formulation is now effectively superseded. A very strong factor in this process has been the serious critique expressed by Ewald Mengel and Michela Borzaga in their collection of essays on trauma, memory, and narrative in South African literature [19]. Mengel and Borzaga and their contributors underscore the fact that trauma theory in Caruth's deconstructionist formulation is inadequate to the analysis of trauma in South Africa. This trauma is inextricably involved with the history of apartheid, which has caused the collective traumatization of several generations, and as such, it is neither an unclaimed nor unclaimable experience. Mengel and Borzaga express strong objections to what they term the "melancholic vocabulary" of theorists like Caruth and Hartman, which is marked by "notions of absence, holes, deferral, crises of meaning, unknowing and dissociation" and which precludes "any possibility for healing for individuals or entire nations" ([19], p. xiii). The hearings by the Truth and Reconciliation Commission in South Africa derive their importance from the understanding that the truth of traumatic experiences can be reclaimed in oral and written narratives, and that these narratives provide ways of coming to terms with the aftermath of apartheid and its atrocities.

Postcolonial literature provides many examples that support the claim that trauma itself instigates a strong need for narrative in order to come to terms with the aftermath of colonial wounding. The work of Māori writer Patricia Grace, for instance, centrally poses that the injustices and wrongs of colonialism produce a restless state, in which trauma must be brought to light through narrative. Narrativization is empowering to individuals and their communities, and is in fact crucial to cultural survival. Grace's novel Baby No-Eyes [20] represents the narration of traumatic memories by the metaphor of unwinding bandages, which, once they have been removed, reveal a core of selfhood; the traumatic event has not invaded this central, authentic sense of self, but has accumulated around it through years of repression, and of compliance with hegemonic, colonialist ways of thinking. Trauma in this novel, then, is neither inaccessible nor inexpressible. On the contrary, the bandages of traumatic memories, in Grace's metaphor, are removed precisely through the process of oral storytelling, exposing many injustices done to individuals and to their communities, and crucially also bringing to light their own acquiescence, guilt, and shame. Telling the story of trauma leads to health: as protagonist Gran Kura states, it is a "ridding oneself of sickness" ([20], p. 148). While trauma is a disorder that can remain latent for a very long time, even then is not beyond healing once it is brought to light in narrative, as my examples from novels by Morrison and Grace demonstrate.

\section{Expanding Trauma Theory}

Since 2008, postcolonial scholars have increasingly discarded the approaches of Freudian psychoanalysis and deconstructionism for their own work, and have expressed preferences for less prescriptive theories, for instance, from sociology and anthropology. In The Splintered Glass: Facets of Trauma in the Post-Colony and Beyond (2011), editors Dolores Herrero and Sonia 
Baelo-Allué argue for a change in postcolonial trauma studies towards a sociological orientation, expressing the general discontent with contemporary trauma theory's deconstructionist and psychoanalytical orientations; they suggest that a sociological framework for a theory of trauma will answer the need to rethink the relation between specificity and comprehensiveness in postcolonial literary studies ([7], pp. ix-xxvi). Decolonizing trauma theory, then, has entailed a movement away from the original Eurocentric theory's foundation in Freudian psychoanalysis and its emphasis on melancholia and stasis. In severing the ties with these tenets of the original theory, postcolonial theory has enabled connections with new directions taken from sociology and anthropology, as disciplines capable of providing new models, including those for collective trauma. Indeed, as Erikson states, in sociology it is "well-travelled conceptual ground" to theorize trauma as collective ([21], p. 229). Trauma is now recognized as displaying both centripetal and centrifugal tendencies; trauma is not coherent in cause and effect, but may affect individuals and communities negatively, forcing open pre-existing fault lines ([21], p. 236), while also possibly affirming a sense of belonging, kinship, and mutual trust. These two tendencies, however opposite in effect, are widely observed and can occur "either alone or in combination," as Erikson remarks ([21], p. 237).

A worthwhile definition of collective trauma for a decolonized trauma theory is provided by sociologist Jeffrey C. Alexander. He defines collective trauma as the result of a sociocultural, narrative act of constructing traumatic experiences. Literature, then, performs a major part in what Alexander calls the "trauma process": the process that gives narrative shape and meaning to "harmful or overwhelming phenomena which are believed to have deeply harmed collective identity" ([22], p. 10). From the perspective of postcolonial theory, this concept of the trauma process involves the construction and interrogation of the history of colonialism and decolonization through narratives. Colonialism is part of that trauma process. It is an established understanding that colonialism's traumatic aftermath continues until the present day. As Achille Mbembe remarks, "In African self-writing the colony is depicted as an original scene which does not merely occupy a space of remembrance, as if reflected in a mirror" but it is also "one of the significant matrices of language, operating on the past and the present, identity and death" ([23], pp. 28-29). It needs no argument that postcolonial literature is a major contributor to the socio-cultural construction of trauma that constitutes the trauma process as defined by Alexander. Postcolonial fiction characteristically dramatizes the notion that the trauma of colonialism can and must be addressed.

Narrativization of trauma allows insight into specifics of the colonial past as a pathway to integration of the traumatic memory. This process of integration may also involve addressing the sensitive issue of complicity. During decolonization, Mbembe states, what needs to be confronted is the complexity of the "entanglement of desire, seduction and subjugation; not only oppression, but its enigma of loss", which may include the realization that the colonized people "have allowed themselves to be duped, seduced, and deceived" ([23], p. 35). In pointing out this complexity, Mbembe invites a positioning towards postcolonial trauma that accords with the findings of the StiN project as summarized by Rothberg, who concludes that "attentiveness to complicity" marks one promising direction for "a differentiated approach" in a decolonized trauma theory ([3], p. 232). 
Whereas the project of decolonizing trauma theory has involved discarding various notions from the first model of literary and cultural trauma theory, the project has also necessitated expansion. An area of expansion that is important to understanding the traumatic legacy of the colonial situation, I would suggest, is the complexity of the entanglement of complicity, agency, and guilt. These themes are still relatively unexplored as areas of research today, whereas postcolonial literature often dramatizes conflicted traumatic memories of individual and collective complicity with hegemonic systems of oppression. Complicity is a major theme in Patricia Grace's work, in particular her three novels Potiki, Cousins, and Baby No-Eyes [23-25], published between 1986 and 1998. Complicity is depicted as a poisonous force that undermines, weakens, and even destroys individual and communal life. Grace's novels offer a detailed scrutiny of the history of a generation of Māori who chose to comply with the government's repression of Māori culture. She presents this decision as part of the internalization of the hegemonic ideology of white supremacy, taught in schools and imposed on parents as the best education for their children. This generation's later realization of the insidious nature of this complicity deepens their trauma of loss and impoverishment, and increases their feelings of shame and guilt. What Grace's fiction foregrounds is that storytelling offers a way to come to terms with this traumatic, repressed wounding and opens the way to recovery. Similarly, in Toni Morrison's novel Home, shame and guilt are central elements in the trauma process that the novel depicts. Protagonist and trauma victim Frank Money tells the story of his life to a nameless scribe, and in the process gradually uncovers the layers of hurt that are wrapped around a central devastating traumatic experience during the war, which involved his shooting of a young girl in the face. It is only slowly, aided by the work of oral narrative, that Frank is able to reconnect with this extremely painful memory and confront and integrate his guilt and shame. Frank's recovery from trauma and PTSD is presented as a result of his telling his story in an oral narrative to an attentive recipient. In Morrison's Home, a further curative force is represented by the community of women in the town of Lotus, whose rituals effectuate Cee's healing and recovery from trauma [15]. In Grace's fiction, storytelling is itself a ritual means to heal from trauma because it connects past and present, drawing upon the ancestors and their sacred power to restore harmony and health. Postcolonial fiction by these authors demonstrates that trauma can be narrated with integrity, and that oral storytelling enables a healing process, which allows insight, acceptance, and access to various modes of redress. Orality, as Najita observes, "provides a language to articulate a new mode of belonging based upon genealogy that leads out of and beyond the traumatic past" and even "through and out of colonization" ([18], p. 23). A decolonized reading of trauma, I would suggest, indeed calls for a recognition of the centrality of oral modes of narrative and their ritual function in indigenous communities.

\section{New Areas of Exploration}

A response to trauma from a respectful cognition of culturally specific spiritual and religious perspectives, analogous to the recognition of historical, national, and ethnic diversification, is necessary for a postcolonial theory of trauma to be truly decolonized. Rothberg, in instigating the decolonizing trauma project in 2008 , already signaled this area of interest for postcolonial criticism in highlighting a response to trauma "that asserts the relevance of localized modes of belief, ritual, 
and understanding, thereby undermining the centrality of Western knowledge and expertise" ([26], p. 27). If dominant Western models of trauma obstruct entry to meanings that underlie indigenous rituals and cultural practices, this may be attributed to the fact that present theorization in literary studies is characterized by a neglect of religion and spirituality, due to the influence of postmodernist theories and poststructuralist antagonism towards religion as "grand narrative". The dominant stance in contemporary cultural theory is to regard the postmodern period as "thoroughly and satisfactorily secularized”, as John A. McClure remarks ([27], p. 141). This limited perspective makes cultural theory inadequate for an engagement with indigenous literatures that situate trauma in the context of ritual and ceremony. Moreover, its normativity is reminiscent of Eurocentric or even colonialist tendencies to impose Western notions of religion-as-superstition on non-Western literary texts. Cultural and theoretical paradigms that equate progressiveness and secularism may mask the fact that this kind of orientalism is still operative. Manav Ratti's The Postsecular Imagination, a recent publication on postcolonialism, literature, and religion, argues convincingly that the secular West sees itself as superior (as modern and progressive) to the non-secular non-West [28]. Western secularism identifies itself with "ideas of modernity, progress, civilization, and the othering of religions that are different from Christianity"; consequently, non-Christian belief systems, especially Islam, are the religious other, seen as intolerant and irrational ([28], p. 7).

A decolonized trauma theory, I would claim, must be one that is sensitive to the cultural bias inherent in the secular perspective that imposes such prejudices. In this area of secular thinking about religion and spirituality, the non-West is too easily contrasted with the West as less civilized, or even backward, and in need of enlightenment; Ratti refers to Ashis Nandy's incisive critique on secularism's hegemonizing the idea of tolerance "so that anyone who is not secular becomes definitionally intolerant" ([28], p. 13). Decolonizing trauma theory must involve an awareness of entrenched Western notions of ideological superiority, as well as a distancing from these cultural prejudices. As Duncan Brown cautions, "the inability to move beyond conventional paradigms can undermine potentially groundbreaking projects in this area" ([29], p. 9). I wish to suggest that the recognition that a respectful and nuanced conceptualization of religious and spiritual modes of addressing trauma is needed would constitute a necessary and major step forward towards a fully decolonized trauma theory.

The dominant influence of secular rational thinking has often been compared to that of colonialism, both leading to a loss of indigenous practices all over the world; according to Erin O'Connor, the "devastating loss of tradition, ritual and belief" has become one of the principal preoccupations of postcolonial writing ([30], p. 227). The erosion of indigenous minority cultures is indeed a central issue in much postcolonial fiction. In her 1995 collection of essays Massacre of the Dreamers, Chicana writer Ana Castillo speaks of the repressive attitude in the United States and "everywhere where primal peoples reside and where white imperialism has reigned", emphasizing the need for minority cultures to gain knowledge of their indigenous heritage in order to "educate the world, including our own communities, about ourselves" ([31], p. 6). Ratti, in expounding the difficulties involved for Western academics in understanding and representing the "religiously-informed lifeworld" and the "otherness" of religious belief and faith, concludes that there is an urgent need to conceptualize what is so resistant to conventional secular rational 
thinking ([28], p. 12). This conceptualization, I argue, must be part of the trajectory of decolonizing trauma theory.

The long-standing debate in postcolonial literary studies about the term "magical realism" presents a case in point. The central question is whether this term, with its binary opposition between magic (as superstition) versus realism (as truth), can be adequate to the reading of postcolonial literature. African writers such as Wole Soyinka, Ben Okri, and Zakes Mda have distanced themselves from this intrinsic binary, stating that such a dichotomy is not relevant to their work, nor to their worldview. Soyinka, for instance, asserted in 1976 that "the harmonization of human functions, external phenomena and supernatural suppositions within individual consciousness merges as a normal self-adjusting process in the African temper of mind" ([32], p. 122). Commenting on the frequent classifications of his work as magical realism, South African writer Zakes Mda has stated in an interview that it is the Western, not the African stance, to refer to magic as opposed to reality, and that to him, as an African, the immaterial is real, natural, and ordinary: "part of the way people live" ([33], p. 8). Derek Alan Barker, in an article presenting an overview of critical views of magic realism in Mda's work, concludes that the term does not provide a "sufficiently full account of any of Mda's texts", but will probably continue to be used by critics for its descriptive function; he warns, however, that it may become "tyrannical" when used as "expedient, modish or dismissive of the narrative truth of a text" ([34], p. 17).

A central concern to be addressed in the context of decolonizing trauma theory, then, is the pervasive influence of the secular ideology of postmodern Western culture, which may obstruct an engagement with spirituality, ritual, and ceremony in postcolonial trauma narratives. As Brown states, the major challenge in postcolonial criticism today is the question of "how do we develop a critical language and framework that avoid the dismissiveness of materialism in its approach to spirituality, while still undertaking studies that are rigorously analytic and critical, but receptive to other modes of identification, identity and being?” ([29], p. 9). Research in social studies supports my claim for a new perspective on trauma in postcolonial criticism that would oppose the limitations of hegemonic poststructuralist resistance against the study of religious and spiritual practice. According to researchers Peres, Moreira-Almeida et al, social studies confirm that in actual therapeutic processes, trauma victims may find in their belief systems pathways to resilience and recovery from trauma, and that forms of spirituality that provide a sense of identity and hope can prevent PTSD [35]. They strongly recommend a respectful approach from therapists working with trauma victims who (even in Western secular nations) themselves often raise existential and spiritual issues, and urge further study of the role of spirituality "in fostering resilience in trauma survivors" as a way to "advance our understanding of human adaptation to trauma" ([35], p. 348). Rather than considering the openness to spirituality as dubious, then, we should realize that this openness may liberate analytic readings in trauma criticism to consider as worthwhile the dimensions of human life and experience as they are expressed in trauma narratives and testimonies. A further example of a study that supports this claim is Renee Linklater's Decolonizing Trauma Work, which explores trauma stories and healing strategies in indigenous communities [36]. Presenting itself as a "decolonizing journey", Linklater's book engages with indigenous health care practitioners who still use traditional approaches to trauma today [36]. 
Conducting a respectful dialogue with spiritual trauma healers, Linklater's work counters the secularist default assumptions of hegemonic trauma theory and its very limited pattern of response to trauma, in which, as Luckhurst states, religion has no place and resilience and recovery have long been ignored or even seen as pathological ([2], p. 210). I would suggest that a turn towards an engagement with spirituality may vitalize the work of criticism in postcolonial trauma studies, in alignment with Ratti's view that the arrogant denial of spirituality in the West has also led to a sense of emptiness and dissatisfaction: "worldviews centered in scientific rationality, which perceived and reinforced perceptions of colonized peoples as subhuman, thus justifying colonial conquest and violence - have resulted in a disenchanted West" ([28], p. 17). The disenchanted Western outlook lacks what Ratti calls the "irresistible dimensions of the human experience", such as faith, awe, and transcendence, which may infuse the mundane with a richness of experience ([28], p. 17).

Disenchantment is a central theme in Ana Castillo's novel So Far from God, which presents the life stories of a Chicana mother and her four daughters. Sofi's daughters, growing up in the dominant culture of American consumerism, seek happiness and fulfilment through education, networking, and career moves. Attracted by the American Dream of success, the young women discard Chicano culture and spirituality and embrace the world of mainstream ideology only to return to the family home "disappointed, disillusioned, devastated, and eventually not at all" ([37], p. 127). All learn that the "enchantment" of American materialism and individualism is in fact an "entrapment" and does not lead to independence, happiness, and freedom. In So Far From God, the eventual deaths of all four daughters (through war, sexual assault, chemical poisoning, and AIDS) reveal the inherent violence, racism, and spiritual emptiness of American culture. In sharp contrast to this disenchantment, Castillo posits the rejuvenating value of communal effort in Chicano culture, and the curative effect of traditional Chicano spirituality and religious observances, which, in combination, result in collective and successful, political activism.

In Castillo's novel, the trauma of colonialist oppression is addressed and resolved through communal rituals that constitute moral and political energizers. It exemplifies Ratti's claim that postcolonial literature is powerfully poised to undo the oppositions between secularism and religion, and that "in its ability to represent a multiplicity of voices and in its acceptance and juxtaposition of contradictory and conflicting perspectives", postcolonial literary criticism can "represent, imagine, and pursue a rich array of possibilities" ([28], p. xxi). Such possibilities are evidenced not only by Castillo's novel, but also by the examples I have so far presented from novels by Morrison and Grace, which dramatize how individuals and their communities employ religious ceremony and rituals to address the traumas of racist discrimination and colonialist exploitation, and in doing so successfully resist the dominant culture's ideology.

An openness to indigenous belief systems and their rituals will give access to explorations of specific ways in which postcolonial fiction expresses new avenues towards the perception of trauma, its aftermath, and possible resolution. An example of such a new avenue is provided by Witi Ihimaera's novel The Whale Rider, which assigns a crucial function to forgiveness as a healing force in the trauma process that the narrative depicts. A cycle of violence, wounding, and suffering is broken and healed by forgiveness. Forgiveness is not a recognized concept in trauma theory, mainly due to what Julia Kristeva diagnoses as the problem of Freudianism, which is that it 
has no place for forgiveness; "forgiveness is not a psychoanalytical concept" ([38], p. 14). Ihimaera's narrative, however, assigns a central place to forgiveness. In its final pages, a formal ritual of forgiveness is enacted, which marks the end to protagonist Kahu's trauma of rejection and exclusion. Forgiveness for causing this trauma is formally asked, in Māori, and ritually repeated several times, and it proves to be a very powerful psychological force, reconciling differences and healing the wounding of the past. Despite its complexity, and the potentially controversial nature of its theorization in view of Western trauma notions, forgiveness invites serious conceptualization in postcolonial trauma studies. A further prospective expansion of trauma theory would not only include attention to resilience, non-Western modes of spiritual counselling, and reception of trauma, but also the place and function of forgiveness as a factor in the engagement with trauma.

\section{Conclusions}

In 2008, Rothberg astutely predicted that in the engagement with postcolonial literature, scholars would critically expose the limitations of trauma theory and would make evident what decolonizing trauma theory must involve [3]. As the retrospective part of this article has shown, since 2008, the project of decolonizing trauma theory has involved a gradual process of moving away from the theory's Eurocentric tendencies, from its orientation on Freudian psychoanalysis, and from its emphasis on melancholia and stasis, as well as a movement towards an expansion of the theoretical field and towards a greater openness to culturally specific modes of addressing and negotiating trauma. In postcolonial studies today, trauma is recognized as a very complex phenomenon. It is not only understood as acute, individual, and event-based, but also as collective and chronic; trauma can weaken individuals and communities, but it can also lead to a stronger sense of identity and a renewed social cohesion. Postcolonial literary studies reflect and reconstruct this full complexity of trauma in its specific cultural, political, and historical contexts. "As a research paradigm, trauma cannot be stabilized according to a predetermined field of theory", Nikro remarks, "but is both embedded in and traverses relational accommodations between disciplines, geographies, histories, implicating flows of material and imaginary resources and the institutions directing their distribution and access" ([5], p. 1). In the complicated and dynamic area of literary trauma studies, postcolonial literary criticism has played an important role, precisely due to its critical engagement with the limitations and contradictions of dominant trauma theory. Bill Ashcroft regards the critical, resistant, and paradigm-changing function of postcolonial studies as crucial, describing it as "a remarkable facility to use the modes of the dominant discourse against itself and transform it in ways that have been profound and lasting" ([39], p. 13). In a recent collection of essays on trauma in literature, editor Michelle Balaev also affirms this positive evaluation of the critical stance of postcolonial scholars, pointing out that in the history of the concept of trauma, which is "filled with contradictory theories and contentious debates" ([40], p. 2), postcolonial theory is one of the major influences that enabled alternatives to "viewing literature as a closed psychoanalytic system" ([40], pp. 4-5), particularly in presenting "a view of trauma as multiply figured with diverse representations in literature and far reaching effects in culture" ([40], p. 10).

The diverse representations mentioned by Balaev, I would suggest, include the potentially fruitful area of investigation of spiritual and religious traditions and ceremonies that are employed 
in non-Western cultures in therapeutic engagement with traumatic experiences and their aftermath. The respectful engagement with these indigenous modes of address will demand nuanced attention to Western preconceptions and their interference with indigenous, culturally specific ceremonies and rituals. Such a re-routing of the secular orientation of literary theory accords with the long-standing call for a diversification of postcolonial modes of reading trauma, already expressed by Rothberg in his first formulations of the project of decolonizing trauma theory [3]. Postcolonial theory has largely sidestepped this area, mainly because indigenous modes of representing trauma in fiction often include emphases on spiritual and religious traditions, which so far have fallen outside the framework of poststructuralist theory. The nuanced exploration and conceptualization of the function of indigenous belief systems in the engagement with trauma would constitute a further necessary development in the project of achieving a fully decolonized trauma theory.

\section{Conflicts of Interest}

The author declares no conflict of interest.

\section{References}

1. Stef Craps, and Gert Buelens. "Introduction: Postcolonial Trauma Novels." Studies in the Novel 40 (2008): 1-12.

2. Roger Luckhurst. The Trauma Question. London: Routledge, 2008.

3. Michael Rothberg. "Decolonizing Trauma Studies: A Response." Studies in the Novel 40 (2008): 224-34.

4. Janet Wilson, Fiona Tolan, and Sarah Lawson Welsh. "Rerouting the Postcolonial." Journal of Postcolonial Writing 45 (2009): 121-23.

5. Norman Saadi Nikro. "Situating Postcolonial Trauma Studies." Postcolonial Text 9 (2014): 1-21.

6. Irene Visser. "Trauma theory and Postcolonial Literary Studies." Journal of Postcolonial Writing 47 (2011): 270-82.

7. Dolores Herrero, Sonia Baelo-Allué, eds. The Splintered Glass: Facets of Trauma in the Post-Colony and Beyond. Amsterdam: Rodopi, 2011.

8. Stef Craps. Postcolonial Witnessing: Trauma Out of Bounds. Basingstoke: Palgrave Macmillan, 2012.

9. American Psychiatric Association. Diagnostic and Statistical Manual of Mental Disorders, 3rd ed. Washington: American Psychiatric Association, 1980.

10. Stef Craps. "Wor(1)ds of Grief: Traumatic Memory and Literary Witnessing in Cross-Cultural Perspective." Textual Practice 24 (2010): 51-68.

11. Cathy Caruth. Unclaimed Experience: Trauma, Narrative, and History. Baltimore: Johns Hopkins University Press, 1996.

12. Ruth Leys. Trauma: A Genealogy. Chicago: University of Chicago Press, 2000.

13. Dominick LaCapra. Writing History, Writing Trauma. Baltimore: Johns Hopkins University Press, 2001. 
14. Eli Park Sorensen. Postcolonial Studies and the Literary: Theory, Interpretation and the Novel. Basingstoke: Palgrave Macmillan, 2010.

15. Toni Morrison. Home. London: Vintage, 2012.

16. Cathy Caruth. Literature in the Ashes of History. Baltimore: Johns Hopkins University Press, 2013.

17. Judith Lewis Herman. Trauma and Recovery: From Domestic Abuse to Political Terror. London: Pandora, 1994.

18. Susan Y. Najita. Decolonizing Cultures in the Pacific: Reading History and Trauma in Contemporary Fiction. New York: Routledge, 2006.

19. Ewald Mengel, Michela Borzaga, eds. Trauma, Memory, and Narrative in the Contemporary South African Novel: Essays. Amsterdam: Rodopi, 2012.

20. Patricia Grace. Baby No-Eyes. Honolulu: Hawai'i University Press, 1998.

21. Kai Erikson. A New Species of Trouble: Explorations in Disaster, Trauma, and Community. New York: Norton, 1994.

22. Jeffrey C. Alexander. "Toward a Theory of Cultural Trauma." In Cultural Trauma and Collective Identity. Edited by Jeffrey C. Alexander, Ron Eyerman, Berhard Giesen, Neil J. Smelser and Piotr Sztompka. Berkeley: University of California Press, 2004, pp. 1-30.

23. Achille Mbembe. "The Colony: Its Guilty Secret and Its Accursed Share." In Terror and the Postcolonial. Edited by Elleke Boehmer and Stephen Morton. Malden: Wiley-Blackwell, 2010, pp. 27-54.

24. Patricia Grace. Potiki. Auckland: Penguin, 1986.

25. Patricia Grace. Cousins. Auckland: Penguin, 1992.

26. Anne Whitehead. "Journeying through Hell: Wole Soyinka, Trauma, and Postcolonial Nigeria." Studies in the Novel 40 (2008): 13-30.

27. John A. McClure. "Postmodern/Post-Secular: Contemporary Fiction and Spirituality." Modern Fiction Studies 41 (1995): 141-63.

28. Manav Ratti. The Postsecular Imagination: Postcolonialism, Religion, and Literature. New York: Routledge, 2013.

29. Duncan Brown. "Religion, Spirituality and the Postcolonial: A Perspective from the South." In Religion and Spirituality in South Africa: New Perspectives. Edited by Duncan Brown. Scottsville: University of KwaZulu-Natal Press, 2009, pp. 1-26.

30. Erin O'Connor. "Preface for a Post-Postcolonial Criticism." Victorian Studies 45 (2003): 217-46.

31. Ana Castillo. Massacre of the Dreamers: Essays on Xicanisma. New York: Penguin, 1995.

32. Wole Soyinka. Myth, Literature and the African World. Cambridge: Cambridge University Press, 1976.

33. David Bell, J.U. Jacobs, eds. Ways of Writing: Critical Essays on Zakes Mda. Scottsville: University of KwaZulu-Natal Press, 2009.

34. Derek Alan Barker. "Escaping the Tyranny of Magic Realism? A Discussion of the Term in Relation to the Novels of Zakes Mda." Postcolonial Text 4 (2008): 1-20. 
35. Julio F.P. Peres, Alexander Moreira-Almeida, Antonia Gladys Nasello, and Harold G. Koenig. "Spirituality and Resilience in Trauma Victims." Journal of Religion and Health 46 (2007): 343-50.

36. Renee Linklater. Decolonizing Trauma Work: Indigenous Stories and Strategies. Black Point: Fernwood, 2014.

37. Ana Castillo. So Far From God. New York: Norton, 1993.

38. Julia Kristeva. Intimate Revolt: The Powers and Limits of Psychoanalysis. Translated by Jeanine Herman. New York: Columbia University Press, 2002.

39. Bill Ashcroft. Postcolonial Transformation. London and New York: Routledge, 2001.

40. Michelle Balaev, ed. Contemporary Approaches in Literary Trauma Theory. New York: Palgrave Macmillan, 2014. 


\title{
The Question of "Solidarity" in Postcolonial Trauma Fiction: Beyond the Recognition Principle
}

\author{
Hamish Dalley
}

Abstract: Dominant theorizations of cultural trauma often appeal to the twinned notions of "recognition" and "solidarity", suggesting that by inviting readers to recognize distant suffering, trauma narratives enable forms of cross-cultural solidarity to emerge. This paper explores and critiques that argument with reference to postcolonial literature. It surveys four areas of postcolonial trauma, examining works that narrate traumatic experiences of the colonized, colonizers, perpetrators and proletarians. It explores how novelists locate traumatic affects in the body, and suggests that Frantz Fanon's model of racial trauma in Black Skin, White Masks and The Wretched of the Earth remains essential for the interpretation of postcolonial texts, including those to which it is not usually applied. The analysis further reveals tensions between different texts' appeals for recognition, and suggests that these tensions problematize the claim that solidarity will emerge from sympathetic engagement with trauma victims. As such, the paper makes three key arguments: first, that trauma offers a productive ground for comparing postcolonial fiction; second, that comparison uncovers problems for theorists attempting to "decolonize" trauma studies; and third, that trauma theory needs to be supplemented with systemic material analyses of particular contexts if it is not to obfuscate what makes postcolonial traumas distinct.

Reprinted from Humanities. Cite as: Dalley, H. The Question of "Solidarity" in Postcolonial Trauma Fiction: Beyond the Recognition Principle. Humanities 2015, 4, 369-392.

\section{Introduction}

Chimamanda Ngozi Adichie's Half of a Yellow Sun is a significant example of postcolonial trauma fiction, a text that examines the complexities of representing catastrophe in non-metropolitan contexts. Set before and during the Nigerian Civil War of 1967-1970, the novel depicts typified instances of the horrors of that conflict, including mob violence, mass starvation, rape and aerial bombardment - events framed as true and historical, epistemological assertions I have analyzed elsewhere ([1], pp. 121-46). Adichie explores both the psychic need for victims (individual and collective) to have their trauma "recognized" by others, and the affective, ethical, and aesthetic tensions inherent in that demand. Adichie's work is thus an archetypal case of what Roger Luckhurst calls our "contemporary trauma culture" ([2], p. 2) - a set of affective dispositions and publishing norms that promote, and sometimes problematize, aesthetic engagement with the pain of others. As the popularity of Adichie's novel attests, trauma culture is now more global than ever-a development that makes the questions it raises all the more significant. This essay explores some of those issues, focusing on the links this novel and others like it draw between trauma, "recognition", and the production of new forms of ethico-political "solidarity".

A representative incident in the novel concerns Adichie's protagonist Olanna, an upper-class Igbo woman who in the build-up to war narrowly avoids being murdered in an anti-Igbo pogrom. 
Visiting relatives in Hausa-dominated Northern Nigeria, she finds them dead, their killer gloating over their corpses, and she must flee South to safety - a terrifying ordeal during which she fears for her life, and is shocked to encounter a woman carrying fragments of a dead child ([3], pp. 146-49). On reaching safety, Olanna, though physically unharmed, suffers the symptoms of Post-Traumatic Stress Disorder, including panic attacks, paralysis, and the compulsion to repeat that for Freud was trauma's defining quality ([4], pp. 12-14). To use Cathy Caruth's description, Olanna's trauma “is not locatable in the simple violent or original event" that caused it, "but rather in the way that its very unassimilated nature - the way it was precisely not known in the first instance - returns to haunt" her ([5], p. 4). In keeping with this model, Olanna's recovery marks step with her growing ability to produce narrative meaning, as she "works through" her experience ([6], pp. 141-46) and "masters the stimulus retrospectively" ([4], p. 32). Her symptoms recede accordingly, suggesting Adichie's debt to the classical trauma paradigm, and her commitment to a notion of the novel as a means to bear witness to suffering. To this extent, her work (as noted, framed explicitly as "truthful" and based on archival sources ([3], p. 435)) is both a way to recognize the reality of Nigeria's historical traumas and, through the healing that comes from such recognition, a move toward more peaceful modes of political belonging [7].

What makes Half of a Yellow Sun challenging is its emphasis on how complex this process can be. Olanna's recovery requires her not only to produce narrative, but also to find listeners able to recognize meaning in it. Olanna's first audience of friends and well-wishers fail in this task, framing her experience vis-à-vis the racial and religious divisions of post-independence Nigeria. They file dutifully past her sickbed and "shake their heads and mutter about the evils of those Muslim Hausa people, those black-as-he-goats Northerners, those dirty cattle rearers with jigger-infested feet" ([3], p. 157). This response signifies a lack of attention to the singularity of her experience, and is actively harmful to Olanna, whose "Dark Swoops" are "worse on the days she had visitors" ([3], p. 157). This may be because her guests' racially-inflected narrative perpetuates the hatreds that led to her victimization, or because they have ignored crucial details-most importantly, that she was saved by her Muslim Hausa ex-boyfriend, whose actions make nonsense of universalizing claims about Northern brutality. Her health improves, by contrast, with the emergence of Biafran nationalism. This movement offers Olanna a new identity as a member of a community founded on the recognition of Igbo victimization, which is re-contextualized as the nation's founding trauma. Olanna takes her first steps as political developments push Biafra irreversibly toward secession, and achieves full mobility to attend a pro-independence rally ([3], pp. 159-63). Healing thus comes when the traumatized victim finds validation through recognition, and a narrative that not only makes sense of her experience, but turns it into the basis for interpersonal solidarity (see [8]). In her joyful assertion of restored subjectivity, Olanna observes students burning effigies of Nigerian President Gowon, and feels "with a sweet surge that they all felt what she felt, [...] as though it were liquid steel instead of blood that flowed through her veins" ([3], p. 163).

Yet if this sequence makes recognition the way to restore victims' wellbeing and create solidarity among them, Adichie reveals her ambivalence when she shifts focus to a broader, trans-national frame. The national and ethnic suffering the novel witnesses is separated from its 
implied audience(s) temporally — by the gap between the 1960s setting and 2006 publication - and, especially for its presumed Western readership, by geography and culture. Adichie foregrounds the problems of distant witnessing by dramatizing the tension that emerges between corporeal (or proximate) and visual (or distant) affects. Thus on the one hand, she emphasizes the centrality of the body as a site where trauma resides. Her novel is replete with evocations of sensual experience, bodies that exist as sites of putative empathy for readers. As Zoe Norridge argues, this stress on physicality makes immediate the reality of traumatic events, conveying psychological affects that might otherwise remain opaque and inviting readers to feel, as though they were there, "painful experiences" ([9], p. 30). At the same time, Adichie stresses the blockages that limit witnesses' capacity and willingness to recognize others' pain, especially when mediated by an aesthetic register or technology of representation. Ugwu, one of the narrators, draws attention to this problem in a poem that rebukes foreign readers for their failure to be moved by images of starving Biafran children: "You needn't imagine. There were photos/Displayed in gloss-filled pages of your Life./Did you see? Did you feel sorry briefly,/Then turn round to hold your lover or wife?" ([3], p. 375). The novel thus betrays an ironical awareness that the African pain it deals in is easy for foreigners to dismiss, especially when geopolitical or economic imperatives lie in other directions. The final section narrates the frantic attempts of the Biafran government to promote international sympathy for its people, in the hope that moral outrage might be parlayed into military backing — and, most important, diplomatic recognition. In this way, recognition acquires an international political dimension that complicates its affective and metaphysical connotations. We are left with the certainty that while the failure of Western citizens to be moved by Biafran trauma is a failure of the imagination, it is also a product of political realism-and perhaps a well-founded reluctance to intervene in distant civil wars.

Much more could be said about this rich and fascinating novel. Rather than pursue that analysis here, though, what I wish to explore are some of the implications of the conjunction of trauma, recognition, and solidarity it brings to light. As the remainder of this paper shows, postcolonial literature is replete with works that represent traumatic suffering, inviting readers to recognize characters' pain, and-perhaps-to use that recognition as the basis for cross-cultural, transnational, or global solidarity. I survey a wide range of texts from four structurally dissimilar sites of trauma, juxtaposing forms of traumatic subjectivity that manifest the concept's wide application, even in situations not normally considered comparable. There exist, I suggest, literary traumas of the colonized, of colonizers, of perpetrators, and of transnational proletarians, among other possibilities. My goal with this comparison is to enact, and thereby demonstrate the complexities of, the cross-contextual integration that I argue trauma discourse (in both literary and theoretical incarnations) posits as its progressive ethical/political corollary. By doing so, I demonstrate that contemporary postcolonial literature betrays an ambivalence about trauma, suggesting that recognition is more complex than it may appear and that, even when it seems unquestionably desirable, it does not necessarily lead to solidarity.

I intend this survey as a contribution to the emerging critical and theoretical scholarship of postcolonial trauma studies. It seems to me that this field is shaped around an implicit hope: that recognizing traumatic pain will facilitate new forms of solidarity; or, to put it differently, that the 
unexpected comparisons trauma enables will be, themselves, a kind of progressive politics in action. My main interlocutor here is Frantz Fanon, a key figure for recent critical attempts to forge a postcolonial trauma studies free of Eurocentrism (see [10,11]). I suggest that foregrounding "recognition" and "solidarity" as objects of analysis facilitates critical reflection on what we hope to achieve by bringing together trauma and postcolonialism. It is not my argument that the trauma-recognition-solidarity nexus is misguided or ill-conceived in toto; on the contrary, this paper is constructed as a wide-ranging survey precisely to demonstrate trauma's value as a mobile "ground of comparison" [12]. Nonetheless, I argue that postcolonial texts demonstrate the need for attention to specificity and a willingness to deal in ambivalence, and the final section of this paper builds upon Fanon's insights to suggest that we may need to consider the possibility of thinking cross-traumatic solidarity without recognition. Such an approach might offer a different angle of view on the complicated, unsettling tableau of bodies in pain that is, so often, the subject matter of postcolonial literatures.

\section{Trauma, Recognition, Solidarity: Critical Contexts for Postcolonial Trauma Studies}

Few intellectual fields seem to have as much to offer each other as trauma and postcolonial studies. From its origins in Freud, the language of much trauma theory relies on an imagery of invasion that brings it close to postcolonial studies' concern with empire. Beyond the Pleasure Principle - the most culturally influential of Freud's accounts - relies at crucial moments on the metaphor of foreign occupation, characterizing the relationship between stressor and subject as one of intrusion, disruption, and chaotic defense. Trauma occurs, he argues, when "excitations from the outside [...] break through the protective shield" of the ego, and "provoke a disturbance on a large scale in the functioning of the organism's energy" - an attack that must be met, like any invasion, by "every possible defensive measure" ([4], p. 29). Though Freud conceives of traumatic invaders in biological terms, his metaphor also invokes colonialism as a source of mental disorder. While his work has been superseded in clinical contexts, it remains influential for those who, like protagonist of Nigerian-American novelist Teju Cole's Open City, look to it for "literary truths" ([13], p. 208). Hence, the ubiquity in trauma studies of imperial metaphors, as in this example from Kai Erikson: "Something alien breaks in on you. [...] It invades you, takes you over, becomes a dominating feature of your interior landscape" ([14], p. 183). As Caruth points out, what is traumatic in such invasions is not the self's encounter with foreignness per se, as the overwhelming, absorptive quality of that encounter, as the invader takes up residence in the self like a settler who resists assimilation ([5], p. 4). "Trauma is a piercing or breach of a border that puts inside and outside into a strange communication" ([2], p. 3); the victim's neurotic symptoms are attempts to control the domineering "foreign body" ([15], p. 121). Ogaga Ifowodo has taken the logical step of literalizing this metaphor, arguing that colonialism ought to be understood as an intrinsically traumatizing force, a disruption par excellence in which one is forcibly reconstituted by the demands of an outsider. "[S]lavery and colonialism shattered the world of the colonized", he observes, producing "utter chaos" and a "sense of being unmoored and cast adrift from any frame of reference" ([10], p. 132) - the historical origin, we might infer, of Caruth's "catastrophic age" of trauma ([16], p. 11). 
The relationship between the two fields becomes more complex when we move to consider the ethical responses demanded by such invasion(s). Trauma studies often highlights to some degree the role of the sympathetic witness. For psychoanalytically-inflected models, the reader or listener of traumatic narrative takes the role of analyst, who plays a transferential role by offering recognition to victims and entering into an affective relationship with them-helping to "work through" trauma in the process of understanding it ([6], pp. 141-46; [17], pp. 11-12). It is this relationship of recognition that forms a potential basis for solidarity between victims and their witnesses - a possibility first implied by Freud's argument, in Moses and Monotheism, that shared trauma lies at the root of Jewish nation-building ([15], pp. 101-17). It appears likewise in Erikson's claim that trauma "can serve as a source of communality in the same way that common languages and common backgrounds can" ([14], p. 186), and in Luckhurst's view that trauma has a "demonstrable power [...] in creating communities"- "volatile and temporary" as they may be, and "weak against the merciless logic of military-industrial complexes" ([2], p. 213). Caruth herself makes much of this possibility, presenting trauma as an "encounter" across boundaries of difference, one that connects disparate experiences of pain and forges a "link between cultures" that might otherwise remain separate ([5], pp. 26, 56). As she puts it elsewhere, trauma means "passing out of the isolation imposed by the event," insofar as its affect "can only take place through the listening of another" ([16], p. 11). In the strongest formulation of this view, Judith Butler suggests that witnessing trauma, and thus acknowledging the capacity for pain that all people share, might ground a new humanism, one critical of exclusionary identities that deny the other's suffering [18]. In the words of Nouri Gana, "Vulnerability becomes [...] a potential psychosocial concept for re-envisioning socio-political, communal and human ties [...] along trauma ties" ([19], pp. 83-84). A trajectory thus lies beneath much trauma theory, moving from pain to recognition to solidarity.

This nexus of concepts also suggests why aesthetics have been so important to trauma critics, for it requires them to explain how, exactly, trauma narratives might elicit recognition from, and establish solidarity with, putative readers. A representative response comes from Gana, who argues that the formal qualities associated with literary modernism are essential to generate the "estrangement" from reality that encodes traumatic memory, and which allows "a transformational and generative formation of subjectivity and community" to emerge in the process of reading ([19], p. 87). Greg Forter makes similar claims, avowing that it is insufficient merely to "represent traumatizing events - since representation risks [...] betraying the bewildering, imperfectly representational character of traumatic memory"; rather, he argues, literary works must "transmit directly to the reader the experience of traumatic disruption" if they are to elicit recognition of affective disorders ([20], p. 260; original emphasis). Hayden White argues that literary realism mystifies traumatic experience, claiming that only non-linear forms can encode its perplexing affects [21]. Jean-Michel Ganteau and Susana Onega similarly argue that by the skillful deployment of modernist "indirection, [...] the art of trauma attempts to re-establish the severed empathetic dialogue with the internal and external Other without which there can be no representation" ([22], p. 4). In this way, and in keeping with the analysis of Half of a Yellow Sun above, trauma critics avow that aesthetic forms mediate the representation of trauma, and are crucial to eliciting 
recognition. At the same time they betray an anxiety, like Adichie's, that pain, like starving Biafran children, may easily be ignored.

When viewed from the perspective of postcolonial studies some of these claims become problematic. Rosanne Kennedy and Jill Bennett point out that the dominant psychoanalytic model of trauma is predicated on an individualized relationship between victim and witness that is both limiting and potentially Eurocentric ([23], p. 3; see also [24]). They argue moreover that privileging literary modernism as the only form adequate to trauma results in criticism that is both "surprisingly prescriptive, and blind to the cultural contexts in which practices of representation and commemoration are produced and enacted" ([23], p. 10). For this reason, the encounter between trauma and postcolonial studies is both essential and potentially fraught. Many postcolonial theorists share Butler's commitment to critical humanism, and the field derives to a large extent from earlier traditions of cross-cultural, international solidarity in opposition to empire [25]. Like trauma studies, postcolonialism is a comparative sub-discipline, and many of its canonical works (like Said's Culture and Imperialism, or The Empire Writes Back [26,27]) are predicated on the desire, analogous to Caruth's, to bring examples of distant suffering into conjunction. The same is true of postcolonial literary works, which, at the risk of a gross generalization, are more often committed to the possibility of "deep seated affinity and community" than to exclusion or isolationism ([25], p. 19). Yet the field is also predicated on its critique of the epistemic violence that occurs when metropolitan formulations (like Freud's theories) are treated as trans-human universals. This branch of postcolonialism avows the singularity of the other's experience (see [28]), and stands opposed to the aggression of the demand that the "subaltern speak" in language amenable to our recognition [29]. From this perspective, Craps points out that Caruth's model of cross-traumatic solidarity in Unclaimed Experience can be seen less as a successful example of cross-cultural connection than as an act of erasure, in which non-European experience is subordinated to the desires of the European self ([11], p. 18). Others have pointed out that the dissemination of traumatic narrative can in some situations lead not to community-building, but to the hardening of exclusions - as in the case of Israeli settler colonialism, where, as Dirk Moses has shown, the circulation of Holocaust memories produce not a "cosmopolitan effect" but the justification of "pre-emptive" violence against Palestinians, whose own suffering is eclipsed by the Nazi genocide ([30], p. 96). Notwithstanding the problems this postcolonial perspective reveals, Craps himself remains committed to trauma's potential to enable imaginative boundary-crossing and solidarity, including with those outside the metropolitan centre. He dedicates three chapters of Postcolonial Witnessing to "cross-traumatic affiliation" ([11] p. 72), suggesting that a trauma theory purged of Eurocentrism may yet be forged into a "link between cultures" ([5], p. 56), enabling "visions of cross-cultural solidarity and justice" ([11], p. 101) to emerge from the recognition of pain.

To focus this discussion further, I follow Craps and Ifowodo in suggesting that a crucial resource for pursuing these goals lies in the work of Frantz Fanon, whose books are at once a critique of Eurocentric psychiatry and an avowal of anti-imperial humanism. Fanon's work enacts the trajectory outlined above, beginning in Black Skin, White Masks (1952) with an exploration of how colonialism produces a traumatizing distortion of practices of recognition, before moving in 
The Wretched of the Earth (1961) to a celebration of the de-alienating effects of solidarity in resistance to empire. Fanon's theories manifest both the potentials and pitfalls of postcolonial trauma narratives, and offer a lens through which to read a wide range of textual examples — starting, as he did, with the trauma of the colonized, but also, I show, connecting colonizers, perpetrators, and proletarians as well. What is at stake here is whether the links trauma draws between disparate subject positions amount to anything of substance: whether or not, that is, they form a basis for achieving what Said sees as Fanon's ultimate goal — to go beyond colonial trauma to a form of solidarity that would "bind the European as well as the native together in a new non-adversarial community of awareness and anti-imperialism" ([26], p. 274).

\section{The Ambivalence of Recognition: Trauma and the Colonized}

Fanon's Black Skin, White Masks draws on the phenomenological existentialism of Jean-Paul Sartre and Maurice Merleau-Ponty to explain how, exactly, colonialism causes mental disorders in the colonized. Recognition is fundamental to Fanon's analysis, as he argues that colonialism is traumatizing insofar as it entails the interpellation of subjects by a racialized social order predicated on their non-existence. Fanon reconfigures Hegel's account of the Master/Slave dialectic to account for the material realities of empire, observing that what the master of a colonial setting "wants from the slave is not recognition but work"-meaning the imperial dialectic is not one of "reciprocity" but of domination and the negation of the humanity of the colonized ([31], p. 195). In the words of his biographer, David Macey, the white gaze for Fanon "reproduces the primal experience of [Caribbean] history: slavery and a colonization so brutal as to be a form of trauma or even annihilation" ([32], p. 166). Fanon's key chapter, “The Lived Experience of the Black Man", describes the denial of recognition in precisely these terms, as a traumatic intrusion in which "inside and outside" come into conflict ([2], p. 3). The colonized subject "appeal[s] to the Other so that his liberating gaze [...] would put [him] back in the world", but is instead addressed as a raced object - a "Dirty nigger" whose inferiority is attested to by the "thousand details, anecdotes, and stories" of the dominant order, which he cannot help but consume ([31], pp. 89, 91). "The black man has no ontological resistance in the eyes of the white man", Fanon observes, meaning that the identity returned to him by the gaze is a kind of non-being, a split subjectivity which is at once nothing in itself, and a site upon which the white world attaches its paranoid fantasies ([31], p. 90). This denial of recognition causes the collapse of the "bodily schema", the internalized imaginary correlate of the physical self, and its replacement by a "historical-racial schema" that is "solely negating", "an image in the third person" with which the subject can only identify at the expense of self-harm ([31], pp. 90-91). To be colonized is thus to be "overdetermined from the outside" and "fixed" into an identity that is a source of "shame and self-contempt" ([31], pp. 95-96).

Fanon's account, like the models summarized above, makes trauma a product of first literal and then metaphorical invasion. His colonized man is the victim of material domination that produces a correlating psychic occupation; the colonizer is present to him not only as an external ruler, but as a pathological presence inside his own skin. In Fanon's words, "the black child subjectively adopts the white man's attitude", and "a way of thinking and seeing that is basically white forms and crystallizes in" him ([31], p. 126; emphasis added). Ifowodo points out that this model reworks 
Freud's oedipal scene for the colonial context. Interpellation by the "racial-epidermal schema" is a moment of symbolic castration, one that occurs not (as in Freud) from the prohibition of desire, but from "the self-abnegating effect of racism and political domination" ([10], p. 10). Fanon, thus, avows that "a normal black child [...] will become abnormal at the slightest contact with the white world" ([31], p. 122). We might observe that insofar as this makes trauma a product of colonial penetration, it produces a profoundly gendered theory, one suspicious of both gender and sexual difference and hostile to, for example, black women whose sexual intercourse with white men seems to literalize the traumatic intrusion ([31], pp. 29-35). Indeed, for Fanon non-recognition gives birth to a pathological feminization, as black men are reduced to the order of the "biological" ([31], p. 143) or even "become homosexuals" - a sign, Fanon implies, of the deranged desire for penetration that comes from internalizing the white world's hatred of blackness ([31], p. 158).

Fanon's later work, The Wretched of the Earth, shares with Black Skin, White Masks its view of colonial trauma as a product of material and psychological non-recognition. He observes that colonialism, "because it is a systematized negation of the other, a frenzied determination to deny the other any attribute of humanity, [...] forces the colonized to constantly ask the question: 'Who am I in reality?'” ([33], p. 182). What shifts between the two works is his understanding - in light of the Algerian War of Independence - of how trauma might be resolved and masculinity regained. Black Skin, White Masks focuses on the colonized subject's attempts to compel recognition from the colonizer. Fanon explores the desire to prove to Europeans the stupidity of their racism, and when this inevitably fails he turns to Negritude as a movement committed to the recognition of black culture as valuable in its own right ([31], pp. 102-11). Yet he remains dissatisfied with this response, noting Sartre's characterization of Negritude as "the weaker upbeat in a dialectical progression," an embrace of the particularizing category of race as but a step on the path to the universalizing humanism of "a society without races" (see [31], pp. 111-13; [34], p. 182). For Fanon the demand of the colonized for recognition in his or her concrete, raced particularity is a necessary but incomplete stage of dis-alienation - one destined to fail because it does not disrupt the Master/Slave binary from which trauma originates. The Wretched of the Earth completes the dialectic accordingly, by affirming the necessity that the colonized unite to destroy the colonial order and liberate themselves from the colonizer's gaze altogether. Revolutionary solidarity in war becomes Fanon's cure for imperial trauma: "At the individual level, violence is a cleansing force", he avows. "It rids the colonized of their inferiority complex, of their passive and despairing attitude" ([33], p. 51). Trauma can be overcome, in other words, through the masculinist assertion of self in opposition to the colonizer, resulting in a (gendered) national movement that overthrows the material structures that instantiated trauma in the first place.

Fanon's work thus represents a complex reflection on the nexus between trauma, recognition and solidarity. At our distance from Fanon's revolutionary context, the exclusions of his model are obvious. Not least is its dependence on a homophobic masculinity that would seem to limit its potential for inclusiveness with other groups subject to traumatic non-recognition, especially those denied existence precisely for their gender or sexual nonconformity. Nonetheless, his account of how non-recognition produces trauma, and his emphasis on the need to disrupt traumatizing structures at the systemic level through collective action, remains powerful. What happens, 
therefore, when we turn from this theory to examples from postcolonial literature, and read them in dialogue with Fanon's work? What, in other words, is the narrative of the "native" who in Sartre's phrase lives in the "neurosis introduced and maintained by the colonist" ([35], p. liv)?

An excellent if unexpected example can be found, I suggest, in the work of Afghan writer Atiq Rahimi, who explores the psychological effects of occupation and civil war in novels such as Earth and Ashes (2000 [2002]) and A Curse on Dostoevsky (2013 [2011]). It may seem unusual to turn immediately from Fanon and his Caribbean/European/African context to Central Asia - but Fanon himself declares that imperial trauma "can be found in any race subjected to colonization" ([31], p. 9), and Afghanistan is an example of a society that has been victorious (at least temporarily) in the kind of anti-colonial war that Fanon celebrates. As such, Rahimi would seem a fine place to start.

Earth and Ashes narrates the mental suffering of an elderly farmer travelling cross-country to inform his son that their family has been killed by Russian soldiers [36]. His trauma is depicted formally by a constant slippage between first and second person narration, as though he does not know whether he is himself or an other - an effect that signals his alienation from himself and objectification before the military power that sees in him "no ontological resistance" ([31], p. 90). Rahimi's later novel expands this insight. Set in the early 1990s in the chaotic interregnum between the Soviet defeat and Taliban takeover, A Curse on Dostoevsky shows the psychological consequences of an invasion that has turned Kabul into a place where killing is an "insignificant act" ([37], p. 181). The symbolic persistence of the Russian presence is marked by the continuing importance of ideological and political structures generated by the anticolonial jihad. The victorious Islamic militias are eager to purge the remnants of the old regime, making each individual's membership of a rival collectivity — as Afghan patriot or traitor to Islam — a matter of life and death. Reflecting this context, the novel is replete with instances of interpellation, as characters are addressed according to the position vis-à-vis the anticolonial struggle they are recognized to hold. Even an entrant to the saqi-khana, or house where marijuana is smoked, must therefore declare whether he is "dabarish, bearded," or "tavarish, military", before admittance ([37], p. 26).

This situation places the protagonist Rassoul in a precarious, traumatizing position. The subjectivity he wishes to embody is that of "a man, a savior, and a protector" of his girlfriend Sophia ([37], pp. 35-36). But as the son of a communist, Rassoul, who studied in Leningrad during the war and is an admirer of Dostoevsky, is viewed suspiciously by others. His friends gesture toward his alienation from the national community by calling him "Rassoulovsky," and when he fails to pay his rent he is arrested by the leader of an Islamic militia who accuses him of foreign sympathies:

If you were in my shoes, you wouldn't want to hear a single word of Russian, my friend. They burned down our village. I found my family's remains, burnt to ashes! [...] And while we were mourning our dead, the destruction of our villages, the humiliation of our sisters...you, you were having a grand old time in the arms of little blond white girls, soft and lively as fish...isn't that right? ([37], p. 63).

The Islamist's accusation makes victimization by Russian forces the defining attribute of Afghan-Islamic identity. Rassoul's physical presence in the Soviet Union during the war, and his 
resulting immunity from colonial violence, renders him abject to the national community. There is nothing he can do to challenge his exclusion, for the novel makes clear that his subjectivity is a product of how he is recognized by others, rather than of his own agency. Thus when Rassoul tries to distance himself from communism by attributing belief in it solely to his father, he is further excluded - because for the militants, disrespecting one's father means disregarding Islam. In these ways Rassoul is alienated from his community, interpellated by externally-constituted social identities (Russophile, atheist, traitor) that deny him a place in post-occupation Kabul.

This alienation has psychological consequences. As in Earth and Ashes, Rahimi signals his protagonist's mental distress by repeatedly switching narrative voice, making much of the novel a dialogue between Rassoul's first-, second- and third-person subjectivities. Even more striking is the degree to which his supposed Russian identity — imposed by his father and Islamic militias - colonizes his selfhood and controls his actions. The defining moment occurs when Rassoul kills an elderly pawnbroker for her money. As he strikes her with an axe, Rassoul realizes that he is re-enacting Raskonikov's deeds in Crime and Punishment. He curses his "naive identification with a fictional character" ([37], p. 16), but finds himself nonetheless compelled to repeat the novel's actions. The futility of his identification is apparent: Rassoul is aware that Crime and Punishment "only made sense within the context of [Dostoevsky's] society, [and] his religion", ([37], p. 211) meaning that to recreate it in Afghanistan produces nothing but an "absurd pastiche" ([37], p. 144). This meaninglessness is reinforced by the fact that after the killing Rassoul becomes mute, unable to respond to the interpretations other people impose on his actions.

Rassoul's trauma can thus be read as an instance of what Fanon calls the "non-being" of the colonized subject, who "hail[s] the world, and the world amputate[s] [his] enthusiasm" ([31], p. 94). The novel traces Rassoul's attempts to demand recognition from his interlocutors, and their continual refusal to concede it. This makes it, I argue, an analysis of the traumatic impact of colonization on Afghanistan. Though technically independent at the time of the narrative, Afghanistan's recent history of colonial control - and looming future of theocracy and American re-occupation - makes Rassoul an example of how the colonized subject is negated by his or her non-recognition within frameworks of affiliation structured according to the Master/Slave binary (in this case, Russian-communist-atheist on one hand, Afghan-Muslim-patriot on the other]. At one point, Rassoul visits a doctor for help and is told that his problem is psychological, the cure for which is to "relive the situation" that caused it ([37], p. 95). Yet working-through by repetition is impossible, for his attempts to do so meet with confusion and disregard from those to whom they appeal for recognition. When he returns to the scene of the crime, for example, he finds the body has disappeared, and "no one is talking about" his victim's death ([37], p. 181). Similarly, when he tries to confess to Sophia she interprets his written narrative — for he cannot speak — as poetry ([37], p. 143), then denies he could be guilty for he is but "an innocent little ant. A nothing" ([37], p. 145). His final attempt to impose selfhood comes when he turns himself in and demands a trial. This fails when the court cannot find a place for his actions in the canons of sharia law. The judge sums up Rassoul's problem when he declares "I don't give a damn about your story. Tell me which faction you're from!" ([37], p. 193). Rassoul's answer-"None"- "makes absolutely no sense" in this 
"war-torn land" ([37], p. 193), and so condemns him to perpetual non-being within the postcolonial Afghan imaginary.

Rassoul is thus forced to ask himself the question that for Fanon is symptomatic of the trauma of colonial non-being: "Who am I in reality?" ([33], p. 182). His trauma is indeed both a literal and symbolic effect of invasion, insofar as it reflects the destructive impact of Russian occupation and anti-colonial war, events that generate a form of psychic colonization in which the Afghan subject becomes a farcical imitation of a character in one of their novels. On this basis, we could compare A Curse on Dostoevsky to any number of literary works from other postcolonial settings - such as Tsitsi Dangarembga's Nervous Conditions (1988), which depicts the psychological alienation of native Rhodesians in a white-dominated school system [38], or V. S. Naipaul's The Mimic Men (1967), which presents Caribbean politics as the acting-out of a "fragmented, inorganic" society in which each person is an "intruder, [...] born for other landscapes" ([39], pp. 206-7). Rahimi's work foregrounds the physicality of colonial trauma, offering the protagonist's corporeal pain for readers' affective engagement. But he makes clear that recognition cannot lead in any straight path to solidarity. After all, it is not only that Rassoul is colonized by an imperial Russian identity, but also that he is excluded from the anti-colonial collective that, with the invader expelled, has now turned on itself. The novel thus asks questions that Fanon, who died before seeing the results of Algerian independence, could not answer: Who, exactly, are we recognizing in a protagonist unsure if he is or is not a native-and what collective subjectivity would emerge were it even possible to do so?

\section{Aggressive Recognition: Trauma and the Colonizer}

As Homi Bhabha suggests in his preface to the recent re-translation of The Wretched of the Earth, Fanon's greatest insights are usually seen to lie in what they reveal about colonial situations in which inequality is raced, and domination is made visible as the divide between black and white ([40], p. xiii). But as I have noted, Fanon saw his work as widely applicable, and Bhabha notes the "universalizing, generalizing tendency" of his theories ([40], p. xvii). Fanon saw race as an effect of colonization rather than its cause, avowing that the object of the racist gaze is fixed into his identity "the same way you fix a preparation with a dye" ([31], p. 89). Identity is the product of power; it is existence rather than essence, meaning "the black man is not. No more than the white man" ([31], p. 206). This understanding of race makes Fanon's theory potentially applicable to a situation like Afghanistan, where race is a minor factor in a social context violent for quite different reasons. What matters is rather the traumatic effect of material domination, as the colonized is disarticulated by the intrusion of identities produced and disseminated by the colonizer, who, as Fanon argues and Rahimi dramatizes, takes up residence within the psyche as a kind of unclean foreign matter. Traumatic alienation is a reflection of inequality, which is why Fanon argues that national liberation - the destruction of the imperial hierarchy and seizure of the material determinants of recognition - is the only way to overcome it.

From this point of view, to suggest that within the structures of that hierarchy the colonizer himor herself could also be a trauma victim seems outrageous, an affront to political realities and a distortion of Fanon's model. Yet consider the following passage by the Australian historical 
novelist Kate Grenville. It describes the moment, in the first decade of the nineteenth century, when her English convict protagonist - a white, working-class man-arrives on the shores of New South Wales as an involuntary settler and encounters his first Aborigine:

It seemed at first to be the tears welling, the way the darkness moved in front of him. It took a moment to understand that the stirring was human, as black as the air itself. His skin swallowed the light and made him not quite real, something only imagined ([41], p. 5).

This passage reproduces the imperial racial binary. William Thornhill, the poor white Londoner, is initially unable to categorize the Aboriginal man, who hovers between the status of human and non-human, real and unreal. The encounter poses an ontological and epistemological challenge to Thornhill on a par with the material obstacles he faces: he must make sense of this strange human in the same way that he must learn to understand the "alien stars" and "cold earth" of his new home ([41], p. 4). The passage continues in a way that shows how Thornhill attempts ontological mastery by projecting an objectifying "racial epidermal schema" to make the Aborigine comprehensible:

His eyes were set so deeply into the skull that they were invisible, each in its cave of bone. The rock of his face shaped itself around the big mouth, the imposing nose, the folds of his cheeks. Without surprise, as though he were dreaming, Thornhill saw the scars drawn on the man's chest, each a neat line raised and twisted, living against the skin ([41], p. 5).

Thornhill's lack of surprise signals the ease with which the Aboriginal man is subsumed to the settler imaginary. Metaphors like "cave of bone" and "the rock of his face" allow the black body to be grouped together with the landscape as elements of the foreign environment. At the same time, Thornhill's hyperawareness of the Aborigine's scarification foregrounds his existence, for the settler, as a being made of skin. The passage thus demonstrates how the settler manages his encounter with racial difference by reducing blackness to the status of object, against which his own subjectivity shines forth.

To this extent, Grenville's narrative accords with Fanon's model, albeit with the psychological consequences of objectification on the Aboriginal man left undescribed. Where The Secret River becomes provocative - and in so doing problematizes the link between recognition and solidarity outlined thus far-is in its suggestion that Thornhill, the settler, is also traumatized by the encounter. The passage continues:

He took a step towards Thornhill so that the parched starlight from the sky fell upon his shoulders. He wore his nakedness like a cloak. Upright in his hand, the spear was part of him, an extension of his arm.

Clothed as he was, Thornhill felt skinless as a maggot. The spear was tall and serious. To have evaded death at the end of the rope, only to go like this, his skin punctured and blood spilled beneath these chilly stars! ([41], p. 5).

Despite his success in subsuming the Aboriginal man into a "racial epidermal schema", Thornhill still perceives in him a physical materiality and power to cause harm that belies Fanon's claim that "the black man has no ontological resistance in the eyes of the white man" ([31], p. 90). On the 
contrary, it is Thornhill, in this moment, who finds himself reduced to corporeality. He becomes "skinless as a maggot" before the black man's spear-a phallus that threatens to penetrate his body and put "inside and outside into a strange communication" ([2], p. 3) in a way that recapitulates Fanon's gendered anxieties. As a convict, Thornhill is in Australia only because he has narrowly avoided execution in England. His encounter with the black man - above all, Grenville's imagery makes clear, with his terrifying blackness - reinforces his awareness of vulnerability. His body, already subject to manipulation and confinement, is again rendered incomplete - "skinless" — by an external force that reveals his inability to maintain subjective boundaries.

The settler's trauma emerges here not only from the abuses of imperial power, but also from the psychic shock of encounter with Australia's Indigenous population. It is worth noting that the scene has a real-life counterpart. Grenville is building upon her own experience in early-2000s Sydney, in which she made eye contact with an unknown Aboriginal woman and felt "a sudden blade of cold" go through her ([42], p. 12). Unlike the settler's literal vulnerability, Grenville's imaginary penetration comes from her recognition that the Aboriginal woman has a more authentic claim to possession of Australia than she - that in comparison to the woman's "sixty thousand years" of history ([42], p. 12), Grenville is "foreign" to her land of birth ([42], p. 194). Thornhill's panicked recognition of his exposure to penetration is a similar moment of castration anxiety, as he discovers his physical and psychic incompleteness when compared to the confident black man, as at home in his own skin as he is on his own soil. This power of blackness to alienate recurs throughout the novel. When Thornhill occupies farmland beyond the frontier, he is forced to acknowledge that his ignorance of the Australian environment undermines his ability to provide for his family, and hence undercuts his masculinity, especially compared to the Aborigines who hunt and eat without effort. Thornhill tries to establish possession of the land by "drawing a line" ([41], p. 235) around his space, but he can never maintain this boundary, as the Aborigines persistently - and eventually violently-breach his flimsy defenses.

Within the symbolic economy of the novel Aborigines are metaphorically indistinguishable from land - a pattern that makes it ambiguous whether the settler is traumatized by the threat of real anticolonial violence, or by his own lack of control in the foreign environment: "Their bodies flickered among the trees, as if the darkness of the men were an extension of bark, of leaf-shade, of the play of light on a water-stained rock. The eye could peer but not know if it was a couple of branches over there, or a man with a spear, watching” ([41], p. 198). By employing such metaphors, Grenville is mobilizing a colonial convention that conceives of the male settler as traumatized by settlement itself. As Ann Curthoys describes,

In the [Australian] pioneer legend, the obstacles the settler-hero must fight are mainly the land itself. [...] While the unknown interiors of colonised places exercised explorers and colonisers everywhere, as in the notion of "darkest Africa", the Australian conception was marked by a sense that it was less the unknown Indigenous people than the waterless interior of the country itself that could induce disorientation, madness, suicide, death ([43], pp. 153-55). 
This notion is central to the Australian settler imaginary, which is replete with such declarations as "no human being can ever know heart's ease in a foreign land" ([44], p. 144), and the novelist Patrick White's famous suggestion that "true knowledge" of the continent "comes only of death by torture in the country of the mind" ([45], p. 446). Indeed, White's archetypical colonist Voss, the psychic vehicle of this claim, ends his attempt to cross Australia in pieces-beheaded by the Aborigines who block his dis-alienation from the country ([45], p. 394), and thus foreclose on the possibility of a unified colonizing subjectivity.

White Australian fiction thus presents settlers as at least as anxious about their bodies "in a spatial and temporal world" ([31], p. 91) as Fanon's colonized "Negroes"-but for different, indeed contradictory, reasons. In fact, Fanon himself seems to have considered this possibility, noting in Black Skin, White Masks that "the body of the black man hinders the closure of the white man's postural schema at the very moment when the black man emerges into the white man's phenomenal world" ([31], p. 138). As we would expect from his anti-colonial focus, however, he does not build on this insight. We can nonetheless look to settler colonial literature for evidence in support of this view. Depictions of the settler's disunity and castration anxiety can be found in numerous colonial contexts, from Naipaul's dismay at the "artificial and fragmented" people of Argentina, "made deficient and bogus by [their] myths" of purity ([46], p. 361), to Stephen Turner's characterization of New Zealand settler culture as defined by "corrosive doubt" about its own legitimacy ([47]; see also [48]). What these discussions reveal is that insofar as the settler is rendered incomplete by the prior and superior presence of the Indigene, so the Indigene becomes psychically indispensable to the settler as the only subject who can grant the right to be in the colony (see [1], pp. 58-68). Hence, as Naipaul observes, the paradox of Argentines inventing a "mystical, purifying claim" to identity with the Indians their ancestors destroyed ([46], p. 354), or of Thornhill, at the end of Grenville's narrative, searching for a sign that the Aborigines he himself killed might yet live to grant absolution ([41], pp. 332-34). Fanon's colonized person is negated by the racist gaze; the colonizer, these settler narratives suggest, is likewise fragmented before those he colonized, to whom he must now address the humiliating plea: make me whole!

Is solidarity to be found in this asymmetric traumatic binary? Each side seeks recognition from the other, yet as the elision of native and landscape in the examples above suggests, the acknowledgement the colonizer demands in no way entails recognition of the humanity of the colonized. What is wanted is symbolic acquiescence; nothing - and certainly no restoration of conquered lands - is offered in return. Indeed, it is precisely to colonize better, to occupy place more completely, that the colonizer requires recognition from the native. From the other side of the binary, what the colonized needs-according to the Fanon-is not really the colonizer's recognition but the end of his domination: "To destroy the colonial world means nothing less than demolishing the colonist's sector, burying it deep within the earth or banishing it from the territory" ([33], p. 6). Fanon accepts that settlers can make a place for themselves within the decolonized community ([33], p. 95) - but only to the extent that they abandon their superiority, and the demand for recognition it entails. For colonists, in other words, solidarity with the native does not mean their trauma is resolved via recognition, but rather it entails the very negation of their subjectivity itself. 


\section{The Limits of Recognition: Trauma and the Perpetrator}

The idea that a colonizer might also be seen as a trauma victim - despite the massive privileges this subject position entails - provokes the kind of discomfort we normally associate with the most troubling figure of trauma discourse: the perpetrator. I suggest that if settler colonialism presents difficulties for the idea of cross-traumatic solidarity by exhibiting an aggressive, negating demand for recognition, the trauma of the perpetrator marks the limits of the recognition ethos. Fanon himself accepts that colonial soldiers could be traumatized by their own actions, and in the final chapter of The Wretched of the Earth provides examples of French torturers haunted by their victims' screams. Yet it is not clear how recognition of such suffering makes for a meaningful response. Notwithstanding Craps' assertion that "calling someone a trauma survivor or trauma victim does not in and of itself confer any moral capital on that person" ([11], p. 15), the overwhelming tendency of trauma narratives - those discussed above and below-is to demand recognition for suffering. Examples of perpetrator-trauma literature, however, show that such figures problematize recognition, forcing us to ask what "cross-cultural solidarity" ([11], p. 2) could mean in this case.

Postcolonial literature is replete with traumatic narratives predicated on recognition for the suffering of perpetrators. Perhaps the most iconic examples come from child-soldier novels. These texts foreground the ambivalence of their readers' response to the perpetrator by making questions of affective engagement central to their narratives. In Ahmadou Kourouma's Allah n'est pas obligé (2000)/Allah is Not Obliged (2006), for example, the narrator Birahima draws obsessive attention to the linguistic and affective dimensions of his story, stressing how difficult it is to create an idiom adequate to the contradictions of his colonial-perpetrator identity, while nonetheless demanding from readers their recognition of his self:

Suis p'tit nègre. Pas parce que suis black et gosse. Non! Mais suis p'tit nègre parce que je parle mal le français. C'é comme ça. Même si on est grande, même vieux, même arabe, chinois, blanc, russe, même americain; si on parle mal le français, on dit on parle p'tit nègre, on est p'tit négre quand même ([49], p. 9).

I'm a little nigger. Not 'cos I'm black and I'm a kid. I'm a little nigger because I can't talk French for shit. That's how things are. You might be a grown-up, or old, you might be an Arab, or Chinese, or white, or Russian - or even American-if you talk bad French, it's called parler petit nègre-little nigger talking-so that makes you a little nigger too ([50], p. 1).

Birahima's story (in its English edition further mediated by translator Frank Wynne) blends Ivoirian French with Malinké vocabulary_- "Black Nigger African talk" ([50], p. 2) used, unlike the Negritude considered as a path to authenticity by Fanon ([31], pp. 102-11), primarily to curse. This mix invokes both linguistic virtuosity and cultural distance to question the implied audience's urge to sympathize with the narrator, even as it implies - ironically — that bad French might be a source of cross-cultural solidarity: a shared identity in which everyone, whether "arabe, chinois, blanc, russe, même americain", is un "p'tit nègre". 
The ambivalence of this call for recognition is reinforced by the difficult ethical position into which Birahima inserts his readers, making them at once witnesses to his crimes and complicit with his jokes:

Suis pas chic et mignon parce que suis poursuivi par les gnamas de plusieurs personnes. (Gnama est un gros mot nègre noir africain indigène qu'il faut expliquer aux Français blancs. Il signifie, d'après Inventaire des particularités lexicales du français en Afrique noire [one of the four dictionaries Birahima regularly consults], l'ombre qui reste après le décès d'un individu. L'ombre qui devient une force immanente mauvaise qui suit l'auteur de celui qui a tué une personne innocente.) Et moi j'ai tué beaucoup d'innocents au Liberia et en Sierra Leone où j'ai fait la guerre tribale, où j'ai été enfant-soldat, où je me suis bien drogué aux drogues dures. Je suis poursuivi par les gnamas, donc tout se gâte chez moi et avec moi. Gnamokodé (bâtardise)! ([49], p. 12).

I'm not some cute kid on account of how I'm hunted by the gnamas of lots of people. (Gnamas is a complicated Black Nigger African Native word that I need to explain so French people can understand. According to the Glossary, a gnama is the shadow of a person that remains after death. The shadow becomes an immanent malevolent force which stalks anyone who has killed an innocent victim.) And I killed lots of innocent victims over in Liberia and Sierra Leone where I was a child doing tribal warfare, and where I got fucked-up on lots of hard drugs. The gnamas of the innocent people I killed are stalking me, so my whole life and everything around me is fucked. Gnamokodé! ([50], p. 4).

Birahima's confession of perpetrator status is rendered ambivalent by his self-positioning as the persecuted victim of spirits. Even as he denies his appropriateness as an object of sympathy ("I'm not some cute kid"), his naivety of phrasing turns killing into something like a game ("j'ai fait la guerre tribale"/"I was a child doing tribal warfare"). At the same time, he demonstrates his comedic control over language by punning on gnama (spirit)/gnamokodé (bastard) — or, in the French, constructing sentences in which serious content is undercut by playful form, as in the alliterative "je me suis bien drogué aux drogues dures". All the while, he is parodying the language of Western descriptions of Africa ("immanent malevolent force") and poking fun at how much he has to explain "aux Français blancs" who think they know everything. This "cheeky foul-mouthed attitude" ([50], pp. 4-5) makes his story immense fun to read, as scenes of horror are punctured by multilingual profanity and an ironic disregard of the sensitivities of his audience. Kourouma's humor calls into question the ethics of his Western readers' consumption of war stories, especially those told by self-proclaimed killers. Birahima invites our complicity, and asks us to ignore the fact that his victims, unlike him, can tell no more jokes. The novel thereby unsettles our presumption of solidarity, problematizing the ethical ambiguity of the traumatized perpetrator even as it constantly reminds us that we are listening to a child — one whose moral culpability is an open question.

A similar set of anxieties can be seen in the motif of silence, central, as for Rahimi's A Curse on Dostoevsky, to Chris Abani's Song for Night (2006). Abani's child-soldier protagonist, My Luck, begins with the declaration that "what you hear is not my voice" ([51], p. 1). Like Rassoul, and in contrast to Birahima, he has been rendered mute by his wartime experience. He must therefore 
struggle to make himself understood to his implied audience, which, he makes clear, is separated from him by linguistic and cultural barriers:

Of course if you are hearing this any of this at all it's because you have gained access to my head. You would also know then that my inner-speech is not in English, because there is something atavistic about war that rejects all but the primal language of the genes to comprehend it, so you are in fact hearing my thoughts in Igbo ([51], p. 3).

The novel is structured around this tension between words and understanding, with each chapter headed by a title drawn from the sign language My Luck composes to grasp the "atavistic" experience of war. This corporeal language strives to communicate affect directly, transforming abstractions into embodied signs. Hence "fear is an open hand beating over the heart" ([51], p. 143), and "lonely is a cold, itchy back" ([51], p. 61). The most striking example of embodiment lies in My Luck's mechanism for remembering his losses. He cuts a series of crosses into his arms, producing a "mnemonic device" or "graveyard" that, "like Braille on my arm" ([51], pp. 7-8), records deaths-left arm for loved ones, right "for each person that I enjoyed killing" ([51], p. 21). My Luck's body thus becomes the medium through which we gain access to the "unrecognizable yet familiar objects" of traumatic memory ([51], p. 21). It also foregrounds the unreliability of that memory, for as the novel develops we learn that My Luck is not the embodied subject he claims to be, but a spirit wandering in search of its corpse.

My Luck's alienation points to one of the sources of deepest ambivalence in perpetrator-trauma narrative. As his muteness and scarification suggest, My Luck's trauma resides in his (imagined) flesh, as both a wound and secondary skin that distances him from full possession of his memories. The most disturbing part of that experience is thus inaccessible to him, except insofar as it is encoded as a set of corporal signs that he, as the medium of transmission itself, cannot access:

What does it mean to hide in a ceiling, in that narrow hot crawl space crouched like an animal smelling my own scent, full of it and grateful for it, while my mother stays below, $[. .$.$] waiting to deflect the anger of people intent on murder, my murder, [\ldots]$ and I watch what happens below and I am grateful that I can smell my smell, smell my smell and live while below me it happens [...] ([51], p. 25).

The event witnessed by this passage is the murder of My Luck's mother, a trauma to which his narrative recurs but never describes. Visual representation of what he saw is always blocked by a switch in attention to bodily sensation, whether of smell as described here or, in a later passage, the extreme heat of a "hiding place" that was like "an oven" ([51], p. 73). In this way, My Luck's body functions less as a vehicle for traumatic communication than as anstacle or limit to understanding, both for his implied audience and himself.

The subjective dissociation created by this blockage is most troubling in a scene in which My Luck recalls committing rape:

John Wayne [My Luck's commanding officer] pulled her out and threw her on the bed.

Ripping her clothes off, he ordered me to rape her. I hesitated [...]. 
"Rape or die", he said, and I knew he meant it. As I dropped my pants and climbed onto the woman, I wondered how it was that I had an erection. Some part of me was enjoying it and that perhaps hurt me the most ([51], p. 65).

My Luck's version of events shields him from subjective participation in his crime. Two independent agents intervene between the narrating "I" and the act committed: John Wayne, who orders it, and his own body, the alienated "some part of me" that participates without apparent consent. The involuntary nature of this rape transforms it from a crime against the woman to a trauma of My Luck himself. "I moved, and as much as I wanted to pretend, I couldn't lie, I enjoyed it" he admits ([51], p. 65). The scene makes his body guilty of raping not only the woman, but, in a sense, My Luck himself-both are forced into non-consensual sex.

In this way Song for Night presents trauma as the subjective disarticulation of the perpetrator. To use Fanon's description, My Luck becomes an object, his body "returned to [him] spread-eagled, disjoined, redone", no longer part of his self ([31], p. 93). This overlap suggests a comparison between the object of racism and the perpetrator of traumatizing crimes-yet to make this comparison seems almost obscene, insofar as it elides the vast ethical and political differences between these subject positions. There is something unsettling about My Luck's dissociation. Like Rassoul, who claims that it was not he, but the spirit of Raskolnikov, who murdered, My Luck's alienation seems to exonerate him from responsibility for his actions. My Luck presents the rape as traumatic for him rather than for his victim - whom he even imagines comforting him as "a boy lost" and undeserving of his fate ([51], p. 65). Both Abani and Kourouma (and other child-solider novelists like Uzodinma Iweala [52] and Ken Saro-Wiwa [53] present their perpetrator narrators as objects of readers' sympathy. But in doing so they bring those readers' ethical responses into question, asking what exactly they are recognizing in a subject whose identity is predicated on the traumatic non-recognition of their own actions. With which entity-the narrating "I" or the perpetrating "it" - are we supposed to forge "cross-cultural solidarity" here ([11], p. 2)? Fanon offers no answers to this question.

A sign of the potential irreconcilability between perpetrator and victim traumas can be found in Edwidge Danticat's The Dew Breaker (2004), a novel concerned with the traumatic impact of political violence in Haiti. A limit example of solidarity can be discerned in the narrative's central relationship, in which the eponymous "dew breaker" or torturer is married to the sister of one of his victims. Each is scarred by his or her experiences (he literally, she emotionally), yet their relationship survives on the pretense that neither knows the other's true identity:

He endorsed the public story, the one that the preacher had killed himself. And she accepted that he had only arrested him and turned him over to someone else. Neither believing the other nor themselves. But never delving too far back in time, beyond the night they met. She never saw any of the articles that were eventually written about her brother's death. She was too busy concentrating on and revising who she was now, or who she wanted to become ([54], p. 241).

Danticat reveals how perpetrators and victims are entangled by trauma, but offers no resolution, no prospect that the other might return lost pieces of the self, and no confidence that narrating pain is a 
necessarily progressive act. Danticat's characters are linked by their refusal to recognize the basis of their connection. In their silence they bear witness to a trauma for which recognition is not a cure, but a limit beyond which survival would be impossible.

\section{Beyond Recognition: Trauma and the Proletarian}

The examples enumerated to this point show that trauma is a mobile concept, one present in various branches of postcolonial literature. I have suggested that comparison reveals significant tensions between modes of traumatic experience, some forms of which exist along axes of contradiction that make the notion of solidarity via recognition problematic. We seem to have reached a point beyond which Fanon cannot take us. There are, however, other ways to conceive of solidarity than through recognition, and in this final section I want to explore one last subject of postcolonial trauma. I suggest that the transnational proletarian or third-world migrant offers a different way to think of trauma, one that goes beyond recognition to an alternative, more critical model of cross-traumatic solidarity - a place from which Fanon's anti-imperial collective comes into view.

The precarious status of migrant workers under neo-liberal globalization has been highlighted recently by the scandal surrounding Qatar's 2022 soccer World Cup bid. According to contested media reports [55-57], as many as one Nepali migrant worker has been killed every two days on Cup-related building sites. This toll likely underrepresents the true scale of the disaster, as it does not include workers from India, Bangladesh, the Philippines, and elsewhere - to name just a few of the countries worldwide that are dependent on remittances from migrant labor. As possessors of nothing but labor power, migrant workers are extremely vulnerable to exploitation, and benefit from few civil or political protections. This has led some reports to describe their experience in Qatar as "forced labor" or even "slavery", as they are forbidden from leaving the country without their employer's consent [56]. This case is symptomatic of material conditions in emergent metropolitan zones in the Gulf and South East Asia, and similar circumstances pertain for many workers in China, Europe, and the Americas. It is rare to think of such subjects as the victims of trauma, but literary texts that explore such experiences frequently draw on exactly that model to conceptualize them.

Chimamanda Ngozi Adichie's 2012 novel Americanah, for instance, focuses on two characters who temporarily occupy the migrant proletarian identity—and, in so doing, present a way to think of traumatic solidarity that goes beyond the more "classical" narrative of Half of a Yellow Sun. Ifemelu and Obinze are not refugees; they migrate in the hope that the United States and United Kingdom, respectively, might offer better opportunities than their native Nigeria. Their status means neither fits the criteria of suffering that metropolitan residents require to extend recognition, making their position on arrival even more precarious:

[The liberal-minded whites Obinze meets in London] all understood the fleeing from war, from the kind of poverty that crushed human souls, but they would not understand the need to escape from the oppressive lethargy of choicelessness. They would not understand why people like him, who were raised well-fed and watered but mired in 
dissatisfaction, conditioned from birth to look toward somewhere else, eternally convinced that real lives happened in that somewhere else, were now resolved to do dangerous things, illegal things, so as to leave, none of them starving, or raped, or from burned villages, but merely hungry for choice and certainty ([58], p. 276).

Despite their relative privilege compared to 'genuine' refugees, both characters experience trauma from the systemic non-recognition of racism, and from their subjection to state institutions designed to harass migrants. For Obinze, life in England is lived "invisibly, his existence like an erased pencil sketch" conditioned by constant alertness to the danger posed by "anyone in a uniform, anyone with the faintest scent of authority" ([58], p. 257). When he is eventually caught and deported he feels "raw, skinned, the outer layers of himself stripped off"-_"ashamed" ([58], p. 281) by his reduction to the confined body of the illegal immigrant, just as Fanon feels "shame and self-contempt" for his raced self ([31], p. 96).

Ifemelu, as a woman as well as a migrant, is even more vulnerable (her experience pointing again to the gendered limitations of Fanon's account). Excluded from legal employment by the terms of her student visa, and yet unable to survive without income, she has no choice but to attempt sex work. Adichie presents this experience as a trauma that alienates Ifemelu from her own body, but not because (as Fanon suggests) sex with a white man marks her internalization of racism, but because it signals her reduction to proletarian objecthood:

She sat naked on her bed and looked at her life, in this tiny room with the mouldy carpet, the hundred-dollar bill on the table, her body rising with loathing. She should never have gone there. She should have walked away. She wanted to shower, to scrub herself, but should could not bear the touch of her own body, and so she put on her nightdress, gingerly, to touch as little of herself as possible ([58], p. 154).

As in Half of a Yellow Sun, the body works here as a vector for both Obinze's and Ifemelu's (different but comparable) traumatic experiences. Yet in Americanah the body functions not just as a site of sympathetic recognition but also as the point at which capital impinges on the migrant subject, transforming him or her into a unit of labor. For this reason, Adichie makes clear that mere recognition is not enough. She dismisses the white consumption of African trauma as "self-indulgence," and attacks the uncritical belief that pity will "smooth all the scalloped surfaces of the world" ([58], p. 163). Recognizing the situation of figures like Obinze and Ifemelu is nothing but a first step: feeling their pain does nothing unless supplemented by a critique of the forces that cause it.

Adichie's shift from her position in Half of a Yellow Sun is further signaled by her account of how Americanah's traumas resolve. Where Olanna works through her pain via narration and subjective recognition, Ifemelu and Obinze recover when they move out of the traumatizing proletarian subjectivity and into social positions that afford them agency and material comfort — as a successful blogger in one case, and businessman in the other. Recognition is not a significant factor. In both instances the move occurs through the intervention of outside forces, as luck and unexpected help combine to lift them out of poverty and vulnerability. Indeed, Adichie openly signals the role of fantasy and wish-fulfillment at this point in her narrative, describing the 
relationship between Ifemelu and Obinze - their triumphant embodiment as satisfied lovers - as a time of "heady days full of cliché" ([58], p. 449). I read this departure from realism not as an aesthetic failing, but as a mark of self-awareness, as Adichie notes that while she has rescued her characters from their fate, the structures that led to their trauma remain in place - and in a more naturalistic narrative, would trap them permanently in a cycle of oppression. Ifemelu and Obinze have been plucked free by the author who plays deus ex machina, but we cannot doubt that others will quickly filled their places. Trauma, the novel thus implies, persists as a structural effect of the social order, brutalizing victims with disregard for who they happen to be.

I suggest that Adichie's shift in focus in this novel points to a way to approach trauma that might avoid many of the tensions described in the previous sections. A critical politics of traumainducing structures would not be derailed by the fact that trauma victims may occupy subject positions (like the colonizer) for which recognition reasserts inequality, or who (like the perpetrator) may not be worthy of sympathetic esteem. This would allow us to read critically a novel like Okey Ndibe's Foreign Gods, Inc. (2014), whose protagonist is marginalized by his inability to find dignified work in New York City, and who, after looting a shrine in his home village, sells the deity to an American trader. This act of sacrilege leads to Ike's psychic breakdown, but rather than simply a trauma, Ndibe's moral schema presents his suffering as both divine justice and an implied critique of the capitalism that reduces sacred objects to commodities, destroys indigenous life-worlds, and exploits workers to whom it offer no hope of social inclusion [59]. In other words, the novel invites readers to respond not merely by recognizing its protagonist's pain (some of which is deserved), but by coming to an enhanced political awareness of the need to change the institutional structures that create it, and that by rendering migrant proletarians abject make their self-destructive acts seem reasonable.

A similar dynamic emerges from Brian Chikwava's Harare North (2009), which offers a corresponding critique of British capitalism [60]. As Madhu Krishnan describes, Chikwava resists his readers' desire for affective identification by focusing on a "fundamentally unreliable" firstperson narrator ([61], p. 45). As an out-of-favor member of Robert Mugabe's youth militia, the narrator is in London trying to raise funds for the bribes he needs to return home safely; he is at once a victim and facilitator of violence. Nonetheless, his psychic breakdown under the pressures of migrant proletarian existence works effectively as a critique of "the schema of global iniquity" that ensures his "dislocation and dissociation" ([61], pp. 48-49), without obscuring his role as a contributor to political violence in Zimbabwe. Chikwava's novel, like Ndibe's, highlights the fact that no individual can fully inhabit the identity of perfect trauma victim. All, like Adichie's Obinze, "raised well-fed and watered but mired in dissatisfaction" ([58], p. 276), will be more or less compromised. Yet once we abandon the presumption that recognition is a sufficient response to pain, we can see that there is a different way to approach trauma: one predicated less on solidarity with the traumatized (who may or may not be an ally for progressive ends) than on solidarity against injustice, and for a more equal world in which traumatizing structures are destroyed. The affective shift takes us from sympathy to anger - an anger that, as David Macey argues, is necessary to do justice to Fanon's radical humanism ([32], p. xv). 


\section{Conclusions}

This survey thus demonstrates that trauma is one of the most widespread and provocative terms in contemporary postcolonial literature. It can be discerned in a huge variety of material and cultural circumstances, many of which differ sharply from the European context of Freud's original theories and from the raced circumstances of Fanon's postcolonial revision. As these differences reveal, not all traumas are equal, and while the term provides a basis for comparison across national, religious, racial and linguistic boundaries, it cannot reduce the specificity of these experiences to a unitary model. The idea that some form of ethical or political solidarity might emerge from the recognition that others bear vulnerable bodies is admirable; as I have argued, however, the ambivalence of recognition for many postcolonial traumas makes this goal problematic. Trauma theory will only be effective for postcolonial analysis if it is supplemented by a critical materialism that pays attention to the specificities of setting, and which is attuned to the power hierarchies that differentiate experiences and make what is progressive in one context regressive in another. The colonized and colonizer, like the perpetrator and proletarian, may indeed all be victims of trauma - but they are not for that reason alone commensurable. Only when that fact is recognized can a genuine critical solidarity commence.

\section{Conflicts of Interest}

The author declares no conflict of interest.

\section{References}

1. Hamish Dalley. The Postcolonial Historical Novel: Realism, Allegory and the Representation of Contested Pasts. Basingstoke: Palgrave Macmillan, 2014.

2. Roger Luckhurst. The Trauma Question. London and New York: Routledge, 2008.

3. Chimamanda Ngozi Adichie. Half of a Yellow Sun. London: Harper Perennial, 2007.

4. Sigmund Freud. "Beyond the Pleasure Principle." In The Standard Edition of the Complete Psychological Works of Sigmund Freud. Edited and translated by James Strachey and Anna Freud. London: Hogarth Press, 1955, pp. 7-64.

5. Cathy Caruth. Unclaimed Experience: Trauma, Narrative, and History. Baltimore: Johns Hopkins University Press, 1996.

6. Dominick LaCapra. Writing History, Writing Trauma. Baltimore: Johns Hopkins University Press, 2001.

7. Chimamanda Ngozi Adichie. “African 'Authenticity' and the Biafran Experience.” Transition 99 (2008): 42-53.

8. Tony Simoes da Silva. "Embodied Genealogies and Gendered Violence in Chimamanda Ngozi Adichie's Writing.” African Identities 10 (2012): 455-70.

9. Zoe Norridge. "Sex as Synecdoche: Intimate Languages of Violence in Chimamanda Ngozi Adichie's half of a Yellow Sun and Aminatta Forna's The Memory of Love." Research in African Literatures 43 (2012): 18-39. 
10. Ogaga Ifowodo. History, Trauma, and Healing in Postcolonial Narratives: Reconstructing Identities. New York: Palgrave Macmillan, 2013.

11. Stef Craps. Postcolonial Witnessing: Trauma Out of Bounds. New York: Palgrave Macmillan, 2013.

12. Natalie Melas. All the Difference in the World: Postcoloniality and the Ends of Comparison. California: Stanford University Press, 2007.

13. Teju Cole. Open City. London: Faber and Faber, 2011.

14. Kai Erikson. "Notes on Trauma and Community." In Trauma: Explorations in Memory. Edited by Cathy Caruth. Baltimore: Johns Hopkins University Press, 1995, pp. 183-99.

15. Sigmund Freud. Moses and Monotheism. Translated by Katherine Jones. New York: Vintage Books, 1939.

16. Cathy Caruth. "Introduction." In Trauma: Explorations in Memory. Baltimore: Johns Hopkins University Press, 1995, pp. 3-12.

17. Dominick LaCapra. History and Memory after Auschwitz. Ithaca: Cornell University Press, 1998.

18. Judith Butler. Precarious Life: The Powers of Mourning and Violence. London: Verso, 2006.

19. Nouri Gana. "Trauma Ties: Chiasmus and Community in Lebanese Civil War Literature." In The Future of Trauma Theory: Contemporary Literary and Cultural Criticism. Edited by Gert Buelens, Sam Durrant and Robert Eaglestone. London and New York: Routledge, 2014, pp. 77-90.

20. Greg Forter. "Freud, Faulkner, Caruth: Trauma and the Politics of Literary Form." Narrative 15 (2007): 259-85.

21. Hayden White. "The Modernist Event." In Figural Realism: Studies in the Mimesis Effect. Baltimore: Johns Hopkins University Press, 1999, pp. 66-86.

22. Jean-Michel Ganteau, and Susana Onega Jaén, eds. Contemporary Trauma Narratives: Liminality and the Ethics of Form. New York: Routledge, 2014.

23. Jill Bennett, and Rosanne Kennedy. "Introduction.” In World Memory: Personal Trajectories in Global Time. Basingstoke: Palgrave Macmillan, 2003, pp. 1-15.

24. Stef Craps. "Beyond Eurocentrism: Trauma Theory in the Global Age." In The Future of Trauma Theory: Contemporary Literary and Cultural Criticism. Edited by Gert Buelens, Sam Durrant and Robert Eaglestone. London and New York: Routledge, 2014, pp. 45-62.

25. Neil Lazarus. The Postcolonial Unconscious. Cambridge: Cambridge University Press, 2011.

26. Edward W. Said. Culture and Imperialism. New York: Vintage, 1994.

27. Bill Ashcroft, Gareth Griffiths, and Helen Tiffin. The Empire Writes Back: Theory and Practice in Post-Colonial Literatures, 2nd ed. London: Routledge, 2002.

28. Peter Hallward. Absolutely Postcolonial: Writing Between the Singular and the Specific. Manchester: Manchester University Press, 2002.

29. Gayatri Chakravorty Spivak. "Can the Subaltern Speak?" In Marxism and the Interpretation of Culture. Edited by Cary Nelson and Larry Grossburg. Chicago: University of Illinois Press, 1988, pp. 271-313.

30. A. Dirk Moses. "Genocide and the Terror of History.” Parallax 17 (2011): 90-108. 
31. Frantz Fanon. Black Skin, White Masks. Translated by Richard Philcox. New York: Grove Press, 2008.

32. David Macey. Frantz Fanon: A Biography. London and New York: Verso, 2000.

33. Frantz Fanon. The Wretched of the Earth. Translated by Richard Philcox. New York: Grove Press, 2004.

34. Jean-Paul Sartre. We Have Only This Life to Live: The Collected Essays of Jean-Paul Sartre 1939-1975. New York: New York Review Books, 2013.

35. Jean-Paul Sartre. "Preface." In The Wretched of the Earth. Translated by Richard Philcox. New York: Grove Press, 2004, pp. xliii-lxii.

36. Atiq Rahimi. Earth and Ashes. Translated by Erdag Göknar. New York: Other Press, 2010.

37. Atiq Rahimi. A Curse on Dostoevsky. Translated by Polly McLean. New York: Other Press, 2013.

38. Tsitsi Dangarembga. Nervous Conditions. Banbury: Ayebia, 2004.

39. V. S. Naipaul. The Mimic Men. New York: Vintage, 1967.

40. Homi K. Bhabha. "Foreword: Framing Fanon." In The Wretched of the Earth. Translated by Richard Philcox. New York: Grove Press, 2004, pp. vii-xli.

41. Kate Grenville. The Secret River. Melbourne: Text Publishing, 2005.

42. Kate Grenville. Searching for the Secret River. Melbourne: Text Publishing, 2006.

43. Ann Curthoys. "Expulsion, Exodus and Exile in White Australian Historical Mythology." In Australian Studies Now. Edited by Andrew Hassam and Amit Sarwal. New Delhi: Indialog, 2007, pp. 143-77.

44. Manning Clark. Speaking out of Turn: Lectures and Speeches, 1940-1991. Melbourne: Melbourne University Press, 1997.

45. Patrick White. Voss. Middlesex: Penguin, 1960.

46. V. S. Naipaul. The Writer and the World: Essays. New York: Vintage, 2002.

47. Stephen Turner. "Settler Dreaming." Memory Connection 1 (2011): 115-26.

48. Stephen Turner. "Being Colonial/Colonial Being." Journal of New Zealand Literature 20 (2002): 39-66.

49. Ahmadou Kourouma. Allah n'est pas obligé. Paris: Édition du Seuil, 2000.

50. Ahmadou Kourouma. Allah Is not Obliged. New York: Anchor Books, 2006.

51. Chris Abani. Song for Night. Carlton North: Scribe, 2006.

52. Uzodinma Iweala. Beasts of No Nation: A Novel. New York: Harper Perennial, 2006.

53. Ken Saro-Wiwa. Sozaboy. Harlow: Pearson, 1995.

54. Edwidge Danticat. The Dew Breaker. New York: Vintage, 2004.

55. Pete Pattison. "Revealed: Qatar's World Cup 'slaves'.” The Guardian, 25 September 2013. Available online: http://www.theguardian.com/world/2013/sep/25/revealed-qatars-world-cupslaves (accessed on 26 June 2015).

56. Owen Gibson, and Pete Pattison. "Death toll among Qatar's 2022 World Cup workers revealed." The Guardian, 23 December 2014. Available online: http://www.theguardian.com/world/ 2014/dec/23/qatar-nepal-workers-world-cup-2022-death-toll-doha (accessed on 26 June 2015). 
57. Christopher Ingraham. "(UPDATED) The toll of human casualties in Qatar." The Washington Post, 27 May 2015. Available online: http://www.washingtonpost.com/blogs/wonkblog/wp/ 2015/05/27/a-body-count-in-qatar-illustrates-the-consequences-of-fifa-corruption/ (accessed on 26 June 2015).

58. Chimamanda Ngozi Adichie. Americanah. London: 4th Estate, 2014.

59. Okey Ndibe. Foreign Gods, Inc. New York: Soho Press, 2014.

60. Brian Chikwava. Harare North. London: Vintage, 2010.

61. Madhu Krishnan. Contemporary African Literature in English: Global Locations, Postcolonial Identifications. Basingstoke: Palgrave Macmillan, 2014. 


\title{
Decolonizing Trauma: A Study of Multidirectional Memory in Zadie Smith's "The Embassy of Cambodia"
}

\section{Beatriz Pérez Zapata}

\begin{abstract}
The present article analyses Zadie Smith's short story "The Embassy of Cambodia" (2013) as a narrative that contributes to the decolonization of trauma studies. In the introduction I will lay out briefly the state of affairs in trauma studies and the relevance of trauma in Smith's work as represented in White Teeth and $N W$. For the purpose of this paper, I will provide a close reading of "The Embassy of Cambodia" and I will rely on Michael Rothberg's theory of multidirectional memory to illustrate how the history of genocide in Cambodia and the history of the protagonist of the story, which is effectively one of slavery, conflate in Smith's text to bring to the fore silenced histories in a more ethical manner that seeks to put an end to competition and hierarchies within traumatic histories and trauma theory. This paper will explore the different juxtapositions that the story offers between individual and collective experiences of trauma and, in its explorations of multidirectional memory, the juxtaposition of collective histories of suffering.
\end{abstract}

Reprinted from Humanities. Cite as: Zapata, B.P. Decolonizing Trauma: A Study of Multidirectional Memory in Zadie Smith's “The Embassy of Cambodia”. Humanities 2015, 4, 523-534.

\section{Introduction}

Trauma, be it individual or collective, has been a constant framework in criticism and literature for the last two decades. As Herrero and Baelo-Allué have remarked, "trauma studies became prominent in the early to mid-1990s as an important sub-strand of 'ethical criticism', whose most defining feature was an intense concern with the demands of otherness" [1]. Trauma was indeed believed to be able to provide a bridge across cultures [2] which may thus acknowledge others' suffering ethically. However, some critics have challenged of late the prevalence of trauma theories and their adequateness to some contexts, namely non-Western and postcolonial ones, thus questioning its potential bridging qualities. Most criticism has challenged an event-based model of trauma in favour of an analysis of what Maria Root defined as insidious trauma, that which "refers to the traumatogenic effects of oppression that are not necessarily overtly violent or threatening to bodily well-being at the given moment but that do violence to the soul and spirit." [3]. More recently, Stef Craps has referred to the trauma of the everyday, which calls attention to the structural violence that results in "daily micro-aggressions [...] [which] can build to create an intense traumatic impact" [4]. Similarly, Mengel and Borzaga have argued that "trauma is deeply linked to economic and political issues [...] inseparable from institutions and structures" and that what is required is "an understanding of trauma that sees it not only as a result of an identifiable event but as the consequence of a condition that came about historically" [5]. Conscious of the recent criticism of trauma theory as inherently Western and Eurocentric, Mengel and Borzaga have argued as well that the way forward in trauma studies does not go only through their decolonization, but through the acknowledgment of "the systemic denial and exclusion from the 
canon of fundamental and insightful studies on the relationship between trauma, colonialism, and racism" ([5], p. ix). Craps and Mengel and Borzaga all coincide as well in acknowledging the fact that situations that Westerners may regard as traumatic are the everyday reality for many subjects who, nevertheless, continue to live through them either without recurring to coping mechanisms or by choosing some that differ from those set out by Western theories, such as silence.

Trauma has equally been a constant in Zadie Smith's work. The narrator of her first novel, White Teeth, uses the term "original trauma" [6] to describe the migrants' experience of diaspora: "immigrants have always been particularly prone to repetition - it's something to do with that experience of moving from West to East or East to West or from island to island. Even when you arrive, you're still going back and forth; your children are going round and round. There is no proper term for it - original sin seems too harsh; maybe original trauma would be better. A trauma is something one repeats and repeats" ([6], p. 161). The novel points to the "tragedy" ([6], p. 162) that migration may represent and, as Ulrike Tancke has argued, it "conceptualises migration as an experience that constitutes a fundamental shattering of identity and a threat to selfhood" [7]. However, the narrator's hesitation and the fact that it is difficult to find the correct term to describe the migrants' experience may also point to the impossibility that trauma theory describe it properly in its entirety. Furthermore, the fact that the narrator doubts between "sin" and "trauma" may point to the fact that, from the perspective of trauma theory, the migrants' experience is censored, diminished, since trauma theory ultimately looks for a centred, unified subject. Indeed, Stef Craps relies on Claire Stock's argument that trauma theory has been based on a Western idea of the self, according to which "a psychologically healthy subject is unified, integrated, and whole, and questions the notion that healing from trauma consists of overcoming the fracturing of the self and the resulting division in identity caused by an extremely disturbing event" ([4], p. 33). White Teeth portrays the lives of characters permanently caught in a state of in-betweeness that can only hope for a balanced relationship between two selves, which from the perspective of trauma theory can thus be traumatogenic.

Trauma theory and the fragmented self are again both central to Smith's latest novel, $N W$, in which one perceives, I would argue, a more conscious criticism of trauma theory. At the beginning of the "Host" chapter, the narrator describes how Keisha Blake, one of the protagonists and a third generation diasporic subject, almost drowns and is saved by another child, Leah, who will later become her best friend: "There had been an event. To speak of it required the pluperfect [...].

It was in this ellipsis that the event had occurred: a child nearly drowned. Yet the significance of the event lay elsewhere [...]. Keisha could neither contradict nor verify this account-she had no memory of it. However, the foreshadowing could be considered suspicious" [8]. Furthermore, later on the narrator emphasises that Leah and Keisha become "best friends bonded for life by a dramatic event and everyone in Caldwell best know about it" ([8], p. 204). This passage clearly becomes a criticism of the event. Although the fact that Keisha almost drowns as a child may be traumatic, the narrator is careful to remark that the significance lays, not in the event itself, but rather in the socio-economic context as portrayed in the fictional Caldwell estate, where the novel takes place. This in turn draws attention to the micro-aggressions and insiduousness of some attitudes found in neo-liberal Western societies, which may be more traumatizing than any particular event. 
In addition, I would argue that the high concentration of trauma vocabulary on these pages, together with the fact that the narrator uses trauma as the foreshadowing of Keisha's life may indicate that, in recent years, trauma theory has been one of the most common frameworks used to analyse the lives of diasporic subjects of different generations.

I would argue that the novel sets a frame which seems to be forced upon the characters, especially Keisha, who looks for wholeness in her identity but cannot find it and develops a new personality as Natalie once she is immersed in a more liberal, upper-class environment. The novel cunningly employs fragmentation, split personality, and excessive intertextuality, among other techniques which have been recurrent in trauma narratives. However, at the end of the novel, after Keisha has allegedly worked through her split personality, the novel refuses to provide her with a unified sense of self and points towards the micro-aggressions that stem from neo-liberal economies and discourses. Therefore, $N W$ draws attention, as is the case of White Teeth, to how trauma theories have been based on the Western model of the unified, centred, stable self, it criticises how somecritics have the lives of migrants as inherently traumatic, and further points to the insidiousness of neo-liberalism.

Smith's short story "The Embassy of Cambodia" also provides examples of how the lens of trauma has been used, albeit in a different manner from Smith's previous narratives. "The Embassy of Cambodia" is set mostly in Willesden, in North West London, in the weeks during and after the Olympic games of 2012. Smith's short story narrates the life of Fatou, an immigrant from Ivory Coast who works as a domestic servant for the Derawals, a wealthy Arab family who employs Fatou in conditions that resemble those of modern-day slavery: they hold her passport, they retain her wages, abuse her verbally and physically, and only allow her to go out to do the shopping, and to go to church on Sundays, when she meets her friend Andrew. Fatou also sneaks out of the house on Mondays to go swimming to a nearby health centre using stolen passes from her employers. It is one Monday that Fatou notices a game of badminton being played behind the walls of the Embassy of Cambodia. The game of badminton, as well as the building itself, had already attracted the attention of some of the neighbours of Willesden. In fact, the story makes both the game and the building of the embassy and Cambodia's history of genocide central to the narration of Fatou's story as a migrant and a "slave" in contemporary London. The story, however, does not only refer to the genocide in Cambodia but to other genocides of the twentieth century, such as those perpetrated in Rwanda, Hiroshima, and the Holocaust.

"The Embassy of Cambodia" opens up with this rhetorical question: "Who would expect the Embassy of Cambodia?" [9]. My aim in this paper is to explore, not so much who, but rather why the Embassy of Cambodia and the connections made with genocide and mass atrocities are so fundamental to the narration of a migrant's story in contemporary times. I will argue that the text's intermingling of different memories and stories of suffering works as a reflection of Michael Rothberg's concept of multidirectional memory, which might work as an effective model to decolonize trauma studies. In addition, I will relate the text to Ella Shohat's concept of relationality as a complement to Rothberg's theory of multidirectionality. I will also argue that this short story is Smith's most conscious attempt towards the decolonization of trauma studies, not only in its use of multidirectional memory, but also in the way in which it represents the gaze with which characters, 
and readers, look at traumatic experiences. For this purpose, in what follows I will provide a close reading of the short story, and connect it with the recent theoretical trends that support a decolonizing view of trauma theory in their attempt to call attention towards the stories which still remain unheard.

\section{Contextualizing Trauma}

"The Embassy of Cambodia" contextualizes the story of Fatou at the time of the Olympic Games of 2012. The first time reference in the short story is 6th August, right in the middle of the Olympics. The second is 20th August, just eight days after the Olympics have finished, but which the narrator describes as "long after the Olympians had returned to their respective countries" ([9], p. 11), as if they had altered temporality. The Olympic Games were heralded as both the triumph of multiculturalism and the triumph of patriotism. During the Olympics, the world also saw an asylum seeker wrapped in the Union Jack. This occasion projected an image of homogeneity despite the fact that, for many, multiculturalism had allegedly failed, and that a year before the Olympics many thought of the Britain of the riots as a nation in crisis. Indeed, some journalists considered at the time that with the Olympics "a new Britain [was] being born out of the best of the old Britain" [10]. It is in this professed celebration of multiculturalism that the story of Fatou and the history of Cambodia are told, and that the story unveils reminiscences of that old Britain. It should not be forgotten that Fatou's life journey goes through three different French and British ex-colonies-Ivory Coast, Ghana, and Libya-which still suffer the consequences of the colonization process. However, it is in one of the colonial metropolis that her story is laid out, that her vulnerable life continues, and that her individual tale of suffering is seen through the eyes of the collective traumatic suffering of a "foreign" genocide. By setting such context, "The Embassy of Cambodia" already points towards a multidirectional understanding of memory which, according to Michael Rothberg, represents a form of "remembrance [which] cuts across and binds together diverse spatial, temporal and cultural sites" [11].

In this entanglement, it is first of all necessary to consider Fatou's status as an immigrant and modern-day slave, as well as her traumatic past. Fatou's legal status in England is never revealed in the story, but her journey from Ivory Coast to Ghana, then to Libya, Italy and, finally, England, follows one of the routes of illegal migration from Africa into Europe. Her alleged status as an illegal immigrant puts her in a position of heightened vulnerability, which is further increased by her working status. As mentioned in the introduction, Fatou is employed as a domestic servant by the Derawals, a wealthy Arab family who keeps her as a modern-day slave. However, Fatou does not regard herself as such. Upon reading in the paper the story of a "slave" working in a rich man's house in London, Fatou wonders if she herself is a slave, led by such evidence as the fact that her passport and wages are retained, and the occasional verbal and physical abuse that she suffers. However, Fatou refuses to identify as a slave on account of her relative freedom - after all, the girl in the paper was a prisoner and she is able to get out of the house, if only for brief periods of time. From a theoretical stance, Fatou is a modern-day slave according to current definitions of slavery [12,13], and most certainly she is a victim of what Michal Rothberg regards as 
"exploitation in the age of globalized neo-liberalism", which he defines as a "system of violence neither sudden nor accidental" that can be opposed to particular violent events [14].

This violence makes of Fatou an "other", who has been made "other" in two ways: first, she is a dislocated (illegal) immigrant and second, her subjectivity is denied in her condition of modern-day slave, whereby she is objectified and commodified, and thus made invisible. In addition to this structural violence, Fatou also suffers the violence of particular events. The story narrates how she was raped by a Russian tourist when she was working as a maid in a hotel resort in Accra, a crime that went unpunished: "He (the Devil) came, this time, in Russian form. Afterwards, he cried and begged her not to tell anyone: his wife had gone to see the Cape Coast Castle and they were leaving the following morning. Fatou listened to his blubbering and realized that he thought the hotel would punish for his action, or that the police would be called" ([9], p. 44). The story portrays the Russian tourist as perpetrator and as victim, an ambiguous relation that is also being currently explored in trauma studies, and further points to systemic gender and structural violence and to the remembrance of slavery, Cape Coast Castle being the door of no return in the transatlantic slave trade. Therefore, "The Embassy of Cambodia" presents these types of violence as inseparable and comes to show, as Rothberg argues, that "an event-focused trauma theory needs to understand the conditions of structural violence" ([14], p. iv).

Fatou's reaction towards an event which would certainly be regarded as traumatic from a Western perspective is also worth analysing for the purpose of this paper. First, it should be taken into consideration that, for some subjects who suffer from what Don Foster has called "continuous traumatic stress syndrome" ([5], p. 106), this is an everyday reality [15]. Fatou registers rape as a sin and finds solace in religion which, although possibly allowing for some numbing effect, can nonetheless work as an alternative coping mechanism. Furthermore, the only apparent traumatic symptom that can be observed is how "fast and angry" her swimming becomes when she thinks about the Devil, as she refers to the Russian tourist and other perpetrators. Fatou shows great resilience, even at the end of the story when she is fired. The narrator describes this uncertain moment in the following terms: "Walking out into the cold grey, Fatou felt a sense of brightness, of being washed cleaned that neither the weather nor her new circumstances could dim" ([9], pp. 68-69). Nevertheless, Fatou's obsession with water and swimming, together with the continuous references to water throughout the story, may suggest that she is still acting-out, since she repeatedly hopes to "be[ing] washed clean" ([9], p. 68) of the sin of having been raped. From another point of view, the water imagery in the short story may also be read as a reference to migration and diaspora. Paul Gilroy and John McLeod have argued that "aquatic metaphors" could be read either as a symbol of "restlessness", even of hybridity, in diaspora, or as a negative view of migration, calling to mind "dangerous floods, waves", rivers of blood [16]. "The Embassy of Cambodia" brings together once again the relationship between the trauma that Fatou experiences at an individual level and the collective experience of migration, reinforcing the idea that one cannot be understood without the other.

As has just been discussed, Fatou's traumatic experiences are exposed in the short story, but always mediated by the voice of the narrator. It is also quite significant that the only time in the short story we hear her direct testimony is when she recounts two different reactions to a 
confrontation with death. She tells this story to Andrew, her friend from church: "I went out and saw nine children washed up dead on the beach. Ten or eleven years old, boys and girls [...]. Some people were crying, maybe two people. Everyone else just shook their heads and carried on walking to where they were going. After a long time, the police came." Some time later, in Rome, Fatou narrates that: "I saw a boy who was about fifteen years old knocked down on his bike. He was dead. People were screaming and crying in the street. Everybody crying. They were not his family. They were only strangers. The next day, it was in the paper". Andrew then replies by affirming that "A tap runs fast the first time you switch it on" ([9], pp. 47-48). This story exposes different reactions to a traumatic experience and shows how much context-specific they can be. It also confirms that non-Western subjects have assumed the witnessing of traumatic experiences as something usual, while Westerners insist on claiming some distance from such events, no matter how theorized they may have been.

In its depiction of two ways of looking at two different traumatic events, although the drowning of the nine children in Ghana verges on the insidious facet of trauma, "The Embassy of Cambodia" exposes the privileged gaze with which Western subjects observe and experience trauma. Many Western subjects will observe trauma from the privilege that security and generalized welfare provide. I would argue that here lies a first possibility for the decolonization of trauma studies since the short story reminds readers how trauma is context and experience specific and, in turn, it forces them to reflect on their own situatedness within particular cultural and socio-economic contexts, which will affect the way they look at and experience trauma. At the end of "The Embassy of Cambodia" the use of the first person plural narrator addresses and involves readers in the act of looking at Fatou, homeless and waiting for Andrew: "Many of us walked past her that afternoon, or spotted her as we rode the bus, or through the windscreens of our cars, or from our balconies. Naturally, we wondered what this girl was doing, sitting on the damp pavement in the middle of the day" ([9], p. 69). The ending of the short story portrays a mere act of looking, not at a traumatic event, but at the embodiment of an insidious trauma which many will fail to acknowledge, and even more, to accept. The story suggests that the Western understanding of trauma is still centred on an event-based model and rejects an insidiousness which is the historical consequence of imperialism, liberalism and globalization. Thus, a privileged, colonial gaze is exposed. In addition, "The Embassy of Cambodia" exposes the failure to take action to solve this problematic situation. The narrator and the implied readers continue to observe Fatou, as a character who has been dehumanized in her condition as a slave, whose live cannot, or will not, be considered grievable, to use Judith Butler's idea [17]. Therefore, the decolonization of trauma studies can be partly achieved by recognizing the privilege from which trauma is observed and experienced. Nevertheless, the failure to take action at the end of the story, may also point out to the gap between theory and action, a gap which must be bridged in order to achieve a better and complete decolonization of trauma.

As this section demonstrates, the story of Fatou already points to the necessity to see individual and traumatic memories in dialogue, for this is the only way in which the structural and institutional links between individual and insidious traumas will actually come to the fore. If Fatou's individual traumas are analysed in the light of institutional and structural violence, one can clearly acknowledge the pervasiveness of colonial discourses which, implemented by a neo-liberal 
system, still allow for the existence of slavery. This reading already shows the decolonizing potential of "The Embassy of Cambodia", which is further increased by the use of multidirectional memory.

\section{Decolonizing through Multidirectional Memory}

Michael Rothberg's concept of multidirectional memory implies the juxtaposition of two or more disturbing memories that work dialogically to bring together different histories of suffering, and is based on an "ethics of comparison that can distinguish politically productive forms of memory from those that lead to competition, appropriation and trivialization" [18]. "The Embassy of Cambodia" juxtaposes two disturbing histories, Fatou's and Cambodia's genocidal past, which operate according to a multidirectional understanding of memory, while also calling attention to the competition and appropriation that, more often than not, still exists when it comes to representing traumatic memories. The first person narrator in Smith's story uses the forced division between Old and New people under the Khmer Rouge regime - that is, the enforced division between rural and urban people - to describe the people of Willesden: "In Willesden, we are almost all New People, though some of us, like Fatou, were until recently, Old People, working the land in our various countries of origin" ([9], p. 40). Although this could be read as an appropriation of the history of others, the division between Old and New People might on the other hand make reference to contemporary constructions of old and new migrants, and to the not so clear-cut distinction between old and new slavery. In addition, I would argue that the fact that the narration chooses Cambodian history and genocide, one that according to Ben Kiernan can be read, as most genocides, as a history of "deportation" [19], suggests a critique against forced global displacements and the current governmental policies which seek the deportation of migrants and asylum seekers in the United Kingdom, so often criticised by Smith [20]. Furthermore, the Khmer Rouge regime was built around race and class divisions, which may draw attention to how immigrants are increasingly divided on a class basis, between those who can afford to become immigrants and those less desirable immigrants who cannot. I would also suggest that the fact that the narrator refers to the inhabitants of Willesden, a suburb in North West London, in terms of Old and New people may also imply that there is a persisting regime which imposes similar dividing terms. Hence, by recurring to Cambodia's history to explain Fatou's and other migrants' situation in contemporary London, the short story denounces the political and socio-economic discourses that allow the persistence of such dividing terms.

In addition, the narrator makes reference to the Khmer Rouge motto "To keep you is no benefit. To destroy you is no loss", and to how New People should show no weakness or vulnerability when turned into Old People. Save for these brief remarks, the first person narrator is only able to connect Cambodia with genocide, which shows that trauma has not only become a master narrative in contemporary history, but also a narrative deeply rooted in our unconscious. In fact, upon the appearance of the Embassy in Willesden the narrator writes that "if we were poets perhaps we could have written some sort of ode about this surprising appearance" ([9], p. 6), but then observes that "we are not really a poetic people. We are from Willesden. Our minds tend towards the prosaic" ([9], p. 6). The narrator thus confirms Adorno's contention about the barbarity and the impossibility of writing poetry after Auschwitz: "to write poetry after Auschwitz is barbaric. And 
this corrodes even the knowledge of why it has become impossible to write poetry today" [21]. The narrator also points to the traumatizing zeitgeist of the twentieth century. Moreover, s/he assumes that all the neighbours in Willesden make an automatic connection between Cambodia and genocide, thus reinforcing the idea that traumatic histories are part of our unconscious. At the same time, the narrator shows a homogenizing attitude that may become dangerous, since it can lead to generalizations and abstractions, two problematic issues in trauma studies according to some critics.

The narrator's attitude contrasts with Fatou's curiosity about Cambodia, which arises after she sees a woman exiting the Embassy. Because of her interest in this particular woman, the narrator accuses Fatou of having a "local, narrow scope" ([9], p. 23) since she is interested in this woman and ignores Cambodia's traumatic past. The narrator admits to having sympathy for her attitude because "if we followed the history of every little country in this world - in its dramatic as well as its quiet times - we would have no space left in which to live our own lives or to apply ourselves to our necessary tasks, never mind indulge in occasional pleasures, like swimming" ([9], p. 23). The narrator attacks Fatou directly in her/his reference to swimming, and her/his condescending attitude ignores the fact that Fatou does not know Cambodia's history because she has had no access to such information. The short story could therefore imply that in our knowledge of global traumatic histories there exists a certain privilege which, ironically, ignores the reality of those subjects most negatively affected by globalization. This would confirm Rothberg's contention that in competitive models there exists "a form of cultural capital that bestows moral privileges" ([11], p. 87). It would seem that, even though the narrator presents Fatou's story through the history of Cambodia, competition persists. It is not only a competition between traumatic histories, but a competition between the collective and the particular, and between those who have access to knowledge and power.

Fatou's interest, however, goes beyond the Cambodian woman. The story makes it clear that she is especially concerned about suffering. She befriends Andrew, a Nigerian immigrant, after he gives her a leaflet with the title "WHY IS THERE PAIN" ([9], p. 46), and in one of their conversations Fatou asks Andrew "Are we born to suffer? Sometimes I think we were born to suffer more than all the rest" ([9], pp. 26-27). It is clear that this "we" includes all Africans, whom she considers to be underrepresented in the history of past and present suffering. In fact, when she is wondering about the suffering of others she starts a conversation with Andrew about the Holocaust. Fatou may ignore Cambodia's history, but the Holocaust comes up as a universal tale of suffering that may be linked to all others. Indeed, this conversation leads them to talk about Rwanda and Hiroshima, even the corrupt Nigerian government. Here, Fatou argues that "more people died in Rwanda [...]. And nobody speaks about that. Nobody" ([9], p. 26), thus rejecting, even within a particular and limited context, the centrality of the Holocaust. Although I would argue that "The Embassy of Cambodia" uses multidirectional memory in its comparison of the history of Cambodia and Fatou's individual and insidious trauma, I would also contend that it criticises hierarchy in trauma and memory studies, which often give the Holocaust a superior position which may silence other histories.

For many critics, the Holocaust has acted as a screen memory which hides other traumatic realities. In the case of Great Britain, Dan Stone, among other scholars, has argued that "the recent 
focus on the Holocaust in British cultural life has until recently acted as a screen memory for the darker side of Britain's imperial past" [22]. Dan Stone warns that "selective interpretation of the British Empire is a direct consequence of the rise of Holocaust consciousness, since the latter clearly seems to identify extremism and evil as something committed by others" ([22], p. 189). Similarly, Paul Gilroy has identified a case of "postcolonial melancholia" in Britain, and argues that the memory of World War II has prevailed "so that Brits can know who we are as well as who we were and then become certain that we are still good while our uncivilized enemies are irredeemably evil" [23]. Furthermore, Gilroy argues that empire and its loss have not been properly mourned, and that the "postcolonial melancholia" affecting Britain has meant that "the nation's intermittent racial tragedies become part of an eventful history" ([23], p. 106). Nevertheless, the perception of the Holocaust as a screen memory is nowadays changing towards a more multidirectional understanding. What is more, Michael Rothberg argues that even screen memory itself is multidirectional since "it both hides and reveals that which has been suppressed" ([11], p. 14).

"The Embassy of Cambodia" refers briefly to the Holocaust and concentrates mostly on genocide in Cambodia which, as Dan Stone has remarked, is now considered to be part of the "canon" of genocide studies, together with the Holocaust, Armenia, Rwanda, and other colonial genocides [24]. However, the Cambodian genocide has by no means the relevance that the Holocaust does. The short story confirms this by emphasizing the location of the Embassy in the suburbs; its de-centralized position may indicate that, although Cambodian genocide has made it into the canon, it still is not as central as other Western genocides. Therefore, the story may suggest that, when it comes to reading traumatic experiences derived from empire, choosing "de-centralized" histories may be more suitable. However, although the references to genocide, canonical or marginal, can be read as multidirectional, their pervasiveness in Smith's short story seems to camouflage the reality of the individual tragedies occurring at home, not in a distant place, and more specifically the tragedies experienced by those subjects from countries that once belonged to the empire but who now find themselves trapped within a violent neo-colonial and neo-liberal system. Smith's short story brings to the fore the flaw of competitive memory and also points towards the potential failure of multidirectional memory. First of all, I would argue that the alleged dialogical relationship of multidirectional memory fails because Fatou is a subject who cannot give voice to her story, she is a subject that has been left out of history in her condition as a, most likely, illegal immigrant and slave. Secondly, Rothberg argues that "When the productive, intercultural dynamic of multidirectional memory is explicitly claimed [...] it has the potential to create new forms of solidarity and new visions of justice" ([11], p. 5). The end of the story hints at two possible outcomes for Fatou, "a violent conclusion" or a "hopeful return" ([9], p. 69). Where she could return to is not specified, but in any case this is not a fair ending for her, who is left alone and abandoned after being fired by the Derawals - if a slave can be possibly fired. Although it could be argued that the narrator, in its reading of Fatou's life through the lens of Genocide in Cambodia, makes an attempt to use multidirectional memory appropriately, it is nonetheless clear that $\mathrm{s} / \mathrm{he}$ remains observing Fatou from a distance, thus avoiding any action that may lead to true solidarity. Lastly, the short story is structured like a game of badminton, in twenty-one sets. This structure, together with the centrality of the game of badminton that Fatou and the neighbours observe in the 
Embassy, seems to favour a competitive model of memory that invalidates the potential of multidirectional memory. According to Rothberg, competitive memory "understand[s] the articulation of the past in collective memory as a struggle for recognition in which there can only be winners and losers" ([11], p. 3). In this way, "The Embassy of Cambodia" makes it clear that some subjects are still struggling for recognition, not only as part of a potentially traumatized collective, but also as human beings and that, as such, they are wholly entitled to be treated with respect and to preserve their dignity.

As has been shown, "The Embassy of Cambodia" brings together many different histories that may be better understood if read through the lens of multidirectionality. This reading, however, may be implemented by incorporating Ella Shohat's concept of relationality. For Shohat, the relational approach entitles a twofold reference within the work of literature itself and as a method of reading which implies the intersection not only of histories, geographies and communities, but also between discourses and disciplines [25]. Irene Visser comments that relationality's "openness to interconnections and interdisciplinarity is based on a firm commitment to a non-competitive approach, aligned with Michael Rothberg's multidirectionality" [26]. Indeed, as Norman Saadi Nikro argues, Rothberg's multidirectionality shows that "in the terrain of trauma studies there has been a tendency to produce a non-relational clash of civilizations scenario that pits a notion of the West against the rest" [26]. Therefore, although Shohat's and Rothberg's ultimate aim is to bring to the fore productive "relational clashes", I would argue that Shohat's concept may help to complete and broaden Rothberg's multidirectionality.

First, as Norman Saadi Nikro concludes, Shohat's "relational approach involves an appreciation of how the work of literature that embodies traumatic inflections or indeed thematises trauma has to accommodate not only a time but also a geography crisscrossed by a number of intersecting trails" [26]. I would argue that this emphasis on geography is of the utmost importance in "The Embassy of Cambodia" since it situates in the geographical space of Willesden many other geographies, each with their multiple histories, past and present. Nevertheless, this geographical space is multicultural but not multivocal, which may diminish the potentiality of multidirectionality. Secondly, the double reference of relationality also implies the need to look across Smith's work. If Smith's novels are thus set in relation, one can acknowledge better the progressive critique of trauma theory and the progressive politicization in Smith's narratives. Furthermore, one can ascertain the contrast between a multivocal novel, such as White Teeth, and the way in which some speak for others in "The Embassy of Cambodia" while Fatou remains silent, invisible. I would argue that the attempt to decolonize trauma studies is strengthen by a relational reading of Smith's work, in which many histories, geographies, communities, discourses, and disciplines entangle to create new ways of understanding fiction, history and trauma.

\section{Conclusions}

In Multidirectional Memory, Michael Rothberg recalls Césaire's contention that "colonization de-humanizes even the most civilized man" ([11], p. 86). In "The Embassy of Cambodia" Fatou has been de-humanized in her condition as a slave, whereby she becomes an object, a commodity in a neo-liberal and neo-colonial system. Thus, the short story seems to confirm that there is still a 
regime that imposes divisions between different subjects, and that this regime is still a colonial one. As has been shown, multidirectional memory is a productive tool to bring to the fore and understand other histories of suffering which have not been so central to trauma and memory studies. Reading Fatou's life story in comparison with the history of genocide in Cambodia provides readers with further insights into the tragic reality of modern day slaves, while bringing to light the history of Cambodia itself, together with other genocides of the twentieth century.

As has also been shown, "The Embassy of Cambodia" denounces the competition that still exists in many theoretical discussions and the privileged positions that trauma theory may grant. The story also highlights the impossibility of bringing justice to those subjects who are not able to articulate their voices, who are still struggling for recognition, waiting to take part in the dialogue between traumatic histories, waiting to become part of history. The narrator, an old person living at a retirement home, may not be able to do much to help Fatou, but the short story's use of the first person plural narrator undoubtedly works to address and implicate readers directly, calling their attention to the need to become aware of the silenced histories of those who have been denied representation. In conclusion, "The Embassy of Cambodia" denounces the existence of a pervasive colonial regime, which is brought to light in comparison with the Cambodian genocide, and consequently works as a narrative which decolonizes traumatic histories of suffering by condemning the lack of representation that such regime inflicts upon subjects like Fatou.

\section{Acknowledgments}

The research for this article has been funded by the Spanish Ministry of Economy and Competitiveness (Ref. BES-2013-063237).

\section{Conflicts of Interest}

The author declares no conflict of interest.

\section{References and Notes}

1. Dolores Herrero, and Sonia Baelo-Allué. The Splintered Glass: Facets of Trauma in the Post-Colony and Beyond. Amsterdam and New York: Rodopi, 2011, p. ix.

2. Cathy Caruth. Unclaimed Experience: Trauma, Narrative and History. Baltimore: The John Hopkins University Press, 1996.

3. Maria Root. "Reconstructing the Impact of Trauma on Personality." In Personality and Psychopathology: Feminist Reappraisals. Edited by Laura S. Brown and Mary Ballou. New York: Guildford Press, 1992, pp. 229-65.

4. Stef Craps. Postcolonial Witnessing: Trauma Out of Bounds. Houndmills: Palgrave Macmillan, 2013.

5. Ewald Mengel, and Michela Borzaga. Trauma, Memory, and Narrative in the Contemporary South African Novel: Essays. Amsterdam and New York: Rodopi, 2012, pp. ix-xi.

6. Zadie Smith. White Teeth. London: Penguin, 2000, p. 161. 
7. Ulrike Tancke. “'Original Traumas’: Narrating Migrant Identity in British Muslim Women's Writing." Postcolonial Text, 2011. Available online: http://postcolonial.org/index.php/ pct/article/viewArticle/1238 (accessed on 20 May 2015).

8. Zadie Smith. NW. London: Penguin, 2012, pp. 201-2.

9. Zadie Smith. The Embassy of Cambodia. London: Penguin, 2013, p. 1.

10. Hasan Suroor. "Suddenly, it's all hail multiculturalism." The Hindu, 10 August 2012. Available online: http://www.thehindu.com/todays-paper/tp-opinion/suddenly-its-all-hailmulticulturalism/article3748460.ece (accessed on 15 June 2015).

11. Michael Rothberg. Multidirectional Memory: Remembering the Holocaust in the Age of Decolonization. Stanford: Stanford University Press, 2009, p. 11.

12. Kevin Bales. Disposable People: New Slavery in the Global Economy. Berkeley: University of California Press, 2000.

13. Rahila Gupta. Enslaved: The New British Slavery. London: Portobello Books Ltd, 2007.

14. Michael Rothberg. "Preface." In The Future of Trauma Theory: Contemporary Literary and Cultural Criticism. Edited by Gert Buelens, Samuel Durrant and Robert Eaglestone. Abingdon: Routledge, 2014, p. iv.

15. Steph Craps. "Beyond Eurocentrism: Trauma Theory in the Global Age." In The Future of Trauma Theory: Contemporary Literary and Cultural Criticism. Edited by Gert Buelens, Samuel Durrant and Robert Eaglestone. Abingdon: Routledge, 2014.

16. John McLeod. Postcolonial London: Rewriting the Metropolis. London and New York: Routledge, 2004, p. 163.

17. Judith Butler. Frames of War: When is Life Grievable? London and New York: Verso, 2009.

18. Michael Rothberg. "From Gaza to Warsaw: Mapping Multidirectional Memory." Criticism 53 (2011): 523-48.

19. Ben Kiernan. The Pol Pot Regime: Race, Power, and Genocide in Cambodia under the Khmer Rouge, 1975-1979. New Haven: Yale University Press, 2005.

20. Jane Martinson. “Zadie Smith calls for end to women's 'walking nightmare' at Yarl's Wood." The Guardian, 14 February 2014. Available online: http://www.theguardian.com/books/ 2014/feb/10/zadie-smith-yarls-wood-detention-centre-campaign (accessed on 23 June 2015).

21. Theodor W. Adorno. "Cultural Criticism and Society." In Prisms. Translated by Shierry Weber Nicholsen and Samuel Weber. Cambridge: MIT Press, 1981, pp. 17-34.

22. Dan Stone. History, Memory and Mass Atrocity: Essays on the Holocaust and Genocide. London: Valentine Mitchell, 2006, pp. 174-75.

23. Paul Gilroy. Postcolonial Melancholia. New York: Columbia University Press, 2006, p. 88.

24. Dan Stone. The Historiography of Genocide. Houndmills: Palgrave Macmillan, 2010, p. 1.

25. Norman Saadi Nikro. "Situating Postcolonial Trauma Studies." Postcolonial Text, 2014. Available online: http://postcolonial.org/index.php/pct/article/view/1865 (accessed on 17 September 2015).

26. Irene Visser. "Entanglements of Trauma: Relationality and Toni Morrison's Home." Postcolonial Text, 2014. Available online: http://postcolonial.org/index.php/pct/article/view Article/1712 (accessed on 17 September 2015). 


\title{
A Journey across Multidirectional Connections: Linda Grant's The Cast Iron Shore
}

\section{Silvia Pellicer-Ortín}

\begin{abstract}
Among the numerous groups that have negotiated their fragmented identities through various literary practices in the last few decades, the Jewish collective has come to symbolize the epitome of diaspora and homelessness. In particular, British-Jewish writers have recently started to reconstruct their fragmented memories through writing. This is an extremely interesting phenomenon in the case of those Jewish women who are fiercely struggling to find some sense of personhood as Jewish, British, female, immigrant subjects. Linda Grant's novel The Cast Iron Shore will be analyzed so as to unveil the narrative mechanisms through which many of the identity tensions experienced by contemporary Jewish women are exhibited. The different stages in the main character's journey will be examined by drawing on theories on the construction of Jewish identity and femininity, and by applying the model of multidirectional memory fostered by various contemporary thinkers such as Michael Rothberg, Stef Craps, Max Silverman, and Bryan Cheyette. The main claim to be demonstrated is that this narration links the (hi)stories of oppression and racism endured both by the Jewish and the Black communities in order to make the protagonist encounter the Other, develop her mature political self, and liberate her mind from rigid religious, patriarchal, and racial stereotypes. The Cast Iron Shore becomes, then, a successful attempt to demonstrate that the (hi)stories of displacement endured by divergent communities during the twentieth century are connected, and it is the establishment of these connections that can help contemporary Jewish subjects to claim new notions of their personhood in the public sphere.
\end{abstract}

Reprinted from Humanities. Cite as: Pellicer-Ortín, S. A Journey across Multidirectional Connections: Linda Grant's The Cast Iron Shore. Humanities 2015, 4, 535-553.

\section{Introduction: British-Jewish Writers and Multidirectional Links}

"A long-standing legacy of violence, compounded by new disasters, has engendered a set of rites - both individual and collective - that have taken many forms: the reconstruction of past histories, the retrieval of lost communities, the activation of historic sites, and a quest for origins" ([1], p. xi). This article starts with Hirsch and Miller's words since they wisely refer to our current era. In the society they describe, individual and collective damaged identities and traumatic memories have been redefined in the public sphere through a good range of cultural practices. Among these "rites", literature offers a valuable space to redefine identity, reconfigure memory and history, and deconstruct stereotypes. This relevant aspect of literature has been invigorated since the 1990s, the moment when Trauma Studies emerged in the field of the humanities to claim that there are some specific literary strategies that may allow the representation and negotiation of trauma.

When drawing on the fields of Trauma and Memory Studies, the Holocaust unavoidably comes to the fore. Due to its extreme and extraordinary nature, the historian Michael Rothberg explains 
that the Holocaust has "come to be understood in the popular imagination, especially in Europe, Israel, and North America, as a unique, sui generis event" ([2], p. 8). Several contemporary thinkers have started to realize that this line of thought could engender some kind of competition for "first place in victimhood" among many other groups that have also been the victims of armed conflicts, genocide or diverse forms of abuse across history ([3], p. 159). In fact, making reference to Jill Bennett and Roseanne Kennedy's ideas, there exists a common agreement that, if Trauma Studies are to be meaningful in the near future, they "must move beyond its focus on Euro-American events and experiences, towards a study of memory that takes as its starting point the multicultural and diasporic nature of contemporary culture" ([4], pp. 13-14). These ideas have become especially significant in the postcolonial context. As Stef Craps explains in Postcolonial Witnessing, there has been a recent broadening in the fields of Trauma and Memory Studies from the national to the transnational so that "traumatic colonial histories" may "be considered in relation to traumatic metropolitan or First World histories for trauma studies to have any hope of redeeming its promise of ethical effectiveness" ([5], p. 72). Together with Craps' ideas, the theories formulated by Michael Rothberg, Bryan Cheyette and Max Silverman will shape the theoretical framework of this study in order to allow me to connect this contemporary interest in fostering multidirectional memory connections with the works produced by some British-Jewish writers such as Linda Grant.

If there is a group where multidirectional connections could and should be established, these are the Jewish communities around the world which have traditionally been defined by their transnational and diasporic nature. This is an aspect which has left permanent traces in their literary creations, as the Jewish people need to come to terms with a past marked by displacement is reflected on the increasing number of literary works problematizing Jewish identity conflicts. Drawing on this, Sheila Jelen, Michael Kramer, and Scott Lerner highlight that Jewish literature "lacks the basic markers of national literatures: it has neither a shared language nor a common geography" ([6], p. 1). Also, it can be asserted that Jewish writings, "hover between places, finding their voice in their sense of displacement [...], bridging geographic centres or spaces" ([6], p. 14). In addition to this, Hana Wirth-Nesher explains that Jewish literature has to do with "a symptom of incomplete assimilation [...], or a lack of self-sufficiency in one language culture" ([7], p. 4). All these thoughts would support the analysis of contemporary Jewish writers' works under the prism of multidirectional models of memory that seek to avoid national markers and promote an extraterritorial awareness.

Regarding the case of British-Jewish writers, this group of authors has recently started to trace the past of their ancestors in their creations as subsequent generations of Jewish immigrants and Holocaust survivors looking for the cross-cultural memories that have configured their identities across time. Just as Bryan Cheyette ([8], p. 26) and Sue Vice ([9], p. 20) have defined their writings according to a deep sense of dislocation, this article will attempt to demonstrate that this lack of territoriality has given place to the need to establish multidirectional connections that can allow today's Jewish subjects to frame their history of exclusion and trauma within a more universal context. The case of contemporary British-Jewish women writers is still more to the point: they have not been perceived either as part of the British or the Jewish literary tradition; and they have been marginalized because of their status as Jews, immigrants and women ([10], p. 10). 
It is in this context that the works of Linda Grant emerge powerfully. This writer and journalist, born in Liverpool in 1951 as a child of Russian and Polish Jewish immigrants, grandchild of Holocaust survivors, belongs to the third generation of British-Jewish women authors who, like Jenny Diski and Zina Rohan, acquired a central role in the British literary milieu of the 1990s. Since her first publication in 1993, her works have recreated many current Jewish and female concerns, such as the conflicting use of space in the construction of Jewish identity and the depiction of fragmented memories across the subsequent generations of Holocaust survivors. Many of her novels revolve around the stories of Jewish women reinventing themselves through multifarious journeys of discovery. In this article, I will analyze her first novel The Cast Iron Shore [11], which was awarded the David Higham First Novel Prize and was also shortlisted for the Guardian Fiction Prize, a retrospective narration of Sybil Ross' life made at the time when, as an adult woman, she re-examines the main events of her life. This bildungsroman depicts the maturation process of a woman looking for roots since the moment she left Liverpool, being a young girl looking for personhood, to her travelling through America and Canada. My main claim is that this novel offers more than a simple portrayal of the life of a beautiful and vain woman, as some reviewers have argued [12]. It displays a model of multidirectional memory as the narrative device that links the (hi)stories of oppression of both Black and Jewish minorities in order to offer invigorated alternatives to solve the conflicting process of Jewish identity formation, and to work through the traumatic feelings experienced by the half-Jewish protagonist. Also, the main character's multidirectional journey will be examined to check whether or not it is targeted at helping the Jewish female subject to overcome her legacy of displacement. Moreover, I would like to contend that this multidirectional model of memory is made possible thanks to the encounters with the Other depicted along the heroine's journey, which will be analyzed from a Levinasian perspective as liberating tools in the construction of the main character's personality. This way, Grant will be aligned to other contemporary writers like André Schwarz-Bart in The Last of the Just, Caryl Phillips in The Nature of Blood, W. G. Sebald in Austerlitz and Richard Power in The Time of Our Singing who, in spite of writing in very diverse contexts, have also been aware of the need to overtake limited Western visions of genocide and trauma. In the end, my ultimate goal will be to demonstrate that novels like Grant's go in tune with Craps' main claim that "breaking with Eurocentrism requires a commitment not only to broadening the usual focus of trauma theory but also to acknowledging the traumas of non-Western or minority populations for their own sake" ([5], p. 19).

\section{Traumatic Departure: Jewishness, Hybridity, and Femininity}

By creating a first-person, autodiegetic narrator that recounts the main episodes of her life retrospectively, Grant renders the character's process of maturation with the insight of the wiser person who has learnt the relevance of the past in the construction of her personality. If the re-visitation of the past is an essential task for all those individuals and communities that have been denied an identity and place of their own ([13], p. 12), this task is even more compelling for the Jews because, as Raymond Federman points out, they have maintained their collective identity through the continuous telling of their (hi)story across generations [14]. This is made clear when 
analyzing the novel from a structural point of view. The narration starts in 1989 in communist Vietnam after the fall of the Berlin Wall, when readers meet a sixty-year-old Sybil who has a profitable business as an antiques dealer. Although the main purpose of this trip has to do with her business, it becomes the narrative device to start a mental journey to the protagonist's past. More concretely, she meets a Jewish man that makes her reflect on her Jewish roots when he asks her: "Do you think that to be a Jew you must only be born in such-and-such place? [...] Ours is a complex identity and Jews have always done what they had to survive. Black Jews, Asian Jews, what's the difference? We carry our identity not in a place but in our story" ([11], p. 14). These words help the narrator realize that, as a Jewish woman, "[she] cannot forget the past, it is with [her] all [her] life" ([11], p. 15); giving place to the flashback that shapes parts one, two, and three of the novel. In these three sections readers encounter Sybil's journey across America and Canada from 1946 to 1965. This travel constitutes the core of the novel, narrated by mature Sybil but focalized by the younger character as the events were happening at that time. This use of narrator and focalizer creates an effect of discordance between the Sybil of the past, who saw the events of her life through the eyes of an innocent and, sometimes, shallow woman, and the narrator's reflections, which belong to a more insightful and reflective Sybil. For example, throughout the first section of the novel her innocent and young self frequently asks her father what it means to be a Jew ([11], p. 30)-some knowledge she gains as the narrative advances, as will be analyzed further on. Then, section four goes back to the present 1990s, creating a narrative gap between the 1960s and 1990s, the time when Sybil lives peacefully in London and agrees to take in her cousin's son as a refugee from the Yugoslav Wars.

To begin with the evocation of the past provided in section one, the feelings and events which are constantly evoked by Sybil when setting off on this recovery of the past appear to be linked to displacement and foreignness - feelings that lie at the core of the Jewish sense of communality. Jewishness cannot be defined by having recourse to a specific place, language, or tradition; on the contrary, Jewish identity is "about belonging to a collective whose parts are scattered around the world, with multiple common sets of values, symbols, and practices" ([15], p. 206). These diasporic feelings are embodied by Sybil Ross when she is initially compelled to face the Jewish legacy of uprootedness that her father attempts to transmit to her in episodes like this:

"When we were slaves in the land of Egypt", he began, "and our forefathers toiled for the pharaohs with the blood of their hands and the sweat of their backs..." He ranged through history, ancient and modern [...]. There was no chronology in anything he said. Our slavery in Egypt could have been yesterday, [...]. The shofar is sounded to announce our freedom and raise the banner to collect our exiles and gather us together from the far corners of the earth, the outcasts of the people of Israel ([11], p. 31, italics in the original).

Her father's words match Elan Ezrachis' definition of the Jews as a group of people condemned to an eternal state of displacement which will be rewarded with the ultimate access to the Promised Land. Nevertheless, the reaction of young Sybil does not consist of accepting her father's Jewish faith, but she rebels against the destiny that he intends to impose on her, as may be seen when she 
argues: "I did not want to be part of the world of pain he described. I did not want to be an outcast; I wanted to belong" ([11], p. 31). Therefore, one of the main identity conflicts that emanate from these words has to do with her refusal to accept the role of the outcast that has conventionally been assigned to Jews by the Christian Western tradition ([16], pp. 123-24). A status that the Jews have also assimilated as an intrinsic facet of their identity, as the exaltation of the tradition of the "shofar" mentioned in the previous extract demonstrates.

Still, Sybil also has to struggle with the fact that she is not a proper Jew. Her mother has German roots and, consequently, she is not one of the chosen people described by her father ([11], p. 32). This complicates the difficult task of assuming Jewishness - an aspect that will remain the most hurtful issue at the heart of Sybil's narration. As her own reflections illustrate, "almost before I was conscious that I was a girl not a boy [...], I knew that I was not a real Jew" ([11], pp. 25-26); this character has grown up being aware of her inbetweeness. Thus, if the task of keeping Jewish memory and history alive is always very complex ([17], p. 32), The Cast Iron Shore proves that this is even more so when the Jewish subject is caught between two or more different cultures at once, and especially if one of these cultures is related to Germany to some extent. In the case of the Jewish population that migrated from Germany to Britain and other European countries during and after the Second World War, some critics like Sue Vice have observed that they destabilised all the fixed categories that had been ascribed to traditional Jewish immigrant communities because they were considered as alien immigrants as well as they came from the enemy country ([9], p. 21). Although this is not Sybil's situation, as her mother is not a German-Jew, the fact that her mother has German blood turns the protagonist into an extremely complex hybrid: half-German, half-Jew, and half-British; a person who will have to struggle to try to be accepted by society all her life-first in Britain, and later on in her subsequent journeys ([11], pp. 87, 145, 165, 322).

Furthermore, these identity problems increase when it comes to Sybil's femininity. The Jewish woman has conventionally been restricted to the private sphere of the house, keeping the Jewish tradition alive and maintaining the unity of the family. This belief draws on the fact that, within the Jewish culture, the preservation of the family ties is one of the most sacred aspects for a collective that has survived thanks to the identity roots that women carry with them. Yet, this is an aspect which, according to current feminist thinkers such as Judith Baskin [18] and Linn Davidman and Shelly Tenenbaum [19], has been one of the main causes for the deprivation of freedom and power endured by Jewish women along history. Sybil's case is again further complicated because she does not have a Jewish female role to identify with, as her German mother does not fulfil the Jewish matrilineal function of preserving the family memories. Just as the novel shows that that Sybil does not want to be a sufferer like his father's chosen people, she is later convinced that she does not want to embody the idea of femininity represented by her mother either. She is very critical towards the feminine stereotype of the woman treated as a beautiful object represented by her mother, as she claims that "I contained my grief that I was not, like my mother, a blonde" ([11], p. 40). Sybil's troubled femaleness is rooted, then, in the lack of identification with a Jewish model of womanhood, her hunger for more progressive models of femininity than those offered by her suffocating family sphere, and the unavoidable fact that her mother belongs to alien Germany, which makes it even more difficult for her to feel a filial bond with her. 
In the end, Sybil's identity conflicts increase when the Second World War breaks out and England is battened by the Blitz. Her adoptive country is being attacked by the German enemy, making her family's lives disintegrate ([11], p. 59); whereas news starts to arrive that many of her Jewish relatives are disappearing under the Nazi regime ([11], p. 68). This moment becomes the turning point for the protagonist. She realizes that her identity is somewhat related to the people who try to kill them in England and who are killing their ancestors in Europe, as observed when she finds out that: "as it turned out, I had Nazi uncles and Nazi aunts, Nazi cousins. The enemy was in me, Nazi blood pumping my empty heart" ([11], p. 65). In the fields of Trauma and Holocaust Studies, much research has been done on the feelings of guilt developed by the different agents implied in the Holocaust: perpetrators, survivors, and bystanders. In Sybil's case, her words describe the feelings of guilt derived from her family connections with Nazi Germany. As Lifton explains, guilt is common among those people who have gone through war, abuse, or natural disasters, and it has been observed in numerous Holocaust survivors as well as in their descendants ([20], pp. 113-26). For Sybil, the impossibility of facing these intricate guilty feelings finally leads her to escape from a "home" that had already been destroyed by the war ([11], p. 69). Together with the burden of this guilt, the traumatic effects of the war on her parents and herself ([11], p. 69), her inability to feel neither Jewish nor German nor English ([11], pp. 25-26), and the entrapment she felt within her patriarchal family ([11], p. 69) are the reasons that force Sybil to escape to New York, thinking that: "Europe was a dark continent, lined with skeletons of burnt-out warehouses" ([11], p. 69). Therefore, even though she initially rejected the stereotype of the Jews as a diasporic people, she ends up embracing her destiny as a wanderer, believing in the possibility of "be[ing] entirely reborn" ([11], p. 70).

\section{The Journey: Multidirectional Connections, the Development of the Political Self, and the Encounter with the Other}

Nowadays, it is broadly accepted that identity emerges from the layered contacts with place; identity is fluid and hybridized. A key factor that has contributed to this hybridization is the rise of migratory movements which have helped to define current identities as born out of exchange, movement, and relationality. Geographical movement has come to be accepted as "a crucial human experience" ([21], p. 1) that produces a change in both the individual and the society during and after the migratory process. In The Cast Iron Shore, Sybil's journey across America represents one of the greatest migratory movements of the previous century, that of the Jews in the post-Holocaust era. In fact, this is a migratory movement that has been represented in many of the narratives by British-Jewish women writers; for instance, Anita Brookner's The Latecomers, Eva Figes' Journey to Nowhere, Anne Karpf's The War After, Lisa Appignanesi's Losing the Dead, Louise Kehoe's In This Dark House are representative of the collective experience of many Jews who lived similar situations of homelessness after the Holocaust by depicting various journeys of self-discovery caused by or derived from the Holocaust. As will happen to Sybil, most of these journeys appear to confirm the difficulties found by the Jewish protagonists when trying to be integrated within the new societies. 
Together with Sybil's initial vision of the journey as an opportunity to rebuild a new life out of trauma and war, we could follow those critics who have seen travelling as "one of the most potent metaphors of our culture for women's transgressive moves" ([22], p. 65). Drawing on the idea that the journey was already a typical motif in the women's writing of the 1980s and 1990s with a plethora of narratives depicting women's journeys escaping from the status quo, Sybil's female identity continues to be problematized in the new land. Sybil's relationships with men are not depicted in egalitarian terms: she embraces her affairs with Stan- "I was at Stan's beck and call. Like a dog, I always came when he whistled" ([11], p. 80) - and Julius - he saw me as a blank sheet of paper he could write on and fill out all his thoughts" ([11], p. 140); but they are not based on love equality. On the contrary, these men attempt to model her personality to the extent that she even wonders "if I was to spend all my life being passed from hand to hand. [...] Each time I lost myself and became whatever they wanted me to be" ([11], p. 161). These comments point out that it is very difficult for Sybil to get rid of the patriarchal models that her family wanted to impose on her in England ([11], p. 43), and they show the difficulties in finding a voice of her own to define her true self, as she is usually described by others throughout a great part of the narrative. For instance, she narrates the way Julius addresses her as a half-human being and she is incapable of showing a critical attitude towards his words ([11], pp. 138-40). Moreover, these relationships are more complex than mere representations of gender roles, as encountering other hybrid male identities will help Sybil reflect on her own diasporic self. Stan is a bisexual seaman travelling around the world and Julius is an Afro-American who is strongly committed to the Communist cause. Through the liminal relationships with these two men, Grant problematizes the notion of stable and rigid identities, favouring dialogic notions of the individual subject whose identity may be molded by external factors, such as meeting Others who defy previous notions of the world. It can be said that, on the one hand, these men limit Sybil's freedom to decide the kind of person she wants to be but, on the other hand, they represent new Others who show Sybil that she is not the only one to have a hybrid identity. From a feminist stance, the early stage of the main character's journey turns out to be quite contradictory since it reveals that, while trying to escape from the burden of war and trauma represented by her Jewish family heritage in Britain, she is being caught up in a patriarchal network that deprives women of free will in America.

This aspect becomes especially evident in the case of her relationship with Julius. The protagonist starts feeling attracted towards the Negroes in the dance club in New York ([11], p. 106). Yet this attraction is not merely sexual, as happens to most of the white girls who felt their attraction towards the animal nature represented by the Negroes as a way of transgressing conservative social rules, since it seems to be based on her unconscious establishment of links with Black people's history of dislocation; an aspect that becomes clear when she thinks to herself that: "No, I wasn't prejudiced. Stan had made sure of that. And who was I, with my own secret history, to lower people for what they were born to be and could not help?" ([11], p. 101) Some early connections are made between Sybil's homeland, England, and the lives of Julius' ancestors. For instance, after meeting for the first time, Julius tells her that Liverpool was the place from which the slaves were shipped ([11], p. 130). This link is emphasized during the first night that Sybil sleeps with him, the first night that she feels "homely like home" in the US ([11], p. 135). Following Rothberg's terms, 
this feeling at home in the presence of another alienated character could be interpreted as Grant's attempt at connecting "shared histories of racism, spatial segregation, genocide, diasporic displacement, cultural destruction, and - perhaps most important - savvy and creative resistance to hegemonic demands" so as to "provide the grounds for new forms of collectivity that would not ignore equally powerful histories of division and difference" ([2], p. 23). Grant's main character starts linking both Jewish and Afro-American histories of oppression, finding in Black people echoes of other minorities who, like her, had been mistreated by hegemonic forces. Moreover, this multidirectional consciousness is reinforced by the symbolic meanings ascribed to the sea, one of the key motifs in the narrative, which is depicted as a natural frontier not only dividing but mainly linking Europe and Africa: "Europe and Africa are that close, just separated by one little sea" ([11], p. 155, my emphasis). This frontier links these continents' traumatic memories across time and space, reinforcing the multidirectional site that this narrative aims to construct, and portraying the Jewish diaspora, embodied by Sybil, in a more universal context, fostered by Julius' experience. This way, this novel displays Silverman's view of memory as following "a principle of transversal connections across time and space which disrupt essentialist readings of cultural identity and ethnic and national belonging" ([23], p. 22).

Subsequently, Sybil starts an affective relationship with Julius and he teaches her about the history of American slavery and the suffering that the Black population had to endure in the US. Learning about this historical episode leads her to establish parallelisms between the racism manifested in the US during and after the time of slavery and in Europe during the Holocaust; as is made evident when she adopts Julius argument that "Denying Negroes their rights and keeping the African people in the slavery of colonialism is the same argument as fascism" ([11], p. 154). She integrates this comparison in her new perspectives on self and world, as shown when she claims that Jews have traditionally been the "niggers of Europe" ([11], p. 183). By doing this, Grant's novel endorses Silverman's argument that the reunion of Jews' and Blacks' (hi)stories of oppression "should be an enriching line of enquiry rather than one that necessarily negates the uniqueness of the Holocaust" ([23], p. 20). It corroborates Paul Gilroy's claims that Jewish and Black (hi)stories should be discussed together without developing a "dangerous competition and without lapsing out into a relativizing mode" ([24], p. 213). In keeping with this, Julius' teachings make Sybil react against her parents, who had hidden from her the traumatic reality both of Nazism and other similar events that happened around the world. For example, this is perfectly illustrated when, after attending several meetings of the Communist Party, she wonders

When he [her father] told me of our slavery in the land of Egypt, why did he never mention the slavery of less than a hundred years ago? And when we freed ourselves and went into the Promised Land, why was there no mention of the Africans and Indians who actually lived in the Promised Land which was made foreign to them by the invader? ([11], p. 185).

This speech symbolizes the clash between traditional Jewish views on the Holocaust and the Jewish Diaspora as a unique and extraordinary event - represented by Sybil's father-and the contemporary theories arguing for the need to develop a multidirectional sense of memory that can 
foster "transversal, transnational, and transcultural solidarities" ([23], p. 21)-embodied by the figure of Sybil. Furthermore, her reaction of anger illustrates that, following Cheyette's terms, here the literary imagination is used "to reclaim a past and a sense of self where diverse histories intertwine metaphorically and, [...], are not eclipsed by a unique sense of victimisation” ([25], p. 113).

It should also be observed that the narration not only links European and Afro-American (hi)stories of genocide but it establishes connections between the racism suffered by Black people in America in the past and the racism exerted in such far away places as Russia during the Cold War. This is concretely depicted when Julius moves to Russia to support the Communist Party, which had previously had liberating synergies for his traumatised self; and then, once back, he admits to Sybil that he has suffered the same racism in Russia as he had experienced in America: "the whole place was white. There was some fuck-up and they put me in prison. A mistake. So what? [...] Some other coloured fellow. Because of course we all look the same" ([11], p. 287). With this episode Grant gets to unveil the universal nature of racism, which has been widely studied by thinkers such as Stuart Hall, Edward Said, and Homi Bhabha in the postcolonial context. All of these critics refer to the process by which Western societies had justified the subordination exerted upon those Others which challenged their status quo on the grounds of establishing binary oppositions between Self and Other. Being a hybrid Jewish subject herself, Sybil had already experienced the negative consequences of this Manichean view of the world, according to which those hybrid subjects "who do not fall easily into any established categories tend to cause anxiety within a given community" ([26], p. 144); following Zygmunt Bauman's understanding of these concepts. Therefore, by establishing these universal links, The Cast Iron Shore fosters a model of multidirectional memory in setting up connections between very diverse traumatic events-Black slavery and the Holocaust and the Jewish Diaspora - and drawing attention to non-European traumatic conflicts. This memory demonstrates an ability to cut "across genres, national contexts, periods, and cultural traditions" ([2], p. 18) and, through it, Grant re-examines the complex relationship between the Jewish and the Black history of discrimination and genocide.

Along with this, the emergence of Sybil's multidirectional awareness leads to a key facet in the evolution of the protagonist's personality: the development of her political self during the second part of the book. Although at the beginning she is not politically conscious, she ends up being a member of the Communist Party in 1948 once she has established the multidirectional connections analyzed, and once the journey across America has revealed not to be as ideal as she initially expected, leading her to assume her soul as that of "every Jew who wanders" ([11], p. 191). The narration shows that the focalizer of the action is now aware of the prejudices that different races encounter everywhere, whether in Britain or America; as the following words illustrate:

the connection between Jews and Negroes was there. When I remembered what had happened in Nazi Germany and how my own relatives had died, [... I feel a mixture of fear and guilt. [...] For I seized my on the Race Question as a way of burning out of my soul that diseased part of it which I had inherited with my mother's blood. So I threw myself into political work ([11], p. 183). 
The repetition of the first pronoun "I" points at the main character's evolution of personhood from a more immature girl, whose voice was hardly heard at the beginning of the narrative, towards a more mature woman who is more aware of her inner thoughts and political opinions, as the frequent use of verbs referring to feelings and emotions demonstrate ("remember, feel, seize"). Then, she takes these more sophisticated personal connections further ahead when she points to the hidden links between Communism and Nazism, the American fight against the Soviet Union at that present moment and the Allies' fight against Nazism some years before. Yet the most intriguing aspect is that these links are established for Sybil to refuse any armed conflict on the grounds that wars are always destructive; as she herself experienced when living the Blitz in Britain: "Everything Red was bad. It was like Germany under Hitler. [...] I replied. I could not bear to live another war where there was still so much from the last one I could not speak of." ([11], p. 213, my emphasis). Still, politics becomes Sybil's way of trying to work through her personal feelings of "fear and guilt" ([11], p. 183); as evinced when she claims: "What could I do to purge myself of that terrible legacy of slaughter and evil? [...] I would stand for justice and equality for all. [...] If the Nazis had persecuted the Jews I would rescue the Negroes and the poor and the hopeless" ([11], p. 234). These words prove that she tries to find her way out of her burden of guilt by finding out what Judith Lewis Herman describes as a "survivor's mission". According to this psychiatrist, many subjects "recognize a political or religious dimension in their misfortune and discover that they can transform the meaning of their personal tragedy by making it the basis for social action" ([27], p. 207). For Sybil, a possible way to liberate herself from guilt consists of fighting against injustices by virtue of her recently acquired multidirectional consciousness.

As has been demonstrated so far, section two-portraying Sybil's and Julius's leaving New York and moving to California to continue their fight for the Communist Party - is focalized by a thoughtful narrator that is able to identify her guilty feelings and elaborate philosophical thoughts. This evolution is identified in the language used by the main character, who compares her teenage preoccupation with "powder compact" ([1], p. 234) with her current reflections on justice, Marxism, and Communism. At this moment, Sybil comprehends the full meaning of the political and transcultural associations exposed, but the "encounter with the Other" depicted in her relationship with Julius should be revisited to understand the changes it produces in both characters. The main premises of multidirectional memory have been influenced to a great extent by Levinasian philosophy in the sense that they are "oriented towards some wider opening, some greater sensibility and a surrender of the same in favor of the other/the infinite, [...], with correlative notions like vulnerability and disinterestedness" ([28], p. 3). That is to say, the openness to the Other fostered by Levinas can be achieved by the establishment of multidirectional connections. The "ethics of alterity", strongly reclaimed in the 1980s, demands the subject's responsibility towards the Other as a basic tenet for the functioning of society. Levinas defined the encounter with the Other as the Self's openness to the Other's suffering, without appropriating his/her experience, "in the exposure to wounds and outrages, in the feeling proper to responsibility, the oneself is provoked as irreplaceable, as devoted to the others" ([29], p. 105). LaCapra's concept of empathic unsettlement follows these assumptions, and he defines it as "a form of virtual, not vicarious, experience [...] in which emotional response comes with respect for the other and the realization that the experience 
of the other is not one's own" ([3], p. 40). In The Cast Iron Shore, Sybil does experience this true encounter with the Other when she gets to know Julius' damaged soul and the traumas he and his ancestors endured. For instance, she thinks, after listening to Julius' story of trauma, that "I barely knew what Julius was talking about, but I did not forget his story and it would come to mean more to me when my own little soul, as shrivelled and as dehydrated as a dried pea, began to sprout and shoot" ([11], p. 153). Her response is not based on appropriating Black slaves' traumas, but on opening her mind to set genocide in a more universal context than she had been taught. Encountering Julius' diasporic and traumatic life makes her accept the responsibility for the vulnerable Other fostered by Levinas, which is exteriorized in the development of her political attitudes.

Nevertheless, Julius does not manage to reach this stage of pure encounter with Jewish suffering, embodied by Sybil's story of migration. In fact, Julius' failed encounter with the Other may have to do with the choice of narrator and focalizer in the novel. As the narration is dominated by an autodiegetic narrator acting as the main focalizer of the story, readers only have access to the action through Sybil's eyes and her point of view is imposed on the narrative. Readers may observe the evolution of her personality while this does not happen to some of the other characters. For example, Julius's story of trauma is narrated from Sybil's eyes, and this makes it hard to really understand the deep nature of his grief. This narrative aspect points out that Sybil's empathical attitude towards the Other's pain does not reach its full potential, as she does not transgress her own self completely and merge her story with that of Julius. What is perceived from Sybil's viewpoint is that Julius rather establishes a relationship that follows the model of master/slave domination, repeating compulsively the trauma he and his community endured in the past; which creates a barrier between the two characters that do not allow Sybil, as the focalizer of the story, to have access to her lover's inner feelings. There are several examples that illustrate Julius's attempts to dominate and look down on Sybil; he tells her that: "I don't see you as a human being at all" ([11], p. 138), and she admits that Julius' mission was meant to turn her into a human being, as well as she reckons that they were only equals in bed ([11], p. 146). Despite this, they get married after Julius has spent four years in Moscow ([11], p. 270) and, even within their marriage, he is not completely able to abandon his resentment and see Sybil as an equal human being.

In the light of this, this narrative constructs a partial development of the multidirectional memory proposed, as it succeeds uniquely for the main character when it comes to race and trauma connections. This model of memory does not manage to connect gendered memories, but rather it fails to reconcile a character that has suffered the negative consequences of patriarchal oppression (Sybil) with a character that has undergone the malaise of racism (Julius). Nevertheless, though gender equity is not reached in this relationship, the fact that the only voice and eyes behind the narrative are female shows Grant's intention of providing (half) Jewish women like Sybil with a voice of their own so that they may tell their silenced versions of history, recounting episodes of such magnitude as the Holocaust, Black slavery, and migration from a perspective that differs from traditional, hegemonic, and male versions. Also, Julius acts in the end as a key agent in Sybil's growing up as a mature political self. He could be considered as the narrative agent that makes the encounter with the Other and with the history of Black diaspora happen, which generates deep changes in Sybil's construction of racial identity, leaving gender roles aside. Therefore, the pattern 
of memory displayed in The Cast Iron Shore would point at two main critical considerations: firstly, it misses the opportunity to place the memories of trauma and war caused by historic episodes such as the Holocaust and Black slavery at the same level as the historic trauma undergone by women under patriarchy [30]; and, secondly, it unveils a partial failure in the theoretical concept of multidirectional memory itself, which seems to have forgotten the history of female subjugation across time and space by mainly focusing on such racial and trauma connections as those displayed in Grant's novel.

Taking all these ideas into account, the question that remains to be answered would be: in spite of the drawbacks mentioned, do the development of Sybil's multidirectional sense of memory and history and her encounter with the Other contribute to the ultimate working through of her feelings of guilt and to her reconciliation with her hybrid Jewish female identity?

\section{The Return: Dissolving the Family Ties, Reaching Freedom?}

In response to the previous question, the motif of the sea appears as a narrative device that alludes to Sybil's identity construction. A very good example appears when she and one of her latest lovers, after separating from Julius, talk about the movement of the waves in the following terms: "When the wave changes, the ocean bed changes as well, but when the bottom changes, so does the wave. The sand is always being rearranged. The land below has its effect but so does that transient foam have its effect'. [...] The wave lasts only a moment, then it spends itself but it leaves the ghost of its form on the ocean bed" ([11], p. 320). Here, the relational process that happens when an individual migrates to a different place is symbolized: just as the movement of the wave changes the ocean's bed and the changes in the bottom of the ocean modify the trajectory of this wave, the immigrant's identity — the wave — changes the adoptive place, while the new country - the ocean's bottom - alters the original essence of the immigrant. Sybil endorses this possibility ([11], p. 246), as she imagines herself as that wave altering the people and the places she has encountered throughout her journey, just as she has been changed by the new places and people she has met along her life journey. This is further explained in the fourth section of the book when, while recalling the past, Sybil admits that she never managed to feel she had roots to any place, and that her role in life always consisted of "skat[ing] along on the surfaces of things" ([11], p. 364) just as the waves do. Sybil's uprootedness is emphasized along the third part of the book. Here, in 1955, Sybil appears as a much more developed character after having travelled around America for six years. Now she is able to recognize the changes the journey has produced in her own self: "I was not the same woman who had left New York" ([11], p. 254). Moreover, she has acquired a voice of her own that allows her to recognize her war trauma- "the constant trauma of imminent capture" ([11], p. 261) — and to admit that she needs to escape from Julius's alienating relationship —an aspect that is symbolized by the oppressive forces associated to the land when she says that "I had witnessed the heart of America [...]. The land had held me down and imprisoned me" ([11], p. 296). In the end, these feelings lead her to escape once again and go back to Canada with Stan.

Along with this metaphoric use of the land and the sea to allude to Sybil's lack of belonging, the crucial moment in Sybil's wandering arrives in this section three when she goes back to England after her father's death, a journey which represents her return to the original conflict that had 
obliged her to leave home many years ago. One could think that this circular journey symbolizes the final stage of reconciliation with the family and that, as she has acquired a multidirectional consciousness, she might come to terms with her hybrid self and be reintegrated in the society. Nevertheless, this journey does not provide an easy resolution. Now that she is an adult she is confronted with her parents' struggles to cope with their own legacy of war and displacement. She discovers that, prior to dying, her father had gone back to Israel "to be with his own kind" ([11], p. 342) and look for the desired Promised Land; and her mother also admits that she would like to return to Germany so as to reconcile with her motherland. Sybil's parents, thus, also endorse the potential belief in healing power of transnational journeys which is fostered in many Jewish narratives. But the most striking moment of Sybil's return is the confrontation with her mother when they finally speak out their feelings about the German and Jewish origins of the family. In this encounter ([11], p. 343), Sybil finally rejects any German connection and blames her parents for her feelings of guilt, showing a similar process to the transgenerational transmission of trauma experienced by many descendants of Holocaust survivors. The so-called second generation has often become the recipient of their parents' traumatic memories, which becomes a burden for them, and may change into feelings of shame, guilt, and exclusion ([31], p. 195). Sybil's feelings are oxymoronic, as she is not a proper descendant of Holocaust survivors; they comprehend both the shame of having German origins, and the guilt of knowing that many of her Jewish ancestors died during the Holocaust while she survived because of living in a different country. On her part, her mother's attitude embodies a common tendency among many post-Holocaust Germans to neglect this historical episode and look the other way when confronted with the Nazi genocide. On account of this conflict, the clash that had been hovering over Sybil all these years is at last encountered as she has to face a mother denying the Holocaust, as well as assimilate the fact that some of her ancestors could have contributed to the Jewish destruction ([11], p. 345). Then, her inability to accept this complicated family background, mainly from an ethical perspective, leads Sybil to finally "dissolve the Ross family" ([11], p. 350).

The contradictory journey of reconciliation turns out to be both a journey of disintegration of family ties and a journey of personal liberation. In fact, it demonstrates that journeys have a strong liberating power, which increases from the perspective of Western feminist thinking that sees the "act of leaving home as a universally desirable movement and event for women" ([32], p. 173). In this sense, Grant's novel goes in line with the feminist facet of many "leaving-home narratives" which envision travels as sites of resistance where the ideas of home and unity are evaded, favouring instead the vision of the journey as not "only politically but also spiritually empowering" ([33], p. 186). This outlook on the idea of the journey is reinforced in The Cast Iron Shore by the fact that the heroine has changed after the journey is complete-developing a multidirectional and political consciousness - but she does not want to be reintegrated in the society when she comes back because she was never an intrinsic part of it. This rupture is, in fact, materialized in the formal structure of the book, as the third section of the novel ends up with this dissolution, closing Sybil's quest and her retrospective narration when she returns to Canada to find out that Stan has abandoned her. However, as has been mentioned, The Cast Iron Shore does not finish when this remembering process is over. The very last section of the book depicts another 
encounter with the Other when Sybil shelters her second nephew, Nebojsa, escaping from the conflict in Yugoslavia. Again, the novel displays the multidirectional connections, but focusing on the more recent dark episode of the Balkan Wars which left young people like Nebojsa completely shattered and traumatized ([11], p. 381). Now, old Sybil recognizes in him the signs of someone who has suffered the disturbing effects of war and tries to get into him in a way she could not do with Julius by, for instance, trying to help him obtain his residence card ([11], p. 391) and transmitting to him the wisdom that life has provided her with. For example, there is a very telling episode when Sybil values some of Julius' lessons in positive terms when he taught her that "there are two ways of changing the world. Either you can first make it work, then you can make it just. Or you can make it just and then make this just society work" ([11], p. 387), and she encourages this young fellow to take the latter path and try to leave the resentment and hatred that war has caused on him behind. Therefore, this encounter proves to be more successful, as mature Sybil can now leave her own ego apart and be aware of Nebojsa's needs. Maturity and her life journey have provided the narrator-focalizer with that ability.

In the end, the very last chapter of the novel recounts the conversation between Sybil and Stan when they meet, both in their seventies, in Liverpool many years after they separated:

"I [Sybil] wish I'd belonged somewhere. I wish I hadn't spent so much time on the edge

of things"

"You belong, all right."

"Who to? What?"

"To yourself."

"That's not enough."

"But it's had to be, hasn't it? [...] I always had somewhere to go back to and here I am. I knew who I was and where I was from. [...] You never knew who you were or what you came from. You were free. [...] You're neither one thing nor the other and that drives people mad, but we've got to have you. It wouldn't do if we didn't' ([11], pp. 400-1).

Drawing on these words, the contradictions embodied in Stan's and Sybil's conflicting views on her freedom epitomize the feelings that diasporic Jews have evoked throughout history since, as the use of the first-person plural pronoun demonstrates, "we" - the non-Jews - have traditionally felt both rejection and attraction towards the Jews - the "you" embodied by Sybil. Also, this fragment shows that Sybil regrets not having found the ties she needed when she left England, as she has only managed to live on the edge of things. Nevertheless, Stan's description of her indicates that this lack of belonging should not be considered as a failure, but as an opportunity to open the hybrid self to other people's traumatic experiences, to explore other silenced traumatic (hi)stories, and to develop a political and multidirectional awareness that makes it impossible for her to adapt to claustrophobic and narrow-minded Eurocentric settings as the one she originally came from. Thus, the universal consciousness she has acquired throughout her life narrative has lastly provided her with the freedom not to be committed to any religion, to any husband, or to any land. 


\section{Conclusion: "Neither the Land nor the Sea, neither Fish nor Beast"}

As this reading of The Cast Iron Shore has shown, this novel proves the current tendency to see historical processes and collective traumatic episodes within a more interrelated global context. It has been proven that Grant's work challenges the competitive models of memory that attempt to politicize the degrees of victimization of different collectives, and the notion that the Holocaust and Jewish suffering are unique. It has also been pointed out that, by seeing the Holocaust in the light of American and Russian racism against the Black population, the novel does not support the discourse which sees the Holocaust as the single referent of the traumatic nature of the twentieth century. On the contrary, this novel highlights the idea that human catastrophes are inherent parts of a history that repeat themselves both for the Jewish people, the Black people, and humanity as a whole. This way, Grant can be said to have succeeded in carrying out the complex task of unveiling the connections between divergent historical processes, which Craps and Rothberg have explained as follows: "the Holocaust, slavery, and colonial domination are in fact interconnected, and by refusing to think them together (except in competitive manner) we deprive ourselves of an opportunity to gain greater insight into each of these different strands of history and to develop a more comprehensive understanding of the dark underside of modernity" ([34], p. 518). Thus, this half-Jewish female character has made the most of this "opportunity" to come to terms with her family inherited trauma by setting her individual story of diaspora and alienation within a more universal context that helps her become a more cosmopolitan human being.

However, it has also been explained that this has not been a completely reciprocal process, since Sybil has been changed by the encounters with the Other and by this physical and spiritual journey of self-discovery, but she has not been so capable of producing similar changes in those characters and places around her. Although the relationship with Nebojsa opens the door to a more fruitful process of mutual encounter and empathy, the narrative closes without drawing further on this relationship. In keeping with this, it has also been noticed that Sybil has gained a multidirectional political consciousness, as well as her longed-for freedom through her travelling, but during that journey she has lost some other things: the possibility of forming a family, the capacity to embrace the Jewish tradition, the desire to feel she belongs somewhere, and the strength to be exclusively defined on her own terms. Sybil's incomplete journey could suggest, then, that her quest represents both an incipient step for current Jewish women to reclaim a more active position in society [17] as well as it suggests a revision of the model of multidirectional memory so that it may incorporate women's traumatic (hi)stories of oppression.

Focusing on the novel's final words, their symbolic meaning also sheds some light on this open-ended quest:

But I had already turned and was looking out of the window. Across the top of the city my gaze sped, to the river as it widened and narrowed and met the sea. My thoughts were rushing down to the sea, and the brass and the ivory horns and the trumpets were sounding on the water, where ships sail on the surfaces of things to the very end of our burning world ([11], p. 403). 
Here, the eternal atmosphere depicted through the use of a poetic style, which reminds readers of the Eliotean depiction of eternity and time in The Four Quartets, demonstrates that Sybil will continue her everlasting wandering just as many Jews had done before her. The novelty in this narrative is that the establishment of liminal multidirectional relationships has freed the female protagonist's mind from rigid racial and religious stereotypes; providing her diasporic eternal state with a refreshing and regenerating potential. Through this character, Grant opens up innovative multidirectional territories for those new-fangled Jewish women who, being "neither fish nor beast" ([11], p. 145), wish to explore hidden facets of their identities. Grant's novel goes a step further in the creation of a woman who does not only try to escape from her initial suffocating situation but who also explores her manifold facets as a hybrid Jew, a woman, a political subject, and an individual human being. This exploration has been carried out through a transnational journey of liberation, the establishment of liminal relationships that have broadened the main character's mind, the development of a multidirectional consciousness that allows her to claim for social justice, the recourse to politics as a possible way of working through painful memories, and the encounter with Others' stories of displacement.

In the light of all the aspects analyzed, it could be concluded that Grant's novel both exceeds and resists the multidirectional model of memory just as some other British-Jewish women writers have done in the last few years. To give some examples, in The Memory Man Lisa Appignanesi connects different male and female generations that are linked to the Holocaust in one way or another across a spatial and spiritual journey of discovery of the Holocaust - its history and individual and collective memories - in Poland. Eva Figes' The Tenancy establishes parallelisms between the economic crisis lived in England in the 1990s after the New Right Policies of the previous decades, the traumatic traces in the lives of the Jewish characters and the Holocaust; turning the novel both into some kind of fictional re-enactment of the Holocaust and a reflection on universal victimhood. Elaine Feinstein in Children at the Rose also travels across time and space to connect places such as Britain, France, and Poland under the common background of war. To sum up, these novels mainly focus on the connections between diverse memories of racism, war, and trauma just as The Cast Iron Shore does, without paying excessive attention to the gender aspect. Nevertheless, it should be mentioned that Grant's posterior novel Still Here, published in 2004, does not only connect divergent places-Britain, Germany, Poland, Israel, USA — and diverse traumatic memories - connected to the Jewish Diaspora, the Second World War, the Holocaust, the post-war period, the Yom Kippur War-but it also connects these divergent memories in terms of gender. The two main characters, Alix and Joseph, do not only travel mentally and physically to the places where their traumatic memories originated but throughout the journey they construct refreshed models of femininity and masculinity that escape stereotypical and patriarchal assumptions. Alix accepts her femininity in a more natural way, and Joseph embraces a new model of liberated womanhood that replaces the patriarchal stereotypes that had been transmitted to him. This is achieved by the alternation of the roles of narrator and focalizer that swift between the two main characters throughout the narration. In keeping with this evolution in Grant's oeuvre, it can be said that The Cast Iron Shore represented an initial step in the depiction of multidirectionality and gender relations in travel; while some of her later works draw on some of the weakness that have 
been analyzed in this study, and continue to develop this author's concept of multidirectional memory by integrating a more feminist stance.

In conclusion, on various occasions The Cast Iron Shore depicts the main character's multidirectional wandering in a negative light — as when Sybil regrets her lack of belonging, when several characters reject her because of being a foreigner, and when the patriarchal hints provided by the male characters are not sufficiently counteracted by the female protagonist - which might foster the reactionary views that Jews, and concretely Jewish women, are eternally condemned to be outsiders wherever they settle, together with the fact that women have to struggle very hard to enjoy their freedom, even at the risk of ending up their lives alone. However, it is my main claim that this pessimistic meaning should be counteracted. This novel means a step forward in the reconciliation of both Jewish, hybrid, and female identities, offering new sites of negotiation which may become the future arena where individual and collective memories of war and conflict continue to demonstrate to be mobile and interconnected, and where traumatic (hi)stories still prove to be implicated in each other ([2], p. 313) when we try to come to terms with the multifarious traumas of displacement and oppression of our contemporary age.

\section{Acknowledgments}

The research carried out for the writing of this article is part of a project financed by the Spanish Ministry of Economy and Competitiveness (MINECO) (code FFI2012-32719). The author is grateful for the support of the Government of Aragón and the European Social Fund (ESF) (code H05). Acknowledgements should be given to the Project for Young Researchers at the University of Zaragoza "Fricciones de la memoria: la negociación pasado-presente y la construcción del futuro en la narrative contemporánea en lengua inglesa” (245216 — JIUZ-2014-HUM-02).

\section{Conflicts of Interest}

The author declares no conflict of interest.

\section{References}

1. Marianne Hirsch, and Nancy K. Miller. Rites of Return: Diaspora Poetics and the Politics of Memory. New York: Columbia University Press, 2011.

2. Michael Rothberg. Multidirectional Memory. Remembering the Holocaust in the Age of Decolonization. Stanford: Stanford University Press, 2009.

3. Dominick LaCapra. Writing History, Writing Trauma. Baltimore and London: The Johns Hopkins University Press, 2001.

4. Jill Bennet, and Rosanne Kennedy. World Memory: Personal Trajectories in Global Time. London: Palgrave Macmillan, 2003.

5. Stef Craps. Postcolonial Witnessing: Trauma Out of Bounds. London: Palgrave Macmillan, 2013.

6. Sheila E. Jelen, Michael P. Kramer, and L. Scott Lerner. Modern Jewish Literatures: Intersections and Boundaries. Philadelphia: University of Pennsylvania Press, 2011. 
7. Hana Wirth-Nesher. What is Jewish Literature? Philadelphia and Jerusalem: The Jewish Publication Society, 1994.

8. Bryan Cheyette. "Englishness and Extraterritoriality: British-Jewish Writing and Diaspora Culture." Literary Strategies 12 (1996): 21-39.

9. Sue Vice. "Writing the Self: Memoirs by German Exiles, British-Jewish Women." In "In the Open": Jewish Women Writers and British Culture. Edited by Claire M. Tylee. Newark: University of Delaware Press, 2006, pp. 189-209.

10. Ulrike Behlau, and Bernard Reitz. Jewish Women's Writing of the 1990s and beyond in Great Britain and the United States. Trier: Wissenschaftlicher Verlag Trier (WVT), 2004.

11. Linda Grant. The Cast Iron Shore. London: Grant Books, 1996.

12. Michael K. Freunt. "The Cast Iron Shore by Linda Grant." Available online: https://michaelkfreundt.wordpress.com/2015/01/27/the-cast-iron-shore-by-linda-grant/ (accessed on 8 September 2015).

13. Marie-Aude Baronian, Stephen Besse, and Yolands Jansen. Diaspora and Memory: Figures of Displacement in Contemporary Literature, Arts and Politics. Amsterdam and New York: Rodopi, 2006.

14. Raymond Federman. "The Necessity and Impossibility of Being a Jewish Writer." Available online: http://www.federman.com/rfsrcr5.htm (accessed on 28 July 2013).

15. Elan Ezrachi. "In Search of Roots and Routes: The Making and Remaking of the Diasporic Jewish Identity." In Dynamic Belonging: Contemporary Jewish Collective Identities. Edited by Harvey E. Goldberg, Steven M. Cohen and Ezra Kopelowitz. New York and Oxford: Berghahn Books, 2012, pp. 206-18.

16. Sander L. Gilman. Inscribing the Other. Lincoln and London: University of Nebraska Press, 1991.

17. Adrienne Baker. The Jewish Woman in Contemporary Society: Transitions and Traditions. London: The Macmillan Press, 1993.

18. Judith R. Baskin. Women of the Word: Jewish Women and Jewish Writing. Detroit: Wayne State University Press, 1994.

19. Lynn Davidman, and Shelly Tenenbaum. Feminist Perspectives on Jewish Studies. Yale: Yale University Press, 1994.

20. Robert Jay Lifton. "The Concept of the Survivor." In Survivors, Victims and Perpetrators: Essays on the Nazi Holocaust. Edited by Joel Dimsdale. New York: Hemisphere, 1980, pp. 113-26.

21. Paul White. "Geography, Literature and Migration." In Writing across Worlds: Literature and Migration. Edited by King Russell, John Conell and Paul White. London: Routledge, 1995, pp. 1-19.

22. Nóra Séllei. "Travelling Agency: Female Subjectivity in Narratives of Home-Leaving and in Foreign Parts." In She's Leaving Home: Women's Writing in English in a European Context. Edited by Nóra Séllei and June Waudby. Bern: Peter Lang, 2011, pp. 65-80.

23. Max Silverman. Palimpsestic Memory: The Holocaust and Colonialism in French and Francophone Fiction and Film. New York and Oxford: Berghahn Books, 2013. 
24. Paul Gilroy. The Black Atlantic: Modernity and Double Consciousness. London: Verso, 1993.

25. Bryan Cheyette. Diasporas of the Mind: Jewish and Postcolonial Writing and the Nightmare of History. New Haven and London: Yale University Press, 2014.

26. Zygmunt Bauman. Modernity and the Holocaust. Cambridge and New York: Polity Press, 1989.

27. Judith Lewis Herman. Trauma and Recovery: From Domestic Abuse to Political Terror. London: Pandora, 2001.

28. Susana Onega, and Jean Michel Ganteau, eds. The Ethical Component in Experimental Fiction since the 1960s. Newcastle: Cambridge Scholars Publishing, 2007.

29. Emmanuel Levinas. Basic Philosophical Writings. Edited by Adriaan T. Peperzak. Bloomington: Indiana University Press, 1996.

30. Laura S. Brown. "Not Outside the Range: A Feminist Perspective on Psychic Trauma." In Trauma: Explorations in Memory. Edited by Cathy Caruth. Baltimore: The Johns Hopkins University Press, 1995, pp. 100-12.

31. Ellen S. Fine. "Transmission of Memory: The Post-Holocaust Generation in the Diaspora." In Breaking Crystal: Writing and Memory after Auschwitz. Edited by Efraim Sicher. Urbana and Chicago: University of Illinois Press, 1998, pp. 185-200.

32. Sara Ahmed. Strange Encounters: Embodied Others in Post-coloniality. New York and London: Routledge, 2000.

33. Danielle Russell. Between the Angle and the Curve: Mapping Gender, Race, Space, and Identity in Willa Cather and Toni Morrison. New York and London: Routledge, 2006.

34. Stef Craps, and Michael Rothberg. "Introduction: Transcultural Negotiations of Holocaust Memory." Criticism 53 (2011): 517-21. 


\section{Australian Aboriginal Memoir and Memory: A Stolen Generations Trauma Narrative}

\section{Justine Seran}

Abstract: This article proposes a re-reading of Aboriginal author Sally Morgan's Stolen Generations narrative My Place (1987) in post-Apology Australia (2008-present). The novel tells the story of Morgan's discovery of her maternal Aboriginal origins through the life-stories of her mother and grandmother; the object of a quest for the past that is both relational and matrilineal; incorporating elements of autobiography and as-told-to memoirs to create a form of choral autoethnography. Morgan's text explores the intergenerational consequences of child removal in the Aboriginal context and is representative of Indigenous-authored narratives in its suggestion that the children and grand-children of victims of colonial policies and practices can work through the trauma of their ancestors. I examine the literary processes of decolonization of the Indigenous writing/written self and community; as well as strategies for individual survival and cultural survivance in the Australian settler colonial context; especially visible through the interactions between traumatic memories and literary memoirs, a genre neglected by trauma theory's concern with narrative fragmentation and the proliferation of "themed" life-writing centered on a traumatic event. This article calls for a revision of trauma theory's Eurocentrism through scholarly engagement with Indigenous experiences such as Morgan's and her family in order to broaden definitions and take into account collective, historical, and inherited trauma.

Reprinted from Humanities. Cite as: Seran, J. Australian Aboriginal Memoir and Memory: A Stolen Generations Trauma Narrative. Humanities 2015, 4, 661-675.

\section{Introduction}

This article explores how the reflexive practice of autobiographical writing contributes to the decolonization of the Indigenous self and forms the root of individual survival and cultural survivance. In the Australian context, Stolen Generations testimonies exemplify the fundamental link between life-writing and trauma. From the late 19th century to the 1970s, Australia enforced widespread child removal policies aiming at taking mixed-race children away from their Aboriginal mothers and raising them as white [1]. Whatever the reasons given by individual states, from the protection of so-called full-blood Aborigines from dying out to the threat mixed-race individuals represented for White Australia's belief in racist doctrines, for the children who were placed on missions and in service, never to see their family again, for the mothers separated from their children, and for the communities deprived of their young, it had the same destructive impact.

Published in 1987, My Place is the life-story of Australian Aboriginal painter Sally Morgan, including the stories of her great-uncle Arthur, her mother Gladys and father Bill (incorporated into Gladys's narrative), and her grandmother Daisy, or Nan [2]. The text is dominated by Sally's own narrative from early childhood memories in the $1950 \mathrm{~s}$ to the writing of the book in the $1980 \mathrm{~s}$. 
Although Daisy and Arthur are the only ones who were removed from their family as part of the Stolen Generations, the consequences of removal are passed down to Daisy's daughter Gladys, sent away to a children's home as a toddler only to see her mother during school holidays, and Sally, whose quest for the past is motivated by the necessity to know and understand her mother's and grandmother's stories in order to know who she is. This article argues that reading My Place as a literary text straddling the generic boundaries between fact and fiction can help scholars of trauma studies to decolonize the discipline through an engagement with hybrid textual forms, alternative conceptions of the self, and marginalized histories.

The use of autobiographical writing expresses a need on the part of the author to look into the self to reveal complex dynamics which I aim to bring to light, following Smith and Watson's exhortation "to investigate the heteronomous meanings of the 'colonial subject' and to explore autobiography as a potential site of decolonization" ([3], pp. xxi-xxii). I therefore propose to re-read My Place in post-Apology Australia and break new ground by approaching a relatively well-known Aboriginal-authored text through the lens of trauma theory to reveal the latter's potential and limitations. Most criticism of Morgan's text to date has been focused on identity politics and a majority of critics has been concerned with judging the validity or truthfulness of her depictions of Aboriginality. Since the publication of a slew of commercially as well as critically successful Aboriginal women's life-writing narratives in the 1980s, these texts have largely fallen off the scholarly radar ([4], p. 169). Despite its recent loss of popularity, My Place remains a seminal text for the analysis of Stolen Generations trauma within Australian literary culture ([5], p. 14). In the following sections I will explore the literary genres associated with Stolen Generations narratives, including autobiography, memoir, and testimony, then I will examine the issues of trauma and witnessing present in My Place, before turning to an exploration of trauma and postcolonial theory in relation to the novel drawing on recent developments in criticism, and finally I will turn to the implications of collective family testimonies of Aboriginal "we-dentity" such as Morgan's for the discipline of trauma studies.

\section{Aboriginal Women's Life-Writing: from Autobiography to Collective Memoirs}

A crucial feature of Indigenous women's life-writing is the challenge to what constitutes historical discourse through what Bart Moore-Gilbert calls "the strategic erosion of established distinctions between the public/political and private/personal spheres, [...] the critique of the supposed 'objectivity' of History, [and] the traditional primacy of archival material [over] sources such as "oral testimonies"” ([6], p. 78). The use of oral sources and the repeated doubts over the veracity of facts in My Place fall within this critique of history as written by white people, a history that traditionally silences Aboriginal voices and their past. Writing the self is then a strategy to rewrite history through the author's personal vision and her experience of dispossession and oppression.

Indigenous women's life-writing enacts what Mary-Louise Pratt calls autoethnography, a counter-discursive practice involving the appropriation of ethnographic idioms as Indigenous self-representation attempts to replace Western ethnological texts as basis for cultural knowledge ([7], p. 7). Morgan's autobiographical narrative is interspersed with transcripts of the 
oral testimonies she tapes of her great-uncle, mother, and grandmother. Sally the narrator researches Aboriginal history at the Battye Library in Perth, Western Australia, but instead of using her findings directly in the narrative, for example by quoting historians or appealing to established arguments, she uses her readings of white ethnographers as arguments to convince her family members to speak out and offer a counterpoint to the dominant discourse. Thus she tells Arthur:

"[T]here's almost nothing written from a personal point of view about Aboriginal people. All our history is about the white man. No one knows what it was like for us. A lot of our history has been lost, people have been too frightened to say anything. [...] I just want to try to tell a little bit of the other side of the story." ([2], pp. 163-64).

There is a strong political desire on Sally's part to rectify history, to make things right again while reversing the othering process by putting her family's stories at the center. For Lizzy Finn, autoethnography is also "a recuperative act of piecing together a collective memory across generations," and this is exemplified by the transcripts of taped interviews that interrupt Sally's autobiographical narrative to weave together all its textual strands and create a collective familial narrative ([8], p. 20).

The proposition to read Indigenous women's life-writing as memoir is informed by Asian American author Maxine Hong Kingston's definition of the genre, as she lauds two reviewers of her novel The Woman Warrior stating that she is "slyly writing a memoir, a form which [...] can neither [be] dismiss[ed] as fiction nor quarrel[ed] with as fact. [...] It is by definition a series of stories or anecdotes to illuminate the times rather than be autobiographical" ([9], p. 64). Memoir as a narrative strategy allows the writer to perform a kind of autoethnography that conflates the personal and the political, the individual and the communal. Lee Quinby's study of the genre of memoir also frames it as a challenge to dominant constructions of the self. She asserts that "memoirs (particularly in their collective form) construct a subjectivity that is multiple and continuous. [...] In relation to autobiography, then, memoirs function as counter-memory" ([10], p. 299). The notion of life-writing forms as allowing for counter-memories, or memories that run counter to the dominant discourse, provides a useful link between literary genres and subjective acts such as remembering.

In My Place, Daisy and Gladys's voices are mediated by their daughter and granddaughter Sally, who filters their spoken stories through her words on the page. The complexity of representation in literary practice functions as a challenge to colonial boundaries and allows for the possible coexistence of past and present as contained in the time of writing. This is made possible through the mobilization of memories and their articulation in the book. Gladys's narrative, embedded within Sally's story, paradoxically opens with the statement "I have no memory of being taken from my mother" ([2], p. 241). She goes on to recollect about her time as a toddler and a child at Parkerville Children's Home, summoning memories she is unlikely to possess since according to modern psychoanalysis adults cannot retain memories of very early childhood. Yet Gladys's toddler memories are simultaneously "true" recollections and fabrications on the model of the actual childhood of many Aboriginal girls placed in such homes. Memoirs are ideal mediums for 
such narratives as they combine the historical authority of testimony with the freedom of individual recollection.

In relation to genre, Kateryna Longley also argues that "flexibility, specifically literary flexibility, is needed so that all genres can continue to be loosened to accommodate differences of personal and cultural vision at any time and in any place" ([11], p. 383). An awareness of the ideological aspect of literary categories is necessary, along with cultural sensitivity, in order to responsibly examine trauma in non-Western texts. For example, Australian Aboriginal life-writing is strongly linked with orality and is often collaborative and collective, as in My Place with the weaving of several first-person accounts to form a unified family story embedded in the main investigative plot. Each secondary narrator takes the reader on a journey backward to her or his chosen beginning, and works her or his way forward through to the day of Sally's recording. The fluidity of literary genres displayed in the text thus leads me to adopt flexibility in this study and characterize My Place as a choral autoethnography. Consequently, I analyze the text as a work of literature in the following sections in order to reveal its potential to decolonize trauma studies.

As Stef Craps points out, trauma theory tends to impose stylistic criteria onto trauma narratives, as it prescribes "a modernist aesthetic of fragmentation and aporia [...]. Theorists," he adds, "often justify their focus on anti-narrative, fragmented, modernist forms by pointing to similarities with the psychic experience of trauma as uniquely suited to the task of bearing witness to trauma" ([12], pp. 46, 50). The failure of narrative to capture the experience is supposed to bear witness to the extreme character of trauma, yet its focus on fragmentation disregards non-Western notions of communal body and memories, and the quest for unity in texts such as My Place centered around the personal and familial expression of colonization and the retrieval of a lost history. Some theorists attempt to police the very language used in the act of telling, with Giorgio Agamben for instance noting that " $[t]$ he language of testimony is a language that no longer signifies and that, in not signifying, advances into what is without language, to the point of taking on a different insignificance - that of the complete witness, that of he who by definition cannot bear witness" ([13], p. 39). The preoccupation with putting pain into words in order to make it "real" for others to believe it, and the Jungian certainty that to heal trauma one must transforming pain into a logical narrative, also fail to acknowledge the language issue in settler countries, where most Indigenous people learn English as a "native" tongue and write the trauma of oppression in the oppressor's words. Although writing in English for Indigenous authors may be a form of self-empowerment and a way to decolonize the language, it is also understandable that some would opt for silence instead ([14], p. 58). Although it can be a conscious choice and a coping mechanism, the silence of the colonized is precisely what the settler state counts on in order to avoid making reparations for the past and acknowledging ongoing suffering ([13], p. 55).

Interestingly, in the social sciences, psychiatrist Dori Laub distinguishes between three separate levels of witnessing: "the level of being a witness to oneself within the experience; the level of being a witness to the testimonies of others; and the level of being a witness to the process of witnessing" ([15], p. 75). In this framework, Daisy's witnessing is on the first level, Sally's is on the second and we as readers witness on the third level. This is not to dilute the "true" experience of the 
witness, but actually to show how interconnected witnessing and testifying are in testimony narratives such as My Place ([16], p. 235).

\section{Writing Trauma as a Witness}

Trauma is commonly understood as the repetitive manifestation of an extreme event not fully digested by consciousness, yet Kay Schaffer and Sidonie Smith argue that this "psychoanalytic model leaves little room for the expression of a critical consciousness on the part of tellers of their knowledge of the politics of oppression" ([17], p. 112). Their remark calls for a revision of the pathological definition of trauma to account for its potentially inherited historical nature, and to take into account non-Western conceptualizations of the psyche, mental health, and ways of healing. In My Place, Daisy's trauma of being removed from her mother as a child as part of the Stolen Generations is compounded with the removal of her elder daughter, Gladys's sister. The repetition of history is also hinted at by allusions to a possible incest, which the reader pieces together from Daisy's confirmation that her father is Howden Drake-Brockman, the white station-owner who employs her as a housemaid, along with her refusal to say who Gladys's father is (since she asserts that everyone knew and nobody talked) as well as Gladys's realization from an old photograph that she and Howden look uncannily alike.

Stolen children and incest are major causes of trauma, and their place in the novel can be understood using Nicolas Abraham and Maria Torok's notion of the transgenerational phantom, which they define as "an undisclosed family secret handed down to an unwitting descendant" ([18], p. 16). Nicholas Rand adds that the definition:

“...enables us to understand how the falsification, ignorance, or disregard of the past - whether institutionalized by a totalitarian state [...] or practiced by parents and grandparents - is the breeding ground of the phantomatic return of shameful secrets on the level of individuals, families, the community, and possibly even entire nations." ([18], p. 169).

Australia's official national narrative and Aboriginal individuals have kept the same secrets with different motivations: the former to conceal its own racist history and the latter for individual reasons. Thus Gladys begs Sally: “'Can't you just leave the past buried, it won't hurt anyone then?' 'Mum', I reasoned, 'it's already hurt people. It's hurt you and me and Nan, all of us [...]. I have the right to know my own history"' ([2], p. 152). Sally raises the issue of the ownership of the past, and the fact that the transgenerational phantom is also an absence that results in the pain of the descendant, the one who is hurt precisely by this lack of knowledge of the past that has been replaced with silence and mythologized narrative. Hence Sally's feeling of incompleteness and her yearning to know her mother and grandmother's stories and digest them in order to know who she is. In the novel, the transgenerational aspects of the narrative through the matrilineal strand anchor the women of Sally's family into Australian history. To Cathy Caruth's fundamental question: "What do the dying bodies of the past [...] have to do with the living bodies of the present?", Morgan answers that they still feed the lives they begat and that their presence must be acknowledged through that of their descendants ([19], p. 26). 
As Craps remind us, however, when using trauma theory to examine Indigenous literature we must bear in mind that foundational texts such as Caruth's "show little interest in traumatic experiences of members of non-Western cultural traditions" ([20], p. 26). Despite calls from critics such as Craps, Schaffer and Smith, and Deborah Madsen, trauma studies scholars still focus largely on Western texts, while postcolonial scholars tend to examine political (as opposed to psychological) issues in non-Western texts. This is not to say that one should apply Western trauma theory uncritically to postcolonial fiction without a thorough adaptation of its frameworks to alternative concepts of the psyche that put an emphasis on collective forms of selfhood, for this would amount to a dangerous form of medical imperialism. For example, Post-Traumatic Stress Disorder (PTSD) is a quintessentially Western construct, and as such it is mostly applicable in My Place to Sally's father Bill, a white Australian World War II veteran whose experience as a prisoner of war in Europe helped turn into a violent paranoid alcoholic ([12], p. 49).

At this stage a distinction must be drawn between the experience of destructive violence as a product or as a process. As a product it is isolated or episodic, like Bill's highly traumatic yet relatively short time in prisoner camp, but as a process, Bruce Lawrence and Aisha Karim argue that "violence is cumulative and boundless. It always spills over. It creates and recreates new norms of collective self-understanding. Violence as process is often not recorded because it is internalized; it becomes part of the expectation of the living” ([21], p. 12). Daisy's entire life as an Aboriginal woman reads like a long list of tragedies: stolen from her family as a child; forced to serve a white family without a wage; sexually exploited, possibly by her own father; made to abandon her first daughter and to leave the second one in a children's home. She has internalized ill-treatment as Aboriginal women's lot, and consequently tries to distance herself from her Aboriginality by concealing her (and their) origins from her family. Rosanne Kennedy reads Daisy's attempts at racial passing as a way of breaking the cycle of abuse of Aboriginal women in Australia, for she "refuses to reproduce herself or the conditions of her own marginality" ([22], p. 344). There are echoes of those fateful expectations when Daisy entreats Sally: "Don't ever let a man do that to you. You watch out for Amber [Sally's daughter]. You don't want her bein' treated like a black woman" ([2], p. 337). Daisy's plea supports Madsen's statement that the pathological definition of trauma as an unexpected and extreme experience "fails to account both for the inherited nature of certain forms of historical trauma and equally for the traumatic nature of everyday life for vulnerable people who daily confront with fear and helplessness the absence of safety or security in their lives" ([23], p. 63; [24], p. 101). Sally, who has led a relatively sheltered life despite poverty and her father's threats, attempts to right the wrongs inflicted upon her relatives by reclaiming her Aboriginal identity and rewriting what it means for her to be a black woman, as opposed to her grandmother.

Although Marianne Hirsch first developed her notion of postmemory in relation to the experience of the Holocaust, the genocide, displacement, and dispossession Indigenous people were subjected to by colonial powers have fostered large-scale individual and cultural trauma, leaving significant marks on contemporary Indigenous psyches. Postmemory describes "the relationship of children of survivors of cultural or collective trauma to the experiences of their parents, experiences that they 'remember' only as the narratives and images with which they grew 
up, but that $[\ldots]$ constitute memories in their own right" ([25], p. 106). The postmemory of the survivor's children enables a pure form of witnessing that is also faith in the witness's account from one who has not experienced trauma first hand, and whose telling is always mediated by her or his parents' experience.

Giorgio Agamben's work on witnessing traces the etymology of the word to the Latin superstes meaning "a person who has lived through something, who has experienced an event from beginning to end and can therefore bear witness to it" ([13], p. 17). I argue that if the victim witnesses the traumatic even "from beginning to end," then the survivor's witnessing goes beyond that, because they have to deal with what comes after, with loss and mourning, and with the knowledge of what destruction and death leave in their wake. Agamben derives his notion from Holocaust survivor Primo Levi's notion of the lacuna of testimony, which posits that survivors are not true witnesses ([13], p. 33; [26], pp. 83-84). The survivor lives with the knowledge and the pain, which they pass on to their children, yet a Eurocentric individualist culture often does not see it as a possibility or a desirable outcome for children to work though their forbears' experience of historical trauma. Where Agamben asserts that the one who bears witness is actually bearing witness to the impossibility of the task of bearing witness, I argue that it is possible to bear witness to the individual and collective consequences of death and trauma through one's children, like Sally who retrieves her mother's and grandmother's traumatic stories and passes them on to the reader (and her own children) through the medium of the book ([13], p. 34).

The children's status as the descendants of those who have known death from the outside, twice removed from the initial trauma, gives them a privileged position to counter the issue brought up by Jean-Francois Lyotard of the doubt of those who have not seen the gas chambers with their own eyes ([27], p. 3). The disbelief of horror and pain has been aptly formulated by Elaine Scarry in The Body in Pain as "to have great pain is to have certainty; to hear that another person has pain is to have doubt" ([28], p. 7). When this great pain leads to death, only the survivors are left with the certainty of what they have witnessed and that they pass down to their children, who although they did not experience trauma first-hand carry that certainty and the witness's burden of telling a doubtful world. Indeed, it is common for testimony and life-writing texts such as My Place that reveal racist discrimination and ill-treatment to be questioned by the revisionist press as inaccurate and inauthentic [29].

In historical studies, Dirk A. Moses' thesis of competing claims to the most traumatic historical tragedy between on the one hand "supporters" of Jewish interests who consider the Holocaust as a unique form of genocide more worthy of scholarly attention than colonization, and on the other hand "supporters" of Indigenous interests wishing to acknowledge colonization as a historical precedent on par with the Holocaust, is disingenuous ([30], p. 36). In literary studies, on the other hand, scholars such as Joe Lockhard have studied side by side Primo Levi and Native American author Gerald Vizenor, for instance, emphasizing what the declarations of survival by Jewish and Indigenous survivors of genocide have in common. Indigenous authors referencing the Jewish experience of displacement and diaspora tend to establish kinship rather than competition [31]. Proponents of the recognition of Indigenous genocides as a European responsibility mainly seek to obtain reparations and legal reforms from the colonial power and the settler state. 
Counter to Moses' position, Michael Rothberg in Multidirectional Memory advocates moving beyond the zero-sum game of competitive memory seeing public memory as a scarce resource that groups who demand recognition must be fighting over. Hence Rothberg's introduction of "the model of multidirectional memory, a model based on recognition of the productive interplay of disparate acts of remembrance and developed in contrast to an understanding of memory as involved in a competition over scarce public resources" ([32], p. 309). In this model, testimonies of genocide and oppression can be used to foster understanding and solidarity rather than rivalry. This is particularly suited to this reading of My Place, as Rothberg highlights two narrative forms appearing frequently in texts about genocides and massacres that mobilize multidirectional memory: "narratives of detection and narratives of intergenerational conflict and transgenerational transmission" ([32], p. 285; original emphasis). The detection of Sally's origins through the intergenerational transmission of trauma in a downward movement, from grandmother to granddaughter, and of healing in an upward direction, from granddaughter to grandmother, enacts multidirectional memory at familial and cultural level.

\section{Neologising the Critical Apparatus}

Faced with the inadequacy of Western trauma theory to account for and provide healing to Indigenous victims and to give satisfactory results according to Indigenous, as opposed to Western, criteria, we may look towards new developments in postcolonial literary criticism to complement trauma theory and adapt it to Indigenous contexts. Following white historian Bain Attwood's criticism, Australian Aboriginal writer and activist Jackie Huggins asserts that "Morgan's Aboriginality is forged through the creation of the text rather than the reverse" ([33], p. 459). This is where communal life-writing comes into play, as Morgan's ties with her Aboriginality and her people's culture and traditions is inextricably tied to her love for her grandmother. Indeed, at the end of the novel after Daisy's death, Sally's sister Jill remarks: "With her gone, we could pass for anything. Greek, Italian, Indian... what a joke. We wouldn't want to, now. It's too important. It'd be like she never existed. Like her life meant nothing, not even to her own family" ([2], p. 354). Morgan's advocacy for Aboriginal rights is tied to the experiences of Daisy, Arthur, and Gladys, and from the discovery of the injustice done to her own relatives, the narrator's awareness expands to encompass Australian Aboriginal collective trauma.

Sally the narrator and writer reclaims her heritage in the name of self-determination, seeks validation from the government through an Aboriginal scholarship, and gains acknowledgement of kinship by travelling north to her family's ancestral land, east of the Pilbara region. Consequently, Attwood has accused Morgan of "claim[ing] her forbears' past as her past and their heritage as her heritage," thus disregarding both specific considerations and the reality of the larger corpus of Aboriginal life-writing ([34], p. 307). Precisely because it encompasses the narratives of her mother and grandmother, My Place belongs to the sub-genre of Aboriginal women's life-stories, which according to Francesca Di Blasio tends to revolve around "a repetitive and impersonal destiny" ([35], p. 34). This is also in keeping with Georg Gugelberger and Michael Kearney's definition of the narrator of testimonial literature as "a speaker who does not conceive of him/herself as extraordinary but instead as an allegory of the many, the people," and thus creates a 
collective identity ([36], p. 8). My Place as testimony brings the story of racism and abuse of Aboriginal women at the heart of Australian culture by de-emphasizing its individual aspects. The story of Sally's female relatives therefore becomes hers at the same time as it becomes the story of a generic Aboriginal daughter-mother and weaves a super-narrative (or ur-text) of abuse and resilience. For Australian Aboriginal scholar Aileen Moreton-Robinson, Morgan and other Aboriginal life-writers from the 1980s have written "their mothers' life herstories" ([37], p. 1). The coinage not only replaces "his" with "her," thus highlighting the female standpoint as Sonya Andermahr and Silvia Pellicer-Ortin remark, but by splitting a very common word it also attracts attention to the presence of the word "stories" in "histories," and to the fact that History is a communal story made of individual stories ([38], p. 4).

Daisy, Gladys, and Arthur have a distinctly personal experience of what it means to be Aboriginal, and Morgan builds her own Aboriginality through the text, incorporating the disjointed, incomplete stories of her relatives without claiming them as her own, but by embracing them as form of we-dentity. This construction of a communal identity is not readily accepted by the dominant culture, and we must bear in mind that My Place was written in 1987, the year preceding the bicentennial celebrations of Captain Phillip's arrival with the First Fleet in Sydney Harbour, five years before the legal recognition of Native Title, acknowledging prior ownership of the land, and twenty years before the Apology and the official acknowledgement of the Stolen Generations in 2008. Finn places the novel back into context: "[t]his is the space in which Morgan begins to write: one where whiteness (white literature, white culture, white history) is the foundation and framework; where to speak is to be dismantled and to dismantle" ([8], p. 16). The very act of writing such a book was and is political, and the choice to identify with her Aboriginal heritage and renounce passing privilege was bound to trigger a backlash against its author, in keeping with the debates surrounding authenticity in the Australian public space. Moreover, Wei Ming Dariotis introduces the term "kin-aesthetic," which she defines as "the understanding of the 'Other' as 'kin', as a member of the in-group" ([39], p. 179). Kin-aesthetic uses the metaphor of the nation as family, with people of mixed cultural and ethnic heritage functioning as mirrors that reflect back the other within us. The conflation of individual stories and national past is evident in My Place with the central space given to Sally's family, but also through the presence of themes linked with the silencing and destruction of Indigenous identity in the context of the Australian nation.

Daisy's story is the final object of Sally's quest. Her narrative remains the most incomplete, full of holes and silences, and unspeakable secrets she takes to the grave. The few revelations she makes to her granddaughter uncover a fertile ground of silence and secrets, ideal for trauma to grow, and it is to dispel these secrets and fill this silence that Sally decides to write the story of her family. As Finn puts it, My Place's layering of utterances is also an attempt to "go back and piece together a cohesive narrative from the fragments that remain. In order to fill in the gaps, each narrative builds on and is built upon by the next, creating layers of meaning in the form of hybridised utterance" and together they form a communal story of transgenerational trauma ([8], p. 20). For Longley, moreover, “[t]hese blank moments (in Daisy's narrative) remind both the reader and the writer of the crudeness and invasiveness of the genre of transcribed autobiography" ([11], p. 16). They are both intrusive and respectful, lending credibility to the text for the central secrets of who 
Daisy's father and who Gladys's father were are never disclosed, or rather the reader is given several names by unreliable sources such as Alice and Judy Drake-Brockman, respectively wife and legitimate daughter of Daisy's employer and possible father (as well as Gladys's possible father) Howden.

Telling her story via the re-enactment of the past through a form of talking cure allows Daisy to shed the layers of fear suffocating her since childhood and for all of her adult life. The main difference with the Western concept of talking therapy, however, is that the stories are not told to a neutral, objective professional, but rather shared with a direct descendant who has a personal stake in the story as one constitutive of her own identity. When Daisy insists on being taken to the hospital so she does not die in her daughter's house, in a surprising twist since she always refused to see a doctor, the change becomes apparent. Re-living and telling her story to her granddaughter (and her daughter) has liberated Daisy and allowed her to be whole again, to remember and be re-membered, the retrieved past acting like a prosthetic limb to support her in her walk into death, just as the act of writing the book permits Morgan to finally feel whole.

Caruth suggests that "history is not only the passing on of a crisis but also the passing on of a survival that can only be possessed within a history larger than any single individual or any single generation" ([19], p. 71). In My Place, Sally records the stories of her elders and relieves them of their pain (Arthur and Daisy die shortly after they complete their recording sessions), thus reproducing the motif of the younger generation healing the older one and allowing them to pass away having made peace with themselves and their racial and cultural allegiances through their descendant. The younger generation is the bearer of postmemory: "the child who is alive because survival was indeed possible" ([40], p. 28). Survival is not only possible but it is also necessary to ward off erasure, and it is my contention that Indigenous literature allow us to explore the postmemory of subsequent generations, such as Sally's, Gladys's, and Daisy's, as the original traumatic events of colonization recede but their consequences remain.

\section{Survival and Survivance}

The trauma of the survivor of colonialism, the Indigenous person who is alive today in a settler country, is also a victory, for to have survived centuries of genocide is to live with the trauma of a stolen identity. Each year on the 26th of January, Aboriginal people and allies "celebrate" Australia Day as Invasion Day, Survival Day or the Day of Mourning, a tradition started in 1988 to mark the bicentennial of the First Fleet's arrival and to remember surviving 200 years of colonization ([41], pp. 358-59). Deborah Bird Rose suggests that such "[p]ublic declarations of indigenous survival challenge the most fundamental legitimacy of the nation by demonstrating that it makes war against its own citizens, that violence continues to be foundational, and that indigenous people are the continuing targets of white aggression" ([42], p. 15). By bringing to light white violence through assertions of survival to genocide, Aboriginal life-writing unsettles the settler nation and settler remembrance (or amnesia) of colonization.

The Apology to Australia's Indigenous Peoples was issued by Prime Minister Kevin Rudd (Australian Labor Party) on 13 February 2008 and presented as a motion in front of the Australian federal parliament. It accepted parliamentary and governmental responsibility for over two 
centuries of oppressive and discriminatory policies with particular references to the large-scale child removal of the Stolen Generations. The Apology was worded as "part of the healing of the country," a remark hinting at a national trauma in the process of being healed and running the risk of appropriating Aboriginal suffering by suggesting that the Stolen Generations did not only impact Aboriginal individuals and communities, but that the very fabric of Australian society bears the marks of their trauma [43]. Following the Apology, however, Rudd's government failed to reverse his predecessor John Howard's (Liberal National Party) suspension of the Racial Discrimination Act to carry out the notorious Northern Territory National Emergency Response, or the Intervention. If as Agamben states legal trials are unsatisfactory because they do not do enough to overcome horror, then what are we to make of the Apology in a context where racist laws and constitutions are still in effect? ([18], p. 19). Does healing entail accepting the ineffectiveness of one's testimony of survival or looking for alternate ways to make oneself heard?

In the words of Gerald Vizenor, "survivance, in the sense of native survivance, is more than survival, more than endurance or mere response; the stories of survivance are an active presence" ([44], p. 15). Vizenor contradicts the idea of survival as desirable, for it is incomplete and unsatisfactory. It is not enough to merely survive, to escape death. If survival is the opposite of annihilation, then survivance is the opposite of loss, defeat, and oblivion, the avowed goals of Indigenous genocides aiming at killing those who resist and assimilating those who cannot. Vizenor also uses the obsolete term sovenance to differentiate it from remembering, as "Native sovenance is that sense of presence in remembrance, that trace of creation and natural reason in native stories" ([44], p. 15; original emphasis). Vizenor's focus is on presence and action, on the will of native writers to re-inscribe themselves into the greater national and global narratives and to bring along elements of their native culture in order to assert their ongoing presence and relevance in the contemporary era. Along with Dariotis' kin-aesthetic, Vizenor's survivance places the minority writer at the center looking outward, asserting and reinscribing kinship and belonging on their own terms.

The concern with passing down memories from ancestors to descendants through the medium of the writing self is present in My Place through Sally's desire to write the book for her children so they know who they are, and to reform a matrilineal identity that was disrupted by Daisy's initial removal. The continuing presence of the ancestor, in this case of the living author-narrator who is in the process of becoming an ancestor herself, is the through line that gives law to the world. The cyclic renewal of generations allows for the renewal of cultural memory, remembering what needs to be remembered and forgetting what needs to be forgotten, in order to ensure the survival of the family and the wider community as well as the survivance of their culture. The possibility of renewal is embedded in the multi-cyclical, or spiralling, nature of the text, with its layering of utterance and time shifts interrupting the linear narrative of Sally's investigation.

The novel's structure anticipates aspects of Bringing Them Home: the 'Stolen Children' Report in 1997, with its detailed summary of the widespread impact on Aboriginal communities of child removal policies. Gillian Whitlock argues that "the emotive force of Bringing Them Home testimony engaged readers in a particular way, one that was generated by the figure of the child as victim, most specifically through the tropes of the stolen child, and the rhetoric of 'coming 
home"” ([45], p. 203). The motif of archetypal return is often subverted in Australian Aboriginal women's writing and rejected as insufficient and overly nostalgic, as opposed to their own narratives that look simultaneously to the past and the present and advocate for a better future. If the return to pre-contact cultures is rarely upheld as possible, nor indeed desirable, by Aboriginal activists, it is because of its assumption that Indigenous cultures are static and monolithic. The three extended flashbacks in My Place containing the stories of Arthur, Gladys and Bill, and Daisy are actual return trips into the past, both in the historical sense and in the sense of the mythic past before the birth of the author when trauma tore their family apart. Remembering is a return into past memories in much the same way as a pilgrimage to visit the birthplace of one's ancestors is a return to a theoretical past, unknown to the narrator, and fictional to the reader, that effects the decolonization of the writing/written self and community in the Australian settler context. It is also a return to the present through the acknowledgement that these memories are indeed reflecting a past era.

Survival in My Place is thus framed in terms of both the retrieval of familial memory and the physical return to an idealized land base. Indeed Sally and Gladys undertake a pilgrimage to a place they have never seen but that is entrenched in the memory of her family: namely Corunna Downs station, which Daisy left when she was removed from her mother and placed into service. Returning to Corunna Downs allows for both women to experience first-hand the living conditions of their extended family and to inhabit, albeit briefly, the same space as their grandmother and mother when she was a child. This is a crucial part of the journey, for on their way back to Perth, Gladys and Sally feel "[1]ike we'd suddenly come home and now we were leaving again. But we had a sense of place, now" ([2], p. 230). This sense of place is inextricable from that of belonging to the people who inhabit the place, as the landscapes in the North are described by Daisy watching the film of the trip according to the human activity that used to take place there ([2], p. 235). Morgan therefore proposes reconnecting with the ancestral land as a possible way to heal the trauma of removal, even the double removal of Daisy who was lost and lost her elder daughter as part of the Stolen Generations. Her severed ties with the Pilbara region are reconnected through her daughter and granddaughter's pilgrimage; even if she does not set foot there, her flesh and blood do, and Daisy herself works through her trauma by the proxy of their family bond. Since the phantoms of child removal and incest were passed down to Gladys and Sally, they have the power to break the circle and propose a form of healing to Daisy.

\section{Conclusions}

Thus, I have argued that by presenting a form of healing of individual and collective trauma as a transgenerational dialogue anchored in Australian history, Morgan echoes a holistic approach to the psyche as a collective consciousness shared by kin, rather than a transcultural collective unconscious. Trauma studies would benefit from a broadening of the definition of trauma and from further engagement with postcolonial theory and Indigenous criticism to interrogate and move beyond a Eurocentric trauma paradigm. Indeed, in Indigenous contexts where intergenerational transmission has been interrupted by colonization, it befalls the younger generations to relieve the older ones of the wrongs inflicted by colonialism by helping them re-live their life-stories to bridge 
the gap between the past and the present. Memory in My Place functions as a multidirectional channel for traumatic returns and renewals, and as such it resonates with new developments in postcolonial and memory studies and offers a productive site for scholarly discussion. As Nancy Van Styvendale notes, the trauma of Native people is "[c]umulative, collective, intergenerational, and intersubjective" as well as "trans/historical" ([46], p. 203). As one of the earliest published text addressing this issue, My Place plays a pioneering role in the narrative transmission of transhistorical Indigenous trauma, and Stolen Generations memory in particular, with Sally's autobiographical testimony creating what Stephen Muecke calls "the conditions for the other stories to appear in the appropriate sequence down a line which represents in a crucial way the deferment of (narrative) authority" ([47], p. 134; original emphasis). Not only does Sally's story open a literary space for Arthur, Gladys, and Daisy's testimonies, but the novel itself garnered critical and public interest which created the conditions for the publication of subsequent Australian Aboriginal women's life-stories.

\section{Conflicts of Interest}

The author declares no conflict of interest.

\section{References}

1. Peter Read. The Stolen Generations: The Removal of Aboriginal Children in New South Wales 1883 to 1969. Surry Hills: Department of Aboriginal Affairs, 1981.

2. Sally Morgan. My Place. London: Virago, 1988.

3. Sidonie Smith, and Julia Watson. De/Colonizing the Subject: The Politics of Gender in Women's Autobiography. Minneapolis: University of Minnesota, 1992.

4. Graham Huggan. The Postcolonial Exotic: Marketing the Margins. London: Routledge, 2001.

5. Tim Rowse. "The Aboriginal Subject in Autobiography; Ruby Langford Ginibi's Don't Take Your Love to Town." Australian Literary Studies 16 (1993): 14-30.

6. Bart Moore-Gilbert. Postcolonial Life-Writing: Culture, Politics and Self-Representation. London: Routledge, 2009.

7. Mary-Louise Pratt. Imperial Eyes: Travel Writing and Transculturation, 2nd ed. London: Routledge, 2008.

8. Lizzie Finn. "Postnational Hybridity in Sally Morgan's My Place." Moveable Type 4 (2008): $11-28$.

9. Maxine Hong Kingston. "Cultural Mis-readings by American Reviewers." In Asian and Western Writers in Dialogue. Edited by Guy Amirthanayagam. London: Macmillan, 1982, pp. 55-65.

10. Lee Quinby. "The Subject of Memoirs: The Woman Warrior's Technology of Ideographic Selfhood." In De/Colonizing the Subject: Politics of Gender in Women's Autobiography. Edited by Sidonie Smith and Julia Watson. Minneapolis: University of Minnesota Press, 1992, pp. 297-320. 
11. Kateryna Longley. "Autobiographical Storytelling by Australian Aboriginal Women." In De/Colonizing the Subject: Politics of Gender in Women's Autobiography. Edited by Sidonie Smith and Julia Watson. Minneapolis: University of Minnesota Press, 1992, pp. 370-84.

12. Stef Craps. "Beyond Eurocentrism: Trauma theory in the global age." In The Future of Trauma Theory: Contemporary Literary and Cultural Criticism. Edited by Gert Buelens, Samuel Durrant and Robert Eaglestone. London: Routledge, 2014, pp. 45-61.

13. Giorgio Agamben. Remnants of Auschwitz: The Witness and the Archive. New York: Zone Books, 2002.

14. Bill Ashcroft. Post-Colonial Transformation. London: Routledge, 2001.

15. Dori Laub. "An Event without a Witness: Testimony and Survival." In Testimony: Crises of Witnessing in Literature, Psychoanalysis, and History. Edited by Shoshana Felman and Dori Laub. New York: Routledge, 1992.

16. Rosanne Kennedy. "The Narrator as Witness: Testimony, Trauma and Narrative Form." Meridian 16 (1997): 235-60.

17. Kay Schaffer, and Sidonie Smith. Human Rights and Narrated Lives: The Ethics of Recognition. New York: Palgrave Macmillan, 2004.

18. Nicholas T. Rand. "Introduction." In The Shell and the Kernel: Renewals of Psychoanalysis. Edited by Nicolas Abraham and Maria Torok. Chicago: The University of Chicago, 1994.

19. Cathy Caruth. Unclaimed Experience: Trauma, Narrative, and History. Baltimore: The Johns Hopkins University, 1996.

20. Stef Craps. Postcolonial Witnessing: Trauma Out of Bounds. Basingstoke: Palgrave, 2013.

21. Bruce B. Lawrence, and Aisha Karim. On Violence: A Reader. Durham: Duke University Press, 2007.

22. Rosanne Kennedy. "Australian Trials of Trauma: The Stolen Generations in Human Rights, Law, and Literature.” Comparative Literature Studies 48 (2011): 333-55.

23. Deborah Madsen. "On Subjectivity and Survivance: Rereading Trauma through the Heirs of Columbus and the Crown of Columbus." In Survivance: Narratives of Native Presence. Edited by Gerald Vizenor. Lincoln: University of Nebraska, 2008, pp. 61-87.

24. Laura S. Brown. "Not Outside the Range: One Feminist Perspective on Psychic Trauma." In Trauma: Explorations in Memory. Edited by Cathy Caruth. Baltimore: The Johns Hopkins University Press, 1995, pp. 100-12.

25. Marianne Hirsch. "The Generation of Postmemory." Poetics Today 29 (2008): 103-28.

26. Primo Levi. The Drowned and the Saved. London: Abacus Books, 1989.

27. Jean-Francois Lyotard. The Differend: Phrases in Dispute. Translated by Georges Van Den Abbeele. Minneapolis: University of Minnesota Press, 1988.

28. Elaine Scarry. The Body in Pain: The Making and Unmaking of the World. Oxford: Oxford University Press, 1985.

29. Keith Windschuttle. "Why There Were No Stolen Generations (Part One)." Quadrant Magazine, 1 January 2010. Available online: http://quadrant.org.au/magazine/2010/1-2/whythere-were-no-stolen-generations/ (accessed on 12 September 2013) 
30. Dirk A. Moses. "Conceptual blockages and definitional dilemmas in the 'racial century': Genocides of indigenous peoples and the Holocaust." Patterns of Prejudice 36 (2002): 7-36.

31. Joe Lockhard. "Facing the Windigoo: Gerald Vizenor and Primo Levi." In Survivance: Narratives of Native Presence. Edited by Gerald Vizenor. Lincoln: University of Nebraska Press, 2008, pp. 209-19.

32. Michael Rothberg. Multidirectional Memory: Remembering the Holocaust in the Age of Decolonization. Stanford: Stanford University Press, 2009.

33. Jackie Huggins. “Always Was, Always Will Be.” Australian Historical Studies 25 (1993): 459-64.

34. Bain Attwood. "Portrait of an Aboriginal as an Artist: Sally Morgan and the Construction of Aboriginality." Australian Historical Studies 25 (1992): 302-18.

35. Francesca Di Blasio. "A path of words: The reception of autobiographical Australian Aboriginal writing in Italy." In Indigenous Biography and Autobiography. Edited by Peter Read, Frances Peters-Little, and Anna Haebich. Canberra: Australian National University Press, 2008.

36. Georg Gugelberger, and Michael Kearney. "Voices for the Voiceless: Testimonial Literature in Latin America." Latin American Perspectives 18 (1991): 3-14.

37. Aileen Moreton-Robinson. Talkin' Up to the White Woman: Indigenous Women and Feminism. St Lucia: University of Queensland Press, 2000.

38. Sonya Andermahr, and Silvia Pellicer-Ortin. Trauma Narratives and Herstory. Basinstoke: Palgrave, 2010.

39. Wei Ming Dariotis. "Developing a Kin-Aesthetic: Multiraciality and Kinship in Asian and Native North American Literature.” In Mixed Race Literature. Edited by Jonathan Brennan. Stanford: Stanford University Press, 2002.

40. Marianne Hirsch. "Surviving Images: Holocaust Photographs and the Work of Postmemory." The Yale Journal of Criticism 14 (2001): 5-37.

41. Heather Goodall. Invasion to Embassy: Land in Aboriginal Politics in New South Wales, 17701972. St Leonards: Allen \& Unwin, 1996.

42. Deborah Bird Rose. "Hard Times: An Australian Study." In Quicksands: Foundational Histories in Australia and Aotearoa New Zealand. Edited by Klaus Neumann, Nicholas Thomas and Hilary Ericksen. Sydney: University of New South Wales Press, 1999.

43. Kevin Rudd. "Kevin Rudd's apology." Creative Spirits Video. Available online: http://www. creativespirits.info/aboriginalculture/politics/sorry-apology-to-stolen-generations (accessed on 17 May 2015).

44. Gerald Vizenor. Fugitive Poses: Native American Indian Scenes of Absence and Presence. Lincoln: University of Nebraska, 1998.

45. Gillian Whitlock. "In the Second Person: Narrative Transactions in Stolen Generations Testimony." Biography 24 (2001): 197-214. 
46. Nancy Van Styvendale. "The Trans/Historicity of Trauma in Jeannette Armstrong's Slash and Sherman Alexie's Indian Killer." Studies in the Novel 40 (2008): 203-23.

47. Stephen Muecke. Textual Spaces: Aboriginality and Cultural Studies. Sydney: New South Wales University Press, 1992. 


\section{Oranges and Sunshine: The Story of a Traumatic Encounter}

\section{Dolores Herrero}

Abstract: This paper will rely on some well-known theories on trauma, memory and ethics to study how Jim Loach's debut film Oranges and Sunshine (2010) testifies to the traumatic deportation of up to 150,000 British children to distant parts of the Empire, mainly Australia, until 1970. Oranges and Sunshine was based on Margaret Humphreys' moving memoir, originally entitled Empty Cradles (1994) but later re-titled Oranges and Sunshine after Loach's film. What these two texts basically claim is the need to recover historic memory through heart-breaking acts of remembrance, which can alone denounce the atrocities that were concomitant with the colonial enterprise and pave the way for disclosing and working through individual and collective traumas.

Reprinted from Humanities. Cite as: Herrero, D. Oranges and Sunshine: The Story of a Traumatic Encounter. Humanities 2015, 4, 714-725.

\section{Introduction}

Contemporary Australia is still trying to cope with the traumatic unsettlement brought about by the publication in 1997 of the polemical Bringing Them Home Report, which disclosed, to use the title of Mishra and Hodge's well-known book, "the dark side of the Australian dream" [1]. What this report disclosed and denounced was the long-term suffering inflicted by the Australian government upon the Aboriginal community, which saw for decades how their children were being wrenched from their families to be brought up in white missions, where they were deprived of their names, their language, their culture, and any kind of contact with their families. "Stolen Generation" was the name given to these Aboriginal children. Conservative Prime Minister John Howard refused to apologize for all of these atrocities. It was Kevin Rudd, Australia's next Labour PM, who in 2008 finally delivered an official apology.

It was only one decade later that yet another skeleton was found in the Australian cupboard, but this time Australia had only been the perpetrators' accomplice. The nation that was years later revealed to have stolen children was not Australia, but England. In 1986, Margaret Humphreys, a social worker from Nottingham, brought to the surface what had for decades remained a well-kept shameful secret. Margaret Humphreys investigated a woman's claim that, at the age of four, she had been put on a boat to Australia by the British government. Much to her shock, this social worker discovered that this was not the only case since, under the postwar Children's Act 1948, up to 150,000 children had been deported from Britain and sent to distant parts of the Empire, mainly Australia, right up until 1970. Many were told that their parents were dead when they were not, or else that their country did not want them, since they were the children of British whores. To make matters still worse, if they had siblings when they arrived, they were often separated from them, too. On the other hand, their parents/single mothers were told that their children had been adopted by families who would offer them a better life. These children were promised a land of oranges and sunshine, but what most of them found instead was a life of physical and sexual abuse in institutions 
where they were put to work as laborers, if not slaves, far away from everything and everyone they knew. It took the British government more than two decades to make a public apology. In 2010, Britain's Prime Minister Gordon Brown followed suit in the House of Commons, for "this shameful episode...this failure in the first duty of a nation: to protect its children" ([2], p. 8).

Jim Loach's debut feature Oranges and Sunshine (2010), based on Margaret Humphreys' moving memoir Empty Cradles (1994), testifies to the need to recover historic memory through heart-breaking acts of remembrance, which can alone pave the way for disclosing and working through individual and collective traumas.

\section{Margaret Humphreys' Empty Cradles}

Humphreys' memoir narrates these child migrants' traumatic stories, together with this social worker's struggle to bring both the British and Australian governments to account for all of these atrocities. It all began when Humphreys tried to find out why British children had been sent overseas to institutions in Australia. She put advertisements in Australian newspapers, asking people with similar stories to come forward. Since several did, she took annual leave and, with an Observer journalist (the only way she could raise the money for the trip), set off for Australia to meet them. On her return, with the help of her husband, who enrolled for a doctorate at Nottingham University in order to have easy access to the archives, she investigated their situations. They soon discovered that these children's parents had not died, and that these kids had been transported overseas without parental consent. The Observer piece, published in July 1987, brought the cases of many more migrants to the surface and, as a result, Humphreys set up the "Child Migrants Trust". This trust received hundreds of queries, which Humphreys began to investigate. The pressure was so great that four months later Humphreys had to give up the day job she had had for 15 years in order to pursue this search full time. When a documentary, Lost Children of Empire, was screened in 1989, the trust was inundated. Something similar happened in Australia. As Kelly Jean Butler argues ([3], pp. 247-50), the traumatic experiences of these child migrants came to the surface there mainly through the publication in the same year of Philip Bean and Joy Melville's history Lost Children of the Empire [4], which was soon followed by hundreds of stories about the ill-treatment of non-migrant children in "care" homes run by the government and religious institutions. The proliferation of these testimonies led the federal government to carry out a series of inquiries into the experiences of all of these children. The outcome of this harrowing process was the release in 2001 of the Senate Community Affairs References Committee report into child migration, titled Lost Innocents. This report was followed in 2004 and 2005 by other reports on the forgotten Australians. Although these inquiries were not as strongly funded as the Bringing Them Home Report, they called for and received a myriad of written personal testimonies of childhood abuse. The Australian government soon afterwards decided to develop a repository of the testimony of the forgotten Australians along the same line as the National Library of Australia's Bringing Them Home Oral History Project [5]. Kevin Rudd's 2008 apology was clearly formulated in response to all of these heart-breaking testimonies. As far as Britain was concerned, the outbreak of indignation unleashed by the aforementioned documentary Lost Children of Empire was nothing compared to the reaction triggered off by The Leaving of Liverpool, a dramatization of the story, 
screened in 1992. Telephone help-lines got jammed, and this shameful episode definitely came to light in British public culture. As it turned out, children had been exported from Britain since the $1600 \mathrm{~s}$, though the practice only gained real pace in the late $1800 \mathrm{~s}$. Although many of those who sent them away seemed to have believed they were doing good, giving the children a new beginning, it is clear that they had no idea what this new beginning might be like. After the Second World War, many families found themselves unable to look after young children, and so put them into care, promising to pick them up again as soon as they could. To these children were added those of single mothers experiencing social stigma and giving their children up for adoption. These children were the victims, not only of irresponsible "do-gooding", but also of the dynamics and anxieties of empire. After all, it was the colonial enterprise that encouraged this abduction and kept it hidden for years. Interestingly enough, most of these children happened to be of Irish descent. Although in 1937 a new Constitution re-established the state as Ireland (Éire in Irish), a self-governing Dominion of the Commonwealth of Nations in the manner of Canada and Australia, and in 1949 the state was formally declared a republic and finally left the British Commonwealth, it is undeniable that, after the Second World War, people of Irish origin were still being regarded and dealt with by the British authorities as if they were subdued colonial subjects. Secondly, like many British convicts decades before, these children were seen as a burden on the state in Britain, and were accordingly treated like trash and transported overseas. Last but not least, just as thousands of blacks were for centuries wrenched from their homelands and transported from Africa to the Caribbean to work the plantations as slaves on account of their skin color, it was these children's "whiteness" that turned them into the tools/commodities that the metropolis used (and abused) to fertilize the Australian continent with the "good white stock" ([6], p. 2) required to neutralize the ever increasing numbers of Asian migrants coming to Australia, who came to be pejoratively labeled as the "yellow peril". The words uttered by the archbishop of Perth when welcoming a shipload of boys in 1938 speak for themselves:

At a time when empty cradles were contributing woefully to empty spaces, it was necessary to look for external sources of supply. And if we did not supply from our own stock, we were leaving ourselves all the more exposed to the menace of the teeming millions of our neighbouring Asiatic races ([2], p. 278).

As Humphreys explains, “this wasn't about giving kids a new start in life. It was a blatant piece of pragmatic social and religious engineering to fill rural Australia with bright, white British stock" ([2], p. 278). Besides, these child migration schemes allowed the local authorities to save money because, whereas "it was costing them 12 pounds a year to support a child in a parish workhouse, $[\ldots]$ for a single payment of 15 pounds they could send them overseas and be absolved of any further financial responsibility" ([2], p. 80). This wave of migration, which took an estimated 7,000 to 10,000 white children to Australia, did not end until 1967. These children were transported by force and prevented from establishing further contact with their homeland and families. They were deprived, as Jenny Edkins would put it, of their "personhood" [7], and were therefore condemned to be perpetually missing. In Giorgio Agamben's words, they became "perpetually forgotten", "irretrievably lost in the history of society and the history of individuals", 
while paradoxically becoming utterly "unforgettable" ([8], p. 40). As Jenny Edkins goes on to explain ([7], pp. 129-30), there are a number of instances where people go missing: people can be ontically missing, ontologically missing and politically missing. Although, ontologically speaking, any person, or indeed any being is, in some sense, "missing" (in Lacanian terms, a person is always incomplete, because his/her entry into the symbolic order always produces a gap - a lack or an excess), it is the ontic and political dimensions that should be paid special attention here. When people are ontically "missing", they disappear from the context that constitutes their known social or symbolic system. According to this, the dead are not "missing", because they have corpses that have been either buried or cremated, and the fact that they have a resting place allows their relatives to move on, somehow. The case of the missing is quite different. They are nowhere to be found, but are not confirmed as dead yet. They are neither symbolically dead (they still occupy a place in the social or symbolic order, as long as there are people who still remember and look for them), nor actually dead, which keeps the lives of their friends and relatives suspended. When it comes to analysing this question in political terms, another sense of "missing" person must be taken into consideration. In Lacanian terms, the symbolic order is produced in relation to a master signifier that authorizes and organizes the symbolic field. In contemporary western politics, the socio-political field is articulated around sovereignty or sovereign power, which thus becomes the master signifier. Furthermore, in the Foucauldian account of biopolitics provided by Agamben [8-11], persons are produced in relation to sovereign power, that is, persons are no longer in the focus of politics, since politics is organized around populations. The person as such is missing, because population is produced as a site of regulation, control and intervention. In keeping with this, under sovereign power what could become the person is instead produced as bare life or homo sacer, in a word, as life with no political status. Personhood is politically missing, because it has no significance in the sovereign symbolic order, where it can only exist as bare life, as something excluded that is no longer taken into consideration.

The aforementioned children could therefore be seen as a milder version of Agamben's Muselmann (the inhabitant in extremis of the concentration camp), that is, to quote Edkins again, as "particular instances where the person is symbolically and politically dead, but remains alive, physically" ([7], p. 130). The production of texts such as Empty Cradles and Oranges and Sunshine turns biopolitically "missing" people into "a crucial site at which sovereign power is challenged" ([7], p. 131). The linear time of sovereign authority (homogeneous, empty time for Benjamin [12] and chronological time for Agamben [8]) is suddenly disrupted by trauma time (messianic time for Benjamin and operational time for Agamben): sovereign social order falters, only to be restored soon afterwards, when linear time is once again resumed. As J. Edkins explains:

The smooth linear time of the state, and its stories of past and future, have been thrown into question by the intrusion of trauma time. Traumas, by definition, are events that are incapable of, or at the very least resist, narration or integration into linear narratives or, in other words, into homogeneous linear time. Trauma is not experienced in linear time; there are no words, no language, through which such an experience could take place. A traumatic event cannot be integrated into our symbolic universe [...]. It cannot be narrated. It is re-encountered through flashbacks that return to the scene, or re-told in 
accounts where the trauma is re-lived, moment-by-moment. [...] Traumatic events are only experienced, if we can call it that, when the past, which has not yet "taken place", intrudes into the present and demands attention ([7], pp. 132-33, Emphases in original).

What these texts manage to do, then, is to acknowledge the void (either as lack or excess) at the heart of our symbolic order without striving to minimize or justify it. As Agamben would put it, they "remain faithful to that which having been perpetually forgotten, must remain unforgettable" ([8], p. 40). Similarly, to rely on Santner's terms [13], it might be argued that, in attempting to bring to the surface and bear witness to these atrocities, Humphreys' memoir and Loach's film explore the "miracle" of the move from homo sacer to the neighbour, this being understood as the acknowledgement of an encounter with the real, with a singular "other" that is also constituted around a lack or an excess, but which nonetheless demands that we should open ourselves up to this alterity in the spirit of love, neighbor-love [14]. The neighbor is, as explained by Edkins: "the personhood that is missing in sovereign politics - and yet available in everyday life. The neighbour is the missing person in my account: it is precisely the lack or gap between the neighbour-person and the social role he or she is supposed to play in the social or symbolic order that constitutes the neighbour as loveable" ([7], p. 137) (Emphasis in original). Taking all of these ideas into account, it could be concluded that these two texts portray these children as missing people who ask for our love, who demand that their plight should become visible, that linear time should be disrupted so that their traumatic lives can come to the surface and take the upper hand, if only for a short while, so that they can seek justice.

As a result of these deportation schemes, all of these children became utterly vulnerable, exploited, and often also sexually abused. Trauma, shame and heart-wrenching loneliness were constant elements in all of the migrant stories Humphreys listened to. As she states in her memoir, "The most repeated line in all the interviews was 'I'm nobody"” ([2], p. 114); these were "people whose genuine pain and hurt came from having been abandoned by their country" ([2], p. 115); children who had been deprived of love and affection since, as one of them exclaimed, "I can't remember anyone putting their arm around me, giving me a cuddle, showing me that they cared" ([2], p. 75). Jim Loach's film also highlights these feelings of utter abandonment and loneliness, especially when Margaret interviews the Bindoon boys who, like Agamben's Muselmann, have unconsciously assimilated the condition of bare and empty life that prompts them to say: "I'm nobody now. Nothing at all", "Who's gonna look after me? I'm nobody" [15]. Everybody failed them, without exception, and they consequently internalized all of this hatred and shame: they "got very depressed, and felt alone and empty", "not entitled to feel love" ([2], p. 71). All of these traumatic stories took a severe toll on Humphreys: she did not take a holiday for seven years; she missed many of her kids' birthdays; in the early 90 s she hemorrhaged and had to be immediately taken to hospital; she lost weight, could not sleep, and ended up with post-traumatic stress disorder symptoms, which hampered her family and professional life for some time. By contrast, the British government was still most reluctant to admit what had happened. In 1993 John Major told parliament that "any concern about the treatment of the children in another country is essentially a matter for the authorities in that country" ([2], p. 352), and effectively washed his hands of this matter. It was only in 1998 that the House of Commons finally decided to carry out an 
inquiry, the outcome of which led them to fund the "Child Migrants Trust" and offer these victims some kind of national apology years later.

\section{Jim Loach's Oranges and Sunshine}

As Cath Clarke explains, Jim Loach was working on the ITV drama Bad Girls when he first visited Humphreys in her Nottingham office. He felt "gobsmacked" ([6], p. 2) by the stories she told him and her courage and determination. "I found that dilemma very compelling," says Loach, "and very relevant to 2011. Working mothers, working parents - it's a circle all of us try to square" ([6], p. 2). Humphreys' main concern was that Loach would make a sentimental, Hollywood movie, in which she would be shown as "a crusading force of nature" ([6], p. 2). Loach's film did not do anything of the kind. Oranges and Sunshine offers a faithful reading of Humphrey's ordeal as told in her memoir. Significantly enough, the beginning of the film shows Margaret undertaking one of her most painful tasks as a social worker: to take a baby away from her incapacitated mother so that the local authorities can look after it properly. Whereas, as is suggested by the film, Margaret's intervention will somehow contribute to providing this child with a better life, the aforementioned government's organized deportation of children in care from the United Kingdom to Australia only brought about much pain and sorrow. Oranges and Sunshine captures on the big screen the plight of some of these child migrants, who were deprived of their former lives, emotional ties and identities by being launched to Australia, that is, to the other side of the world, and by being placed in an unknown and unfriendly space, which could only aggravate their trauma of stolen memories and estranged and desecrated lives, to the point that they ended up having no idea who they really were. As Jim Loach claimed, this is a film about identity, about what makes us who we are and how we cope with it. In keeping with the films made by his father, internationally-acclaimed director Ken Loach, known for his naturalistic, social realist directing style and for his socialist attitude, which are evident in his film treatment of social issues such as homelessness (Cathy Come Home) and labor rights (Riff-Raff and The Navigators), Jim Loach's film succeeds in creating a disturbingly realistic atmosphere, and has Emily Watson giving one of her "unshowy, grippingly real performances" ([6], p. 2), which compels spectators to see everything through her eyes and partake, however vicariously, of the enormous suffering she went through during her quest.

Cinematography and mise-en-scene are often used in the film to bring to the fore the shame and traumas that this British "Stolen Generation" is still trying to work through, together with Margaret Humphreys' unrelenting courage in the face of absolute opposition on the part of both British and Australian authorities. Many scenes take place inside cars on the move, cars which take people who desperately go from one place to another in search of names, of clues, very often to get no answers. As regards open spaces (in particular the beach and the pier), although they can at times have some soothing effect upon the victims, it is nonetheless clear that they cannot offer them the peace they lack and so desperately need. Institutions of all kinds (medical, political, religious) are given special attention too. One of the most interesting scenes in the film is that in which Margaret visits the man confined in a psychiatric hospital. The hospital is shown as a gloomy and confining place. Margaret is accompanied by the nurse, who informs her that this man has been acting out his 
childhood trauma for years. It was only after listening to Margaret on the radio that he could remember the traumatic event that was to change his life forever. As has already been explained, it is only when this belated hyperarousal/re-enactment of the trauma occurs that the amnesiac circle which blocks the victim's psyche can be broken. Since the traumatic event is not fully acknowledged at the moment when it occurs, but is repressed and locked in the unconscious, its after-effects imply a return of the repressed in the form of unexpected and ceaseless acting-outs of the trauma, which will keep on haunting the victim for the rest of his/her life. If the traumatized individual wants to work through his/her trauma, s/he must be able to articulate/verbalize what happened, that is, must establish some critical distance between him/herself, the traumatic event and its loss so that these phantoms can finally be specified and mastered ([16], pp. 65-66). However, this is a long and difficult process, since the re-enactments of the trauma inexorably bring about terribly painful, and humiliating, memories that the victim is ashamed to relive again. Shame makes the victim feel afraid of being rejected by the people s/he loves and the community s/he belongs to ([17], p. 126; [18], p. 62), and the victim's immediate reaction to this loss of face is that of covering and concealment. The more the mourner exposes her/his grief, the more aware $\mathrm{s} / \mathrm{he}$ becomes of the vexatious feelings attached to it, and thus the more s/he resists facing them. Trauma and shame are closely linked notions, and shame can often become a barrier that prevents working through $[19,20]$. This is why the existence of an empathic and supportive witness with whom the individual can feel confident enough to talk is of the utmost importance. Margaret knows this, and this is why she comes to the hospital to listen to this man's heart-breaking testimony. She and the nurse walk through the dark corridor that leads to the entrance of the porch where this encounter will take place. Interestingly, it is on this portico, that is, partly in the open and outside the building, that this man's confession is possible, and light comes through a door in the background, as if celebrating the fact that this victim is at last going to be able to verbalize what happened to him in the past, a necessary step for his much needed healing working-through process. However, it must be noted that this is a barred portico, and that, as this man begins to talk, this background light gets hazy and diffused, which somehow suggests that, in spite of Margaret's help, this trauma will leave perennial marks on this victim. It is by no means accidental that he cannot actually finish up the sentence to say he was brutally raped. He feels ashamed, abandoned and neglected by everybody. Two nurses walk towards the door, totally oblivious to what is going on the porch, as he begins to speak. A medium shot shows Margaret and this man sitting together on a bench and, as their conversation progresses, close-up shots give prominence and moral authority to both the victim and the witness. Last but not least, the camera cuts away from one scene to another. As is well known, cross-cutting is an editing technique often used in films to connect actions occurring, either at the same time or at different moments, in different locations. In this case, the actions are not simultaneous, and cross-cutting is used to establish parallels and contrasts. The film cross-cuts between the traumatized man's confession, Margaret's feelings of anguish and impotence when she goes back to her hotel room right after she has listened to him, and Margaret's post-traumatic stress disorder symptoms when she returns home for Christmas and watches on TV the altar boy singing the "Ave Maria". Margaret is suffering vicarious trauma; she can't help connecting this angelic boy on TV with this man's brutal rape. Viewers are clearly encouraged to compare the different shots 
and both characters' emotions. Just as Margaret is this man's empathic witness, Margaret's husband becomes, during their phone conversation, the recipient of the paralyzing anguish that oppresses Margaret when she reaches her hotel room, overwhelmed by this man's grisly testimony and the other bloodcurdling stories contained in the files she carries in her arms. And neither can the light coming through her window reassure her that this nightmare will some day be over. Finally, the length of time between cross-cuts also contributes to slowing down the rhythm of the scene. This man's confession is somehow postponed, which adds tension while creating a strong emotional effect.

Not even are the medical professionals able to show some empathy for the wrenching pain of these victims. On another significant scene Margaret is guided by a nurse, who takes her into the room in which she is to break the sad news to Jack that, although they finally managed to find his mother, they were a bit too late, since she had died the year before. Jack has been totally unable to overcome the traumatic loss of his mother; he has always felt an indescribable emptiness inside which has prevented him from leading a normal life and being a good husband and father, and is still in need of psychiatric treatment. However, once again, this health institution lacks any kind of sensibility. The first room Margaret is offered is far too small and suffocating, with bunk beds and a broken blind. The next one she is led to is even worse, since the window gives on to a wall, which clearly echoes the indifferent attitude shown by all kinds of official institutions towards these child migrants, to whose plight they systematically turned a blind eye and a deaf ear. Margaret does not give up until she is offered a room with a beautiful view, a vase of flowers, and a mirror (there are lots of mirrors in the film, which clearly point to the identity crises undergone by these people; the rear view mirror onto which Jack's face is projected when he and Margaret go in search of his mother in England is another case in point). Beauty, Margaret wants to believe, might somehow help alleviate Jack's pain and turn this tragic moment into a less shattering event in his life. As soon as Margaret sees Jack, she hugs and kisses him. She does her best to provide him with some of the love and affection he was denied as a child. Close up shots encourage spectators to identify with both characters' feelings during their heart-breaking conversation. Then another close up shot frames the flowers in front of Jack and Nicky's mother's grave, and then the tomb inscription: "Always in our thoughts", which clearly highlights the importance of preserving one's family ties and memories in order to build up one's identity. A medium shot now shows the two siblings, disconsolately crying and hugging each other, and surrounded by tombs in the middle of the silent cemetery, which seems to preside over the city below. Only Margaret keeps them company, but at a distance, as a clear sign of respect.

The media are not particularly interested in airing this scandal either. Margaret is unjustifiably attacked by the woman who interviews her on the radio, and the TV set within which she is placed is far too big and intimidating, all the more so when the camera chooses to show it through a high angle shot. Likewise, government and church agencies are totally indifferent to the inexcusable suffering they have inflicted upon these child migrants, and Margaret and her husband are completely on their own in their struggle to redress the damage done. A voice-over is superimposed at the end of the scene previously discussed: some government official alludes to the particularly convoluted historical context of those years to justify the child migrant schemes. Once again, 
Margaret and her husband are completely alone. They reach this government building in a black London cab, and must go through a gate to enter the precinct. What they have to face up to once they get into the building is no more reassuring. They are both made to sit on one side of a big oval table, in front of a collection of representatives of several political and religious agencies who, significantly enough, find it difficult to look this couple in their eyes. Moreover, a big portrait of the British Queen is hanging on the wall opposite them, thus making it clear that what they are confronting and questioning is a national and imperial enterprise. It must be noted that close up shots are only used to show Margaret and her husband's faces, which clearly grants them the moral authority that the other people in the room are deprived of. These official representatives will only offer the Child Migrant Trust some help providing they can be trustees and control the trust movements, which Margaret adamantly rejects. The meeting has been a complete failure, and they leave. The camera now moves from top to bottom to show the impressive dome over their heads. Human beings are only tiny and insignificant specks by comparison. It is only political power and national interests that matter. In contrast, the camera now frames a statue with open arms presiding over the majestic staircase. This, together with the fact that one of the few women present at the meeting catches up with them and appeals to Margaret's motherhood, somehow leads spectators to harbor some hope. Against all odds, this hope will soon be shattered: this woman reminds Margaret of her condition of mother only to tell her to mind her own business and stop meddling with this unfortunate past episode. Once again, the camera likes Margaret's face better, as the close up shot that reveals her stupefaction and incredulity when hearing this makes clear. The scene in this official building could in turn be related to the one that takes place at the refectory of Bindoon college, when Margaret sits in front of all the brothers, who do not dare to look at her, let alone to speak to her. There is a deafening silence, only broken by Margaret when she defies and scolds them by saying: "Have I disturbed you, brothers? Have I frightened you? What have you got to be frightened of? Grown men like you" [15]. Bindoon college is shown as an overwhelming and sinister place, difficult to reach and impossible to escape. At the entrance there is yet another impressive dome over a huge staircase, which renders the figures of Len, one of the Bindoon boys, and Margaret utterly insignificant as they slowly climb it. Religious institutions are no better: the ones who had the moral duty to provide these children with care and affection only used them as cheap labor force they could ill-treat and sodomize.

As this film clearly shows, the alleged unspeakability of trauma is related to its shattering effect, not only on the subject, but also on the community as a whole. Acknowledging political and social atrocities also implies acknowledging the fact that our community is anything but harmonious and perfect ([18], pp. 1-7). Besides, shame is not only a noun (a "state of being") but also an action ([17], p. 25). The cruelty and indifference shown towards these child migrants by both the British and the Australian authorities, whereby they tried to cover up their own shame by looking away, relegated these victims to absolute oblivion. This lack of recognition, together with the inhumanity shown towards them, is one of the factors that undoubtedly contributed to reinforcing their feelings of shame, self-hatred and paralysis, to the point that many of these victims ended up believing that they were nobody and deserved nothing. Prime Minister's John Major' refusal to apologize to these child migrants could thus be seen as an act of shame. The release of Lost 
Children of Empire and The Leaving of Liverpool brought these atrocities to light, and offered the victims the opportunity to become visible and audible, to denounce what had shamefully remained hidden for decades, and to try to establish connections with some of the relatives they lost sight of when they were only children. However, as can be concluded after reading Humphreys' memoir and watching Loach's movie, it is not enough to listen to the victims. The last scenes of the film, in which black and white photographs of these innocent children are shown, together with the epilogue, denounce that the search for their lost families still goes on, and demand that these victims should also be offered an official apology and some kind of material and psychological reparation. The past cannot be changed, but it is only when past sins are properly atoned that the present can become more bearable and a better future is somehow possible.

\section{Conclusions}

As this analysis has tried to show, trauma theories can be quite useful when it comes to studying texts that attempt to denounce the atrocities resulting from the enforcement of colonialist policies, no matter when or by whom, but providing that these theories expand the event-based trauma model that was initially put forward by such important scholars as Cathy Caruth, Shoshana Felman and Dori Laub [21,22], among others, with a view to regard trauma, as Michael Rothberg would put it, as "collective, spatial, and material (instead of individual, temporal, and linguistic)" ([23], p. 228). Specific socio-historical factors must always be taken into consideration, since the traumatic histories of subordinated groups can only be understood when pitted against the histories of the groups holding power. Moreover, these theories should also be able to go beyond ever-lasting victimization in order to make room for rather more healing and empowering processes, which can alone pave the way for renewed life and expectations. While, as is shown by Humphreys' memoir and Loach's film, many of those child migrants will never be able to overcome their traumatic past, many others are fighting to rebuild their lives by creating ever-growing links with the relatives they left behind many years ago. To conclude, the two texts discussed here testify to the need for narratives that, not only strive to come to terms with the injustice and suffering inflicted by colonial policies, but also bring to light collective traumas, being these understood, in Jeffrey C. Alexander's words, as "harmful or overwhelming phenomena which are believed to have deeply harmed collective identity" ([24], p. 10). Trauma is nowadays understood as a very complex phenomenon: it can debase individuals and whole groups but, when properly acknowledged and confronted, it can also lead to a rather more resolute sense of identity and community. Postcolonial literary and filmic texts like the ones discussed here undoubtedly contribute to disclosing this complexity by delving into the social, political and cultural aspects concomitant with trauma, while also demanding some kind of justice and reparation on the part of society as a whole.

\section{Acknowledgments}

The research for this article has been funded by the Spanish Ministry of Economy and Competitiveness (MINECO) and the European Regional Development Fund (ERDF), FFI2012-32719. 


\section{Conflicts of Interest}

The author declares no conflict of interest.

\section{References and Notes}

1. Vijay Mishra, and Bob Hodge. Dark Side of the Dream: Australian Literature and the Postcolonial Mind. Sydney: George Allen and Unwin, 1991.

2. Margaret Humphreys. (Empty Cradles 1994) Oranges and Sunshine. London: Corgi Books, 2011.

3. Kelly Jean Butler. Witnessing Australian Stories: History, Testimony and Memory in Contemporary Culture. New Brunswick and London: Transaction Publishers, 2013.

4. Philip Bean, and Joy Melville. Lost Children of the Empire. London: Unwin Hyman, 1989.

5. For information on some of the websites which contain these testimonies, see Katherine Karr. "The Lost Children of Britain." Oxford Monitor of Forced Migration 2 (2012): 41-46. Available online: oxmofm.com/wp-content/uploads/2012/06/The-Lost-Children-of-Britain.pdf (accessed on 11 October 2015).

6. Cath Clarke. "The Son Also Rises: Jim Loach Directs His First Film.” The Guardian, 31 March 2011, pp. 1-3. Available online: http://www.theguardian.com/film/2011/mar/31/jimloach-oranges-and-sunshine (accessed on 16 July 2015).

7. Jenny Edkins. "Time, Personhood, Politics." In The Future of Trauma Theory: Contemporary Literary and Cultural Criticism. Edited by Gert Buelens, Sam Durrant and Robert Eaglestone. London and New York: Routledge, 2014, pp. 127-39.

8. Giorgio Agamben. The Time That Remains: A Commentary on the Letter to the Romans. Translated by Patricia Dailey. Stanford: Stanford University Press, 2005.

9. Giorgio Agamben. Homo Sacer: Sovereign Power and Bare Life. Translated by Daniel Heller-Roazen. Stanford: Stanford University Press, 1998.

10. Giorgio Agamben. Remnants of Auschwitz: The Witness and the Archive. Translated by Daniel Heller-Roazen. New York: Zone, 1999.

11. Giorgio Agamben. State of Exception. Translated by Kevin Attel. Chicago: University of Chicago Press, 2005.

12. Walter Benjamin. Walter Benjamin: Selected Writings: 1938-1940. Edited by Howard Eiland and Michael W. Jennings. Cambridge: Belknap Press of Harvard University Press, 2006, vol. 4.

13. Eric L. Santner. "Miracles Happen: Benjamin, Rosenzweig, Freud, and the Matter of the Neighbor." In The Neighbor: Three Enquiries in Political Theology. Edited by Slavoj Zizek, Eric L. Santner and Kenneth Reinhard. Chicago: University of Chicago Press, 2005, pp. 76-133.

14. These theories clearly echo, and rely on, Emmanuel Levinas's well-known "ethics of alterity" as formulated in his seminal works. Emmanuel Levinas. (1961) 1969. Totality and Infinity. Translated by Alphonso Lingis. Pittsburg: Duquesne University Press and (1974) 2004. Otherwise than Being: or Beyond Essence. Translated by Alphonso Lingis. Pittsburg: Duquesne University Press.

15. Oranges and Sunshine. Directed by Jim Loach. Bristol: Icon Film Distribution, 2011. 
16. Dominick LaCapra. Writing History, Writing Trauma. Baltimore and London: Johns Hopkins University Press, 2001.

17. Victoria Burrows. "The Ghostly Haunting of White Shame in David Malouf's Remembering Babylon." Westerly 51 (2006): 124-35.

18. Judith Lewis Herman. (1992) 2001. Trauma and Recovery. London: Pandora. Citations refer to the 2001 edition.

19. Ashwin Budden. "The Role of Shame in Posttraumatic Stress Disorder: A proposal for a Socio-emotional Model for DSM-V.W." Social Science and Medicine 69 (2009): 1032-39.

20. Jeffrey Kauffman, ed. "On the Primacy of Shame." In The Shame of Death, Grief, and Trauma. New York and London: Routledge, 2010, pp. 3-22.

21. Cathy Caruth, ed. Trauma: Explorations in Memory. Baltimore and London: The John Hopkins University Press, 1995.

22. Shoshana Felman, and Dori Laub. Testimony: Crisis of Witnessing in Literature, Psychoanalysis, and History. New York and London: Routledge, 1992.

23. Michael Rothberg. "Decolonizing Trauma Studies: A Response." Studies in the Novel 40 (2008): 224-34.

24. Jeffrey C. Alexander. "Toward a Theory of Cultural Trauma." In Cultural Trauma and Collective Identity. Edited by Jeffrey C. Alexander, Ron Eyerman, Berhard Giesen, Neil J. Smelser and Piotr Sztompka. Berkeley: University of California Press, 2004, pp. 1-30. 


\title{
Manilaner's Holocaust Meets Manileños' Colonisation: Cross-Traumatic Affiliations and Postcolonial Considerations in Trauma Studies
}

\author{
Jocelyn Martin
}

\begin{abstract}
After interrogating the (non-)referential status of the Holocaust for Asians, this essay examines Frank Ephraim's Escape to Manila and Juergen Goldhagen's Manila Memories. In particular, cross-traumatic affiliation is studied between two groups of people: the Manilaner and the Manileños: the former were Europeans who fled Nazism and sought refuge in Manila; the latter were Filipino residents of Manila who, during the Second World War, found themselves under Japanese Occupation. A closer reading of the memoirs, however, also reveals latent orientalism in the portrayal of Filipinos. This essay thus echoes present postcolonial concerns in recent Trauma Studies research which ask the place of serial colonisations, martial law, climate catastrophes and the sacred in Trauma theory.
\end{abstract}

Reprinted from Humanities. Cite as: Martin, J. Manilaner's Holocaust Meets Manileños' Colonisation: Cross-Traumatic Affiliations and Postcolonial Considerations in Trauma Studies. Humanities 2015, 4, 818-833.

\section{Introduction}

Among Trauma Studies theorists, it is well known by now that the place of the Holocaust has been, and perhaps still is, considered as the foundation and paradigm of trauma theory scholarship so much so that it has become a "floating signifier" of other traumatic events ([1], p. 3). As Craps has noted, designations of other extreme events only confirm its signifying position: "Kosovocaust", "African Holocaust", "American Holocaust", "nuclear Holocaust” and "abortion Holocaust” ([1], p. 75). Levy and Sznaider even argue that the Holocaust has become a "cosmopolitan memory" which "harbors the possibility of transcending ethnic and national boundaries" because its changing representations have become politically and culturally symbolic ([2], p. 4).

However, as one can observe in recent debates within Trauma Studies, not all regard this "universalistic" characteristic of Shoah discourse in a positive light. Although its founding scholars - Cathy Caruth, especially—should be acknowledged for developing Trauma Studies; for articulating the link between trauma and literature; and for claiming that "trauma itself may provide the very link between cultures" ([3], p. 11), Caruth's claim to solidarity has since been challenged by Postcolonial Studies-inspired scholars who have expressed complaints about the field: its elitist content and form; its Western Holocaust event-based model of PTSD and trauma; and its preference for melancholia rather than resistance. Such views since then paved the way for Trauma Studies' postcolonial turn — or postcolonial reconsideration — since some critics, such as Rothberg [4], Craps [1], Tal [5] and Mengel and Borzaga [6], return to the seminal texts of Frantz Fanon [7], W.E.B. Du Bois [8] and Aimé Césaire [9] in order to underscore their contribution to other types of trauma such as colonisation and racism. Consequently, today, postcolonial-enriched trauma theory 
allows one to consider other forms of suffering originating from, for example, the colonial experience and natural disasters. Such a turn also lets one interrogate the paradigmatic status of the Holocaust.

For example, critics, such as Huyssen ([10], p. 14), point out the risk of the Holocaust serving as "screen memory" which may hide other episodes of history that also merit attention. Likewise, in his recent work, Postcolonial Witnessing, Stef Craps calls for traumas of non-Western or minority populations to be acknowledged for their own sake and in their own terms ([1], p. 19) lest "well-meaning attempts...result in the appropriation or instrumentalization of his or her suffering in the service of articulating the trauma of the self" ([1], p. 3).

Similarly, in his seminal work, Multidirectional Memory, Rothberg draws attention to the fact that "the ever-increasing interest in the Nazi genocide distracts from the consideration of other historical tragedies" ([4], p. 9). Rather than advocating competitive memory, Rothberg underscores the two pitfalls of sacralisation and trivialisation of the Holocaust memory. Thus, he proposes a multidirectional memory which allows a dialogical approach to discussions on traumatic events, thus taming any universalisation or Americanisation of the Shoah.

Ironically, even until today, in a place like the Philippines, there is no danger of an overdose of Holocaust memory, rather, a lack of it. Indeed, although aware of the Holocaust through my European education and personal trips to, for instance, Yad Vashem, I have been struck by the different degree of (un)familiarity with the Holocaust in Philippine classrooms as compared to European ones. It is not surprising to see only a few raised hands in classes of 25 first-year college Filipino students aware of the Kristallnacht. This is not a case of ignorance, rather, in my opinion, a case of referential events of WWII. However, if this example may be deemed anecdotal, the work of colleague and Filipino scholar Jo-Ed Tirol, not only sheds light on the role of the Philippines in the rescue of Holocaust refugees, but also justifies the non-referential status of the Holocaust in Philippine social memory. In fact, he even makes an interesting call for a proactive social memorialisation of the Holocaust within Philippine history. That Tirol's PhD dissertation on Jewish Holocaust victims rescue in the Philippines was only completed in 2015 is revealing enough of the recent interest on the subject. In his study, the Filipino scholar explains why the story of Holocaust refugees in Manila remained hidden for years. Because of immediate post-WWII priorities of the Philippines, this white Jewish population's small number and, thus, homogenisation to other foreign groups, hid them from the limelight. Consequently, the account of their escape from Nazism also remained secondary to other more pressing concerns. However, the current re-surfacing of the significant involvement of President Quezon and the Filipinos towards Jews during WWII sheds new light to the status of "the Holocaust" within the Philippine context. Thus, for Tirol, while "Filipinos may already have a working memory of the war [with a focus on] studying military chronologies, the Japanese occupation, and the road to liberation by the United States," one should campaign for a firm anchoring of "the Holocaust as part of the Philippine experience of the Second World War" ([11], p. 264). Such a position of the Filipino scholar actually offers an Asian point of view of "the Holocaust" for the Filipinos: a non-referential trauma, nor a one-time trigger traumatic event of the Second World War.

Perhaps the most visible event that established the role of the Philippines was the unveiling of the Open Door Monument on June 2009 in Tel Aviv. Conceptualised since 2005, the monument was a 
joint project of "the Embassy of the Philippines to Israel, the Filipino Community, the Holocaust survivors and their families in Israel and from all over the world" to memorialise the help extended by the Philippines to more than a thousand Jews escaping Kristallnacht [12]. One can observe that, since then, there has been an increasing interest in the rescue story which again was recently recognized through a posthumous award given by the Israel Embassy to the Manuel Quezon last August 2015 [13].

After 2009, in these last three years, aside from Tirol's research, personal encounters with scholars Racelle Weimann and Sharon Delmendo have contributed to the increasing relevance of the Shoah from the perspective of the Philippines. Through the initiative of the Israel Embassy in Manila and the late Isabel Kenny, Racelle Weimann, from Temple University, was invited last November 2012 to hold talks in a few universities in Manila. Thanks to her (and later on, through newspaper articles), I learned that the first Asian anti-Kristallnacht rally took place on 19 November 1938 within the compound of the old Ateneo de Manila University, thus, her interest in presenting in my institution [14]. A year after her visit, on November 2013, an exhibit and talk, the "Courage to Remember", was again initiated by the Israel Embassy. Invited as a panellist due to my specialisation in Trauma Studies, I met, during this occasion, fellow scholar Jo-Ed Tirol, whose work I briefly explained above. Once more, in June 2014, researcher Sharon Delmendo from John Fisher College in Rochester, delivered a more comprehensive talk on Quezon's Open Door Policy. With Noel Izon, Delmendo produced the documentary film “An Open Door: Jewish Rescue in the Philippines" [15], the trailer of which is available on Youtube. What is interesting to point out, however, is that these scholars came primarily, not to present the events of the Holocaust, but the role of the Philippines in welcoming Jewish refugees. In other words, the events of the Shoah come secondary to the main topic: the Philippine rescue.

This standpoint confirms what other critics claim as well. In his work, The Meanings of Social Life, Jeffrey Alexander asks the following question: "is the Holocaust Western?" In other parts of the world, he acknowledges, the Holocaust is not a common reference of WWII ([16], p. 83): "Obviously, non-Western nationals cannot "remember" the Holocaust, but in the context of cultural globalization, they certainly have become gradually aware of its symbolic meaning and social significance" ([16], p. 84). The author reminds us that, at the beginning of WWII, the "Holocaust" was not yet as we know it now. When the concentration camps were discovered by the Allies in 1945, these were first seen as "atrocities", among many others. Interestingly, the term used, "atrocities", according to Alexander, first described the Japanese brutalities in the Philippines ([16], p. 28)! Therefore, before it had become a paradigm of trauma, the Holocaust, at one time in history, was referred to as an "atrocity" among others.

Indeed, in Southeast Asia, for example, "Hiroshima" and "Nagasaki" - the bombings of which we commemorate seventy years this year — or the Japanese Occupation might be the more prominent traumatic references evoked. In Craps' analysis of Anita Desai's Baumgartner's Bombay, for example, he observes how "the Holocaust is not a major concern of people in India, if they are aware of it at all” ([1], p. 116).

However, far from disregarding the relevance of the Holocaust in an Asian setting, I share Stef Craps concern to "bridge a disciplinary divide between Jewish and postcolonial studies preventing 
the Holocaust and histories of slavery and colonial domination from being considered in a common frame" ([1], p. 73). In particular, I am interested in Craps' notion of cross-traumatic affiliation, which he talks about in the sixth chapter of Postcolonial Witnessing. This idea merits further theorisation.

In an interview, Craps defines cross-traumatic affiliation as "a way of bringing different historical traumas into contact in an ethically responsible manner; that is, without collapsing them into one another, preserving the distance between them" [17]. This idea not only emphasises discussions on ethical witnessing within Trauma Studies, but also bears similar concerns with La Capra who already elaborated on "empathic unsettlement". In his work, Writing History, Writing Trauma, LaCapra proposes a desirable dimension of inquiry that should complement and supplement empirical research, that is, empathic unsettlement which "involves a kind of virtual experience which one puts oneself in the other's position while recognizing the difference of that position and hence not taking the other's place" ([18], p. 78). When asked how cross-traumatic affiliation is different from La Capra's idea of empathic unsettlement, Craps describes the latter as "a general way of relating to traumatic experiences whereas the former concerns a relationship specifically between such experiences" [17]. Cross-traumatic affiliation should thus hopefully encourage transcultural empathy in which two or more different cultures, which have undergone different types of traumas, seek to understand the other's trauma for their own sake and in their own terms ([1], p. 19). Therefore, cross-traumatic affiliation presupposes differentiation and solidarity.

Cross-traumatic affiliation, in my sense, also proposes an ethical attitude to counter a current "triumph of victimhood" ([19], p. 26) "wound culture" ([20], p. 124) or even a "vicarious victimhood" ([21], p. 47). A work such as Fassin and Rechtman's The Empire of Trauma: An Inquiry into the Condition of Victimhood traces the trajectory from suspicion of victimhood to one that even "excites sympathy and merits [financial] compensation" ([21], p. 5). In Todorov and Belos' words, "To have been a victim gives you the right to complain, to protest, and to make demands" ([22], p. 143).

Much like Rothberg's multidirectional memory, cross-traumatic affiliation avoids a "hierarchy of victimhood" in which the loudest lobby gains legitimisation of victim status over others. While Rothberg encourages a non-privative on-going discussion of memory, Craps complements such a notion by suggesting an ethical attitude which does not pit one trauma or victim status over another. Cross traumatic affiliation is a disposition which allows one party to relate to the trauma of another based on the former's own trauma experience while, at the same time, recognising the uniqueness and difference of each culture's experience. By avoiding such homogenisation or dilution of two distinct experiences, one acknowledges pain according to the terms of that particular culture. Last but not least, cross-traumatic affiliation encourages solidarity independent of (political, financial, mediatised) justifications of one's "hierarchy" of victimhood.

Consequently, this essay examines Frank Ephraim's Escape to Manila [23] and Juergen Goldhagen's Manila Memories [24] which reveal cross-traumatic affiliations between two groups of people: the Manileños and the Manilaners. The former name refers to Manila-based Filipinos, who, during World War II, found themselves under Japanese Occupation in an already-U.S. dominated Philippines. The latter, meanwhile, designates a hybridised German name which Europeans gave themselves after seeking refuge in Manila in order to escape Nazi persecution. 
That both memoirs recount the Holocaust and (Japanese) colonial domination in Asia constitute an interesting area of study. First, they testify to the role of the Philippines as haven to persecuted Jews. Second, they put together the referential traumatic references of the East and the West during World War II. Third, these stories show how each community's pain and suffering become bridges of cross-traumatic affiliation and responsibility toward the other.

Although researchers such as Delmendo and Izon [15], Harris [25] and Tirol [11] are expounding on this rescue story from a historical perspective, my interest in these Manilaner memoirs comes from the point of view of Literature, Memory and Trauma Studies which, as I have explained in the first paragraphs, have drawn a lot from Holocaust texts. My main objective therefore is to examine the Holocaust in the context of a colonised Philippines. To this end, I shall first introduce the two memoirs which will be followed by an examination of cross-traumatic affiliations between the Manileños and Manilaner. A closer reading of the memoirs, however, also reveals latent orientalism in the portrayal of Filipinos. This essay thus echoes present postcolonial concerns in recent Trauma Studies research which ask the place of serial colonisations, martial law, natural catastrophes and the sacred in Trauma theory.

\section{Results and Discussion: Manilaner's Holocaust}

During the years of the Second World War, the Philippines, which was transitioning into independence, was under the leadership of Commonwealth President Manuel Quezon who was put into power since 1935. Along with McNutt and Frieder, Quezon was a key figure in transporting more than a thousand Jews - a number surpassing that of Schindler's List [15]. These German and Austrian Jews escaping Kristallnacht were provided with homes and jobs in Manila. Unfortunately, the Japanese occupation would soon again disrupt their lives. In other words, for these emigrants, the memories of WWII included both the Holocaust and the Japanese Occupation.

The memoirs of these survivors have been compiled in Frank Ephraim's Escape to Manila [23] and Juergen Goldhagen's Manila Memories [24]. Both published in 2008, these books bring together personal memoirs, historical data, archival research and oral testimonies. Although hard to read, Ephraim's book has the merit of gathering the stories of 36 survivors from pre-Kristallnacht up to the end of the War. Frank Ephraim dedicates his book to "all the Manilaner who, fleeing from one tyranny to another, acquitted themselves with honor" [23]. Born in Berlin in 1931, Frank Ephraim, with his parents, fled to the Philippines in 1939. He then worked as a naval architect and served in the U.S. Department of Transportation. He died in 2006.

Goldhagen's book, meanwhile, collects the memoirs of four men who, 65 years later, remember their childhood during Japanese-occupied Manila. Between nine to twelve years old, all of them were students in the American School in Pasay. Of the four, only two can really be considered as "Manilaners" because they belong to those who have fled anti-Semitism in Germany. Goldhagen explains that "the idea for this book grew out of a seminar on war experience held at an American School of Manila reunion for the Classes of 1945-55. Fellow alumni and authors...encouraged us all to put down our memories. Here are ours" ([24], p. 9). Juergen Goldhagen also gives another reason for writing the memoir. In a television interview in 2009, he revealed his interest in compiling the stories of Americans who were not interned in the University of Santo Tomas [26]. Through 
e-mail, telephone and personal conversations, he thus gathered the accounts of three other friends, two of whom live in the U.S. and one in London. A more organised book, it is published by Old Guard Press. Although he stayed in Germany until he was seven years-old, the young Juergen admits not having "the sense of being Germanic" but, rather, American, having grown up in a U.S.-occupied Manila. Today, he still lives in the States. Both books are therefore authored by Americans of German origin who have lived in Manila and later moved to the U.S. Both dedicate their books to their parents and, in the case of Ephraim, to his family and to the Manilaner.

\subsection{Cross-Traumatic Affiliations of East to the West}

Escape to Manila recounts of a historic anti-Kristallnacht rally in Intramuros, the Walled City of Manila, on 19 November 1938, ten days after "the Night of Broken Glass" ([23], p. 38). This demonstration gathered more than a thousand people, among whom the Catholic Archbishop and twenty speakers who condemned Nazism. Frank Ephraim explains the singularity of the event:

The Philippines was a country of 18 million Filipinos; most of whom were Catholics, so these events could hardly have been the work of the Jewish community in Manila, which by early November 1938 numbered between 300 and 350 refugees whose political muscle was nonexistent...The events of November 19, 1938, in Manila were therefore all the more remarkable ([23], p. 39).

A month after this rally, on 5 December 1938, President Quezon declared his ambitious intention of reserving lands in Mindanao (the second largest island) for the settlement of two thousand Jewish refugee families in 1939 and then 5000 families yearly until 30,000 families would have arrived. This project was met with stark opposition from the U.S. State Department which described the Jews as "another troublesome group" whose entry they might have to fund should the settlement fail ([23], p. 44; [24], p. 15). In fact, in November 1938, the State Department ordered that "visas should not, repeat not, be issued to refugees proceeding to the Philippine Islands" ([23], p. 40). In spite of these difficulties, the President allocated three hectares of his own land in Marikina in order to shelter Jews. Fortunately, Quezon obtained invaluable help from two other key players of this immigration scheme: U.S. High Commissioner Paul McNutt, who was sympathetic to Jews and Filipinos; and Herbert Frieder, head of the Jewish community in Manila and founder of the Helena Cigar Factory ([15], p. 13). Thus, on 23 April 1940, Marikina Hall was inaugurated in the presence of 300 members of the Jewish community ([23], p. 68).

According to U.S. historian Sharon Delmendo ([15], p. 12) and current Philippine President Noynoy Aquino, Quezon felt a fraternal link with the Jews who, like him, were suffering from racial discrimination. Izon and Delmendo write: “Quezon, who felt the brunt of many Americans' racial discrimination against Filipinos, felt a fraternity with the Jews who were suffering so acutely as Nazi power grew" ([15], p. 12). More subtly, in a speech on 7 August 2014, during the premiere of "Rescue in the Philippines Refuge from the Holocaust" in Malacañan Palace, President Benigno Aquino, Jr. declared that " $[t]$ hough the Philippines was thousands of miles removed from these events [of the Holocaust], our forefathers knew that oppression like this could not go unnoticed" [27]. Thus, Quezon's experience of discrimination under colonial rule allowed him to relate to the atrocities 
suffered by a people across the globe. In other words, cross-traumatic affiliation allowed solidarity between one Asian nation to a European one.

\subsection{Cross-Traumatic Affiliations of West to the East}

While the Jews received a haven during the Commonwealth period, during the Japanese Occupation from 1941 to 1945, in this part of the world, these Manilaners would experience, on the one hand, favour from the Japanese; on the other hand, contempt. In January 1940, as a measure of restriction, the German embassy in Manila refused to renew the passports of some families because they were Jewish ([23], pp. 28, 41). Paradoxically, during the Japanese Occupation, "Jews with expired German passports were still considered [by the Japanese as] German citizens in the Philippines - refugee status did not count" ([23], p. 63). In his preface, Juergen Goldhagen declares that "while the Japanese in Manila considered us friendly allies, Hans Hoeflein and I would have been treated differently back in Germany" ([24], p. 9). Thus, in spite of their statelessness, when asked for identification, these Manilaners would not hesitate to show their expired German passports. The child Juergen even occasionally played with a Japanese neighbour and accepted toys and candy from the Japanese soldiers who were described as fond of kids ([24], pp. 45-46). All the same, his family kept a distance: "At that time, none of us knew what was happening to the Jews in Germany, but it was a good thing that Dad didn't approach the officers" ([24], p. 59). Moreover, services continued in Temple Emil, although, because of curfew implementations, attendance decreased to $30 / 50$ people ([23], p. 94). Goldhagen even goes as far in saying that "the Japanese were not anti-Semitic" ([24], p. 59). It appears, then, that while being allies of Germany, the Japanese seemed to be unclear about the Jewish Question. An interesting account in Escape to Manila may offer an explanation to the Japanese attitude towards German Jews. In a conversation between Rabbi Schwarz and the Lt. Col. Narusawa, one of the heads of the "Religious Section" of the Japanese army, the officer admits not fully understanding the Judenfrage. After an hour of explanation and negotiation for German Jews to be considered as "third-party citizens" or neutral foreigners ([23], p. 92), the Rabbi finally received the Lieutenant's promise of protection for his people ([23], pp. 93-94).

However, around 1943, attitudes towards Jews started to change. The first explicit anti-Semitic warning came on 25-26 January 1943: "Jews given stern warning. Chinese profiteers also warned by administration" ([23], pp. 107-8). (It is interesting to note that Jews and Chinese were put under the same umbrella. The Roma are not the ones discriminated along with the Jews, rather, the Chinese. Such a situation reminds us that Nazism, in this case, is experienced in an Asian setting). After an increase in Jewish restrictions on February 1944 ([23], p. 117), the Japanese started unjustly arresting aliens who, if they were unfortunate, were brought to the infamous Fort Bonifacio, a place of torture ([23], pp. 119-25).

Finally, even the Temple Emil was occupied on 14 October 1944 ([23], pp. 130-31) and set afire in February 1945 ([23], p. 156). For Frank Ephraim, this "act of desecration", "brought back the terror of Kristallnacht seven years earlier" ([23], p. 156). This statement by Ephraim is interesting because it encapsulates two referential memories of WWII: the Holocaust and the Japanese Occupation.

Tirol writes that, of the more than a thousand original refugees, only 250 remained at the end of 1948 ([11], p. 194). Indeed, most Manilaners would migrate to the U.S. after the War. In contrast, 
some, like the Hoefleins, stayed on until the Marcos regime ([23], pp. 190-91). Indeed, even some years later, Ephraim maintains his affiliation with the Philippines:

After spending a couple of days in Berlin, I realised that this was not my land anymore...even though we spoke the same language...The more than twelve hundred German and Austrian Jews who found refuge in the Philippines would soon fade into history, and that is why I sought out my surviving fellow "Manilaner", as we call ourselves, to tell their stories in this book ([23], p. 4).

The particular story of a certain Ernst Juliusburger is an interesting example of cross-traumatic affiliation. Only 18 when he escaped Kristallnacht, Ernst was later captured by the Japanese. After being informed of his pending execution, he suddenly likened himself, interestingly, to Filipino hero Jose Rizal who "was shot nearby on the grounds of the Luneta Park" ([23], p. 124). Although the Japanese apparently drew their pistols after his remark, nothing happened. Hailed as the (unofficial) national hero, Rizal embodies the Filipino who gave his life for his country, both in his lifetime and in his death. Author of two novels which contributed to fuelling the Philippine revolution against Spain, Rizal was also a linguist, a medical doctor and a romantic personage. That a European would identify himself to Rizal is proof of enculturation.

Similar to Quezon, Juliusberger's own experience allowed him, not only to relate to the atrocities suffered by a different people, but even to turn to their own reference: colonisation. In other words, cross-traumatic affiliation allowed solidarity between a European and an Asian people.

As shown in the examples above, although the types of trauma of two peoples were different to and, up to a certain extent, unexperienced by the other party, the familiarity to injustice was sufficient, not only to express, but to show solidarity to one another. Again, cross-traumatic affiliation allows for differentiation and solidarity, each group considering the others' experience for their own sake and in their own terms.

\section{Results and Discussion: Manileños' Colonisation}

Until this point in the essay, I have almost only focused on the main plot of the two memoirs: the exodus of Europeans from Nazism and their unfortunate experience under Japanese Occupation in Manila. However, one should not forget that what constituted as backdrop of the escapes was the colonisation of the Philippines.

As a reminder, the Philippines was colonised by Spain for over 400 years (from 1565 to 1898) until the U.S. occupied the islands from 1898 until the Japanese bombed Pearl Harbour on 8 December 1941. Thus, Japan subjugated an already-American-occupied Philippines. After the Second World War, Manila has been described by MacArthur as "the most devastated city in the world, next to Warsaw" [28].

Shifting my analysis now from the European refugees to the Filipinos who underwent colonial domination, I inquire how Filipinos were represented in Escape to Manila and in Manila Memories. In the following sections, I will thus employ a postcolonial reading and argue for evidences of orientalism in at least one book._Although the depiction of Filipinos remains understandably limited 
in both works, I observe that, while Filipinos are described in a more positive light in Escape to Manila, this is not the case in Manila Memories.

\subsection{Representing Filipinos in Manila Memories}

When Juergen Goldhagen arrived in Manila on 8 December 1937, his first reaction towards the new country was naturally in a mode of surprise: "Filipinos were brown, and I was totally surprised and bewildered" ([24], p. 19). Later, as the only white child in English class in Philippine Normal School, he understandably felt alone: "I was so lonely that I wished I had black hair and brown skin like a Filipino, instead of being blonde and white" ([24], p. 19). At first, therefore, the boy felt the weight of his foreignness through the difference of skin colour.

This initial yearning for belongingness continued some years later, but in a different way: "Boba, Florence and I often had stone fights with the Filipinos...They would call us 'white monkey' and we would reply 'Black monkey, white monkey better than black monkey"' ([24], p. 20). A few years after the initial reaction, therefore, Goldhagen would participate in mutual racist name-calling.

In other sections of Goldhagen's testimony, his few descriptions of Filipinos allude to disloyalty, theft and menial jobs. For instance, he would chance upon Filipinos singing "God bless Japan" ([24], pp. 48-49); or stealing: “Around this time, probably in 1943, a rash of electric wire thefts started. The Filipinos would cut the electric wires from the poles and sell the copper wire. Many people were poor and desperate for food money" ([24], p. 54).

Goldhagen's elite background can also be deduced from the following excerpts: "The goat herd was under the care of a Filipino because labor was cheap and my parents felt it was too hot for me to be out in the sun" ([24], p. 56). There is one instance, however, when the boy Juergen was mentioned playing again with a Filipino, Peping, the son of Mr. Egea, mayor of Cubao whose compound was let to the Goldhagen family ([24], p. 59).

Likewise, Hans Hoeflein, who also escaped from Germany, betrays his family's elite status and only mentions the Filipinos in the following light: "As was typical of most of the foreign families, my family did not have much to do with Filipinos on a social level ([24], p. 26); "Most of my playmates at that time were Spanish or mestizos, namely, half-Spanish and half-Filipino" ([24], p. 65). With Filipino kids, however, as with Goldhagen, he "occasionally got into stone fights" with them ([24], p. 27). Elsewhere, Hoeflein admits assuming that Filipinos were behind some thefts: "I did not see any atrocities committed by the Japanese during the Occupation, though from time to time I would see some Filipinos tied to telephone poles and just left there. They were still alive when I saw them. I assumed that they had been thieves who had been caught in the act" ([24], p. 65).

Like Goldhagen, Hoeflein's memories of Filipino natives - not mestizos - were associated to stone fights, theft and lower social status. It is interesting to note as well that Goldhagen and Hoeflein restricted their relationships to mestizos and the elite of Philippine society, such as the mayor of Cubao.

Unlike Goldhagen and Hoeflein, Roderick Hall was born to a Scottish father and a Spanish-Scottish mother on 7 November 1932 in Makati, the commercial district ([24], pp. 15-16). Hall recalls how, in his family, they "all spoke Tagalog and changed from one language to another depending on whom we were with" ([24], p. 25). At that time, a lot of the Manilaners attended Filipino colleges. While most boys were sent to the Christian Brothers of De la Salle College, the women attended St. 
Scholastica's. It is no surprise then that some Jewish children, among whom, Rod Hall, would learn some Tagalog. Growing up with the elite of Manila ([24], pp. 61, 63), most of whom mestizos and mestizas, Hall would soon meet President Quezon himself: "I well remember Ian and I being presented to Manuel Quezon" ([24], p. 25).

Finally, Hans Walser was also born in Makati on March 1933. His father was a French-speaking Swiss who arrived in Manila in July 1920, while his mother was an American who came to teach in the University of the Philippines ([24], p. 18). Like his other friends, Hans Walser's environment was privileged: "My parents played bridge monthly with the MacArthurs and the Eisenhowers" ([24], p. 28). His memories of Filipinos are only described at the end of Liberation: "More and more of the young Filipino kids were walking around the neighbourhood with bodies showing a lot of bone under their skin, but also with distended bellies, the sign of beri-beri" ([24], p. 91); "Filipino looters moved right in and stripped the houses of everything" ([24], p. 91). In his short testimony, Walser portrays Filipinos as sickly, a normal situation in war, but again, like Goldhagen and Hoeflein, as looters. Once more, his family was among the privileged few, frequenting the MacArthurs and Eisenhowers.

Among the four boys, Hall appears to be the one more integrated in local society. His capacity to speak Tagalog is, at the very least, a gauge of enculturation. However, except for mestizos and mestizas, the general description of Filipinos in Manila Memories - whether true or not, since what I am interested in is representation - is associated with disloyalty to Americans, stone fights, theft, lower social status and sickness.

\subsection{Representing Filipinos in Escape to Manila}

On the contrary, in Escape to Manila, Frank Ephraim's representation of Filipinos can be divided into three classifications: a generally positive one; a more specific one which is mediated through the person of Manuel Quezon; and one negative portrayal only.

The first series of excerpts describe the hospitality and care Filipinos are known for: "Filipinos knew little about Jews, but the few Jews living in Manila in 1924 were accepted and never threatened" ([23], p. 15); "The Philippine press was quick to respond to the events of Kristallnacht" ([23], p. 38); "Filipinos were a tolerant people...Temple Emil on the Taft Avenue was very visible and Jews attended services and congregated in front of the temple without the slightest disturbance. There was never a ghetto in Manila, and Jews lived in close proximity with Filipinos" ([23], p. 53). Likewise, when Ernst Juliusburger was confined to the hospital, his recovery is described as follows: He "began to gain strength with the extraordinary care of the Filipino medical and nursing staff. With insufficient food at the hospital, the nurses picked vegetables from the gardens in the area and cooked them for their patients" ([23], p. 127). In short, Filipinos were first of all seen as welcoming and caring.

Undoubtedly, Escape to Manila allotted a lot of space in portraying Manuel Quezon: "President Quezon has indicated his willingness to set aside virgin lands in Mindanao for larger groups of Jewish refugees" ([23], p. 43); "Quezon was prepared to accept two thousand Jewish refugee families for settlement in Mindanao in 1939 and five thousand families yearly thereafter until thirty thousand families had been landed" ([23], p. 43); "President Quezon had donated three hectares, seven and one-half acres, of his country property [in Marikina] for the establishment of a working farm for 
Jewish refugees" ([23], p. 68). It is therefore no surprise that, when Quezon died on August 1944, the "Jewish community mourned-who could forget his determined speech welcoming the immigration of Jewish refugees at the dedication of the Jewish home in Marikina in 1940, on land he had provided" ([23], p. 126)?

So far, the Filipinos in Escape to Manila — care givers, sponsors and hosts - are a far cry from the thieves and black monkeys in Manila Memories. In the former memoir, the only negative portrayal of Filipinos is found in the following excerpt, confirming a difference in cultures: "Filipino staff were slow, late, or capable of making up a hundred excuses for not showing up for work. The refugees had to adapt to delays, a major change from the typical German promptness and precision" ([23], p. 52).

To be fair, it is only proper to mention that not all Filipinos were as hospitable as Quezon. General Emilio Aguinaldo himself opposed to the Mindanao plan because, according to him, some Filipinos might want to settle there and therefore should be given preference. Moreover, he was quoted saying that "the Jews are dangerous people to have around in large numbers" ([23], p. 45). Indeed, isolated anti-Semitic statements such as this can also be identified.

Unlike the boys in Manila Memories, Ephraim's witnesses were most of the time poor Europeans who sometimes even had to take on jobs as cocheros or horse-drawn drivers. According to Ephraim, Siegried Eichholz and sons, for example, were the only white cocheros in Manila at that time ([23], p. 110). Ephraim adds: "we were probably the first whites they [the Filipinos] had met who were not rich" ([23], p. 39).

The fact that most refugees that Ephraim interviewed were beneficiaries of the Quezon plan perhaps contributes to the more thankful tone in Escape. Additionally, a statement like the following reveals Ephraim's empathy towards the Filipinos: "To the Filipinos, a white man always seemed to have advantages denied them, and the occupation sometimes brought this into sharp focus...this situation (the Japanese change of opinion against German Jews) became a leveller" ([23], p. 109). In a nutshell, he goes a step further by trying to understand their situation under colonial eyes.

In Manila Memories, the four boys who attended the American school in Donada Street in Pasay naturally saw the Americans as their heroes: "[I] dream of the Americans' return" ([24], p. 56); “The Americans were our friends. How could they hurt us" ([24], p. 77)? Moreover, in a television interview, Goldhagen shares: "My thoughts were the States. I was oriented in being an American. I didn't feel Germanic" [26]. One can therefore imagine and understand the status and mentality of American-educated children in a society under U.S. domination. Perhaps such context and upbringing explains the latent orientalist [29] representations of Filipinos in Manila Memories.

Furthermore, in both works, but especially in Manila Memories, the question of epidermal colour comes to fore. How ironic that some refugees would acquire, not only jobs and homes, but also, by virtue of white skin colour, a higher social status than the natives of a host country. More than just a skin colour, whiteness or brownness/blackness signified a certain social status, a situation typical of postcolonial states. Such bias was so strong that separating whiteness from its usual high social status at that time would create confusion, as this comment from Hans Walser attests: "When we first saw the soldiers, we did not think they were Americans. They were very tan. In Manila, the Caucasians tried very hard to stay white and we just assumed that the American soldiers we would see would be white. It took us about a minute to really believe they were American" ([24], p. 111). The question 
of colour bias, therefore, which was brought on by colonisation, was therefore an inseparable reality for both Manilaners and Manileños. This question of racism brings me back to what I have already alluded to in the introduction, the appeal to other trauma paradigms.

\section{Results and Discussion: Postcolonial Considerations in Trauma Studies}

In line with other postcolonial trauma critics, I would therefore like to interrogate the place of other possible trauma paradigms which, I think, not only apply to the Philippines, but also to other countries. I briefly name at least three here: serial colonisations, martial law and natural disasters. Lastly, I argue for a consideration of "the sacred" as part of the postcolonial turn in Trauma Studies.

It is not the first time that an appeal to include colonisation as traumatic event is introduced. Mengel and Borzaga's important volume [6] precisely draws attention to the effects of colonisation on the African continent. By suggesting colonisation to be included in trauma discourse, the authors depart from the one-time trigger event of wars or the Holocaust, thus interrogating the status of PTSD as exclusively event-based.

Similarly, many Asian nations have experienced colonisation, not only from one country, but from two or several. The Philippines is no exception. Colonisation has been one of the main topics, if not the subject of predilection, of fiction over the centuries since Jose Rizal's Noli Me Tangere [30] and El Filibusterismo [31] in the 19th century. Until today, Miguel Syjuco's Man Prize 2010 novel, Ilustrado [32], for example, generously refers to years of colonisation under the Western and Japanese powers. Is the perennial apparition of colonisation as theme an attempt by authors to articulate and come to terms with the past? Is it a case of using the narrative in order to address a historical nachträglichkeit [33]? It could well be. At the same time, narration can also be an act of resistance and resilience. Indeed, although Rizal's novels would cost him his life, his acts would bear fruit with the breakout of the revolution.

Considered as a "true trauma" by writers such as Pantoja-Hidalgo [34] and Montiel [35], the Martial Law years of Ferdinand Marcos, are a second favourite theme among fictionists. Gina Apostol's Gun Dealer's Daughter, for example, can certainly be read as trauma fiction-even on Western aesthetic standards of fragmentation, non-linearity and aporia. However, the content definitely distinguishes itself as part of Philippine history with Filipino concerns.

In addition, proposals for a disaster-based trauma, combined with postcolonial theory, would absolutely benefit a typhoon-prone country like the Philippines. Not only these 7100 islands are visited by approximately 20 typhoons per year, they are also home to volcanic eruptions, earthquakes, storm surges and drought [36] The most recent disaster is undoubtedly the infamous super typhoon Haiyan in November 2013 which claimed approximately 6000 lives [36]. Latest studies, such as "Obliged to be Grateful", interrogate the conflicts that ensue from contacts between foreign aid and local cultures [37]. This document problematizes the Filipino principle of debt of gratitude or utang na loob which underpins social relations. It implies reciprocity or gratitude towards someone who has extended aid. However, when combined with the long history of the Philippines' colonial relations where benefactors can also be regarded as patrons, how relevant is feedback from affected communities towards humanitarians to whom they owe a debt of gratitude? Furthermore, the same document also interrogates the effectivity of targeted aid in local communities which value group 
culture. The Filipino sense of kapwa which "implies that people's sense of self is most intensely relational" comes into conflict with targeted interventions "within tight-knit communities...when people are excluded from aid" ([37], p. 8). Thus, petty jealousies may result if one neighbour does not benefit and the other does. One low-income woman, aged 40, thus exclaims: "[T]hese NGOs have only caused conflict among my neighbours... Whenever I receive help and my neighbour does not, they'll stare at me down and look at me from head to toe like it is all my fault!” ([37], p. 40). Other studies, such as those by Anthony Carrigan and Elizabeth Deloughry, also seek to theorise natural disasters, thus bringing such events to the fore of literature and postcolonial inquiry. Such research would also be relevant for other Southeast Asian countries which are constant preys to drought, earthquakes, floods, landslides, storm surges and tsunamis.

A final point, which Trauma Studies still has to develop, concerns the importance of the "sacred" in the process of healing. Asia is home to the oldest religions of the world whose influence to the mental and philosophical outlook of its peoples should not be underestimated. Van der Merwe makes the same case for Africa where religion becomes "a provider of inspiration, strength, and creativity in both the Muslim and Christian traditions in South Africa" ([38], p. 214). Likewise, Craps draws from Watters to argue that, in the context of the Sri-Lankan tsunami in 2004, "the remarkable psychological resilience shown by the Sri Lankan population, its capacity to live in the face of horror, can be partly accounted for by protective beliefs in Hindu and Buddhist traditions" ([1], p. 23). Against the colonisation of Western secularism towards cultures steeped in spirituality, acceptance of the sacred marks a postcolonial turn. For instance, in the recent edition of The Post-Colonial Studies Reader, Ashcroft, Griffiths and Tiffin maintain that:

The sacred has been an empowering feature of post-colonial experience in two ways: on one hand indigenous concepts of the sacred have been able to interpolate dominant conceptions of cultural identity; and on the other Western forms of the sacred have often been appropriated and transformed as a means of local empowerment. Analyses of the sacred have been one of the most neglected, and may be one of the most rapidly expanding areas of post-colonial study ([39], p. 8).

\section{Conclusions}

This essay, hopefully, contributes in examining the Holocaust in the context of a colonised Philippines. This has been delineated through at least five points. Firstly, it sought to offer a Filipino perspective on the traumatic references of the Second World War which, contrary to a European point of view, does not look to "the Holocaust" as a signifier; rather, "colonisation", the "Japanese Occupation", "Hiroshima" and "Nagasaki". Such a view thus tempers the paradigmatic status of the Holocaust in Trauma theory.

Secondly, rather than pitting one traumatic referential event over another, I attempted to develop Stef Crap's notion of cross-traumatic affiliation as way of bringing different historical traumas into contact in an ethically responsible manner. As a disposition which underscores difference and solidarity in relations of empathy, cross-traumatic affiliation avoids collapsing different traumas into 
one another, thus preserving the distance between them, allowing each culture's trauma to be considered in their own terms.

To exemplify cross-traumatic affiliation between a group of Europeans and Filipinos, thirdly, two memoirs, Juergen Goldhagen's Manila Memories and Frank Ephraim's Escape to Manila were studied. In particular, the examples of Manuel Quezon towards the Jews and Ernst Juliusberger towards the Filipinos proved how each one used their own referential atrocities or traumas, not only to relate the other, but to go further by extending solidarity. Moreover, such narratives further highlight the almost unknown role of the Philippines in the rescue of more than a thousand Jews, a story which a monument in the 65-hectare Rishon Lezion National Park near Tel Aviv now stands for. Aptly called the "Open Door Monument", it fittingly commemorates Quezon's "open door" plan ([11], p. 264). Also of interest in the study of the two works is the fact that they gather the memories of both the Holocaust and the Japanese Occupation in Asia.

Consequently, fourthly, this essay also pointed to another Asian-based referential traumatic event, namely, colonisation in the Philippines. By shifting the focus of the essay to representations of Filipinos, one could note, however, latent orientalism in Manila Memories. With and in spite of the solidarity that Goldhagen's memoir reveals, unfortunately, the colonised situation of the natives, mostly portrayed as thieves and "black monkeys", almost only served as a backdrop to the Holocaust escape and Japanese Occupation survival story of four American-educated boys. In Escape to Manila, on the contrary, a more favourable representation of the host country is shown. That most testimonials from Escape were gathered from beneficiaries of the Quezon plan perhaps accounts for its more thankful tone.

Hence, fifthly, the orientalist underpinnings in Manila Memories, for instance, those which pertain to the "colour line" in the context of colonisation, led me, in agreement with other postcolonial trauma critics, to interrogate the place of other possible trauma paradigms, such as serial colonisations, Martial Law and climate disasters. Lastly, I also discussed the importance of including the sacred as part of the postcolonial reconsideration in trauma discourse.

The names Manileños/Manileñas and Manilaner, as they are morphologically constructed, betray a hybrid origin which is both European and Filipino. The two indicate a belonging to Manila and to either Spain or Germany and Austria. While both designations reveal Manila's colonial subjugation and the city's open doors; a land invaded and a hospitable abode, they also allude to Europe as colonisers and Europe as victims. While the label Manileños/Manileñas embody, on the one hand, Filipinos' suffering under colonisers, this name also testifies to appropriation and decolonisation. Likewise, while the designation Manilaner cannot be dislodged from recalling its origin - the pain of escaping Nazism - at the same time, the name has also been appropriated by this small group of European settlers to signify their freedom in the Philippines. Thus, the names Manileños/Manileñas and Manilaner are both charged with significations of difference and solidarity, trauma and resistance.

\section{Acknowledgments}

I would like to thank historian Sharon Delmendo for introducing me to the book by Juergen Goldhagen; my colleague, Jo-Ed Tirol for giving me a copy of his PhD dissertation; and Stef Craps for his time during the few encounters with him in Ghent and Leeds. Through the Kritika Kultura 
team of the Ateneo de Manila University English Department, I was able to meet Sharon Delmendo - many thanks to them. I also acknowledge receiving other background references on the Jewish presence in Manila thanks to Racelle Weimann, the archives of Manila Bulletin, and videos from the Jewish community in the Philippines. Lastly, this essay is a developed version of a paper presented last January 2015 in the University of Leeds, thanks to the partial financial help of the Ateneo de Manila.

\section{Conflicts of Interest}

The author declares no conflict of interest.

\section{References and Notes}

1. Stef Craps. Postcolonial Witnessing: Trauma Out of Bounds. Basingstoke: Palgrave Macmillan, 2012.

2. Daniel Levy, and Natan Sznaider. The Holocaust and Memory in the Global Age. Philadelphia: Temple University Press, 2006.

3. Cathy Caruth. Unclaimed Experience: Trauma, Narrative, and History. Baltimore: Johns Hopkins University Press, 1996.

4. Michael Rothberg. Multidirectional Memory: Remembering the Holocaust in the Age of Decolonization. California: Stanford University Press, 2009.

5. Kali Tal. Worlds of Hurt. Cambridge: Cambridge University Press, 1996.

6. Ewald Mengel, Michela Borzaga, eds. Trauma, Memory, and Narrative in the Contemporary South African Novel: Essays. Amsterdam: Rodopi, 2012.

7. Frantz Fanon. Black Skin, White Masks. New York: Grove Press, 1967.

8. W.E.B. DuBois. The Souls of Black Folk. New York: Dover Publications, 1994.

9. Aimé Césaire. Discourse on Colonialism. New York: Monthly Review Press, 2000.

10. Andreas Huyssen. Present Pasts: Urban Palimpsests and the Politics of Memory. California: Stanford University Press, 2003.

11. Jose Maria Edito Tirol. "Of Forgetting and Remembering: Commemoration and the Jewish Refugees in the Philippines during the Second World War." PhD Dissertation, University of the Philippines, May 2015.

12. Philippine Embassy. Available online: http://philippine-embassy.org.il/index.php?option=com content\&view=category\&id=11\&layout=blog\&Itemid=2 (accessed on 5 November 2015).

13. GMA Network. Available online: http://www.gmanetwork.com/news/story/533519/ news/nation/late-president-quezon-awarded-for-helping-jewish-refugees (accessed on 5 November 2015).

14. Racelle Weimann, email message to Jocelyn Martin, et al., 20 February 2013.

15. Noel Izon, and Sharon Delmendo. "An Open Door: Jewish Rescue in the Philippines" Film Brochure. New York: Izon and Delmendo, 2013.

16. Jeffrey Alexander. The Meanings of Social Life. New York: Oxford University Press, 2003. 
17. An interview which I conducted by e-mail dated 18 May 2015. This correspondence has been preceded by personal meetings with Stef Craps during other occasions in Ghent and in Leeds.

18. Dominick LaCapra. Writing History, Writing Trauma. Baltimore: Johns Hopkins University Press, 2001.

19. Jeffrey Olick, Vered Vinitzky-Seroussi, Daniel Levy, eds. The Collective Memory Reader. New York: Oxford University Press, 2011.

20. Mark Seltzer. "Wound Culture: Trauma in the Pathological Public Sphere." October 80 (1997): 3-26.

21. Didier Fassin, and Richard Rechtman. The Empire of Trauma: An Inquiry into the Condition of Victimhood. Princeton: Princeton University Press, 2009.

22. Tzvetan Todorov, and David Belos. Hope and Memory: Lessons for the Twentieth Century. Princeton: Princeton University Press, 2003.

23. Frank Ephraim. Escape to Manila. Chicago: University of Illinois Press, 2008.

24. Juergen Goldhagen. Manila Memories. Exeter: Old Guard Press, 2008.

25. Bonnie Mae Harris. From Zbaszyn to Manila: The Holocaust Odyssey of Joseph Cysner and the Philipppine Rescue of Refugee Jews. Santa Barbara: University of California Press, 2009.

26. Stacey Cochran. "Juergen Goldhagen Manila Memories." In The Artist's Craft. Raleigh: Stacey Cochran Productions and Raleigh Television, 2009.

27. Benigno Aquino, Jr. "Premiere of Rescue in the Philippines Refuge from the Holocaust." Speech presented at Malacañan Palace, Manila, Philippines, 7 August 2014.

28. Jose Ma. Bonifacio M. Escoda. Warsaw of Asia: The Rape of Manila. Quezon City: Giraffe Books, 2001.

29. Edward Said. Orientalism. New York: Vintage Press, 1979.

30. Jose Rizal. Noli Me Tangere. Berlin: Berliner Buchdrukkerei AG, 1887.

31. Jose Rizal. El Filibusterismo. Ghent: F. Meyer van Loo Press, 1891.

32. Miguel Syjuco. Ilustrado. New York: Farrar, Straus and Giroux, 2010.

33. Sigmund Freud. "Remembering, Repeating and Working-Through." In Standard Edition. Edited by James Strachey. London: Hogarth Press, 1958, vol. 12.

34. Cristina Pantoja Hidalgo. A Gentle Subversion: Essays on Philippine Fiction in English. Quezon City: University of the Philippines Press, 1998.

35. Cristina Jayme Montiel. "Multilayered Trauma During Democratic Transition: A Woman's First-Person Narrative." Journal of Peace Psychology 21 (2015): 197-211.

36. Asian Disaster Reduction Center (ADRC). Available online: http://www.adrc.asia/ nationinformation.php?NationCode $=608$ (accessed on 19 August 2015).

37. Jonathan Corpus Ong, Jaime Manuel Flores, and Pamela Combinido. "Obliged to be Grateful: How local communities experienced humanitarian actors in the Haiyan response." Working paper, Plan International, Woking, UK, 2015. 
38. Chris N. Van der Merwe. "Rethinking Religion in a time of Trauma." In Trauma, Memory, and Narrative in the Contemporary South African Novel: Essays. Edited by Ewald Mengel and Michela Borzaga. Amsterdam: Rodopi, 2012, pp. 195-215.

39. Bill Ashcroft, Gareth Griffiths, and Helen Tiffin. The Post-Colonial Studies Reader. New York: Routledge, 2006. 


\title{
Postcolonial Trauma Theory in the Contact Zone: The Strategic Representation of Grief in Edwidge Danticat's Claire of the Sea Light
}

\section{Silvia Martínez-Falquina}

\begin{abstract}
This article starts by engaging in a dialogue with the most relevant postcolonial emendations to trauma theory, addressed to both its aporetic and its therapeutic trends, and it goes on to reflect on the state of the decolonizing trauma theory project, critically examining the motivations behind it as well as some of the problems it still encounters, like the risk of objectification and revictimization of postcolonial peoples, the blurring of their trauma particularities, and the appropriation of their experience. Then, it proposes an alternative understanding of postcolonial trauma theory as a contact zone where trauma criticism and the postcolony are interrelated and mutually transformed, and where unequal power relations are also attended to. Acknowledging the postcolony as a site of theory production rather than the object of external definition, it proceeds to analyze Edwidge Danticat's short story cycle Claire of the Sea Light: its strategic representation of grief-which she achieves through the short story cycle structure and overall in-betweenness and ambivalence in symbols and characterization-puts Haitians on the critical map of trauma, fighting invisibility and oblivion, but it simultaneously resists an appropriation of Haitian experience by rejecting any monolithic view on Haiti and refusing to fit into a predetermined template.
\end{abstract}

Reprinted from Humanities. Cite as: Martínez-Falquina, S. Postcolonial Trauma Theory in the Contact Zone: The Strategic Representation of Grief in Edwidge Danticat's Claire of the Sea Light. Humanities 2015, 4, 834-860.

\section{Postcolonial Emendations to Trauma Theory}

In her accurate overview of the relation of trauma theory and postcolonial studies in this volume, Irene Visser examines the current state of the project of decolonizing trauma theory [1]. As she acknowledges, it was Michael Rothberg who, in his contribution to the special issue of Studies in the Novel dedicated to that relation in 2008 [2], first discussed the need for a "decolonized" trauma theory, and this entailed a turning point in the development of trauma studies. In 2015, Visser appropriately refers to the project of decolonizing trauma theory as an ideal and she outlines some of the remaining objectives to reach it, arguing that "[a] response to trauma from a respectful cognition of culturally specific spiritual and religious perspectives, analogous to the recognition of historical, national, and ethnic diversification, is necessary for a postcolonial theory of trauma to be truly decolonized" ([1], p. 259). The project has, however, already borne some important fruits, mainly because the need to radically question and expand the trauma paradigm is now generally assumed by the critics, and a number of articles since 2008 have included a series of emendations, to use Visser's term [3], to mainstream trauma theory. These emendations are a reaction to the inadequacy of trauma theory to properly account for postcolonial experiences and texts, for as 
Michela Borzaga puts it, although trauma may be a legitimate category in the field of psychiatry ([4], p. 74), it is problematic to work with Western psychiatric and cultural theories of traumas in a postcolonial situation ([4], p. 65), to such an extent that in its current mainstream use, “"trauma' becomes more of a barrier than a fruitful epistemological tool” ([4], p. 68).

The main target of criticism has been trauma theory's lack of interest in the traumas experienced by members of non-Western cultures. As appropriately phrased by Stef Craps and agreed upon by many more critics, "if trauma theory is to adhere to its ethical aspirations"-it is worth recalling Cathy Caruth's famous idea that "trauma itself may provide the very link between cultures" ([5], p. 11) - "the sufferings of those belonging to non-Western or minority cultures must be given due recognition" ([6], p. 13). There has also been a generalized call to interrogate and move beyond a fundamentally Eurocentric trauma paradigm. Pat Bracken, for example, denounces how PTSD has been brought to the developing world "without any great thought of the great cultural, social, and other difficulties there would be with that move" [7]. Trauma criticism's lack of historical particularity and careful attention to context is contrasted to the postcolonial focus on historical, political and social factors, which explains the generalized claim to attend to specific postcolonial experiences, like the trauma of racist oppression, or the negative consequences of (neo)colonialism.

A further ramification of trauma theory's Eurocentrism is its excessive focus on experimental (post)modernist textual strategies to represent the acting out of trauma, which has resulted in a prescriptive and narrow trauma paradigm that seeks to impose Western narrative criteria in order to assess the representational value of texts that deal with trauma. Critics like Craps have responded by deauthorizing a predetermined relation between aesthetic form and political or ethical effectiveness, and suggest instead that trauma theory should attend to "the specific social and historical contexts in which trauma narratives are produced and received, and be open and attentive to the diverse strategies of representation and resistance which these contexts invite or necessitate" ([6], p. 43). Critics of postcolonial texts are therefore encouraged to attend to indigenous cultural traditions, knowledge systems and ways of perceiving the world, including the understanding of spirituality or the storytelling tradition.

The traditional event-based model of trauma ([2], p. 226) — or "accident model of trauma", as Nancy van Styvendale calls it ([8], p. 207) — which cultural trauma theory continues to adhere to and "according to which trauma results from a single, extraordinary, catastrophic event" ([6], p. 31), has also proved inadequate to account for experiences of exclusion or marginalization. Merlinda Bobis, for example, talks about poverty as a violent phenomenon, "and yet", she notes, "it is hard to say one is traumatized by this violence, because it seems the concept of trauma is something that happens suddenly, disrupting normal life" ([9], p. 62). It is a sad fact that poverty, like discrimination or natural calamities, is, for many peoples, simply normal life. Some of the critical challenges to trauma as a singular, recognizable and chronologically-bound incident are articulated by Michela Borzaga, who argues for an analysis of the conditions, rather than events, in which life - with its corresponding traumas - unfolds ([4], p. 68); Laura S. Brown, who works with Maria Root's notion of insidious trauma to refer to "the traumatogenic effects of oppression that are not necessarily overtly violent or threatening to bodily well-being at the given moment but that do violence to the soul and spirit" ([10], p. 107); or Nancy van Styvendale, who uses the concept of 
trans/historicity to refer to "a traumatic event-which-is-not-one" and to gesture toward "a trauma that takes place and is repeated in multiple epochs and, in this sense, exceeds its historicity, conventionally understood as its singular location in the past" ([8], p. 204).

A further point of contention with traditional trauma theory is its focus on psychic trauma to the detriment of a proper attention to the material conditions - economic, sociological, political, etc.which affect people and determine their reaction to traumatic experience. As Dolores Herrero and Sonia Baelo-Allué contend, mainstream trauma theory's "focus on an individual/psychological perspective may pose the danger of separating facts from their causes, thus blurring the importance of the historical and social context, which is particularly relevant in postcolonial trauma narratives" ([11], p. xi), and that is the reason why these authors argue for a fruitful dialogue between the psychological conception of trauma defined by Caruth and the sociological definition of cultural trauma articulated by prominent sociologists like Arthur G. Neal, Ron Eyerman or Jeffrey C. Alexander, to name but a few ([11], pp. xi-xii). This also reminds us of the fact that, in the postcolonial context, "[i]n addition to psychological work, social consensus and reparation are also necessary" ([11], p. xiii). Needless to say, the sufficiently proven statement that the personal is always political becomes even more evident when we are referring to accounts of the effects of colonialism or racism.

Also in relation to the psychic model of trauma is its questioning of the reliance on the Western conception of the self as a psychologically healthy and unified subject, in such a way that trauma is understood as a shattering experience that fragments a previously coherent sense of self. As Stef Craps contends, drawing on Claire Stocks, "for many disempowered groups [...] trauma is a constant presence, $[\ldots]$ meaning that there is no pre-traumatized state of being that can be restored in any straightforward manner" ([6], p. 33). The Western individualistic conceptualization of man and society is additionally challenged by the emphasis on the healing resources of family and community $[4,7,12]$, which becomes perhaps the most outstanding vindication of postcolonial fiction. Irene Visser shows an additional reaction to the emphasis on Freudian melancholia and stasis when she argues that

$[u] n l i k e$ what is currently the dominant idea in trauma theory, social fracture, alienation, and a weakening of social cohesion, are not the only, nor perhaps even primary characteristics of trauma. In fact, while trauma may cause divisiveness, it can also lead to a stronger sense of belonging and can in fact create community ([13], p. 109, original emphasis).

The fact that in the postcolonial world time is not necessarily understood as linear or based on cause-effect relations has also been emphasized to question the idea of traumatic atemporality, together with "the predominant model that suggests traumatic memory remains frozen and separated from 'normal' memories" ([14], p. 163). Since in many postcolonial cultures the past, present and future are not considered separate but part of "a unified tangle", then "the repetition and re-living of traumatic experiences as well as the potential for overcoming trauma: i.e., the process of working through it, are not separate and set at the two ends of the spectrum but coexist and struggle with one another in complex and unexpected ways" ([4], p. 78). One good way to 
account for this complexity would be to combine an approach to trauma as both concrete event and part of a trans/historical process, as van Styvendale does [8], but in any case, a more careful attention to the culturally specific way of understanding time - and space, for that matter — is still required in this respect.

The questioning of an excessive emphasis on the post-traumatic condition-with a focus on the shattering experience of trauma, the disorder and destitution resulting from it - is also present in some critiques of mainstream trauma theory, which underscore the possibility of healing that is obvious in postcolonial literatures and cultures [4,6,12]. As Melvin Konner states, "resilience and/or independent recovery are by far the most common responses to potentially traumatic experiences" but this is not often shown in studies of trauma ([12], p. 320). Agency, empowerment, affirmative politics, or "post-traumatic growth", to use Borzaga's term ([4], p. 74), are some of the ways of responding to trauma that can be observed in the postcolonial context.

All of the above emendations are mainly addressed to the deconstructionist approach to trauma, whose main representatives are Cathy Caruth and Geoffrey Hartman, and which remains the dominant model in mainstream trauma studies today. However, when it comes to the supposed inaccessibility of trauma, famously identified by Caruth, we find an alternative understanding of the function of narrative, resulting in an important point of contention that made Roger Luckhurst talk about the trauma theory contradiction ([15], p. 82). As Visser summarizes it, there are two opposed views of the trauma narrative, the former-with Caruth and Hartman as main representatives - considering it "aporetic, leading to increased indeterminacy and impossibility", and the second - associated to the work of Judith Herman, who argues that narrative is a powerful and empowering therapeutic tool—seeing it as 'therapeutic, enabling a 'working through' and eventual resolution of trauma" ([16], p. 274). As it has become clear in literary criticism, the second approach to trauma - which allows for a "historically and culturally specific approach to trauma narratives" that sets a necessary contrast to Caruth's "homogenizing tendencies" ([16], p. 274) —is more appropriate to account for postcolonial texts, thus confirming Jenny Edkin's perception that "there is an imperative to speak, and a determination to find ways of speaking that remain true to the trauma" ([17], p. 15). In fact, for many, if not all, postcolonial authors, speaking out about their traumatic experiences - which they do each time their texts explore the consequences of (neo)colonialism and/or discrimination-becomes the best possible act of resistance to the silencing of their voices and the recovery of a self-defining subject position.

In spite of the affinity of the therapeutic view on trauma to postcolonial realities, some emendations to this trend have also been made, which, because they have had a more discrete presence in criticism, should be brought to the fore lest we encounter the problems of Herman's model of understanding trauma while trying to revise the Caruthian one. On the one hand, as Craps has warned, it is important for a text to unsettle "triumphalist accounts of the postcolonial that deny the continuing effects of racial and colonial trauma" ([6], p. 71), as well as to avoid "[p]utting pain at the heart of demands for political recognition", for this "severely limits the possibilities for political transformation" ([6], p. 126). It is undeniable that the traumatic condition in postcolonial contexts is ongoing and far from being solved, and a vision of trauma which celebrates healing through narrative runs the serious risk of denying the continuing impact of trauma. In this respect, 
Jo Collins wonders whether "an approach which sees literature as a vehicle for healing can fully recognize the political concerns of postcolonial writings" ([18], p. 6). Needless to say, the erasure of the political vindications present in a text becomes an ethical problem, for it entails the silencing of unequal power relations and of the call for political engagement to revert them, both of which are key motivations in much of postcolonial writing.

On the other hand, we need to be very attentive to the possibility of neo-colonial appropriation in this way of reading trauma. Stef Craps cautions that "the traumas of non-Western or minority populations need to be acknowledged for their own sake" ([6], p. 3), while Jo Collins also refers to a serious limitation of the therapeutic approach, namely the risk of appropriation of the trauma of others, what Spivak calls "epistemic violence" ([18], p. 8). The problem is not only that, in Craps's words, "rather than reflecting a postcolonial sensibility, well-meaning attempts to reach out to the racial, ethnic, or cultural other can effectively result in the appropriation or instrumentalization of his or her suffering in the service of articulating the trauma of the self" ([6], p. 3), but also that this may allow for an even more unethical opportunity to expiate colonial guilt: "Reading such novels through western paradigms of trauma may seem like an ethical act of recuperating memory, but may ultimately be a way of appeasing guilt about the West's imbrication in such trauma without impelling real intervention" ([18], p. 14).

All in all, two aspects should have been made clear in the account of the emendations to trauma theory above: firstly, that since neither the aporetic nor the therapeutic views of trauma is free of problems, it is not enough to simply adopt either variant of trauma theory and apply it to postcolonial texts and contexts. The fact that critics analyzing postcolonial texts engage in a critical relation to Western theoretical models before using them is probably the best thing that could have happened to trauma theory, for it has given it a great opportunity to transform itself and improve; and secondly, that the ideal of decolonizing trauma theory is certainly still not a reality, which is why, in what follows, I am offering some further critical reflection on the motivations behind it which are intended to contribute to this ongoing project.

\section{The Decolonizing Ideal: Open Issues}

As it has been mentioned above, Rothberg was the first to talk about the need to decolonize trauma theory while he acknowledged the Studies in the Novel contributors' "creation of an alternative canon of trauma novels that should have significant pedagogical implications", and their "insight that theory needs to globalize itself more thoroughly and responsibly" ([2], p. 226). His references to an "extended" model of trauma ([2], p. 229) and to "the project of decolonizing and globalizing trauma studies" ([2], p. 226) have been continued by various critics, among others Herrero and Baelo-Allué, who focus on "worlding" or "postcolonizing" trauma studies ([11], p. xvii); or Visser, who offers suggestions aimed at reaching the ideal of a "truly" or "fully" decolonized trauma theory ([1], pp. 259-60) and associates globalization and trauma theory thus:

the global impact of western cultural trauma theory may be understood under this same rubric of globalization, and it may also be understood as a movement from the west to 
the non-west: it is informed by western psychoanalytic theory and brought to bear on non-western literary studies ([3], p. 40).

This reference to a transition from the west to the non-west evidences the basic motivation of the decolonizing trauma project: that of expanding the paradigm, of incorporating other experiences and texts as objects of trauma theory analysis. However, such an expansive movement also points at a colonial power dynamic that should be critically attended to, namely that between a center of theoretical definition and its margins, which may end up being reinforced rather than questioned. The relational approach to postcolonial trauma theory that Visser conceptualizes in a different article - "a comparative and relational notion of trauma at the center of a tangled complexity of theories and concepts about trauma" ([19], p. 4) -further illustrates this dynamic: in spite of its “"unsayable' nature" ([19], p. 3), trauma is at the center of definition of that "intricate knot" ([19], p. 3). Notwithstanding the usefulness of this idea-which allows Visser to offer the most insightful analysis of Toni Morrison's novel Home that I have encountered so far-it should be noted that it also contains the potential risk of sustaining trauma in the central position that was originally questioned as a new type of cultural imperialism ([4], p. 69) and a new master narrative ([20], p. 229). If decolonizing is the ideal - with all the self-reflective questioning that this should always involvethen we should at least reconsider whether sustaining the centrality of trauma is desirable or convenient, and whether the relation of trauma and postcolonial theory is equally beneficial for all of the parts involved.

It is obvious that trauma theory has benefitted and will keep benefitting from its expansion, but whether the opposite influence is also true still needs to be more thoroughly discussed, mainly because most of the critics who argue for a postcolonial trauma theory take it for granted that its expansion to the postcolony is a positive, even ethical move, without entering into much more debating. As argued above, the interaction with postcolonial theory has offered trauma studies a great opportunity to face many of its inconsistencies and improve itself in the process. In Irene Visser's words,

[p]ostcolonial literary texts often engage with trauma in ways not envisioned in the currently dominant trauma theory, or in ways that reverse trauma theory's assumptions, for instance by depicting victims' resilience, resistance, and eventual triumph over trauma, or a community's increased cohesion and enhanced sense of identity after a traumatic event ([13], p. 127).

A number of authors also underscore the positive contribution of trauma theory for the understanding of previously ignored issues, like Herrero and Baelo-Allué, who point at trauma theory's usefulness “in analyzing and understanding colonial traumas such as forced migration, sexual, racial and political violence, dispossession, segregation, genocide, and the intergenerational transmission of trauma, to mention but some" ([11], p. xvii); or Craps, who illustrates the contribution that a decolonized trauma theory can make to our understanding of "postcolonial literature that bears witness to the suffering engendered by racial or colonial oppression" ([6], p. 5), and remarks how it can act "as a catalyst for meaningful change", enabling us to "expose situations of injustice and abuse, and open up ways to imagine a different global future" ([6], p. 8). 
Clearly, the fact that previously silenced or forgotten traumas are given further visibility on a global scale is very positive indeed, and the possibility of using linguistic and diagnostic categories that are sanctioned by the dominant culture surely allows many people to "hold out the hope of having [their] pain recognized, legitimated, and compensated for" ([8], p. 205). Nonetheless, there must be a reason why some writers and critics in the postcolony are resisting the trauma terminology; Merlinda Bobis reflects on the way that the Western word "trauma" is perceived as being part of an industry whose terminology simply does not suit Filipinos ([9], pp. 61-62), which could explain why many indigenous people resist becoming the object of Western definition once and again. On the other hand, as van Styvendale observes, the paucity of research on the particular case of Native American trauma "reveals a necessary political resistance to the potential revictimization of Native peoples through the nomenclature of trauma - or, in other words, to the reification of Native victimhood and the pathologizing of Native communities through the imposition of yet another Euroamerican framework designed to 'figure out' and 'fix' Native peoples" ([8], p. 206). For this critic, the danger of institutionalizing the fact of trauma in Native communities - which can be extrapolated to other marginalized communities in the world - is "the danger of revictimization", and while she has to admit to have "no easy safeguard to protect against this danger", she shows her conviction that it is necessary to proceed, "aware of the possible pitfalls, to recognize post-contact Native experience as traumatic" ([8], p. 206).

The dangers of objectification and revictimization are only a part of a series of pitfalls encountered by the expansion of trauma theory for the postcolony. Another not less relevant one is the risk of homogeneization, or the silencing of different ways of perceiving, responding to and representing trauma that may ultimately reinforce (neo)colonial relations. In the application of trauma theory to a diversity of postcolonial experiences there is an obvious risk of uniformizing, of using trauma studies as an umbrella term that will erase differences and particularities. The attempt on the part of trauma studies to export its model to the postcolony threatens to absorb particular experiences into a global theoretical frame and to erase differences that should be made visible and vindicated. Visser's list of questions in her article on globalization and trauma point at what are still very open issues, when she wonders

whether the ever-growing influence of trauma theory in literary and cultural studies in academia worldwide is to be seen as a beneficial development for the critical development with postcolonial non-western literatures. What promises does cultural trauma theory hold out for a global understanding of trauma, and how adequate are they to the agenda of postcolonial literary criticism? May a critical approach that draws on trauma theory in its engagement with non-western, local literatures be seen as contributing to the beneficial or perhaps rather to the more questionable effects of colonization? ([3], p. 41).

As Merlinda Bobis pondered, "[t]he collectivization of loss can lead to further loss of justice in specific lives" ([9], p. 78), and we should not minimize the consequences of this for many people. But again, as in van Styvendale's case above [8], critics usually acknowledge this risk but decide that the advantages make up for the pitfalls, as shown by Herrero and Baelo-Allués reflection that 
"[a]lthough literary criticism may run the risk of homogenizing trauma, especially when applying trauma theory to a postcolonial context, it is undeniable that it can shed light on the interpretation of postcolonial traumatic fiction" ([11], p. xv). Even if the necessity to attend to culturally specific features of trauma is generally agreed upon-Borzaga for example talks about the need to unmask the points of difference, discontinuities and ruptures ([4], p. 70) - there is also a counter-call for the need "to generalize and build theoretical models" ([2], p. 232) in order to avoid what is perceived as "the tendency toward hyper-particularism" ([2], p. 228). This points at the difficult balance between over-homogeneization and hyper-particularization that will also have to be negotiated in the process of decolonizing trauma studies. In any case, clearly more work still needs to be done especially in the direction of specificity, both in the analysis of the literary representation of trauma and by paying more attention to theories about and especially originating in those contexts.

All in all, it seems obvious that there are two relevant issues that remain open and which a "decolonized" trauma theory should not fail to address. Firstly, the very motivation behind it ought to be critically questioned, for one of the problems we face is that we may be talking about mainly Western needs here. I agree with Kansteiner and Weilnböck when they state that "there is no such thing as neutral by-standing - politically, personally, or scientifically — and this insight should be reflected in our scholarly work" ([20], p. 238), so it is worth asking a series of questions: What is the purpose of aiming at a "truly" or "fully" decolonized trauma theory?; is it equally desirable for all of the agents involved in it? Secondly, and relatedly, we need to seriously face the delicate issue of appropriation, which evidences itself each time the center is interested in the margins for some reason. Lately, trauma criticism seems to have discovered postcolonial texts as an occasion to reinforce some of its tenets, but it remains to be seen whether the actual bases of colonial/theoretical power will really be shattered, that is, whether this power can actually be decolonized, or ultimately reinforced, therefore involving an unwanted recolonization, in the process. Needless to say, we should always critically examine the interests behind the wish for expansion, of the yearning for connection to others, for in them we may find a hidden wish to expiate for colonial guilt by focusing on the colonized victim's role. Although perfectly satisfactory answers may never be found to these open issues, it is an ethical obligation to keep addressing them for the project of decolonizing trauma theory to remain truly postcolonial.

\section{Postcolonial Trauma Theory in the Contact Zone}

Having argued that the motivations behind the project of decolonizing trauma theory should be revised while it is still in the making, I contend that, in order to raise awareness of the power relations involved in postcolonial trauma theory, it is worth recovering the critical concept of transculturation. Coined by Fernando Ortiz in the 1940s, Mary Louise Pratt famously defined it in 1992 as the term that could be used to describe "how subordinated or marginal groups select and invent from materials transmitted to them by a dominant or metropolitan culture" ([21], p. 6). As she also emphasized,

[w]hile subjugated peoples cannot readily control what emanates from the dominant culture, they do determine to varying extents what they absorb into their own, and what 
they use it for. Transculturation is a phenomenon of the contact zone. [...] While the imperial metropolis tends to understand itself as determining the periphery (in the emanating glow of the civilizing mission or the cash flow of development, for example), it habitually blinds itself to the ways in which the periphery determines the metropolis ([21], p. 6).

Because transculturation, itself a reaction to the traditional view that minority groups should be acculturated, focuses on mutual interaction between different groups or cultures, it becomes useful in order to underline both the way the center influences the margins, and the way the margins influence the center too. Thus, it resists the idea of a unidirectional flow of influence from the center to the margin, emphasizing the fact that marginalized cultures are not passive recipients of what comes from the mainstream but usually voice non-conformist responses to the center of representation, a good medicine against the risks of epistemic violence. Applying this to the relation of trauma and postcolonial studies, we are compelled to examine both what the postcolony can and does offer trauma theory, and what trauma theory can and does offer the postcolony, as well as the ways in which both are mutually transformed and interrelated.

The very debate on the articulation of postcolonial trauma theory may be seen as functioning under the dynamics of transculturation, a dialogic process where each participant depends on and is transformed by the other, establishing a reciprocity that questions the idea of cultural purity and which, very importantly, never loses sight of unequal power relations. In other words, postcolonial trauma theory is in itself the result of a new contact zone, a "space of colonial encounters, the space in which peoples geographically and historically separated come into contact with each other and establish ongoing relations, usually involving conditions of coercion, radical inequality, and intractable conflict" ([21], p. 6). In order to make even more emphasis on the unequal relations of power usually involved in contact zones, Pratt adds that these are spaces "where disparate cultures meet, clash, and grapple with each other, often in highly asymmetrical relations of domination and subordination - like colonialism, slavery, or their aftermaths as they are lived out across the globe today" ([21], p. 4). A look at postcolonial trauma theory as a critical contact zone evidences the fact that the relations of power between trauma theory and other critical frameworks still has to be properly acknowledged, and a careful observation of inequality will have to counter the sometimes excessive optimism of theories of hybridity or relationality. This is the only way that the risk of erasure of theories and experiences coming from the margins can be resisted and unequal relations of power can be acknowledged, challenged, and whenever possible, reverted.

Replacing the focus on the expansion, globalization or opening of trauma theory with an attention to postcolonial trauma theory as a phenomenon of a critical contact zone additionally gives us a more adequate insight into different ways of representing and dealing with traumatic experiences. Instead of interpreting them as devalued copies of Euro-American understandings or of measuring them from a predetermined template, this view lays emphasis on the singularity that they usually vindicate, and which is more often than not threatened. Correspondingly, due attention needs to be paid to postcolonial criticism's merit in anticipating some of the conclusions that mainstream trauma theory is only recently beginning to see, and, in general, more work needs to be done to recognize the influences of other paradigms on the trauma one. In addition, a stronger 
emphasis should be laid on the authors and critics outside mainstream trauma theory who have dealt with past and more recent traumas in their many forms. Stef Craps argues that Frantz Fanon already anticipated "the criticisms of the individualizing, pathologizing, and depoliticizing tendencies of the dominant trauma model" ([6], p. 28), whereas Borzaga vindicates trauma theory from the postcolony - most notably authors like Frantz Fanon, Achille Mbembe or Ashis Nandy — and criticizes the censoring mechanisms in trauma discourse, "its resistance to more creative modes and less orthodox ways of approaching this topic, its intolerance towards those scholars who write about the wound of colonialism without using the specific lexicon of trauma" as aspects that require urgent investigation ([4], p. 80). For decades now, postcolonial critics have been talking about the traumatic effects of colonialism and the literary responses to them-healing and not - without using Caruth or Herman as a framework, and it might even be argued that all postcolonial theory - which deals with colonial relations, racism, or gender violence, to name but a few of their main concerns - is always related to trauma in some way or another, without necessarily naming it so or understanding it on the same terms as mainstream trauma theory does. In fact, a good exercise in critical ethics would be to recognize that each time that references are made to something new in trauma studies - like the new opening of the paradigm, the new attention to marginal texts, or the need to look at new elements like ritual and spirituality-we may actually be referring to something new to trauma studies only, and this is a problematic rhetoric of discovery that we should obviously try to avoid.

Part of the effort to decolonize knowledge should be directed at recognizing the postcolony as a site of theory production rather than merely as an area to be studied. In this respect, I am interested in the way that fictional texts can illuminate theory too, instead of trying to make a specific text fit into some kind of predetermined template. Apart from the aforementioned risks of appropriation and re-victimization, the frequent negative reaction of marginalized groups to trauma theory-and Western theory in general for that matter - may be explained by the fact that they have their own ways of representing and dealing with various forms of traumatic processes - violence, grief, pain, suffering, dispossession, loss...-but they still have to vindicate them in order to counterbalance the invisibility and silence imposed on them. One way to do this is through literary creation, a discourse which is different from but closely related to that of theory; fiction often responds to critical expectations, but literature can also illuminate criticism, question it, call for its revision, transform it. To illustrate this, in the next section, I offer an analysis of Haitian American writer Edwidge Danticat's recently published Claire of the Sea Light [22], looking at how the text rejects appropriation of Haitian American experience in the terms of either the aporetic or the therapeutic trends of trauma theory. As I will try to prove, by offering a strategic representation of grief, the text resists fitting into any kind of template and demands a careful reading in its own terms, all of which compels us to further reflect on the process of decolonizing trauma theory.

\section{Edwidge Danticat's Claire of the Sea Light and the Strategic Representation of Grief}

Haitian-American writer Edwidge Danticat's short story cycle Claire of the Sea Light is full of parents losing their children, and children missing their dead or absent parents; of death, rape and murder; of poverty, loneliness and grief. Previous texts by Danticat have often been analysed as 
trauma fiction, an approach that interprets her as a witness to the traumas suffered by her peopleboth Haitians and Haitian-Americans - and at the same time recognizes her merit in articulating narratives of memorialisation, resilience and hope [23]. One of the issues related to this frequent approach to Danticat is the fact that she is generally viewed by critics as the voice of Haiti, and her work as representing the entire culture, something that the author herself is very aware of and has commented on: "It is a burden that most writers who are from smaller groups face. There is a tendency to see our work as sociology or anthropology, an 'insight' into a complex culture. Readers have to remember that we're writing fiction, telling stories" ([24], p. 190). The burden Danticat acknowledges is also made manifest in criticism on the part of Haitians, who have not always reacted encouragingly to her works, especially when these do not project a positive image of Haiti and Haitians [25]. The only possible answer to the kind of accusations she occasionally faces - "That is not us. The things she writes, they are not us", or "You are a parasite and you exploit your culture for money and what passes for fame" ([26], pp. 32-33) - is to vindicate, once and again, her status as nothing more and nothing less than a storyteller, a fiction writer.

External views have a lot to do with the way Danticat sees herself as a Haitian American and as an immigrant artist, one who is full of self-doubt ([26], p. 19) as she struggles to keep "the dangerous balance between silence and art" ([26], p. 10). In both national and artistic affiliation, the author identifies as a "dyaspora", a Creole word whose multilayered meaning she has often struggled to explain [26], and which defines her as a member of an ambivalent in-between space:

My country, I felt, both as an immigrant and as an artist, was something that was then [in the 1990s] being called the tenth department. Haiti then had nine geographic departments and the tenth was the floating homeland, the ideological one, which joined all Haitians living outside of Haiti, in the dyaspora ([26], p. 49).

Such an affiliation emphasizes the complexities of belonging and not belonging, it proves the need to de-essentialize identity - both Haitian and Haitian American, in this case - and reminds us that being a person of the in-between, an inhabitant of a contact zone, is not always an easy thing. As a writer, the way for Danticat to respond to the risk of appropriating the experience of an "other"-Haitians who may feel they are not faithfully or properly represented in her fiction, fundamentally - is to assume that just as identity should never be claimed to be pure, through language, she is allowed to construct a reality that is not exactly Haitian but hybrid and métisse, a product of the contact zone, through what she calls "my self-created folkore, my fake-lore" ([26], p. 68).

Since, as argued by some of the trauma critics mentioned above, there are different, culturalspecific ways of representing trauma other than through the use of experimental (post)modernist textual strategies, and since there is ample agreement that the understanding of trauma should be expanded from the early narrow model of event trauma to incorporate examples of insidious or transhistorical trauma, the way a text like Claire of the Sea Light represents trauma deserves careful critical attention. In my analysis, I am taking one specific aspect of trauma which has not often been the focus of criticism, namely the grief caused by the losses derived from colonization, racism or gender violence. I am offering a look at the strategic representation of grief as a means to, on the one hand, denounce the continuing effects of colonial trauma on contemporary Haitians and, on the 
other, to vindicate agency, empowerment and resilience for colonized peoples in a way that complicates the risk of appropriation and exotization. I start from the assumption that, in Leeat Granek's words, “[t]he expression of grief is always mediated by one's social context and is always political" ([27], p. 61), and that, as Erika Lawson puts it, "grief is an epistemological site for interrogating the detrimental impacts of racial/social inequalities" ([28], p. 2104). The representation of grief is particularly relevant when we are dealing with a community where it has often been disenfranchised like the Haitian, with the Code Noir of 1685 that made it illegal for the slaves to practice their African religions openly and forced them to convert to Christianity ([29], p. 475). To a large degree, the issue here is to disrupt, through literary texts, the division of the world population into grievable and ungrievable lives that Judith Butler famously noted [30], by vindicating everyone's right to count as a subject. Moreover, quoting Granek again, "the recognition of everyone's grief and loss is the only solid foundation from which social change can begin" ([27], p. 67), which makes the representation of grief politically charged too.

Claire of the Sea Light exemplifies the relevance of analysing the representation of specific aspects of grief in the contact zone from a dyaspora liminal perspective. The text is constructed as a string of stories of grief, most of which can be traced back to the inheritance and persistence of colonialism in Haiti. In spite of its having been the first country to overthrow slavery as early as the 1790s, and establishing the first black republic in the world in 1804, as Andrew Flood argues Haitians have not been able to defeat the colonial system which has continued to punish them to this day, and which has resulted in centuries of invasion, the robbery of Haiti's natural resources, and the impoverishment of its people [31]. Reactions after the 2010 earthquake confirm established representations of Haiti as a dangerous place incapable of running its own affairs and requiring foreign intervention, which throughout its history justified the interference of Spain, Britain, France or the USA. In fact, the internationally accepted idea of Haiti today, Flood goes on to argue, is a nation "riddled with (poor, black) terror gangs waiting to pounce on naïve (white) visitors" that goes back to the anti-slavery insurrection. But the truth is that Haiti is the poorest country in the Americas, most of its population lives in abject poverty, and the Western response to this situation is to encourage the fear of the poor [31], a view that, far from being helpful, manages to sustain the interests of neo-colonialism.

Danticat's poor are not fearful. However, part of the author's strategy in this particular work, aimed at contradicting images like those mentioned above, is not to point an accusing finger at the forces responsible for Haiti's suffering, at least not directly [32]. Instead, she manages to involve the reader in the working out of the political implications of the personal, presenting as many points of view as possible and providing a panorama of contemporary Haitian society that is quite different from the dominant views on the country. All throughout the text, she remains faithful to her position as a dyaspora, a Haitian American in-between two worlds who is very aware of the risks of appropriating the experience of others, and will accordingly resist representing any final truth, resorting to the representation of liminal and complex meanings instead. For that purpose, she constructs a hybrid text that incorporates symbols and stories that originate in the Haitian tradition-like the view of the sea, Haitian beliefs and other cultural references - and also the western tradition - including references to The Waste Land, La Fontaine or the Brothers Grimm. 
The narrative is set in and around the fictional town of Ville Rose, considered by its inhabitants "a small and unlucky town" ([22], p. 14), where events like the public school collapsing and "killing 112 of the 216 pupils enrolled there" ([22], p. 15), are by no means uncommon. Ville Rose "was home to about eleven thousand people, five percent of them wealthy or comfortable. The rest were poor, some dirt-poor" ([22], p. 5). The difficulty to make progress can be blamed on "the town, its lack of opportunities, its rigid social hierarchies" ([22], p. 186), and the social determinism implied here points at global, powerful and unknown forces that the individual cannot really fight on his/her own.

The play between the personal and the political, the individual and the collective in Claire of the Sea Light is brilliantly articulated through literary form. The short story cycle-which, as opposed to either the novel or the short story, allows for its parts to be read independently, for each story stands on its own with some sense of closure, or sequentially, in such a way that meanings are added to the whole and the connection of the separate parts is emphasized-combines two apparently opposed but ultimately complementary forces: a centrifugal impulse towards isolation, loneliness, the individual and the focus on open wounds; and a centripetal movement towards healing, connection, the community and its chorus of voices. The former impulse is concerned with the denouncing of traumas and requires a more clearly political reading and involvement in the text, one that recognizes the agency behind these traumatic experiences and acknowledges its victims, while the latter entails a vindication of the colonized people's affirmation and self-empowerment in spite of their condition, it is centered on recognizing post-traumatic growth and resilience, and it contributes to the reversal of the negative images of Haitians that sustain neo-colonial interests today [33].

Although the short story cycle generic form is not necessarily connected to any specific identity [33], its cyclic structure, which emphasizes circularity and the aforementioned closure and openness recurrent impulses, does prove particularly useful to articulate the dyaspora condition in all its ambivalence. Interestingly, it can also be related to the cyclic, repetitive and circular - rather than linear and progressive-movement of water backwards and forwards which Kamau Braithwaite conceptualized as "tidalectics", often associated to Danticat's texts [34,35]. Tidalectics is a poetics of the sea "which is the ripple and the two tide movement", and that involves "the rejection of the notion of dialectic, which is three - the resolution in the third" ([36], p. 145). It embodies "the Haitian Weltanschauung of life's dualities" by "[r]efusing closure in determining paradigms and resisting spatial confinement" ([34], p. 86). Through the short story cycle structure and sea symbolism, Claire of the Sea Light responds to the two problems faced by Caribbean writers who put their island onto fiction: on the one hand, they have to tell the horrors and violations, past and present, suffered on that land; and on the other, they have to restore a balanced relationship to the landscape that differs from and resists colonial and neocolonial representations. This explains why the discourse on tropical islands is generally ambivalent, for it has to incorporate the idea of earthly Paradise and that of an alien and hostile land ([35], p. 1). Needless to say, this dilemma is made even more complicated by the drastic change of the landscape of Haiti after the 2010 earthquake, for Claire of the Sea Light is set right before that moment that changed everything. 
In the most common reading of the text, the sequential one that focuses on the whole and looks for connection and some resolution through an accumulation of meaning, we start the book with fisherman Nozias trying to give away his daughter Claire to fabric vendor Gaëlle, a member of the local accommodated class. Rather than a full member of a new family, this would make Claire a restavek - from the French "rester avec" - and possibly one of the abused domestic servants that abound in Haiti as a result of this extended system derived from extreme poverty. In spite of the pain this decision brings him, Nozias, who lost his wife to childbirth, is so poor that he is incapable of providing Claire - whose life is dramatically marked by the absence of her mother-with a decent life, and he sees this as the only way for the girl to have a future while he goes away "[p]ou chèche lavi, to look for a better life" ([22], p. 8). This is the only chance that, should he die at sea, she would not be left "completely parentless and end up in a brothel or on the streets" ([22], p. 17). Gaëlle Lavaud is also damaged herself: the day that she gave birth to her daughter Rose her husband was murdered, which made her think "that everyone should die" ([22], p. 144). This is why she accepts the offer of some friends to seek another type of justice and have Bernard Dorien, the suspected intellectual author of the crime, killed. But Gaëlle's own violent act does not bring her the relief she had expected; in fact, seven years later her daughter dies in a car accident—and the young man responsible for it ends up psychologically wounded too ([22], p. 156)—which, due to her guilty conscience, she interprets as "some terrible cosmic design engulfing everyone involved" ([22], p. 146). Gaëlle becomes, as defined by herself, "a shell, a zombie" ([22], p. 148). Her losses "had not made her stronger; they had made her weak. They had given others control and power over her" ([22], p. 159). She also suffers from survivor's guilt, as shown when she says, "Too many people die here, and why do the rest of us get to live?" ([22], p. 162). In an attempt to break with the chain of painful events that keep haunting her, Gaëlle decides to take Claire on the anniversary of her own daughter's death, but Claire will not accept this externally decided destiny willingly.

Bernard Dorien was not really guilty of Gaëlle's husband's murder. He was just a resigned inhabitant of Cité Pendue, which some people called "the region's first circle of hell” ([22], p. 63) because of all the violence and corruption that grow there, like the tumor of gangs, that "new urgent and deadly plague" ([22], p. 62). Bernard's death makes his parents disappear and never again be heard of, but we do hear about the impact, even 10 years later, of his absence on his special friend Max Ardin, Jr., secretly in love with Bernard and incapable of openly admitting his homosexuality. After ten years in Miami-he is one of the dyasporas who encounter "the difficulties of starting a new life in another land", whose humiliation is imprinted on their skin, showing in their eyes whenever they come back to visit ([22], p. 160)-Max, Jr. returns home and meets the son he fathered when he raped his house servant Flore Voltaire just to prove to his own father and to himself that he could be with a woman. Flore goes to Louise George's radio show Di Mwen, Tell Me, to talk about "one moment that changed [her] life. A moment that made everything that had come before it seem meaningless" ([22], p. 172), partly out of revenge, partly for fear that Max and his powerful father might take her son from her. Although the little boy's pain is not addressed directly, we do see a drawing he makes of his unknown father, with a blank $\mathrm{O}$ for a face that perfectly illustrates the hole left on the child by his father's absence, and which 
reminds us of the vevés, or Haitian ceremonial drawings based on outlined emblems that are meant to call forth the spirits ([26], p. 129). In the words of Max's friend Jessamine, who is described as "[t]oo damaged herself to be judgmental" ([22], p. 91), the worst possible case of unrequited love is "feeling abandoned by a parent" ([22], p. 99), a statement that rings true for several characters in this narrative.

A look at this entanglement of traumatic stories in a sequential reading of the text uncovers the complex relations of victims and perpetrators and of all the people affected by each event, and Danticat takes great pains to provide all the points of view of the people involved, incorporating, for instance, the rapist and his guilt; the raped woman and her burden; the son's loss; even the rapist's father considering the "horrible act" his son committed and feeling unable to forgive himself in turn ([22], p. 184). The author's attention to different characters' participation in the various acts of violence disrupts easy polarizations of victims and perpetrators, as it points at the complicated issue of complicity, one of the areas that still require more theoretical attention in postcolonial trauma studies ([1], pp. 258-59; [2], pp. 231-32). Additionally, she attends to the encounters, often tense but sometimes productive, of members of the higher and lower social classes: class divisions and differences of power are obvious in the separation between the schoolmaster Max, Sr., or Gaëlle, the fabric vendor, and the larger group of fishermen and the rest of poor villagers. However, in a sequential reading, the ending provides a hopeful resolution to the text, with Claire returning home after having escaped when she was about to be given away, and Max, Jr. being returned from the sea and welcome by the community, the poor and the rich attending to him together. In this reading, time becomes cyclic too, for although several cycle stories go back in time, the final one takes place on the night of the same day the narrative started. The elemental symbolism can also be read as reinforcing such resolution: the terrifying freak wave which, personified and monsterized as "a giant-blue-green tongue" ([22], p. 3), swallows a poor fisherman and his boat at the beginning of the text becomes the friendly hand of a spiritual presence-perhaps Claire's own mother-which rises from the sea and touches her shoulder ([22], p. 235), then a mother who bears a grown man back into the world of the living: "In the middle of the lamp circle, half of which was now in the water, she saw someone pull a man in a red shirt out of the sea. Like a dying fish, the man's body jerked about" ([22], p. 236). The images of a wasteland in the summer when all the frogs had disappeared, and the "cosmic design" of death it accompanied in "Starfish" ([22], pp. 123-43) are now replaced by images of reconciliation, community, and home. The text's very last words seem to suggest that amends can be made, one's fate can be accepted and grief may be overcome:

She had to go back and see her father and Madame Gaëlle, whose own sorrows could have nearly drowned them. She had to go down to the water to see them take turns breathing into this man, breathing him back to life. Before becoming Madame Gaëlle's daughter, she had to go home, just one last time ([22], p. 238).

Together with these implications, clearly privileged in a sequential reading, the author also strives to represent how the community is not monolithic or even consistent in its grief. In fact, the recognition of everyone's grief in the story responds to the author's wish to provide a diversity of 
perspectives on Haiti; as she has said on interview, "I want a multiplicity of stories to be told about Haiti; I think it is one of those places that is often portrayed in a very singular way and I certainly wouldn't want to participate in that. [...] Haiti is not a monolithic community" [37]. She does so by individualizing the experiences of the poor like Claire, Nozias, or Caleb; homosexuals like Max, Jr. and Bernard; lonely people like Gaëlle; the violated, like Flore; or dyasporas like Jessamine and others who live in the US and come back to visit. These characters are all members of the same community but in an independent reading of the cycle parts, the stories of grief of each individual character are brought to the fore, images of isolation and openendedness abound, the search for connection is often frustrated and healing does not seem to be so easy to achieve.

All the separate stories share a Haitian setting of liminality, for both Ville Rose and Cité Pendue, the village and the beach are contact zones full of conflict and tension, but each cycle story also has a title and some degree of structure, narrator, character, symbolism and theme. In the first cycle story, entitled "Claire of the Sea Light", Nozias is trying to give Claire away, and when Gaëlle finally agrees to take her, Claire escapes. The story is structured around images of life and death: it is Claire's birthday, which is also the day in which her mother, and years later, Gaëlle's daughter, died. Claire and Nozias' visits to the cemetery to visit the girl's dead mother are repeated year after year on this day in a tidalectic kind of flow: the same dress worn, the same ritual performed - and, to Claire's dismay, the same stories not told. Ironically, the town mayor is also the owner of the funeral home, the same person taking care of the villagers in life and of their bodies in death, the difference thus being deliberately blurred. Gaëlle decides to take Claire to replace death with a new life, for she says, "I need another way to remember this day" ([22], p. 32). In the final scene, Nozias and Gaëlle are in his cabin, waiting for the girl to appear, and for a brief moment they seem to approximate like the waves touching the beach where the cabin is located. If only they did, then Claire would not have to be given as a restavek; if only the two would come together, then a family would be created out of their grieving, isolating selves. But the high tide is always followed by a low tide, and vice versa, and the story flows again and closes on distance and silence: "[Gaëlle's] eyes were like two vacant pits, and in them he recognized a void that [Nozias] could easily identify but could never soothe, not even in himself. She was there but not really. At one moment, her mouth opened and closed but nothing came out" ([22], p. 40). Both Gaëlle and Nozias lack the language to put their memories into words, and finally he leaves.

"The Frogs" starts with a plague of exploding frogs full of biblical resonances and ends with the modern plague of gangs. In-between, images of the broken cycle of natural events abound: the terrible heat, wasteland imagery, a pregnant woman eating a dead frog and nibbling at new fabric, rivers swelling and swallowing houses "in response to the lack of trees, the land erosion, the dying topsoil" ([22], p. 52). In "Ghosts", Cité Pendue is a hellish place full of violence and loss, the poor have nowhere to hang on to, the differences between the gangs and the police are blurred, for they share the same methods, and the protagonist, Bernard Dorien, dreams of transcending boundaries through the radio station waves by bringing in the side of the gang members, the "chimè, chimeras, phantoms, or ghosts" ([22], p. 68). "Home", focused on Max, Jr. and his reflection on abandonment, guilt and homosexuality, is structured around racial, gender and class boundaries that are blurred in grief, shared by all: victim and executioners are equaled in death ([22], p. 89), 
whereas the schoolmaster and the mayor-undertaker, live "the same life", follow "the same emotional path" ([22], p. 87). Ville Rose is connected to Little Haiti, in Miami, by the dyasporas' movements to and from home, accompanied with their exile dislocation. Max, Jr.'s coming to terms with a ten-year-old crime, and the son that came out of it, is illustrated by his metaphorical road to hell, from Ville Rose to Cité Pendue, where the beauty of the landscape becomes "mountains of trash, tires, and thousands of plastic juice bottles and foam food containers" ([22], p. 112), and the sea turns from green-blue to brown to ashen black ([22], p. 107). However, after all, the story ends on a fragile image of home and return.

"Starfish" is structured around this animal's symbolic death and regeneration, a piece of the self breaking and then becoming something new. But the image becomes an external patriarchal imposition on Louise George, an isolated and lonely woman who is misunderstood by the community because of a strange feminine ailment and who is betrayed and humiliated by her powerful lover. In "Anniversary", a grieving woman reflects on the circle of violence she contributed to when she tried to take revenge on her husband's violent death. Gaëlle Lavaud's grief makes her lonely, but it also ties her to this town, where her ghosts are, and although in her mourning she searches for guidance - symbolized in the broken lighthouse she plans to fix - and for male companionship, mainly through the temporary union that sex involves. The story closes on distance: "He walked out. He left anyway" ([22], p. 165). "Di Mwen, Tell Me" is a short story cycle in itself: the first part centers on a poor woman's rape during a hailstorm, with "the echoes of swelling waves meeting in the seashore" ([22], p. 169), which contribute to characterize home as an uncertain and unsafe place: just like the ocean cannot be stopped, the ceiling does not provide isolation from the rain, the door does not provide protection from her rapist. Flore takes refuge in beauty, a symbol of resilience, and becomes empowered, if only temporarily, when she tells her story through the radio waves and her voice is heard all over the city and the surrounding towns. In the second part the rapist's father offers a reflection on guilt and forgiveness, with a series of references to the generational gap that separates parents and children. The third section recreates the final scene of Kate Chopin's The Awakening, with the rapist, Max, Jr., recounting all the flowers, insects and birds he can think of, in connection to his memories, as he slips into the water. In the last part, a connection between this young man and Nozias, who is looking for his daughter on the beach, is established and the communication with the ocean sounds and spirits brings Nozias to his own grief at having lost his wife and feeling compelled to give his daughter away. The last cycle story, "Claire de Lune", is focused on the young girl's coming to terms with her own grief at having lost her mother through a transcultural inheritance of stories, some originally from the Haitian tradition, some those of western origin she learned at school. Marked by her mother's absence, the story — and the full text — ends with a promise of community and rebirth.

As the short story cycle reading shows, while Claire of the Sea Light ends in an optimistic note with renewed relations in this Haitian community, the gaps and wounds that are also part of this community should not be obscured. It is true that, at the end of the full text, Claire is coming back home, but that home is undefined, the ending left open, and in any case, home is far from an ideal of comfort and security, for she is either going back to her destitute father or to a surrogate mother, and both are homes where grief seems to have settled. It is obvious that there are strong relations 
between the different stories and characters, but there are also silences, gaps, and frustrated attempts at connecting, at finding meaning in one's mourning, and a clear emphasis on separation and grief. In accordance to its short story cycle generic structure, we could argue that a sequential reading of the text, with its accumulation of meanings, guides us towards a view of community and a possible healing in the end. However, each independent story focuses on pain. Strategically, then, the emphasis on the trauma articulated in each particular story makes the wounds more visible and it helps avoid a totalizing, redemptive kind of narrative, which might become a form of traumatic denial and obscure the colonial responsibility behind it.

Together with the short story cycle structure and its tidalectic rhythm, which emphasize the tension between openness and closure, approach and distance that are typical of the definition of dyaspora identity, the politics of the contact zone is represented through female characterization and natural symbolism. The text is particularly concerned with uncovering the violence exerted on the bodies of women, who are doubly affected by the colonial inheritance, and it does so by emphasizing their liminal status. The rape of the maid shows how helpless poor women can be: Flore does not even consider filing a complaint against her rapist, for she knows that police officials are easily bought by powerful men and that justice is not usually obtained by a person in her situation ([22], pp. 174-75). She therefore raises her son in constant fear that the wealthy and influential Ardins may steal him from her. In the end, her fear makes her another exile, another unhappy victim of the dyaspora.

Another illustrative example of trauma in relation to the female body is that of Louise George, the hostess of the radio program Di Mwen, who suffers from a strange ailment - she has been coughing up blood during her periods since the age of thirteen - that many doctors and tests cannot explain. Marginalized because of the strangeness of her female body, Louise is a mystery to most people in town, where "all things unexplained were attributed to the spirit world" ([22], p. 123), and there are rumors about her being a cat eater, or an alcoholic ([22], p. 126). An isolated and liminal character, she not only finds it impossible to fit in the community, but she has also internalized the external definitions of her own self: "she was floating through her life, looking for some notion of who she was, and in those scowls and rumors she often caught a glimpse, even if a distorted one, of what that might be" ([22], p. 127). Her lover Max Ardin, Sr. tries hard to "describe [the taste of blood] to her in great detail as though his tongue were not inside her mouth" ([22], p. 136, original emphasis). In fact, he is trying to define her just like everybody else, only more closely, while she remains silent in her suffering:

It is salty [...]. It is sweet. He was convinced that the taste was based on her moods, and she would let him go on and on about it, expressing the same thoughts with different words. And she would daydream of other things as he spoke and she would daydream of how free she would feel without this affliction and she would marvel at how some things could destroy a person's life, like being housebound for a few days when you were bleeding out of your mouth and you had trouble remembering when you had not. And all of a sudden, the past was your haven and the time you felt 
freest was when you least understood your body, [...] when you were a little $\operatorname{girl}([22]$, p. 136).

When Max, who eventually stops being attracted to her strangeness - "the intrigue of her biblical affliction waning as she moved deeper into middle age" ([22], p. 136) — not only leaves her but publicly humiliates her, Louise's "dreadful feeling of loneliness" returns ([22], p. 143).

While their stories denounce the woman's subordinated role in a hierarchical and patriarchal society, Flore and Louise are also presented as producers of a view on grief, rather than mere objects of analysis or definition. In spite of her victim role as a raped woman who can obtain no justice, Flore speaks out, using the resources she has at hand-including those provided by Louise's radio show - and then goes away to avoid having her boy taken from her by the Ardins. Undoubtedly, Flore is a victim of a social dynamic that leaves a humble woman disempowered, but she is also represented as a symbol of resistance who does not exactly conform to social class expectations. Louise, in turn, although largely defined by others, becomes a committed storyteller, reading stories to the children at school and especially through her successful radio program, which also manages to give a voice to the previously unheard part of the population: the poor, the excluded, the disempowered. In spite of her isolation, Louise has found a way to express herself and also a chance to take revenge on Max, Sr. by bringing Flore to her show to denounce his son. Moreover, Louise looks for connection with other people like little Claire, an outcast like herself but probably one who might be able to understand her own traumas, suggesting a female community in solidarity:

The girl was so quiet that Louise worried that there might be some other frightful things about Claire that would link them. Had she, also like Louise, been born with absolutely nothing, from people who had absolutely nothing? Was she the surviving twin who had lost a sibling at her birth? Had she been born with a sixth finger on each hand, which had been forced to atrophy by having strings tied tightly around them? Did she have a spider-shaped birthmark on her belly? ([22], p. 127).

Both Flore's denounce and Louise's corporal response to the traumatic experiences she has internalized can be related to the manner in which nature responds to its own violation, also resisting being a passive recipient of external definition and control. The chain of useless violence described in the text does not escape nature, and in Cité Pendue, for example, Bernard's parents sell pigeons not for racing, to train as carriers or as pets for their small children as they used to do in the past, but for a violent ritual previous to the local young men's first sexual encounter:

They'd slit a squab's throat, then let it bleed into a mixture of Carnation condensed milk and a carbonated malt beverage called Malta. Sometimes their fathers would come with them and, after their sons had held their noses and forced down the drink, the fathers would laugh and say, as the pigeon's headless body gyrated on the ground, "I pity that girl", ([22], p. 65).

As the context changes, their main customers become gang members who come for the drink before going on a political demonstration encouraged by ambitious business owners as well as local 
politicians, who give them guns and use them whenever a crisis is needed ([22], p. 65). This ritual is one of the most obvious examples of violence-which is here associated to power and masculinity - in this contact zone.

Nature responds loudly to this and other examples of violation and corruption. Because of the overexploitation of the land and the excessive cutting of trees - which poor peasants cannot really afford to abandon, for economic forces beyond them do not allow them to find another way to make a living - devastating floods are more and more common, destroying houses and displacing people. The sea, acting as a character in itself, is not giving enough to fishermen like Nozias, either, burying them deeper and deeper in their poverty. In fact, the sea can simply make people disappear, as it did when a freak wave measuring between ten and twelve feet high-"a wall of water [that rose] from the depths of the ocean, a giant blue-green tongue, trying, it seemed, to lick a pink sky” ([22], p. 3) — sunk a fishing boat and swallowed poor fisherman Caleb, never to surrender him again.

All throughout the telling of their stories, the characters' bonds with the natural world are emphasized, especially through ritual and storytelling. The sea is the ultimate protagonist in this respect, and the ambivalence in its symbolism can be illustrated thus:

People like to say of the sea that lanmè pas kenbe kras, the sea does not hide dirt. It does not keep secrets. The sea was both hostile and docile, the ultimate trickster. It was as large as it was small, as long as you could claim a portion of it for yourself. You could scatter both ashes and flowers in it. You could take as much as you wanted from it. But it too could take back ([22], p. 199).

The sea brings death, as it is clear at the very beginning when fisherman Caleb disappears ([22], p. 3), but it can also bring new life, as seen in Nozia's wife Claire's moonlit swim when she is pregnant of Claire and chooses her name ([22], pp. 32-35). The sea offers the possibility of rebirth to Max, Jr., when he surrenders to it but the sea brings him back to life, hopefully renewed after having faced his secrets and fears ([22], pp. 197-99, 236-38). The sea's ambivalence is especially obvious in the case of little Claire. To her, the sea is a way to imagine being in her mother's body for the short time that he knew her, before she was born ([22], p. 215). But she is also afraid of the sea and its deadly threat, afraid that it will take her father, and because, when she imagines that the sea would disappear, she knows she would miss it too much, she sings a sad fisherman's song about loss as a ritual to prevent bad things from happening ([22], pp. 219-21). In the dialectic between grief and healing - the two opposite reactions to the Haitian landscape faced by writers like Danticat - the poetics of the sea incorporates the two but does not allow for a resolution in a third element. The two tide movement resists closure and confinement, and as Danticat has consistently articulated elsewhere in her fiction, the sea can bring people closer-like Haitians and Haitian Americans, who are located on two opposite shores of the same ocean - but it is often an insurmountable border; it involves the hope of communication and a new life for those who try to flee the island, but it is also a massive grave full of the dead bodies of those who did not succeed at escaping. 
The view of nature and its ambivalence symbolizes the latent forces in this society, and it becomes a warning about its power. Like nature, these people cannot be expected to just be quiet and submissive. Like the frogs who disappeared for no explainable reason and died out mysteriously, the people are also threatened. But like the sea, they cannot be tamed; they are unpredictable, changing, alive. This is part of Danticat's strategic representation of grief, and it is additionally supported by a series of traditional elements which are articulated in the narrative. Most instances of Haitian wisdom, myth and lore in the text are related to the natural and the supernatural realms, and they are kept alive through stories. There is one story to explain drizzle, or ghost rain, which is also a story of violence and pain: "The devil was beating his wife and marrying his daughter. [...] The drizzle was both the wife's and daughter's tears" ([22], p. 58). When Claire is born and her mother dies, she is immediately incorporated in a storytelling tradition by just pronouncing one word to greet her, revenan:

To most people, Claire Limyè Lanmè was a revenan, a child who had entered the world just as her mother was leaving it. And if these types of children are not closely watched, they can easily follow their mothers into the other world. The only way to save them is to immediately sever them from the place where they were born, even for a short while. Otherwise they will spend too much time chasing a shadow they can never reach ([22], p. 16).

As these examples make clear, many of the Haitian beliefs present in the text have to do with death, too common in this community. People are very aware that "the dead were never to have shoes. Shoes could weigh a person down in the afterlife" ([22], p. 206), and some are afraid that their dead might be "snatched from the cemetery and turned into zombies" ([22], p. 207). In addition, expectedly, there are a series of rituals related to the sea: The fishermen throw rock salt in the fire to make sparks, hoping to draw the lost fisherman's spirit out of the sea ([22], p. 28); "Some of the fishermen's wives would throw a pinch of crushed salt in the air for good luck, before their men left for the sea. (Some would also refuse to eat, or wash, or comb their hair until their men came back.)" ([22], p. 212). Danticat also incorporates a mythical figure with western and Haitian resonances, Lasirèn, the

long-haired, long-bodied brown goddess of the sea. With an angelic face like a bronzed Lady of Charity, Lasirèn was, it was believed, the last thing most fishermen saw before they died at sea, her arms the first thing they slipped into, even before their bodies hit the water. Like most fishermen he knew, Nozias, in his boat, next to his trap, net, hook, line, and tin can full of bait, kept a burlap sack in which he had a mirror, a comb, and conch shell, an amulet to attract Lasirèn's protection ([22], p. 34).

Another way in which the presence of Haitian stories and beliefs becomes a strategic response to (neo)colonialism is by contributing to the redefinition of community, and this is where Claire of the Sea Light's role becomes central in the narrative. Claire has always been searching for connection. Hungry for stories, especially those that could fill in the gaps left by her dead mother's absence, she has often resorted to traditional song to express her fears and yearnings, and when she escapes 
from home after having learned that her father is finally giving her away, she makes herself part of ritual by incorporating her experience into a song:

Yo $t$ ap chèche li...

They were looking for her

Like a pebble in a bowl of rice

They were looking for her

But no, no, no, she didn't want to be found ([22], p. 233).

While running to the top of Mòn Initil, from where she can see the village and the beach, Claire incorporates herself in the storytelling tradition of the community: she becomes complicit with the maroons who, as told in "Madame Louise's stories", had escaped slavery and hidden in this mountain ([22], pp. 126, 234). Like the maroons, whose presence is latent all throughout the text, Claire decides, she will survive by hiding in the mountain; she will come and visit her father during the night, and be an accompanying spirit, "the girl at the foot of the sky" ([22], p. 234). The phenomenon of maroonage, or the communities of fugitive slaves who often fled into the mountains and lived in small bands while eluding capture, was "crucial for the fight of Haiti's independence" [38]. As Ricky K. Green states, the Maroon communities "develop the potential for sovereignty" ([39], p. 27), as in the case of the Haitian revolution and the nation of Haiti, and "they stand as the first communities to institutionalize Black identity beyond the level of family" ([39], p. 27). Characterized by pluralism, they were organized around the experience of resistance, their strongest common bonds being self-determination and the importance of African spirituality ([39], p. 28). The reference, therefore, is by no means coincidental, for it points, once again, at the latency of rebellion in the text.

The presence of the maroons, however, and in accordance to the way Danticat represents the complexity of identity, is vindicative and oppositional but not simply so. Although she wishes she could "go away without really leaving, without losing everything, without dying" ([22], p. 235), up in the mountain Claire goes through a process of reconnection, then comes back home. When she looks back at the village from the lighthouse, she sees her neighbors: "These familiar people and the fires that made them visible to her, these points of light, now seemed like beacons calling her home" ([22], p. 232). She feels a spiritual presence-perhaps her own mother-coming from the sea, just as the sea pulls Max Jr., almost drowned, onto the beach. This is not the disappeared man the villagers were expecting the sea to return, but the view of her father, her adoptive mother-to-be, and the rest of the people in a circle, trying to breathe the man back to life, makes Claire reconsider her place in this community and come back. This final scene nicely stages the way that Danticat presents the town as the hero of her narrative, in her vindication of a communal system that she believes has sustained the country and which characterizes "a way of life that is sometimes not heard or talked about when people talk about Haiti" [37].

All in all, the fact that Claire finds inspiration in the oppositional, resisting identity of the maroons but finally chooses community — as shown in a sequential reading of text-demands a reflection on identity as a dynamic and complex combination of difference and relation which was also reflected in the analysis of the short story cycle structure. The maroon reference could be 
associated to what Édouard Glissant characterizes as the atavistic identity or a community of filiation, which is stable, oppositional, based on fixed places of origin and necessary for decolonial resistance; but it would live together with and be undermined by Glissant's idea of Relation, which rejects dialectical positions and searches for sites of connectivity through the dismantling of barriers of difference, and which is best exemplified by créolization [40]. In Glissant's words, "[w]e are not prompted solely by the defining of our identities but by their relation to everything possible as well - the mutual mutations generated by this interplay of relations" ([41], p. 89). Accordingly, identity cannot be seen as simply oppositional or purely relational, in an either/or way, for both impulses - identification and inter-subjectivity-are entangled in a complex relationship, and the recognition of this dynamic strategically contributes to resisting the view of Haiti as monolithic.

\section{Conclusions}

For Danticat - and this can of course be extrapolated to many other postcolonial authors - writing is an act of resistance that challenges the supposed unspeakability of trauma as well as extended stereotypical images of Haitians and their history, emphasizing that, as she states, "It is not our way to let our grief silence us" ([42], p. 188). On the contrary, grief may be precisely the impulse that makes her speak, and its representation strategically denounces the effects of the traumas of Haitians as it vindicates the particular ways in which a victimized but resilient community confronts them. In Claire of the Sea Light, Danticat denounces the poverty and the terrible conditions that much of the Haitian population has to live with, as well as the wounds inflected on the body, focusing especially on women, who are doubly marginalized in this strict patriarchal context, but also referring to homosexuals, "dyasporas", the poor. Neither the community nor its transcultural experiences of grief are monolithic but complex, changing, and depicted without falling into the spectacular or over-sentimental. In fact, although we know that poverty and the class division that characterize Haiti are largely the result of colonial and neocolonial exploitation of the island, the ultimate causes of peoples' traumas are left off scene in this text, which resists a polarized conception of victims and perpetrators. As we get a good view on grief in this community, we are also witness to inequality at its roots, with a part of society being privileged and therefore at least partly responsible for the sustaining of injustice and the poverty of the majority. However, while she denounces the persistence of class boundaries, Danticat also opens a window to solidarity, for at times, the rich and the poor do come together in their grief. Talking about her motivation when writing the text on a 2013 interview, Danticat explained that she placed the story in 2009, right before the 2010 earthquake, to "stick to something that was" [37], and as readers we are allowed to hope that the solidarity that makes a community has survived the earthquake, but we are also reminded that the situation of confrontation and inequality has worsened significantly after the tragedy [43].

In any case, divided and together, the Haitians in this short story cycle are certainly victims, but also agents who strive to define and speak for themselves, rather than have somebody else do the speaking and defining for them. They constantly affirm their own ways of representing and dealing with their grief, an act that becomes political insofar as it challenges a very long history of 
disenfranchised grief associated to colonization. Focusing our attention on such a strategic representation of grief allows us to appreciate how the text resists an appropriation of Haitian traumatic experience, for it cannot be easily framed in either the aporetic or the therapeutic trend of trauma theory. In contrast to the Caruthian model, trauma here is obviously not unspeakable but spoken, represented, symbolized, sung, played upon, struggled with, denounced. It is not merely psychic, either, for the individual recovery of characters is not privileged over social and political aims. Besides, the isolating or shattering effects of trauma described in the text are largely countered by the healing resources of the community, which is reinforced in renewed structures of solidarity. However, it should also be noted that in spite of this positive reading, healing is not always simple or even that clear: poverty, dislocation and discrimination persist, and the ending of the text is left quite open in this respect, which complicates our attempt to apply a therapeutic kind of reading too. As we see, the text's strategic ambivalence and its rejection of any single story or monolithic understanding show a resistance to erasure by denouncing grief, which is very real and urgent, but also a resistance to revictimization in a conventional trauma narrative. All in all, the difficulty to classify the characters and their stories as simply victims or perpetrators, heroes or failures, individualistic or communal; the ambivalence in symbol; or the play between opposition and relationality in the understanding of individual and communal identity all point at the attempt to escape easy classifications and the derived risk of critical appropriation. Needless to say, while we are in the process of reflecting on the articulation of a postcolonial trauma theory, we should not only try to expand the mainstream trauma paradigm to find texts that fit in it, but be particularly open to appreciate the texts that resist it.

Interestingly, a text like Claire of the Sea Light demands an interpretation in its own terms, and it resists critical appropriation by refusing to submit to any kind of monolithic story of Haitians, which is something that any theoretical background that we may want to apply to the text should consider along with the generalizations that necessarily have to be made while analysing. Although, by vindicating Haitian lives as grievable, Danticat is also putting them on the critical map of trauma, engaging in a dialogue with contemporary theories, and this will counter those lives' invisibility and silencing. We could say that just as Claire goes back to the community after symbolically associating herself to the maroons, moving in-between affiliative identity and relation, postcolonial texts like Claire of the Sea Light are also constructed on the tension between difference from and relation to contemporary literature and criticism in a global scale. As long as we never lose sight of unequal power relations, the interplay between affiliation and relation may thus contribute to illuminate the debates on the relationship between trauma theory and the postcolony in the development of a postcolonial trauma body of theories. All of these elements should be seen as participants in a contact zone where trauma and postcolonial theories, contexts and texts interact with local symbols and traditions, like the Haitian and Caribbean ones in this case.

The most positive impact of the emendations to the trauma critical paradigm detailed at the beginning of this article is without a doubt that trauma theory has been postcolonialized - challenged, debated, revised from a postcolonial way of looking at the world-which has made it better, and the most promising aspect of postcolonial trauma theory may be precisely that it is still in the process of being articulated. The pitfalls of applying a theoretical framework like trauma theory to 
postcolonial contexts, texts and experiences may never be completely overcome, and the relation between trauma theory and the postcolony will probably continue to be more tense and contentious than balanced or harmonious. Even if reaching a "truly" or "fully" decolonized trauma theory may not even be possible, postcolonial trauma theory seen as process, rather than conclusion-with all the constant self-questioning that this entails - will allow for the exploration of new encounters, new contact zones, places of dialogue, opposition, contradiction, and this will undoubtedly make it a fruitful epistemological tool.

\section{Acknowledgements}

The research carried out for the writing of this article is part of a project financed by the Spanish Ministry of Economy and Competitiveness (MINECO) (code FFI2012-32719) and the University of Zaragoza (JIUZ-2014-HUM-02). The author is also thankful for the support of the Government of Aragón and the European Social Fund (ESF) (code H05).

\section{Conflicts of Interest}

The author declares no conflict of interest.

\section{References and Notes}

1. Irene Visser. "Decolonizing Trauma Theory: Retrospect and Prospects." Humanities 4 (2015): 250-65.

2. Michael Rothberg. "Decolonizing Trauma Studies: A Response." Studies in the Novel 40 (2008): 224-34.

3. Irene Visser. "Trauma Theory: Global Aspirations and Local Emendations." In The Local and Global in Postcolonial Literature. Edited by Punyashree Panda. New Delhi: Authorspress, 2014, pp. 40-57.

4. Michela Borzaga. "Trauma in the Postcolony: Towards a New Theoretical Approach." In Trauma, Memory and Narrative in the Contemporary South African Novel. Edited by Edwald Mengel and Michela Borzaga. Amsterdam: Rodopi, 2012, pp. 65-91.

5. Cathy Caruth. "Trauma and Experience: Introduction." In Trauma: Explorations in Memory. Edited by Cathy Caruth. Baltimore: Johns Hopkins University Press, 1995, pp. 3-12.

6. Stef Craps. Postcolonial Witnessing: Trauma Out of Bounds. London: Palgrave Macmillan, 2012.

7. David van Nuys. "Post-Traumatic Stress Disorder: An Interview with Pat Bracken." Community Counseling Services Inc., 1 January 2010. Available online: http://www.communitycounselingservices.org/poc/view_doc.php?type=doc\&id=33858 (accessed on 1 July 2015).

8. Nancy van Styvendale. "The Trans/historicity of Trauma in Jeannette Armstrong's Slash and Sherman Alexie's Indian Killer." Studies in the Novel 40 (2008): 203-23. 
9. Merlinda Bobis. "Passion to Pasyon: Playing Militarism." In The Splintered Glass: Facets of Trauma in the Post-Colony and Beyond. Edited by Dolores Herrero and Sonia Baelo-Allué. Amsterdam: Rodopi, 2011, pp. ix-xxvi.

10. Laura S. Brown. "Not Outside the Range: One Feminist Perspective on Psychic Trauma." In Trauma: Explorations in Memory. Edited by Cathy Caruth. Baltimore: Johns Hopkins University Press, 1995, pp. 100-12.

11. Dolores Herrero, and Sonia Baelo-Allué. "Introduction." In The Splintered Glass: Facets of Trauma in the Post-Colony and Beyond. Edited by Dolores Herrero and Sonia Baelo-Allué. Amsterdam: Rodopi, 2011, pp. ix-xxvi.

12. Melvin Konner. "Trauma, Adaptation, and Resilience: A Cross-Cultural and Evolutionary Perspective." In Understanding Trauma: Integrating Biological, Clinical and Cultural Perspectives. Edited by Laurence J. Kirmayer, Robert Lemelson and Mark Barad. Cambridge: Cambridge University Press, 2007, pp. 300-38.

13. Irene Visser. "Trauma and Power in Postcolonial Literary Studies." In Contemporary Approaches in Literary Trauma Theory. Edited by Michelle Balaev. New York: Palgrave MacMillan, 2014, pp. 106-30.

14. Michelle Balaev. The Nature of Trauma in American Novels. Evanston: Northwestern University Press, 2012.

15. Roger Luckhurst. The Trauma Question. London: Routledge, 2008.

16. Irene Visser. "Trauma Theory and Postcolonial Literary Studies." Journal of Postcolonial Writing 47 (2011): 270-82.

17. Jenny Edkins. Trauma and the Memory of Politics. Cambridge: Cambridge University Press, 2003.

18. Jo Collins. "The Ethics and Aesthetics of Representing Trauma: The Textual Politics of Edwidge Danticat's The Dew Breaker." Journal of Postcolonial Writing 47 (2011): 5-17.

19. Irene Visser. "Entanglements of Trauma: Relationality and Toni Morrison's Home." Postcolonial Text 9 (2014): 1-21.

20. Wulf Kansteiner, and Harald Weilnböck. "Against the Concept of Cultural Trauma (or How I Learned to Love the Suffering of Others without the Help of Psychotherapy)." In $A$ Companion to Cultural Memory Studies. Edited by Astrid Erll and Ansgar Nünning. Berlin and New York: Walter de Gruyter, 2010, pp. 229-40.

21. Mary Louise Pratt. Imperial Eyes: Travel Writing and Transculturation. London: Routledge, 1992.

22. Edwidge Danticat. Claire of the Sea Light. New York: Alfred A. Knopf, 2013. Some of the ideas on my analysis of this text were part of a paper presented at the 38th AEDEAN Conference, Universidad de Alcalá de Henares, Alcalá de Henares, Spain, 12-14 November 2014. 
23. For an overview of the authors who have analysed Danticat's texts as trauma fiction, see Silvia Martínez-Falquina. "Postcolonial Trauma Theory and the Short Story Cycle: Edwidge Danticat's The Dew Breaker.” ES: Revista de Filología Inglesa 35 (2014): 171-92. This article and a previous one entitled "Memory, Diaspora and the Female Body in Little Haiti: Edwidge Danticat's 'Reading Lessons'." Revista de Estudios Norteamericanos 17 (2013): 93-111, also offer a critical engagement with trauma theory through the analysis of other works by Edwidge Danticat.

24. Bonnie Lyons. “An Interview with Edwidge Danticat." Contemporary Literature 44 (2003): 183-98.

25. The most obvious case in point is the controversy over the issue of virginity "testing" that she represented in Breath, Eyes, Memory. London: Abacus, 1994, and which she has commented on extensively. See for example "I am Not a Journalist" (Create Dangerously: The Immigrant Artist at Work. New York: Vintage: 2011, pp. 41-58), or her interview with Bonnie Lyons [24].

26. Edwidge Danticat. Create Dangerously: The Immigrant Artist at Work. New York: Vintage, 2011.

27. Leeat Granek. "Mourning Sickness: The Politicizations of Grief." Review of General Psychology 18 (2014): 61-68.

28. Erika Lawson. "Disenfranchised Grief and Social Inequality: Bereaved African Canadians and Oppositional Narratives about the Violent Death of Friends and Family Members." Ethnic and Racial Studies 37 (2014): 2092-109.

29. Leslie G. Desmangles. "The Maroon Republics and Religious Diversity in Colonial Haiti." Anthropos 85 (1990): 475-82.

30. Judith Butler. Frames of War: When Is Life Grievable? London: Verso, 2009.

31. Andrew Flood. "Haiti: A History of Intervention, Occupation, and Resistance." 2010. Available online: http://anarchism.pageabode.com/sites/anarchism.pageabode.com/files/ HaitiHistory.pdf (accessed on 1 July 2015). Flood offers a succinct account of the foreign intervention of Haiti throughout its history, which he sees as escalating after the 2010 earthquake. In his words, "[i]n the modern world, imperialism almost always wears a humanitarian mask", and the terrible consequences of the earthquake are part of the crises that, as studied by Naomi Klein in The Shock Doctrine (2008), capitalism often uses to impose restructuring on people that would otherwise resist. As a result, in recent years the people of Haiti have suffered greatly under occupation-imposed restructuring programs.

32. She does adopt a more directly combative stance in lectures and interviews, and in other works such as her memoir Brother, I'm Dying. New York: Vintage, 2008, about Danticat's father and uncle's lives and deaths, including her uncle's persecution in Haiti and his detention and tragic death in Krome detention center.

33. For a full definition of the short story cycle, a peculiar case of the simultaneity of closure and openness, both formally and in terms of meaning, and an analysis of its relevance to interpret the representation of trauma, see [23]. 
34. Brinda Mehta. "Diasporic Trauma, Memory, and Migration in Edwidge Danticat's The Dew Breaker." In Notions of Identity, Diaspora, and Gender in Caribbean Woman's Writing. New York: Palgrave, 2009, pp. 63-88.

35. Elvira Pulitano. "Landscape, Memory and Survival in the Fiction of Edwidge Danticat." Anthurium: A Caribbean Studies Journal 6 (2008): Article 5.

36. Paul Naylor. Poetic Investigations: Singing the Holes in History. Evanston: Nortwhestern University Press, 1999.

37. Edwidge Danticat. "Edwidge Danticat Reaches Back and Forward in her New Novel. An Interview with Jeffrey Brown." PBS Newshour, 17 September 2013. Available online: http://video.pbs.org/video/2365081056/ (accessed on 1 July 2015).

38. Kona Shen. "History of Haiti: 1492-1805." Available online: http://library.brown.edu/ haitihistory/index.html (accessed on 1 July 2015). In "Recovering the Fugitive History of Marronage in Saint Domingue, 1770-1791." The Journal of Caribbean History 46 (2012): 121-53, Jason Daniels tries to dismantle this generalized view by studying the decline of maroonage in the eve of the revolution, whereas Richard D.E. Burton offers an interesting deconstruction of the maroon myth in Le Roman marron: études sur la littérature martiniquaise contemporaine. Paris: L'Harmattan, 1997. In spite of these and other revisions of the maroon relevance, its romantic impact in the articulation of Haitian national identity is undeniable, as illustrated by the "Le Negre Marron" sculpture in front of the National Palace in Haiti's capital Port-au-Prince, which still stands while the Palace was destroyed by the earthquake. When interviewed, Danticat has openly stated "I'm maroonage", and this "situates her writing in the long history of black resistance and survival" Isabela Penier. "Engendering the National History of Haiti in Edwidge Danticat's Krik? Krak!" Anglica: An International Journal of English Studies 19 (2011): 123-31.

39. Ricky K. Green. Voices in Black Political Thought. New York: Peter Lang, 2005.

40. The echoes of Édouard Glissant in Danticat's fiction have been accounted for by Elvira Pulitano [35], and Carole Sweeney. "The Unmaking of the World: Haiti, History, and Writing in Edouard Glissant and Edwidge Danticat." Atlantic Studies 4 (2007): 51-66.

41. Édouard Glissant. Poetics of Relation. Translated by Betsy Wing. Ann Arbor: The University of Michigan Press, 1997.

42. Renee H. Shea. "A Family Story: Danticat Talks about her Newest and Most Personal Work." In Edwidge Danticat: A Reader's Guide. Edited by Martin Munro. Charlottesville: University of Virginia Press, 2010, pp. 187-93.

43. Sam Jones. "Aid, Cholera and Protest: Life in Haiti Five Years after the Earthquake." The Guardian, 12 January 2015. Available online: http://www.theguardian.com/ global-development/2015/jan/12/haiti-earthquake-five-years-on-village-solidarite (accessed on 1 July 2015). 


\section{Decolonization of Trauma and Memory Politics: Insights from Eastern Europe}

\section{Dovile Budryte}

Abstract: The movement to decolonize trauma theory conceptualizes traumas as rooted in particular contexts. Scholars working within this framework caution against the monumentalism of traumas as singular events and press for the acknowledgment of traumas experienced by minorities and liminal groups. In addition, this body of literature suggests a question of fundamental significance to memory politics: How to make sure that postcolonial attempts to memorialize the traumatic histories of colonialism do not become sources of state subjugation and oppression? Using examples from Eastern Europe, this article analyzes the complexity of memory landscapes in this region and the difficulty of acknowledging traumas of "non-Western" groups on their own terms. Drawing on works by three authors from the region (Ene Kõresaar, Svetlana Aleksievich and Jasmina Husanovic'), this essay identifies alternative ways of thinking about the nexus of trauma and difference by addressing how complexity and vulnerability can help to transcend competing victimhoods in Eastern Europe and elsewhere.

Reprinted from Humanities. Cite as: Budryte, D. Decolonization of Trauma and Memory Politics: Insights from Eastern Europe. Humanities 2016, 5, 7.

\section{Introduction}

Stef Craps argued persuasively for a reshaping of what he described as Western, event-based models to address traumas. In Postcolonial Witnessing, Craps went as far as to suggest that "the traumas of non-Western or minority groups must also be acknowledged on their own terms" ([1], p. 3). In the eyes of Craps and other authors advocating for the decolonization of trauma theory, such an approach requires the inclusion of the lived experiences of subordinate groups by paying attention to real human bodies, power politics and humiliations that can last a long time (for example, under colonization). Similarly, the contributors to this special journal issue engage with various experiences from the global South (e.g., the Philippines and Cambodia; [2,3]) and its neighborhood (e.g., the Australian aborigines [4]) to address the issues raised by Craps and to outline an alternative to what is considered to be Western trauma theory. These cases fit into postcolonial modes of analysis, with the identifiable hegemons and subalterns.

This essay aspires to contribute to the attempts to decolonize trauma theory in two ways. First, I propose that attempts to decolonize trauma theory should acknowledge multiple challenges associated with the proposed recognition of the traumas experienced by "non-Western" or minority groups on their own terms. These challenges include ethical and practical issues related to the existing global power structures, cultural norms, historical legacies and raise complicated questions, such as: "Who has the power to engage in politics of recognition?" and "What should be done with potentially problematic 'non-Western' narratives that can introduce new lines of division and competing victimhoods?" It is important to remember that there is a crucial distinction between 
surviving a trauma and receiving its memory or representation of memory. As Debarati Sanyal pointed out, "the overwhelming focus on victimhood in the reception of such [traumatic] memory can lead to appropriation of stories that are not our own and can even become alibis for the perpetration of violence" ([5], p. 8). I illustrate my point about challenges presented by potentially problematic "non-Western" narratives by discussing several cases of memory politics and memory entrepreneurship from Eastern Europe, mostly from the Baltic states - the region with which I feel most familiar.

Second, as implied by those who argue for decolonization of trauma theory I suggest that carefully listening to traumatic stories told by various groups, may allow us to search for connections between individuals and groups with different traumatic experiences. Highlighting the complexity of traumatic situations such as political violence, war or genocide, as well as understanding the common vulnerabilities of humanity can help us to transcend competing victimhoods and resist political exploitation of trauma. I support my proposal with insights from several authors who wrote about traumatic experiences and explored trauma narratives in Eastern Europe.

Why is Eastern Europe a suitable region for discussion? Also known as the "Other Europe", the former Soviet sphere of influence, or postcommunist Europe, this region experienced some of the worst political violence in human history during the previous century, including the Holocaust, the two World Wars, widespread repression of human rights, mass deportations, and ethnic cleansing. Parts of the region are still reeling from "low intensity" political violence today. As a result of these developments, there are still areas of this region where various groups compete for recognition of "their" trauma, "their" past and refuse to acknowledge the right of other groups' pasts to co-exist in the same memory space. As argued astutely by Alexander Etkind, in contrast to the Nazi terror, where the line between victims and perpetrators was clear, the Soviet terror during the Stalinist time targeted various ethnic and social groups. Often the lines between the victim and perpetrator were not clear, and the same person could be a perpetrator during one wave of terror, and the victim during the next ([6], p. 8).

This historical context provides many opportunities to test the main tenets of trauma theory (including the "eventness" and "monumentalism" of traumas) and think about the ways to decolonize it, in order to do justice to these various complex experiences. Perhaps most importantly, the cases from Eastern Europe may challenge us to think about the assumptions embedded in the use of the term "the West", especially now, when a large part of this region, including the former Soviet republics of Lithuania, Latvia and Estonia, have been part of the Western international institutions, including the European Union, for a while, and were able to affect the European mnemonic landscape by introducing different trauma narratives.

These observations and questions, however, do not negate the value of the main tenets of the movement to decolonize trauma theory - specifically, its call to pay attention to real bodies, power politics and everyday traumatic experiences. In particular, I believe that a call to focus on real bodies and everyday traumatic experiences instead of "monumental traumas" has the power to transcend the both real and imagined divisions between the "West" and "non-West" and similar entities. 
Paradoxically, the proposed foci on real bodies brings us back to some of the original insights of trauma theory as articulated by Cathy Caruth [7] and others - that experiences of traumas do not need to be divisive; they can become sources of compassion and radical relationality, transcending ethnic and cultural divisions. To make this point, the essay engages the works of Nobel Prize winner Svetlana Aleksievich [8] and political philosopher Jasmina Husanovic' [9,10]. I believe that the approaches to the study of trauma developed by these thinkers embody a search for the ways to belong to both the "West" and "non-West" at the same time. In addition, it seems that these authors have successfully challenged problematic and exclusionary national myths and ethno-nationalist identities based on traumas that probably should not be acknowledged "on their own terms". To give examples of problematic trauma stories and explain how they are related to postcolonial identities, I draw on a case of memory entrepreneurship studied by ethnologist Ene Kõresaar $[11,12]$.

In their works, these authors have presented different ways to think about war, a major traumatic experience. In Western discourses and imaginations, war is often depicted as a monumentally traumatic event, usually with a clear beginning (for example, 1 September 1939 for World War II) and a clear end (8 May 1945 for World War II). However, in parts of Eastern Europe, for example, the Baltic states, World War II and its aftermath are remembered very differently, as a long lasting trauma related to colonization with no clear beginning and no clear end. The approaches the three authors addressed in this essay help us to think about war as a traumatic experience in a "non-eventful" way, paying attention to "mundane" everyday details (Aleksievich), focusing on its aftermath (Husanovic') and linking it to colonization (Kõresaar).

Aleksievich wrote about the experiences of Soviet women veterans and the ways that they remember World War II (known as the "Great Patriotic War" in Russia and Belarus); Husanovic' explored the possibilities of safe spaces for mourning for women who have suffered from war in the Balkans, and Kõresaar analyzed the ways in which World War II is remembered by men in Estonia, some of whom fought for the Soviet Union, and others-for Nazi Germany. In addition, these three authors outlined different ways to think about individual traumatic experiences and political structures simultaneously, thus proposing new ways to decolonize trauma theory. Hopefully, looking for the intersections between individual traumatic experiences and political power structures in their works will help me to distill specific strategies to acknowledge traumas experienced by individuals belonging to different groups but at the same time remain cognizant of common humanity. By engaging with their work, I hope to move closer to the goal articulated by Craps in Postcolonial Witnessing: namely that trauma theory "need not be abandoned altogether but can and should be reshaped, resituated, and redirected so as to foster attunement to previously unheard suffering" ([1], p. 37).

Consequently, this essay is structured in the following way: First, by paying attention to various hierarchies and power constellations, I will identify the leading traumatic memory discourses and outline the contours of memory cultures in Eastern Europe. Second, I will briefly discuss a complicated relationship between the "Other" Europe and political discourses about (post)colonialism, analyzing how discourses about colonialism could and have been used in ethnic entrepreneurship and memory politics. While acknowledging fascinating insights about Eastern Europe from various perspectives that can be described as "postcolonial studies" (e.g., [13-17], 
etc.), I am particularly interested in exploring how political discourses about colonialism can help to claim ownership of historical traumas, and how this ownership can turn into potentially problematic narratives. Finally, drawing on the works of the three authors mentioned above, I will discuss what I believe are promising ways to think about the intersections between traumatic memories related to war and power structures in Eastern Europe and elsewhere, thus contributing to the movement to decolonize trauma theory.

\section{Dominant Memory Discourses and Memory Cultures in the "Other" Europe}

To make sense of memory cultures in Eastern Europe in 2004 (the year when the European Union, accepted ten new members from the region), Stefan Troebst developed four categories of societies. The first category was used to describe societies, such as the Baltic states, in which there has been a strong anticommunist feeling regarding recent history ([18], p. 58). This feeling could be detected by looking at legislation condemning the previous communist regime and the international actions of those state leaders who pushed for the inclusion of the remembrance of the Stalinist regime into the European mnemonic landscape. The second category was used to describe societies such as Ukraine or Poland with fierce memory battles over the recent past, with camps that included "anticommunist liberals" and "postcommunist socialists" ([18], p. 58). The third category was used to describe states such as Bulgaria or Albania where there was little willingness to address the recent past. Troebst put Belarus and Russia into the fourth category of societies that viewed communism in a mostly positive light, arguing that most people had positive memories about their experiences during that time ([18], p. 58).

Like many attempts to make generalizations about the region, Troebst's scheme does not capture those memory battles that took place within societies associated with each category. For example, Eva-Clarita Pettai's collection of case studies focusing on memory politics in the Baltic states has convincingly documented the pluralism of memories within these three states [19]. Without denying the existence of this pluralism of memories and counter-memories, it is still possible to identify several leading discourses about traumatic memories in Eastern Europe.

One of those discourses relates to nation-building myths rooted in traumas, often with the use of the term "genocide". As argued by Evgeny Finkel [20], after the disintegration of the Soviet Union, the use of the term "genocide" to describe the crimes of Communist regimes has been embraced not only by Lithuania (which is probably one of the internationally most well-known cases; see [21]), but also by other post-Soviet states. Similarly, many authors explored the ways in which memory of Holodomor (death by hunger) has become one of the founding myths of the post-Soviet Ukrainian state (e.g., [22-24] and others). This discourse has been subject to intense criticism by those who believe that it is used to engage in "comfortable victimhood", and even to obscure other major traumas, including the Holocaust (e.g., [24,25]).

Given the enormity of the Stalinist repressions (including deportations, widespread imprisonment and death by hunger), it is understandable that such enormous traumas are remembered and commemorated - not only in the geographical areas where they occurred, but also beyond. Instead of attempting to find commonalities with the traumas experienced by other groups, memory entrepreneurs (especially in multiethnic areas) often attempt to claim exclusive ownership 
of these traumas, an approach that can become a reason for concern and an example of how such traumas can become transformed into problematic narratives. Memory entrepreneurs tend to mobilize their energies to promote the version of the past that they strongly believe in, and they get engaged in various political and social activities to gain support for their cause. However, attempts to minimize the extent of these repressions and trivialize their memories can be equally, if not more, problematic.

There are some signs that traumatic memory regimes based on exclusive national traumas are being challenged. During the past decade, in many East European societies Holocaust commemorations became much more common and visible. Both international and local actors have been engaged in various memory projects such as exhibitions, ceremonies, films, plays, and marking of the sites of mass killings, to mention just a few. There are many attempts to localize the Holocaust memories by organizing impactful commemorations in the places where mass killings took place. An example of such impactful monuments is a road of candles in the forest where mass killings of Lithuania's Jews took place. In the words of one of my students at Vilnius University (where I taught a course on trauma and memory in Fall 2015), who made a distinction between "usual" and "unusual" monuments: "The one in Varnikai (a small town in Eastern Lithuania), near lake Skaistis, where about 1500 Jews were killed [is an unusual monument]. It's a long pathway through the forest which you enter through a wicket . . . an eerie flat pathway surrounded by trees, that's unusual but powerful ... candles put in the ground."

Arguably, this is a drastic change in remembrance practices, and it is happening not only in the states that such as Lithuania (which is a member of the European Union, and the Holocaust remembrance was encouraged by this international organization), but also in Ukraine, which is not a member of the European Union. This observation implies that the Holocaust memory is becoming a transnational memory in Eastern Europe. In the words of Volodymir Kulyk, "To be frank, because of the organizations of Ukrainian Jews, interested in memory work, activism demonstrated by the states of Israel and Western states who influenced the government of Ukraine and intellectuals, this narrative [of the Holocaust] has transcended ethnic boundaries and became part of Ukraine's popular history. This also has happened in the West, and during the recent years - also in post-Communist states" [26].

Kulyk's assessment of the degree to which the Holocaust became part of popular histories in Eastern Europe is probably a bit too optimistic. There are studies showing that a lot of work that still needs to be done in this area, especially pertaining to education regarding the Holocaust (e.g., see chapters on Poland, Lithuania, Latvia and Estonia in a recently published book on the Holocaust education in various countries [27]). There are anthropological and cultural studies suggesting that the Holocaust is still seen by many ethnic Lithuanians as a tragedy that has affected the "others" (e.g., see [28], p. 4). In addition, at least in the case of the Baltic states, many have trouble identifying with the narrative about World War II in which the victorious powers (including the Soviet Union) are portrayed as heroes, and the losers together with their allies - as villains. As explained by Sužiede lis and Liekis, the leading Holocaust scholars in Lithuania, even the usual dates for World War II (1939-1945) have little resonance in Lithuania, as most ethnic Lithuanians were killed in the war 's aftermath (1945-1953), during the irregular war known as pokaris ("post- 
war"). The "Grand Alliance narrative" in which the USSR is presented in a positive light, is not popular in the Baltic states, and this has led to political difficulties, including Lithuanian-Jewish and Lithuanian-Russian relations ([29], p. 325).

In the Baltic states, many still view the USSR's role in World War II and especially its aftermath (with mass deportations and executions) as disastrous for the fate of the Baltic ethnic Lithuanian, Latvian and Estonian communities. As noted earlier, narratives about World War II are often linked to the broader theme of colonization by the Soviet Union. At the same time, a narrative about the Great Patriotic war and heroism of the USSR is still very popular in Russia, and it is embraced by many Russians, especially those living in Latvia and Estonia. Such situations (when different groups embrace seemingly opposing narratives) makes it challenging for members of those groups to acknowledge their traumas publicly on their own terms. In the Baltic states, state-supported narratives presented in the museums, textbooks and similar spaces do not (and probably cannot) support the "Grand Alliance" or the Great Patriotic war narrative, telling a story about loss of sovereignty instead.

In addition, as pointed out by Alexander Etkind in his analysis of memory in post-Soviet Russia, there are other difficulties with commemorations in Eastern Europe, particularly in those areas which have been subject to severe Stalinism for a long time (such as Belarus and Ukraine) ([6], p. 24). In those areas, various groups cultivate their own militant memories about the past, and thus engage in politicized memory wars. Memories about the Stalinist terror and World War II can become especially salient when memory entrepreneurs who embrace opposing "truths" start fighting for broader recognition of "their" particular traumas and "their" particular histories. Polarizing discourses, including the language about colonialism and oppressive colonial practices, can be used as a weapon in such memory wars and even nation-building projects. Aggressive actions by the former colonial power and its inability to engage in "responsibility in complicity" by acknowledging the crimes of the past related to the colonial legacies (Debarati Sanyal's term, [5], p. 14) can only empower such discourses.

\section{The "Other" Europe and Discourses about (Post) Colonialism}

In the field of postcolonial studies, colonialism is usually associated with shameful actions of the Western powers (also known as the global North), such as extraction of resources, exploitation of populations that are seen as "lesser" than the colonizers, subjugation of the system of education to the norms of the colonizers, etc., in the places now known as the global South. Postcolonial scholars tend to embrace theories and perspectives stemming from Marxism and its focus on "the haves" and "the have-nots". However, many scholars and practitioners in Eastern Europe find the focus of postcolonial perspectives on the issues of inequality distasteful, preferring to support liberal theories extolling capitalism and individual liberties instead. In addition, many such scholars and practitioners see themselves as belonging to Europe and, in the words of Violeta Kelertas, "find being lumped together with the rest of colonized humanity unflattering" ([30], p. 4).

Although Kelertas' insight about the unwillingness to be considered part of the "underdeveloped world" was meant to capture the relationship between the Balts (Latvians, Lithuanians and Estonians) and their pasts, evidence from other parts of Eastern Europe suggest that the attitudes 
toward the label of postcolonialism may be similar there as well (see, for example, a description of the ways in which the Polish elites have misused this term presented by Claudia SnochowskaGonzalez [31]). Belonging to Europe and, by extension to the West, has been considered to be a much more desirable circumstance than belonging to the "Third World", or the "developing world“. Furthermore, belonging to Europe (and thus to the West) implies a certain level of superiority vis-à-vis Russia, which is seen as a former non-Western, non-European colonizing power from the East. As David Chioni Moore pointed out, postcolonial identities of Central and Eastern Europeans are intertwined with a desire to "return to Western-ness that once was theirs" and thus escape from Russia's "colonial grasp". His observation applies to the Baltic states as well [32].

Academics and politicians in Eastern Europe have used and still use discourses about colonialism to address the Soviet past. For example, after an examination of the main historical developments in the Baltic states during the 20th century, Epp Annus concluded that "colonization" may be an appropriate term to describe the Soviet rule starting with the 1950s (until 1991 when the Baltic states regained their independence from the Soviet Union). During this time, after a long period of resistance, the local populations started to cooperate with the Soviet authorities. She suggested using the term "occupation" to describe the turbulent years of 1941 and 1944-1953 when the Baltic states were occupied by the Soviet Union and experienced mass deportations and other forms of repression ([33], p. 36). There were many criteria to select people to be deported, and "the enemy of the Soviet state" was one of them. Many innocent people were subject to this form of repression. Annus described the Soviet colonialism of this period as including "a diverse spectrum of models of repression and subordination, dependent on the prehistories of separate regions" ([33], p. 26).

In contrast, the term "colonialism" is used differently in politics. For example, in Estonia and Latvia, the terms "colonialism" and "colonists" were widely used in political discourse during the late 1980s and early 1990s when decisions about who would be part of an independent nation and who will not had yet to be made. Traumatic memories about the Stalinist deportations by the Soviet Union that affected many Estonians and Latvians became part of public debates. These Stalinist deportations from Estonia and Latvia to Siberia and immigration of Russian-speakers from other parts of the Soviet Union to Estonia and Latvia were described as unlawful practices by an occupying power, the colonizer. "Decolonization" implied that the creation of an ethnic democracy where the restoration of citizenship only to those who lived in Latvia and Estonia prior to the occupation by the Soviet Union and their descendants (mostly ethnic Balts) was portrayed as legitimate ([34], p. 70). Due to the pressure from the European Union and other international organizations, the two Baltic states made their citizenship laws more inclusive and consistent with the relevant international norms; however, the use of discourse about traumas associated with colonialism was a powerful tool in the hands of ethnic entrepreneurs in the beginning stages of democratization, deepening the lines of ethnic divisions.

This comparison of the ways in which the term "colonialism" was used in different contexts and different settings suggests that this phrase can be integrated into trauma vocabulary and thus incorporated into politics. In such cases, there is a movement away from real lived experiences, real 
bodies, and real people. Then there is a danger that problematic collective trauma narratives can be constructed - especially if politicians using trauma vocabularies act as "mnemonic warriors", not "mnemonic pluralists", believing that they are the only ones who possess the historical truth and know what aspects of this truth need to be retained in collective memory ([35], p. 13). Consequently, it becomes important to study "memory entrepreneurs" who, in the words of Elizabeth Jelin, "seek social recognition and political legitimacy of one (their own) interpretation or narrative of the past. We will also find them engaged and concerned with maintaining and promoting active and visible social and political attention on their enterprise" ([36], pp. 33-34). Ene Kõresaar 's work analyzes the life and work of one such memory entrepreneur.

\section{Deconstructing the Dominant Discourses, Engaging Trauma Theory: Three Perspectives}

In a collection of narratives Soldiers of Memory: World War II and Its Aftermath in Estonian Post-Soviet Life Stories, Ene Kõresaar wrote about the life and narrative of Estonian Boris Takk, who in 1943 was mobilized by the Germans to join the Waffen SS (a German military unit) when he was still a teenager. In 1944 he decided to stay in Estonia (instead of retreating with the German military). This meant a life under the Soviet rule until 1991. In the early 1970s Takk joined the Communist Party of Estonia. In his narrative recorded by Kõresaar, he argued that "he wanted to serve the Estonian cause from inside the system" ([12], p. 347, italics original). Similar phrases were used by many former Communist party members in the Baltic states after the disintegration of the Soviet Union who wanted to show their commitment to the cause of nationalism and convince others that they were not true believers in communism.

After Takk joined the Communist Party, his story gets even more interesting. In the late 1980s and early 1990s, when Estonia regained its independence from the Soviet Union, he started to organize gatherings of Estonian veterans of the German military, arguing that theirs and his decision to join the Waffen SS was a "continuous fight for Estonia's freedom", against the Communists ([12], p. 348), italics original). Takk became active politically as a memory entrepreneur, interested in disseminating and fighting for his version of historical "truth". To a degree, he succeeded as his story was heard in Estonia, and he was able to attract followers amongst some Estonians.

The core of Takk's story was a metaphor of "a prolonged rupture" (referring to the long period of the Soviet rule from 1940-1941 and then again from 1944 until 1991), referring to the break in the Estonian national sovereignty caused by the Soviet occupation. In the words of Ene Korresaar, "the life story of Boris Takk . . represents the dominant view of history that evaluates the entire history of Estonia in the 20th century from a postcolonial perspective" ([12], p. 344). According to this perspective, a story about World War II is framed as colonization by Nazi Germany, and the life before and after World War II is also described as survival under another colonizer, the Soviet Union. Perhaps such perceptions of history make "responsibility in complicity" [5], which implies reflexivity and awareness of the past crimes as well as the acceptance of collective guilt, next to impossible. The crimes committed by the locals who collaborated with the occupying powers could be attributed to someone else, that is, the colonizing powers, not the individuals who have committed those crimes. 
Like all entrepreneurs of memory, Takk had a strong explicit ideological message, arguing that the Estonians could not lead a "normal" life under the Soviet rule without their own nation-state. Takk's World War II story was not about glory and victories. It was also about excessive drinking, abusing the civilian population, uneasy encounters with pro-Soviet partisans, and sometimes strained relationship with the Germans whom many Estonians (even the ones serving in Waffen SS) saw as colonizers. Interestingly, Takk's story was the only one in this collection of eight narratives (edited by Ene Kõresaar) that mentioned the Holocaust. According to Kõresaar, Takk spoke openly about the Holocaust even before this sensitive topic was openly discussed in public sphere. Takk mentioned the "disappearance" of the Jews and described a concentration camp in Klooga as a "dismal site" ([37], p. 193). There was virtually no discussion of the killing of the Jews during the Holocaust during the Soviet times. The term "katastrofa" was used to refer an immense suffering of the "Soviet people", without referring to separate ethnic groups. The Baltic émigrès in the West avoided this topic as well. Therefore, Takk's willingness to write and talk about the Holocaust in 1993 (a relatively early stage in democratization) can be described as rather unusual.

Takk's story is definitely different from the Western discourses about World War II; therefore, it can be described as "non-Western" or "postcolonial", due to its description of World War II and the Soviet times as colonization. However, what would it mean to acknowledge it on its "own terms"? This story, especially the metaphor of "prolonged rupture" became quite popular in postSoviet Estonia in the 1990s. However, Takk's memory politics did not achieve a full international or even national recognition. In the nineties, when Estonia was trying to get into the European Union (which was often compared with the re-entry into the West), it became clear that anything related to the glorification of Waffen SS (including a monument depicting an Estonian soldier equipped with an automatic rifle and wearing a German uniform) would not be tolerated by the European Union and many Western-minded Estonian politicians. However, how should the students of memory politics interested in a decolonization of trauma theory handle such "politically incorrect" stories that attract popular imagination but simply do not sound "right"? Simply pretend that they do not exist? Silence them? Condemn them?

First, it may be useful to acknowledge the complexity of the situation. According to Kõresaar, not only the politics of remembrance, but an "autobiographical memory work of those who fought in World War II also takes place on this field of tensions" ([11], p. 10). These tensions stem from various international, national and domestic sources, including geopolitical factors, international norms and memory wars. Second, it is necessary to keep in mind that story-tellers have their own interests and agendas. When performing an interview with Boris Takk, Korresaar recorded (in an endnote) her own feelings, suggesting that Takk may have been "using me as a 'microphone' and addressing the 'Western countries' directly" ([12], p. 358). Third, it is important to recognize other stories about similar traumatic experiences, including counter-memories. As noted earlier, Takk's story was only one out of eight stories about the war experiences of Estonian men, and two out of eight stories are by men who joined the Red Army. Kõresaar decided to include both the original stories and scholarly interpretations of those stories, written by academics (separately from the autobiographical narratives), arguing that "through this prism and approach, we have tried to provide a view into the complexity of commemorating World War II at the end of the 20th century 
and the initial decades of the 21 st century" ([11], p. 2). Biographies were selected to reflect various trajectories of the lives lived by the Estonian men, many of whom ended up fighting their own countrymen as they were mobilized by militaries and governments that fought each other. For example, the photograph from an Estonian family archive on the book cover shows two men standing next to each other and staring into camera, with one wearing a Soviet military uniform, and the other, whose shoulder is touching his companion, wearing a German uniform.

Thinking about similar unruly stories can help those interested in decolonizing trauma theory to ask important questions, such as: "Which lives, and which stories are included into the dominant discourses?" and "Which stories get silenced and why?" As Tiina A. Kirss, one of the contributors to Kõresaar 's volume, has observed, the Estonian case of commemorating World War II helps us to think about the hierarchies that are embedded in memory regimes [38]. In the case of the Estonian memory regime that developed after 1991, the highest "honors" were awarded to men who fought with weapons against the Soviet military during World War II and immediately after it. Those who were deported to Siberia were respected as well; so did those who deserted the Soviet military and fled to the West. In contrast, Kirss argues that those men who remained with the Red Army were "in the lowest position" ([38], p. 379). Finally, it appears that women who participated both in this World War II and its aftermath may have been invisible in this particular memory regime.

In her famous book War's Unwomanly Face, Svetlana Aleksievich put forward a compelling narrative, which serves as an alternative to masculine memory regimes. Acknowledging the ongoing appeal of the Great Patriotic war narrative in Russia and Belarus ("we were the children of the victory" ([8], p. 7); "yes, they had Gulag, but also they had Victory" ([8], p. 16), she set out to write a story "not about war, but about a human being in war". Unapologetically, she made her political agenda clear: "Human beings should be larger, greater than war" ([8], p. 7). Aleksievich decided to depict war as experienced by women, which should have "its own colors, its own smells, its own space and its own words" ([8], p. 8). In presenting this perspective, Aleksievich did not hide her frustration that many women, even the ones who fought in the war, were eager to talk about someone else's war and argued that it was time for women to write their own history about war, choosing their own words and using their own feelings.

Similar to Aleksievich's approach to war was feminist scholar Christine Sylvester whose approach, named "touching war", holds that an effective study of war must include the study of the ways in which individuals "touch war and are touched by it in physical, emotional and intellectual ways" ([39], p. 3). Sylvester, Aleksievich and other feminist writers who are not afraid to "touch war", by transcending the narrow focus on military strategy, weaponry, and battlefield tactics that is still embraced by many scholars studying war and related memories. "Touching war" focuses on concrete bodily experiences and therefore makes gender central to the study of war.

Aleksievich was not interested in writing a history of war. Instead, her goal was to write "a history of feelings"; a history of "a small (ordinary) human being" who became subject to the forces of history ([8], p. 13). Yet through listening to the stories and trying to capture "mundane" details about everyday war experiences, Aleksievich wants to also capture "the eternal human being" ([8], p. 13); the essence of humanity. She gives memorable examples of how simple human 
acts of kindness were able to transcend even the front lines, such as how a woman who fought for the Soviet Union extended a piece of warm bread to a suffering German prisoner, and how Soviet nurses decided not to tear off bloody bandages from the German soldiers who served in the hated SS forces ("Protection Squadron").

Her book is full of moving stories about the experiences of women who were active combatants. Aleksievich gives them voice, lets them act; her story tellers are not "merely witnesses; least of all they are witnesses; they are actors and creators" ([8], p. 13). In this way, she helps to "decolonize" traumas by empowering those women who are sharing stories with her. Even their unwillingness to talk, to remember becomes a story narrated by Aleksievich. For example, Aleksievich writes about a woman who wanted to choose silence, asserting her right to silence: "I do not want to remember. Those three years of war . . During these three years, I was not a woman. My body was dead. I did not have menstruations; I did not have female desires. And I was beautiful ... " ([8], p. 11).

One of the findings of Christine Sylvester and others who embraced the same methodology was that there is not one "female" war experience based on victimhood and/or peacemaking. Yet the portrayal of women as "naturally linked to peace" is essential for gender stereotypes and war mythology. As argued by Megan Mackenzie, to challenge these stereotypes it is essential to bring in the individual experiences of female warriors to gain a better understanding of a war 's rules ("what is seen to be predictable and standard behavior" during a war) and to "complicate war myths, particularly the warrior/victim myth" ([40], p. 65). Similar conclusions can be made after reading Alexievich's stories about women in war. She writes about women who could not wait to get to the frontlines and fight; women who grew up during war; women who lost their sensitivity to watching and even committing murder, having seen the ashes of their burnt countrymen. She wrote how she was reprimanded by Soviet censors for focusing on "little things" instead of victory in war. However, those "little things" are essential for her story. Alexievich gets in trouble with a Soviet censor who asks her: "Why this biology? You are diminishing women by using this primitive naturalism. Women, who were heroes. . . They become ordinary women. We (the Soviet regime) treat them as saints" ([8], p. 17).

This scene raises important questions about the relationship between feminist writers and the state. One of the main functions of a state is to protect its citizens from various threats, real and imagined. If needed, war is waged. The sad truth, pointed out by feminist writers about war, is that women and children as well as other vulnerable groups are most likely to suffer during wars. How can they find safe spaces to tell stories about war that are similar to the one written by Aleksievich, in which war emerges as a horrid experience?

In the eyes of Jasmina Husanovic', a feminist philosopher and activist from Tuzla in Bosnia, such spaces exist separately from the state institutions. Husanovic' argues that it is necessary to pay close attention to power structures that commodify trauma and find ways to transcend them. She starts out by articulating a set of questions inspired by feminist thinking: "What is her voice, where is her space, how is her politics?" and maps out a series of "feminist theoretical and political interventions" that include art ([9], pp. 100-1).

Dwelling on the ways to deal with traumas in societies that have experienced political violence (such as Bosnia), Husanovic' articulates a stinging critique of liberal attempts to handle traumatic 
memory with "white gloves" and nationalist attempts to own memory [10]. When writing about liberals trying to handle memory with "white gloves", she is referring to the attempts by the international community to apply instruments of "transitional justice". Such instruments can include trials of perpetrators, truth commissions, and reparations for the victims. Unfortunately, often, as described by Etkind, the lines between the perpetrators and victims are unclear, and transitional justice becomes an illusion [6]. Likewise, the attempts of politicians to claim their exclusive rights to certain pasts (and to use these pasts to pursue their own political goals) can be equally detrimental.

Husanovic' outlines a third way to deal with traumatic memories. She believes that it is important to search for openings in civil society, which include spaces free from state intervention where art can help societies to deal with trauma. Similarly to Alexievich, Husanovic' pleads for attention to be paid to real women's bodies, so as to create spaces for radical relationality. This is a type of feminist politics, a "politics of witnessing and hope" ([9], p. 103). The goal of this type of politics is to restore dignity to the bodies that have been "defaced, erased and/or violently made non-relevant in the operative biopolitical regimes" ([9], p. 103). By making these bodies visible, and by providing resources to those at the very bottom who struggle for justice and survival, such politics can be transformative.

In her works, Husanovic' emerges as a scholarly activist, as a writer who embraces action research, working together with civil society activists in searching for ways to undermine the power structures that commodify trauma and impose polarizing stories about traumatic experiences. Husanovic's story suggests another dimension that scholars interested in the study of trauma could reflect on; her argument is that someone who writes about trauma needs to be an activist as well, to not be afraid to commit to social and political change. If taken seriously, this argument has serious methodological and philosophical implications.

\section{Conclusions}

In this essay, I attempted to challenge the proposition by Craps to accept "non-Western" traumas on their own terms and warn against an unquestioning acceptance of postcolonial trauma narratives, even if they are produced by the groups who describe themselves or have to live with a prescribed identity of being "non-Western". I also argued that it may be useful to go beyond the "West" and "non-West" dichotomy, looking for the ways to transcend ethnic and national boundaries by working with trauma narratives. The proposition to focus on real bodies and lived human experiences articulated by the movement to decolonize trauma theory suggests one way to resist the attempts to own trauma and memory by various groups.

Engaging works by three authors from the "Other" Europe helped me to support my argument with examples. Boris Takk's story, as told by Ene Kõresaar, can be read as a story about a mnemonic warrior, interested in promoting his version of the past and shaping collective memory in a certain way. Politically motivated stories told by mnemonic warriors and their use of traumatic past may be examples of potentially problematic postcolonial narratives. Svetlana Aleksievich's War's Unwomanly Face, a story about World War II based on the lived experiences of former Soviet women fighters, and Jasmina Husanovic's account about "politics of witnessing and hope" 
and her own political activism are examples of the ways in which engaging trauma narratives can help to transcend the boundaries imposed by specific political groups. My choice of the "Other" Europe was not accidental; there is no shortage of historical trauma and memory politics in this region. Furthermore, the questions raised by the movement to decolonize trauma theory, especially about the ways to avoid new sources of pain and subjugation when trying to address the traumas of the past, are of critical importance in this context.

My analysis of these three articles addressing the commodification of trauma suggest several additional conclusions. First, there are multiple variables affecting the construction and, perhaps most importantly, the reception of postcolonial trauma stories. They include power structures, broader political contexts and existing local and international norms. Not all postcolonial stories get heard, especially internationally. It is important to identify those power structures that make some stories heard (and conversely keep other stories hidden) and ask questions that sometimes may be uncomfortable about the reasons why some stories get heard and some do not.

Second, the evidence from Eastern Europe suggests that "decolonization" of trauma theory does indeed imply a disaggregation of monumental traumas. This approach is especially visible in Kõresaar 's and Aleksievich's works. Kõresaar shows how war "touched" individual lives and became part of complicated and even problematic life stories. Aleksievich deconstructs the myth about victory in the "Great Patriotic War" by zooming in on details experienced by women during war. Paying attention to everyday politics, everyday history is a way to "disaggregate" traumas and thus show respect for their complexity. Disaggregation of monumental traumas and challenges to political myths that are likely to accompany such moves do not necessarily have to be classified or described as "non-Western" or "anti-Western". Perhaps moves such as the one successfully completed by Aleksievich can be best characterized as attempts to search for commonalities between different traumatic experiences on the micro (individual, family, or community) level.

Third, Jasmina Husanovic's story raises intriguing questions about the knowledge of widespread trauma (including everyday trauma resulting from discrimination and injustice that those who argue for decolonization of trauma theory emphasize), writing about the trauma and getting engaged in political actions to address the trauma. Husanovic' is actively engaged in creating safe transcultural spaces for empowering activities for people who have experienced trauma to take place. In fact, it is possible to argue that activism is what (at least partially) makes Husanovic's story so powerful and appealing; she is not afraid to become part of the story that she is writing about; she is not afraid to show her empathy for the bodies whom she is describing. As an openly feminist writer and activist, she goes beyond recording and acknowledging the suffering of "others". Their pain becomes her pain. For such writers and scholars, an "attunement to previously unheard suffering" ([1], p. 37) comes with a personal commitment to political and social change.

Acknowledgments: I would like to thank the faculty, administration and staff of Georgia Gwinnett College for their generous support during my academic leave in Fall 2015 when this essay was written. I would also like to thank Michael Lewkowicz, Ian Peddie, Violeta Davoliū tè, Dalia 
Cidzikaite, the anonymous reviewers and the academic editor of this issue for their useful comments and suggestions on the previous drafts of this essay.

Conflicts of Interest: The author declares no conflict of interest.

\section{References}

1. Stef Craps. Postcolonial Witnessing: Trauma Out of Bounds. Basingstoke: Palgrave Macmillan, 2012.

2. Jocelyn Martin. "Manilaner 's Holocaust Meets Manileŭos' Colonization: Cross-Traumatic Affiliations and Post-Colonial Considerations in Trauma Studies." Humanities 4 (forthcoming).

3. Beatriz Pérez Zapata. "Decolonizing Trauma: A Study of Multidirectional Memory in Zadie Smith's 'The Embassy of Cambodia'." Humanities 4 (2015): 523-34.

4. Justine Seran. "Australia Aboriginal Memoirs and Memory: A Stolen Generation Trauma Narrative." Humanities 4 (2015): 661-75.

5. Debarati Sanyal. Memory and Complicity: Migrations of Holocaust Remembrance. New York: Fordham University Press, 2015.

6. Alexander Etkind. Warped Mourning: Stories of the Undead in the Land of the Unburied. Stanford: Stanford University Press, 2013.

7. Cathy Caruth. Unclaimed Experience: Trauma, Narrative, and History. Baltimore: Johns Hopkins University Press, 1996.

8. Svetlana Alexievitch. U Voiny-Ne Zhenskoie Litso (The Unwomanly Face of War). Moscow: Palmira, 2004.

9. Jasmina Husanovic'. "The Politics of Gender, Witnessing, Postcoloniality and Trauma: Bosnian Feminist Trajectories." Feminist Theory 10 (2009): 99-119.

10. Jasmina Husanovic'. "Economies of Affect and Traumatic Knowledge: Lessons on Violence, Witnessing and Resistance in Bosnia and Hercegovina.” Etniškumo Studijos/Ethnicity Studies 2 (in print).

11. Ene Kõresaar. "Introduction. Remembrance Cultures of World War II and the Politics of Recognition in Post-Soviet Estonia: Biographical Perspectives.” In Soldiers of Memory: World War II and Its Aftermath in Estonian Post-Soviet Life Stories. Edited by Ene Kõresaar. Amsterdam: Rodopi, 2011, pp. 1-34.

12. Ene Kõresaar. "Boris Takk-An Ambiguity of War in a Post-Soviet Life Story." In Soldiers of Memory: World War II and Its Aftermath in Estonian Post-Soviet Life Stories. Edited by Ene Kõresaar. Amsterdam: Rodopi, 2011, pp. 343-63.

13. Alexander Etkind. Internal Colonization: Russia's Imperial Experience. Cambridge: Polity Press, 2011.

14. Ewa Thompson. Imperial Knowledge: Russian Literature and Colonialism. Westport and London: Greenwood Press, 2000.

15. Dariusz Skórczewski. Teoria-Literatura-Dyskurs. Pejzaz Postkolonialny (Theory-LiteratureDiscourse: The Postcolonial Landscape). Lublin: Wydawnictwo KUL, 2013. 
16. Gayatri Chakravarty Spivak. "Are you Postcolonial? To the Teachers of Slavic and Eastern European Literatures.” PMLA 121 (2006): 828-29.

17. Mark R. Beisinger, Crawford Young, eds. Beyond State Crisis? Post-Colonial Africa and Post-Soviet Eurasia in Comparative Perspective. Washington: Woodrow Wilson Center Press, 2002.

18. Stefan Troebst. "Halecki Revisited: Europe's Conflicting Cultures of Remembrance." In $A$ European Memory? Contested Histories and Politics of Remembrance. Edited by Małgorzata Pakier, and Bo Stråth. New York: Berhahn Books, pp. 56-63.

19. Eva-Clarita Pettai, ed. Memory and Pluralism in the Baltic States-Rethinking the Relationship. London: Routledge, 2011.

20. Evgeny Finkel. "In Search of Lost Genocide: Historical Policy and International Politics in Post-1989 Eastern Europe.” Global Society 24 (2010): 51-70. [CrossRef]

21. Dovile Budryte. "We Call It Genocide': Soviet Deportations and Repression in the Memory of Lithuanians." In The Genocidal Temptation: Auschwitz, Hiroshima, Rwanda, and Beyond. Edited by Robert S. Frey. Lanham: University of America Press, 2004, pp. 223-51.

22. Johan Dietsch. Making Sense of Suffering: Holocaust and Holodomor in Ukrainian Culture. Lund: Lund University Press, 2006.

23. Rebekah Moore. "'A Crime against Humanity Arguably Without Parallel in European History': Genocide and the 'Politics' of Victimhood in Western Narratives of the Ukrainian Holodomor." Australian Journal of Politics and History 58 (2012): 367-79.

24. Georgii Kas'ianov. "The Holodomor and the Building of a Nation." Russian Social Science Review 52 (2011): 71-93.

25. John-Paul Himka. "The Lontsky Street Prison Memorial Museum: An Example of Post-Communist Negationism." In Perspectives on the Entangled History of Communism and Nazism: A Comnaz Analysis. Edited by Klas-Go" ran Karlsson, Johan Stenfeldt, and Ulf Zander. Lanham: Lexington Books, pp. 137-66.

26. Volodymir Kulyk. "Tautiškumas prieš sovietiškuma: Istorine' atmintis nepriklausomoje Ukrainoje (Nationalism against Sovietism: Historical Memory in Independent Ukraine)." In Atminties Kultūru, Dialogai Ukrainos, Lietuvos, Baltarusijos (ULB) Erdve je (Dialogues of Memory Cultures in the Ukrainian, Lithuanian and Belarussian Space). Edited by Alvydas Nikžentaitis and Michał Kopczyn' ski. Vilnius: Lietuvos Istorijos Instituto Leidykla, 2015, pp. 181-95.

27. Zehavit Gross, and Doyle Stevick, eds. As Witnesses Fall Silent: 21st Century Holocaust Education in Curriculum, Policies and Practice. Cham: Springer International Publishing, 2015.

28. Violeta Davoliū tè. The Making and Breaking of Soviet Lithuania. London: Routledge, 2013.

29. Saulius Sužiedèlis, and Šarūnas Liekis. "Conflicting Memories: The Reception of the Holocaust in Lithuania." In Bringing the Dark Past to Life: The Reception of the Holocaust in Post-Communist Europe. Edited by Joanna Michlic and John-Paul Himke. Lincoln: University of Nebraska Press, 2013, pp. 319-51. 
30. Violeta Kelertas. "Introduction: Baltic Postcolonialism and Its Critics." In Baltic Postcolonialism. Edited by Violeta Kelertas. Amsterdam: Rodopi, 2006, pp. 1-10.

31. Claudia Snochowska-Gonzalez. "Post-Colonial Poland-On an Unavoidable Misuse." East European Politics and Societies and Cultures 26 (2012): 708-23.

32. David Chioni Moore. "Is the Post- in Postcolonial the Post- in Post-Soviet? Toward a Global Postcolonial Critique." Atlas of Transformation. Available online: $\mathrm{http}: / /$ monumenttotransformation.org/atlas-of-transformation/html/p/postcolonial-post-soviet/ is-the-post-in-postcolonial-the-post-in-post-soviet-toward-a-global-postcolonial-critique-davidchioni-moore.html (accessed on 14 January 2016).

33. Epp Annus. "The Problem of Soviet Colonialism in the Baltics." The Journal of Baltic Studies 43 (2012): 21-45.

34. Dovile Budryte. Taming Nationalism? Political Community Building in the Post-Soviet Baltic States. Aldershot: Ashgate, 2005.

35. Jan Kubik, and Michael Bernhard. "A Theory of the Politics of Memory." In Twenty Years after Communism: The Politics of Memory and Commemoration. Edited by Michael Bernhard and Jan Kubik. Oxford: Oxfrod University Press, 2014.

36. Elizabeth Jelin. State Repression and the Labors of Memory. Minneapolis: University of Minnesota Press, 2003.

37. Boris Takk. "My Youth as the Turn of History." In Soldiers of Memory: World War II and Its Aftermath in Estonian Post-Soviet Life Stories. Edited by Ene Kõresaar. Amsterdam: Rodopi, 2011, pp. 187-208.

38. Tiina Ann Kirss. "When is the War Over? Ylo-Vesse Velvelt's Life Story and Surviving the 'Czech Hell'." In Soldiers of Memory: World War II and Its Aftermath in Estonian Post-Soviet Life Stories. Edited by Ene Kõresaar. Amsterdam: Rodopi, 2011, pp. 365-83.

39. Christine Sylvester. "Experiencing War: An Introduction." In Experiencing War. Edited by Christine Sylvester. London: Routledge, 2011, pp. 1-7.

40. Megan Mackenzie. "Ruling Exceptions: Female Soldiers and Everyday Experiences of Civil Conflict." In Experiencing War. Edited by Christine Sylvester. London: Routledge, 2011, pp. 64-78. 


\section{Shock and Awe: Trauma as the New Colonial Frontier}

\section{Natalie Clark}

Abstract: The health of Indigenous girls in Canada is often framed and addressed through health programs and interventions that are based on Western values systems that serve to further colonize girls' health and their bodies. One of the risks of the recent attention paid to Indigenous girls' health needs broadly and to trauma more specifically, is the danger of contributing to the "shock and awe" campaign against Indigenous girls who have experienced violence, and of creating further stigma and marginalization for girls. A focus on trauma as an individual health problem prevents and obscures a more critical, historically-situated focus on social problems under a (neo)colonial state that contribute to violence. There is a need for programs that provide safer spaces for girls that address their intersecting and emergent health needs and do not further the discourse and construction of Indigenous girls as at-risk. The author will present her work with Indigenous girls in an Indigenous girls group that resists medical and individual definitions of trauma, and instead utilizes an Indigenous intersectional framework that assists girls in understanding and locating their coping as responses to larger structural and systemic forces including racism, poverty, sexism, colonialism and a culture of violence enacted through state policy and practices.

Reprinted from Humanities. Cite as: Clark, N. Shock and Awe: Trauma as the New Colonial Frontier. Humanities 2016, 5, 14.

\section{Introduction}

Indigenous Hawaiian scholar Manulani Aluli Myer says "See your work as a taonga (sacred object) for your family, your community, your people-because it is" ([1], p. 219). Opaskwayak Cree researcher Shaun Wilson calls for starting from our intentions, our beliefs in the work we do. Similarly, protocol within many Indigenous communities requires a person to situate themselves and their relationships to the people and the land [2]. I write this paper from unceded Musqueam territory, but the coming to know, slexlexs, of my readings and learning on the land was completed from my time spent in Secwepemlux. This work is grounded in my own intersecting relationships to Indigenous communities and the systems in which our lives are shaped. I was born in Saskatchewan, Canada in Cree territory but have been on Secwepemc territory since I was young. In many ways, my worldview has been shaped by Secwepemc land and through kinship relationships. My identity is formed not only through my own metis roots but also through my own connection to the Secwepemc community, through what Mohawk scholar Audra Simpson calls a "feeling citizenship" ([3], p. 173). I know whom I am accountable to, and whom I belong to. These are the important questions that define my responsibility and my role within the Secwepemc nation. My work is informed and mobilized through my interconnected identities as a solo-parent of three children who are Secwepemc and from the lands of the Secwepemc peoples, and my twenty years as a community based researcher, activist and trauma counsellor with Indigenous girls in urban and 
rural spaces. Furthermore, I draw upon the insight I have gained through conducting interviews and sharing stories with many Indigenous therapists who address violence, healing and trauma in the Secwepemc nation, and who have also witnessed the ongoing resilience, survivance, and positive resistance of Indigenous children and youth.

\section{Context}

Several years ago a 14-year-old Indigenous girl walked into a girls group I was facilitating and asked if she could make an announcement. She proceeded to tell the other girls that she had been sexually abused since age seven by her stepfather, and that she was not going to remain silent anymore, and, moreover, wanted them to know that they did not need to tolerate abuse. In the weeks and months that followed this act of truth-telling and collective witnessing, she was labeled, stigmatized, pathologized and ignored by police, social workers and mental health professionals who she encountered. Instead of focusing on the disclosure, it was suggested that she was "using drugs", her mental health repeatedly questioned. These were provided as evidence of her credibility, her believability, and her motivation.

Weeks passed, and I then saw this young woman walking on the street. I stopped the car and said hello and asked how she was doing. We exchanged cell phone numbers and the advocacy began. The other girl's group facilitator and I began making phone calls. I became more strident with each one as I encountered the labeling of this young woman. It was clear that a very different narrative had been formed by the agencies and health care providers of a young woman who made up a story in order to leave her small community. I was told that she used drugs, that she is a lesbian, and that she had a clear plan to leave her community. Together, the other facilitator and I supported this young woman in calling a meeting, where she, together with us as supports, presented a different "picture" of herself. She was articulate, strong and clear about the abuse and about her right to live in a safe home and attend school where she chose. She got her day in court and the judge marveled at her strengths and her ability to represent herself and her needs. She became a leader in the new girls group she was attending, speaking up and naming her feelings, and her challenges. She wrote a support letter about the need for Indigenous girls groups and presented the model at a School District board meeting.

Caught in a web of government policies and community norms around violence towards Indigenous girls and women, her act of resistance to longstanding abuse was shaped by intersecting colonial discourses and practices. On paper, these relevant policies and practices may have appeared to acknowledge the unique intersecting factors that impacted her safety, health and mental health, but they (and the people who administered them and had written them) lacked an analysis of colonialism and were, in fact, part of a legacy of colonialism in perpetuating violence against her and other Indigenous girls.

I suggest that the current construction of trauma continues to create a colonial subject who requires intervention, support and saving. A focus on trauma as an individual health problem, as in this girls story, prevents and obscures a more critical, historically-situated focus on social problems under a (neo) colonial state that contribute to violence and harm. This paper will consider the following: What are the historic and current impacts of the creation of a "trauma industry" within 
Indigenous communities, and how does the individualized and medicalized approach to trauma undermine community and individual girls' resilience and resistance?

The young woman's story that begins this paper joins with the voices of Indigenous girls and women who have been truth-telling and speaking about violence at the intersections of Indigeneity, gender, age, and geography since colonization began. These "word warriors" are and were always writing, re (membering), and re-telling complex stories of Indigenous girls and women. Zitkala-Sa, Lee Maracle, Maria Campbell, Jeanette Armstrong, Joy Harjo, Gloria Anzaldúa, Chrystos are a few women among many others. As Indigenous feminist Dian Million states, "Our voices rock the boat and perhaps the world. They are dangerous. All of this becomes important to our emerging conversation on Indigenous feminisms, on our ability to speak to ourselves, to inform ourselves and our generations, to counter and intervene in a constantly morphing colonial system. To 'decolonize' means to understand as fully as possible the forms colonialism takes in our own times" ([4], p. 55, emphasis added). The young woman in the girl's group I was facilitating was not only speaking to other Indigenous young women, as Million describes it speaking to ourselves in order to inform ourselves a form of Indigenous storytelling, but she was also engaging in this truthtelling in an intimate relational space of Indigenous witnessing. This young woman and the circle of girls and women who received her story, were all engaged in an intimate act of decolonizing, both through theorizing about violence and the forms that it takes, but through the telling in certain spaces and relationships, such as the Indigenous girls groups that facilitate and allow for relational witnessing and accountability.

\section{Shock and Awe}

In a discussion on trauma, Freud states, "the causal relation between the determining psychic trauma and the hysterical phenomena is not of a kind implying that the trauma merely acts like an agent provocateur in releasing the symptom, which thereafter leads an independent existence" but "the psychical trauma — or more precisely the memory of the trauma - acts like a foreign body which long after its entry must continue to be regarded as an agent that is still at work" ([5], p. 6). This begs the questions: How is trauma theory and practice not the same invader that is reverberating in Indigenous communities and mental health practice? In what way is trauma as it is currently constructed and enacted within Indigenous health, an invader, and a colonial form of warfare that continues to act long after?

Health programs and interventions that are based on Western values systems and/or regulated through State interventions serve to further colonize and pathologize Indigenous children and youths' health and their bodies. This is evidenced through increasing rates of Indigenous child and youth incarceration, mental health diagnosis, and child welfare intervention. Moreover, the increased attention to Indigenous mental health needs both broadly and through the framework of trauma more specifically, is contributing to what I call the "shock and awe" campaign against Indigenous children and youth who have experienced violence. This leads to ineffective interventions resulting in the ongoing removal of children from their land. I utilize the term "shock and awe," from Naomi Klein's seminal work The Shock Doctrine (2007) and apply it to the ongoing colonization of Indigenous children and youth through trauma discourse, policies and 
practices that perpetuate statistics of horror and shock in order to justify child protection intervention and ongoing colonial control and intervention [6]. It is well recognized within critical scholarship that in order to get to the land, the colonizers had to remove the power and central role of women in Indigenous communities [7-9]. Similarly, I would argue that neo-colonialism has extended this to Indigenous children and youth through child welfare removals, incarceration, and mental health interventions.

Policy and policy processes have been, and continue to be, central to the colonization of Indigenous peoples, locally and globally [7,8,10,11]. In order to understand the violence experienced by Indigenous children and youth today, it is necessary to situate this violence within the violence of colonization and consider how it continues to be enacted through policy. Colonization required the silencing of Indigenous women, as the matriarchal and co-operative societies did not fit within the individualistic and patriarchal ways of the colonizer. To get to the land, they had to remove the women and children [9-13]. In Canada, this violence did not end with the closing of residential schools. It continues within the Indian Act and with the removal of children through child welfare policies and practices that further disconnect and displace Indigenous children and youth through adoption and foster placement [10]. In my own practice, I continue to witness the harm and violence that intersecting policies have on Indigenous children, youth and families Indigenous children and youth are more likely to be in the child welfare system, and in the juvenile justice system, not only in BC and Canada, but internationally [12]. Indigenous lawyer and scholar Patricia Monture-Angus asserts that criminalization is as a strategy of colonization that not only locks up Indigenous children and youth but also does not address the violence, including through state policies of child welfare that first criminalized them in the first place [13].

Trauma discourse has become part of the mainstream narrative in Indigenous and non-Indigenous communities, globally and locally. Alternatively described as the "age of trauma" [14] an "empire of trauma" [15] and as a "trauma economy" [4], trauma has become an umbrella term that includes experiences ranging from single incident experiences such as car accidents, to genocide. Maurice Stevens describes how trauma is the centre of thousands of articles within social work, psychiatry, literature; however, a universal notion of trauma is yet to be defined [16]. The dominant discourses of "trauma" continue to define violence within normative neo-colonial constructions, thereby functioning to obstruct and erase the naming of certain kinds of violence such as experiences of racism, structural violence enacted through state policy [11], and violence to Indigenous lands through mining and other development [17]. Craps suggests that definitions of trauma are rooted in European hegemony, resulting in psychiatric and medicalized definitions of trauma, thereby perpetuating a subsequent form of cultural imperialism [18]. Foucault describes discourse within the colonial project as the "way of seeing that is produced and reproduced by various rules, systems and procedures - forming an entire conceptual territory on which knowledge is produced and shaped" ([19], p. 3). Trauma theory has emerged out of a time, place and history of ideas, and since its original formation, has been raced, classed and gendered [16,20]. Young argues that trauma theory "is glued together by the practices, technologies, and narratives with which it is diagnosed, studied, 
treated, and represented and by the various interests, institutions, and moral arguments that mobilized these efforts and resources" ([21], p. 5).

Examples of the "conceptual territory" of trauma can be evidenced in state funded and controlled research and media coverage of Indigenous children and youth that ultimately perpetuates statistics of horror and shock in order to justify intervention and ongoing colonial control and intervention. In fact, there is a global phenomena and expansion of trauma into Indigenous and racialized communities and Nations throughout the world, with a focus on children and youth as inherently vulnerable and in need of Western intervention, and with practices rooted in Western models of trauma and ideas of childhood and adolescence [22,23]. As Summerfield asks "whose knowledge is privileged and who has the power to define the problem?" ([22], p. 1449).

Some scholars argue that even the Indigenization of government services in many ways continues the colonial project [24,25] as it has increased the reach into the community, with trauma often being used as a justification for child welfare removals [24]. As Landertinger writes, "they do not establish an alternative but rather carve out the same space within a system that continues to work in favour of the settler society" ([26], pp. 81-82). This echoes the work of both Fanon and Coulthard who call for a turning away from the state for the solutions, as in the words of Secwepemc leader George Manuel, "they must convince the conquered" [27-29].

Evidence of the use of trauma as a justification for child welfare intervention and removals is also found within recent child protection responses within Australia. In 2008, the Howard government launched a national emergency response to address the sexual abuse of Indigenous children in the Northern territories. This program utilized the "shock and awe" terminology that is most often associated with going to war and deployed troops to over 70 Aboriginal communities. The Howard government seized control of these Aboriginal communities in the Northern Territory and forced Aboriginal parents to follow strict conditions in order to receive their welfare and family support payments. One newspaper described how "the troops posed for the cameras as they were dispatched into action, and the government issued an urgent national call for volunteer recruits, as policy was unfurled on the run. A year later, and the military analogy still seems appropriate for a campaign that has been, in the words of one doctor, like a bomb going off'. Dr. Tamara Mackean, the president of the Australian Indigenous Doctors Association, spoke of the link to colonization and further trauma, stating, "If you take away people's sense of autonomy and control, we know that's bad for their health," she says, "like any act of fear and disempowerment, it's another layer of trauma for Indigenous people. People are exhausted. They're overwhelmed and overloaded by this whole thing that's been called the intervention." ([30], p. 7).

Left uninterrogated and unchallenged, this dominant discourse of trauma not only erases the harm done to Indigenous children and youth through policy but can also function to silence the local and Indigenous ways of knowing and of addressing the wellness of our children and youth. The definitions of trauma and the meanings we make of it are historically constructed and defined, and are shaped by the intersection of structural factors, including our access to power and our experiences of oppression. Further, these constructions of trauma shape what we consider as violence, what kinds of violence are erased, and the kinds of supports and access to services that flow from this. 


\section{The Master's Tools May Not Dismantle the House but Will Get You in the Door}

It is important to assert that knowledge of how to address violence and wellness in our communities has always existed. This knowledge of what Indigenous scholar Eduardo Duran called the "soul wound" has been with us since time immemorial. Engagement with the discourse and language of trauma emerged within Indigenous communities in the 90s [31], and there has been an increase in Indigenous writings on Indigenous mental health and trauma in the last 20 years [32-39]. Eduardo Duran and Bonnie Duran assert that situating the discourse of the "soul wound" within current Western constructs of trauma was important to bring "some validation to the feelings of a community that has not had the world acknowledge the systematic genocide perpetrated on it" ([31], p. 341).

Other Indigenous scholars such as Maria Yellowhorse Brave Heart, an Oglala Lakota social worker also worked within the mainstream model of trauma, while widening the frame through the development of what she called Historical Trauma Theory [34]. Brave Heart developed this out of her over 20 years of clinical experience with Indigenous communities and in response to what she saw as the inadequacy of post traumatic stress disorder as a diagnosis within Indigenous communities. More recently, Indigenous scholar and social worker Tessa Evans-Campbell (Snohomish) offers what she calls Colonial Trauma Response (CRT) as a theory that links historical and contemporary acts of trauma within Indigenous communities [38]. It is important to honour the work of these scholars in expanding the framework of trauma to include naming colonialism and genocide within the discourse of trauma.

In spite of the work to expand the framework of trauma to include the experiences of Indigenous peoples, there has continued to be a domination of Western constructs of trauma and the related evidence-based practices with Indigenous peoples. Further, the failure of these approaches with Indigenous people who have experienced violence has been well documented [39-41]. Consequently, there is widespread recognition, both within Indigenous [39,42,43]. and non-Indigenous critical scholarship [44] of the need for a radical re-visioning of theoretical and practical approaches to "trauma" theory, intervention and training in Indigenous mental health. My past scholarship and that of other Indigenous and critical trauma scholars have attempted to address this need through offering new ways of understanding trauma within decolonized, feminist, intersectional, social justice, liberatory and politicized approaches [45-48].

Recently, Indigenous critical scholars have been at the forefront of rejecting state interventions and western defined framing of Indigenous communities health and healing. Duran, Firehammer, and Gonzales describe counsellors as the "new priests" of the society, the authors argue that therapists perpetuate racism and injustice through imposing incongruent helping paradigms [46]. Similarly, Indigenous psychologist Joseph Gone writes, "mental health professionals are the missionaries for a new millennium" ([39], p. 391). Further, Kirmayer, Simpson, and Cargo argue that there is great danger in framing this ongoing violence of the state in mental health language, as it may in fact "deflect attention from the large scale, and, to some extent, continuing assault on the identity and continuity of whole peoples"([49], p. 597). 
Indigenous critical theorists and activists such as Leanne Simpson, Dian Million and Glen Coulthard, argue that sovereignty and the future health of Indigenous nations will not be found through state recognition, and that the "processes of engagement" including state recognition, and the resulting discourses of healing, can and will replicate the very harms of colonialism $[4,28,50]$.

As Leanne Simpson says "We need to rebuild our culturally inherent philosophical contexts for governance, education, healthcare, and economy. We need to be able to articulate in a clear manner our visions for the future, for living as Indigenous Peoples in contemporary times. To do so, we need to engage in Indigenous processes, since according to our traditions, the processes of engagement highly influence the outcome of the engagement itself. We need to do this on our own terms, without the sanction, permission or engagement of the state, western theory or opinions of Canadians" ([50], p. 17).

In his seminal essay Subjects of Empire: Indigenous Peoples and the "Politics of Recognition" in Canada, Coulthard engages with the work of Fanon in the context of Indigenous peoples in Canada. Coulthard argues that Indigenous communities need to be less concerned with the politics of recognition by a settler society, and instead focus on recognizing Indigenous ways and practices, in what he describes as "our own on-the-ground practices of freedom" ([28], p. 444).

I echo the work of Indigenous scholar Dian Million in applying this same reasoning to the concept of trauma and suggest that the theory, practice and ways of doing trauma in Indigenous communities, and with children and youth in particular, are part of the process of reproducing the colonial system, and are an example of what Foucault called "power-knowledge" [19]. This powerknowledge, through the discursive framework of trauma functions to efface the naming and addressing of the real harm and violence done through colonial systems, at both the structural, and what Fanon called the "psychoaffective" level [27]. I would argue that trauma theory and practices function at both levels of colonialism, that is, they simultaneously erase the naming of the structural acts of violence, while creating and exacerbating the psychological symptoms, through a form of colonial recognition or misrecognition [51]. According to Taylor, "Nonrecognition or misrecognition can inflict harm, can be a form of oppression, imprisoning someone in a false, distorted, and reduced mode of being" ([51], p. 25). I suggest that this is what has happened within trauma theory. We have moved from a space and place of nonrecognition of the harms of colonialism, to what I would argue is misrecognition of these harms through the frame of trauma, as put forward by Indigenous trauma scholars and others. Both are, as Coulthard and Fanon argue, a form of oppression, and over time these images and the power relations that co-construct them will then be related to as natural $[27,28]$.

I do not want to take away from the work by Indigenous scholars and other critical scholars who have worked to make space for the recognition of the violence and genocide that have, and continue to, impact Indigenous peoples worldwide. However, I do believe that it is time to evaluate the impact and effectiveness of including these acts of violence within the frame of trauma.

\section{Red Intersectionality}

As the early writings of Sioux activist Zitkala-Sa and Sarah Winnemucca remind us, the binary of gender and race as a result of colonization were identified long before the writings of the early 
African American women activists part of the Combahee Collective or Kimberle Crenshaw, the critical race scholar who coined the term intersectionality [52-55]. These early activists were central in fighting the issues of violence on the land and on the body as they witnessed it at the turn of the century. They did not separate out their activism around tribal rights and water rights from their activism against violence under colonialism. Sarah Winnemucca describes not only her own experience of being buried alive as a child by her mother to protect her from the settlers, but also her own sister 's rape at the hands of settlers: "My people have been so unhappy for a long time they wish now to disincrease, instead of multiply. The mothers are afraid to have more children, for fear they will have daughters, who are not safe even in their mother's presence ([53], p. 48). Similarly, Zitkala-Sa ${ }^{1}{ }^{1}$ was instrumental in collecting the testimonies of three Indigenous girls violated by the imposition of capitalism through oil and mining in the tribal lands. Zitkala-Sa put together the legal argument of gender, race, and age in her essay "Regardless of Sex or Age", describing how "greed for the girl's lands and rich oil property actuated the grafters and made them like beasts surrounding their prey" ([56], p. 52). Zitkala-Sa reminds us again and again in her writing that violence has always been gendered, aged and linked to access to land.

This paper argues for an Indigenous wholistic and intersectional-based framework of violence, which I call Red Intersectionality. Red intersectionality is inspired and informed by Sandy Grande's "Red pedagogy" [57], Dory Nason's "Red feminism" [56] and the rich tradition of Indigenous critical scholars including Rigney [58], Grande [57], and more recently Tuck and Wang [59] who advocate for methodologies that are rooted in Indigenous sovereignty and are grounded in specific Indigenous Nations' ontologies and epistemologies. Red intersectionality is grounded in five principles: respecting sovereignty and self-determination, local and global land-based knowledge, holistic health within a framework that recognizes the diversity of Indigenous health; agency and resistance, and approaches that are rooted within specific Indigenous nations relationships, language, land, and ceremony [57,60,61].

This critical analysis allows us to consider the construction of Indigenous girls within policy and the structural intersections of this in their life as a form of violence. An anti-colonial and Indigenous intersectional perspective of violence does not center the colonizer but instead attends to the many intersecting factors including gender, sexuality and a commitment to activism and indigenous sovereignty. It helps understand and address violence against Indigenous girls as it foregrounds context, which in Canada's case has to include gendered forms of colonialism and dispossession of Indigenous lands.

\section{Decolonizing Trauma: Implications for Wise Practice}

Indigenous social workers Yellow Bird, Coates, Gray and Hetherington challenge social work to not only address the complicity in the past colonial projects, but also the ongoing colonial interventions: "Decolonizing social work requires that the profession acknowledge its complicity and ceases its participation in colonizing projects, openly condemns the past and continuing effects

1 I had already found the writings of Zitkala-Sa and Winnemuca but I am indebted to Dory Nasson (2010) for the three cases describing Zitkala-Sa's activism. 
of colonialism ... and seeks to remove the often subtle vestiges of colonization from theory and practice" ([62], pp. 6-7). Decolonization and transformation within trauma requires us to note sites of struggle between Western and indigenous and the need to reclaim the intellectual knowledge of Indigenous communities, healers and to reassert Indigenous epistemologies and ontologies ([44], p. 41) Indigenous scholar Renee Linklater in her 2011 doctoral thesis describes her research as decolonizing in two ways: not only the critique of mainstream approaches but also the importance of advancing "principles of self-determination and community control in regards to Indigenous health in the context of healing" ([43], p. 243).

"Mom I know what you do. You don't think I know history, I do. Why would you be a social worker? How does that help children?" (Cohen Clark, age 9). Present in the question from my Secwepemc twin son is the truth-telling, or naming of the harms past, and ongoing to Indigenous children and youth through State interventions, in this case through social work. However, in my son's question is also the resistance of Indigenous children and youth through acts of naming, and relational accountability through questioning and processes of relational witnessing. In this next section, I will outline how a framework of Red intersectionality that centers resistance and resistance spaces, can point the way forward.

Wesley-Esquimaux and Snowball reveal how Indigenous healing approaches and epistemologies have been ignored and erased within the Western health care system [63]. The authors argue that an Indigenous "wise practices" model of healing is required in order to move forward and address the inequities within our current system. This paper will build on the call for "on the ground practices of freedom" ([28], p. 456), through the framework of Red intersectionality to identify examples of "wise practices" or practices rooted in Indigenous communities' "unique body of knowledge, manifested through oral histories and lived experiences" ([64], p. 3). Thoms proposes the term "wise practices" as better suited to reflect "the fact that the Aboriginal world is culturally heterogeneous, socially diverse, and communally 'traditional' while at the same time ever-changing" ([65], p. 8). Furthermore, "wise practices" are called for given the diversity of Indigenous communities, in particular within British Columbia where there are "more than 200 contemporary bands, that collectively speak 14 mutually uninterpretable languages, occupy a territory bigger than Western Europe, live in sharply different ecological niches and spiritual worlds, and have radically different histories" ([64], p. 3).

Trauma treatment and social service agencies exist within a web of evidence-based treatment approaches that are evaluated, and "proven" through empirical testing and evidence-based research. These "best practices" however are often deeply rooted in Eurocentric perspectives, and biased testing that fails to recognize the realities of Indigenous peoples [39,40,65], and Indigenous young people in particular [66]. In a review of the evidence-based literature on Indigenous youth mental health promotion in Canada, researchers Williams and Mumtaz note "of equal concern are the glaring absence of Aboriginal epistemologies in recognized approaches to evidence and largely unquestioned acceptance of this situation by policy makers. Indeed, it would appear that much work needs to be done with communities in re-discovering traditional knowledges and ensuring their legitimization within institutions" ([66], p. 29). 
Further, best practice approaches to mental health and trauma or "West knows Best" [39] approaches are foreground, or Indigenous needs are addressed through an add-on approach of culture through cultural competency while specific Nations and community approaches are ignored, decimated, and systematically eroded within these dominant paradigms [67]. An example of this can be found in the Aboriginal Healing Foundation (AHF) review of 103 projects to examine what they called "promising healing practices". Their research revealed that more than $80 \%$ of these projects included Indigenous cultural activities and traditional healing interventions [68]. These included a range of activities such as "[E]lders' teaching; storytelling and traditional knowledge; language programs; land-based activities; feasts and pow wows; learning traditional art forms; harvesting medicine; and drumming, singing, and dancing" ([68], p. 130). Further, in the AHF review of five healing programs they attempted to identify best practices but realized these could not be identified, and, in fact, the language of best practice can often contribute to a panIndigenous approach as healing [69]. The authors conclude, however, that given the diversity of Indigenous nations and their respective healing approaches, there is no one Indigenous best practice approach [69].

I would argue that best practices are colonial practices, and often these forms of covert colonization are difficult to see and name. These medical model approaches towards mental health issues further label and pathologize Indigenous children and youth, and result in increased criminalization or medicalization. These approaches often do not address the long-term wellness needs of children and youth who have experienced structural and individual acts of violence, nor the intersecting factors of age, gender, and rurality that put Indigenous children and youth at risk for violence. The resulting coping mechanisms and acts of resistance that place Indigenous children and youth in contact with mental health or the criminal justice system are also left unaddressed.

We need programs that provide safer spaces for Indigenous children and youth to address their intersecting and emergent health needs, without furthering the discourse and construction of Indigenous girls and women as "at-risk", or further criminalizing and medicalizing our children, our families and our communities. Programs such as the Indigenous girls group model offered in the next section resists medical and individual definitions of trauma, and instead uses an Indigenous wholistic, or intersectional framework that assist girls in understanding and locating their coping as responses to larger structural and systemic forces including racism, poverty, sexism, colonialism and a culture of trauma.

\section{Centering Resistance and Activism}

The issue of violence against Indigenous children and youth, as represented in the State discourse, media, mental health and counseling systems, and child welfare interventions are important to understand. At the same time other images of strength, resilience and resistance, beyond narratives of risk and harm of Indigenous children and youth, are missing from the discourse. Many studies have focused on the harms of colonization, and this deficit-based research has identified disproportionately high health challenges as a result of the interlocking oppressions for Indigenous youth such as higher rates of sexual and physical abuse, suicide as a leading cause 
of death especially for Indigenous males, higher rates of violence for Indigenous females, experiences of racism, and increased tobacco and marijuana usage [70-73].

Research has only recently begun to consider Indigenous understandings of resilience and healthy child development [73] in contrast to the deficit and binary construction of children within Western child development. Recent research has linked strong cultural beliefs and values with resiliency among youth and with positive health outcomes, including improved educational achievement, self-esteem, and less risky drug and sex activities [70-76]. Research linking positive health outcomes for Indigenous youth living in reserve communities where there is strong cultural continuity has been established [75]. Further, there has been an increased focus on Indigenous youth in large cities. Similarly, Mohawk scholar Rod McCormick describes how in his research Indigenous youth with a strong cultural identity identified this as key in recovering from suicidality [74]. There is a need for research that documents and centers the ongoing resilience, survivance, and positive resistance of Indigenous children and youth by Indigenous youth themselves. The work of the Native Youth Sexual Health Network is one example of research and practice that exemplifies this.

There is a gap in the literature in considering what healing practices exist with Indigenous children and youth who have experienced violence, and, in particular, their acts of resistance. In my recent research with Indigenous youth in the Secwepemc nation, my colleagues and I attempted to address this gap of strengths-based research. We found that, $96 \%$ of the youth were proud of their Indigenous identify, and those youth who spoke their language and practiced their culture and traditions, rated their health the highest [76]. Furthermore, consistent with other research with urban Indigenous youth [75], we found that the binaries of rural and urban and on-reserve and off-reserve need to be challenged, as cultural identity is formed within a wide circle of activities including access to Elders, language, First Nations education workers in schools, community health spaces such as in Friendship Centres, and the internet [76].

I turn again to the work of Fanon and the role of resistance, what Fanon has been critiqued for as advocating for violence, but instead I take up resistance in all its forms as necessary to free oneself and to create a "change of fundamental importance in the colonized's psycho-affective equilibrium" ([27], p. 148). Indigenous communities have always resisted colonialism not only individually but through the creation and maintenance of "resistance communities" [48]. This I would argue is an essential element of healing for Indigenous children and youth and Nations, not in acts of violence themselves but in acts of resistance for liberation [77]. Cree Elder and Scholar Madeline Dion Stout describes in her powerful memoir of residential school how her parents' resilience is working through her now, and how even her triggers give her life: "Their resilience became mine. It had come from their mothers and fathers and now must spill over to my grandchildren and their grandchildren" ([78], p. 179). Similarly, Indigenous scholar Vizenor describes survivance, as "a narrative resistance that creates a sense of presence over absence, nihility and victimry" ([79], p. 41). I know that many of the young women I work with write poetry, songs, short stories, plays, and these truth-telling, theorizing narratives need to be centred in our work. Part of my practice with Indigenous girls is supporting their writing and art making, reframing and restorying their behaviors as resistance to larger colonial systems, instead of the 
mental health labels they are invited to carry and identity with. Resilience and survivance are thus not viewed as individualistic but are instead linked to past, present and future generations.

\section{Indigenous Girls Groups as Relational Spaces of Resistance and Witnessing}

Returning to the young woman's story that begins this paper, I invite the reader as a witness to this to consider the meaning of her sharing in the context of the Indigenous girls group she was part of. Bahtkin writes that "a word uttered in that place and at that time will have a meaning different than it would have under any other conditions; all utterances are heteroglot in that they are functions of a matrix of forces practically impossible to recoup, and therefore impossible to resolve" ([80], p. 2631). Thus, if context is primary, then the spaces that Indigenous girls name acts of violence, and the witnessing of this naming through spaces such as girls groups are important.

In 1992, in my Master 's thesis I wrote, "I believe that all young women engage in daily acts of resistance" and I situated the key role of women as partners in the resistance, to witness and name girls resistance and to receive their stories ([81], p. 133). Trinh T. Minh-ha writes, "the world's earliest archives or libraries were the memories of women" ([82], p. 121). The storyteller in Indigenous communities is often a mother, sister, auntie, poet, teacher, warrior, musician, historian and healer of her community. Minh-ha states that storytelling involves a speech, which is "seen, heard, smelled, tasted and touched" ([82], p. 121); and the process of telling the story "destroys, brings into life, nurtures" ([82], p. 121) bell hooks echoes this when she writes, "It should be understood that the liberatory voice will necessarily confront, disturb, demand that listeners even alter ways of hearing and being" ([83], p. 16). Thus, as listeners or receivers of these stories, we are witnesses and essential partners in the resistance of young women. Indigenous women and girls have always resisted the construction of themselves within policy and media. Storytelling and other forms of creative writing have been a political act and have provided an important space for Indigenous women to resist and replace the colonial images. Choctow scholar Devon A. Mihesuah writes that poetry and literature are a source rarely utilized, and yet are essential as they reveal the complexity and diversity of Indigenous women: "Indeed, it is through their writings that we can learn that Native women were and are powerful, they were and are as complex as their cultures are diverse" ([84], p. 5).

Indigenous women and girls' stories can provide understandings of strategies and unique solutions to challenges facing indigenous communities. For example, Leslie Marmo Silko writes about the Laguna Pueblo's concept of story as: "the old folks said the stories themselves had the power to protect us and even to heal us because the stories are alive; the stories are our ancestors" ([85], p. 152). Similarly, intersectionality scholar, Patricia Hill Collins also describes the importance of story-telling, in particular, the process of call and response, in order to link emotion with reason and as such situates knowing, within the context of the relationship with the larger community [86]. This is similar to practices such as "counter-memory" as described by Foucault, it is a form of storytelling that "combats our current modes of truth and justice, helping us to understand and change the present by placing it in a new relation to the past" ([87], pp. 160, 163-64) while problematizing the dominant discourse and understanding of a particular issue. 
Indigenous witnessing invokes not only a responsibility to the stories, but truth-telling and activism linked to what we have heard [88]. Indigenous scholar Sarah Hunt says, "As witness we have a role that is not to take up the voice or story of that which we have witnessed, nor to change the story, but to ensure the truths of the acts can be comprehended, honored and validated" ([88], p. 38). Similarly, Rwandan social worker Rwigena, in writing of the ethics of witnessing with Rwandan survivor communities, describes the power of relational and intimate spaces of witnessing within family and community where testimony is woven into every day alongside laughter and food and is part of building an intergenerational collective knowledge [89]. She calls for attending to the context of relationships and spaces involved in listening. Spaces such as the Indigenous girls groups that I have been part of.

Through a violence-informed and Indigenous intersectional approach, the groups that my colleagues and I have developed provide the girls with the space to name, comprehend, honour and validate their experiences of abuse, sexual exploitation, body image and violence, as well as their strengths and daily lived realities in a safe and non-threatening environment $[45,90,91]$. My work in partnership with the Secwepemc community through the Interior Indian Friendship Centre and school district 73 has involved developing an Indigenous girls' group within a framework that reintroduces Secwepemc Nation specific cultural teachings of girlhood, or "rites of passage". The model for the group was developed in a unique format-with youth, Elders, community leaders and practitioners in a traditional circle and facilitated by an Elder in the community. This talking circle identified the key issues for Indigenous youth in our community, and how to address them. Through partnerships with community, the school district and Elders, the goal of these groups are to provide Aboriginal/First Nations girls, aged eight to 18, with a space to explore a range of issues affecting their daily lives.

A violence-informed and intersectional girls' group locates the source of girls' challenges within structural and systemic problems such as racism, poverty, sexism and the intersections of these in their lives. We support the young women in healthy resistance to these problems, and in their efforts to move back into connection with themselves and others. We do this through a range of violence-informed strategies of naming, educating and supporting healthy resistance strategies [78]. Violence-informed practice allows us to provide girls with safety, support and the tools to deal with violence and its effects in their daily lives within an intersectional framework. Key violence-informed practices that inform my work include truth-telling and conscious use of self, safety and containment, naming and noting, and fostering healthy resistance strategies. These practices are elaborated on in our girls' group manual [90] and in a chapter on trauma informed practice [45].

In addition, the essential elements of the groups include indigenous worldview through the traditional Secwepemc values and seven sacred teachings, a focus on strengths and healthy resistance, and trauma-informed wholistic and relative safety that recognizes the diversity within and between Indigenous girls and their identities and communities. In an interview with my friend and colleague Sarah Hunt, I described Indigenous girls groups as forms of ceremonial models of supporting girls through adolescents into adulthood: "If the circle is that piece of 
ceremony we can reclaim until the other ways of witnessing violence are returned or remembered or rehonored then that's maybe why in itself it's been of value" ([88], p. 40).

The following key questions are important to consider in our work to decolonize trauma: Honouring coping: How do we name and frame girls' coping as healthy resistance strategies and support their movement toward healthy resistance while honouring their current strategies? Locating violence, strength and resistance: What are the daily experiences girls are resisting? What strengths and resistance can you identify in their stories?

\section{Conclusions}

Indigenous scholar Eve Tuck has called for a need to stop research focused on problems in Indigenous communities in order to "suspend the damage" of "deficit-based" research [92]. Extending this to the concept of trauma, I propose that we need to develop models for addressing violence that are aligned with Indigenous values, Indigenous paradigms and epistemologies and that are based in strengths, resistance and survivance. I suggest that we should move beyond decolonizing Western models of trauma, and instead attend to the centering of "wise practices" and specific Indigenous Nations approaches to within a network of relational accountability. A form of "hands forward, hands back" that holds us accountable within non-linear ideas of time and space [93]. This paper offers an alternative model, one that centers, remembers and revitalizes the historic and ongoing resistance of Indigenous girls and women, and articulates an Indigenous relational process of decolonizing and centering "wise practices" such as the example offered through Indigenous girls groups.

As Indigenous activist Winona La Duke challenges us "And the question, I think, that should be asked and needs to be asked of each of us is how much and how brave we are in our ability to deconstruct some of the paradigms which we have perhaps embraced. If we are able to liberate our minds to be the people that are going to be here on this land. The people who are going to protect our mother, and care for ourselves" [17].

Acknowledgments: My work with Indigenous girls is rooted in my over 20 years of front-line work with Indigenous girls as an activist, auntie, sister, violence counselor, community-based researcher and group facilitator, and finally my own journey of identity as an Indigenous woman and mother. I acknowledge the many children and youth I have been privileged to work with and who have been my teachers, any mistakes in this are mine alone. I also would like to acknowledge the peer reviewers of this paper, in particular the truth-telling of one who wrote "I am I am an Indigenous grandmother raising grandchildren because of addictions in the family. Counseling is, hopefully, saving our family from replicating the dysfunction in a future generation. It's easy for us in the university to theorize and critique, but the rubber hits the road when we are working with our communities where people are suffering.". Kucstemc for this truth.

Conflicts of Interest: The author declares no conflict of interest. 


\section{References}

1. Manulani Aluli Meyer. "Indigenous and Authentic: Hawaiian Epistemology and the Triangulation of Meaning." In Handbook of Critical and Indigenous Methodologies. Edited by Norman Denzin, Yvonna Lincoln and Linda Tuhiwal Smith. Los Angeles: Sage Publications, 2008, pp. 217-32.

2. Shaun Wilson. Research Is Ceremony: Indigenous Research Methods. Nova Scotia: Fernwood Publishing, 2008.

3. Audra Simpson. "To the Reserve and Back Again: Kahnawake Mohawk Narratives of Self, Home and Nation.” Ph.D. Thesis, McGill University, Montreal, QC, Canada, January 2003.

4. Dian Million. "Felt theory: An indigenous feminist approach to affect and history." Wicazo Sa Review 24 (2009): 53-76.

5. Sigmund Freud, and Josef Bruer. Studies on "Hysteria: 1893-1895”. The Standard Edition of the Works of Sigmund Freud. 24 Volumes. Edited by James Strachey. London: Hogarth Press, 1953-1966, vol. 2.

6. Naomi Klein. The Shock Doctrine: The Rise of Disaster Capitalism. Toronto: Alfred A. Knopf Canada, 2007.

7. Karina Harry. The Indian Act and Aboriginal Women's Empowerment: What Front Line Workers Need to Know. Vancouver: Battered Women's Support Services, 2009.

8. Bonita Lawrence. "Gender, race and the regulation of native identity in Canada and the United States: An overview." Hypatia 18 (2003): 3-31. [CrossRef]

9. Kerrie Charnley. "Introduction: Concepts of anger, identity and power and vision in the writings and voices of First Nations women." Gatherings The En'Owkin Journal of First North American Peoples 1 (1990): 141-47.

10. Jessica Yee. "Presentation at Intersectionality Reading Group Workshop." Ph.D. Thesis, Simon Fraser University, Vancouver, BC, Canada, 2011.

11. Natalie Clark. "Perseverance, Determination and Resistance: An Indigenous IntersectionalBased Policy Analysis of Violence in the Lives of Indigenous Girls." In An IntersectionalBased Policy Analysis Framework. Edited by Olena Hankivsky. Vancouver: Institute for Intersectionality Research and Policy, Simon Fraser University, 2012, pp. 133-59.

12. Representative for Children and Youth \& Office of the Provincial Health Officer. Kids, Crime and Care: Health and Well-Being of Children and Care: Youth Justice Experiences and Outcomes. Victoria: Representative for Children and Youth, 2009.

13. Patricia Monture-Angus. "Confronting power: Aboriginal women and justice reform." Canadian Women's Studies 25 (2006): 25-33.

14. Nancy K. Miller, and Jason Tougaw, eds. Extremities: Trauma, Testimony, and Community. Urbana: University of Illinois Press, 2002.

15. Didier Fasson, and Richard Rechtman. The Empire of Trauma: An Inquiry into the Condition of Victimhood. Princeton: Princeton University Press, 2009.

16. Maurice Stevens. "From the Past Imperfect: Towards a Critical Trauma Theory." Letters 17 (2009): 1-5. 
17. Winona La Duke. Recovering the Sacred: The Power of Naming and Claiming. Brooklyn: South End Press, 2005.

18. Stef Craps. Postcolonial Witnessing: Trauma out of Bounds. New York: Palgrave MacMillan, 2013.

19. Michel Foucault. Power/Knowledge: Selected Interviews \& Other Writings 1972-1977. New York: Pantheon Books, 1980.

20. William Halse Rivers Rivers. Medicine, Magic, and Religion: The Fitzpatrick Lectures Delivered Before the Royal College of Physicians of London 1915 and 1916. London: Kessinger, 1924.

21. Allan Young. The Harmony of Illusions: Inventing Post-Traumatic Stress Disorder. Princeton: Princeton University Press, 1995.

22. Derek Summerfield. "A critique of seven assumptions behind psychological trauma programmes in war-affected areas." Social Science \& Medicine 48 (1999): 1449-62.

23. Chris Gilligan. "Political Violence and the Social Construction of Traumatized Children." Journal of Peace Research 46 (2009): 119-34.

24. Sarah de Leeuw, Margo Greenwood, and Emilie Cameron. "Deviant Constructions: How Governments Preserve Colonial Narratives of Addictions and Poor Mental Health to Intervene into the Lives of Indigenous Children and Families in Canada." International Journal of Mental Health and Addictions 8 (2010): 282-95.

25. Wayne Warry. Ending Denial: Understanding Aboriginal Issues. Toronto: University of Toronto Press, 2007.

26. Laura Landertinger. "The Biopolitics of Indigenous Reproduction: Colonial Discourse and the Overrepresentation of Indigenous Children in the Canadian Child Welfare System." Master 's Thesis, Queen's University, Kingston, ON, Canada, 2011.

27. Frantz Fanon. Wretched of the Earth. New York: Grove Press, 1963.

28. Glen Coulthard. "Subjects of Empire: Indigenous Peoples and the 'Politics of Recognition' in Canada." Contemporary Political Theory 6 (2007): 437-60. [CrossRef]

29. Janice Billy. "Back from the Brink: Decolonizing through the Restoration of Secwepemc Language, Culture, and Identity." Ph.D. Thesis, Simon Fraser University, Burnaby, BC, USA, 2009.

30. Melissa Sweet. "When the Smoke Clears: The NT Intervention One Year On." Australian Rural Doctor, (July 2008): 1-12.

31. Edward Duran, and Bonnie Duran. Native American Postcolonial Psychology. Albany: State University of New York Press, 1995.

32. Judy Atkinson. Trauma Trails, Recreating Song Lines: The Transgenerational Effects of Trauma in Indigenous Australia. North Melbourne: Spinifex Press, 2002.

33. Caroline Lisbeth Atkinson. "The Violence Continuum: Australian Aboriginal Male Violence and Generational Post-Traumatic Stress.” Ph.D. Thesis, Charles Darwin University, Casuarina, NT, Canada, 2008. 
34. Maria Yellow Horse Brave Heart. "The Return to the Sacred Path: Healing From the Historical Trauma and Historical Unresolved Grief Among the Lakota." Ph.D. Thesis, Smith College, Northampton, MA, USA, 1995.

35. Ernest Hunter. "Considering Trauma in an Indigenous Context." Aboriginal and Islander Health Worker Journal 22 (1998): 8-18.

36. Harold Napoleon. Yuuyaraq: The Way of the Human Being. Fairbanks: Centre for CrossCultural Studies, University of Alaska Fairbanks, 1991.

37. Cynthia Wesley-Esquimaux, and Magdalena Smolewski. Historic Trauma and Aboriginal Healing. Ottawa: Aboriginal Healing Foundation, 2004.

38. Teresa Evans-Campbell. "Historical Trauma in American Indian/Native Alaska Communities: A Multilevel Framework for Exploring Impacts on Individuals, Families, and Communities." Journal of Interpersonal Violence 23 (2008): 316-38.

39. Joseph Gone. "So I Can Be Like a Whiteman': The Cultural Psychology of Space and Place in American Indian Mental Health.” Culture and Psychology 14 (2008): 369-99.

40. Lydia Jackson, Peter Schmutzer, Amy Wenzel, and John Tyler. "Applicability of Cognitive Behavior Therapy with American Indian Individuals." Psychotherapy: Theory, Research, Practice, Training 43 (2006): 506-17.

41. Sigrid Herring, Jo Spangaro, Marlene Lauw, and Lorna McNamara. "The Intersection of Trauma, Racism, and Cultural Competence in Effective Work with Aboriginal People: Waiting for Trust." Australian Social Work 66 (2013): 104-17.

42. Michael Hart. "Am I a Modern Day Missionary? Reflections of a Cree Social Worker.” Native Social Work Journal/Nishnaabe Kinoomaadwin Naadmaadwin 5 (2002): 299-309.

43. Renee Linklater. "Decolonising Trauma Work: Indigenous Practitioners Share Stories and Strategies.” Ph.D. Thesis, University of Toronto, Toronto, ON, Canada, January 2011.

44. Jill Hill, Michael Lau, and Derald Sue. "Integrating Trauma Psychology and Cultural Psychology: Indigenous Perspectives on Theory, Research, and Practice." Traumatology 16 (2010): 39-47.

45. Natalie Clark. "Opening pandora's box: Girls groups and trauma-informed intersectional practice." In Moving the Addiction and Mental Health System Towards Being More Trauma-Informed. Edited by Nancy Poole and Lorraine Greaves. Vancouver: British Columbia Centre of Excellence for Women's Health, 2012.

46. Edward Duran, Judith Firehammer, and John Gonzalez. "Liberation Psychology as the Path towards Healing Cultural Soul Wounds." Journal of Counseling \& Development 86 (2008): 288-95.

47. Suzanne McKenzie-Mohr, John Coates, and Heather McLeod. "Responding to the Needs of Youth who are Homeless: Calling for Politicized Trauma-Informed Intervention." Children and Youth Services Review 34 (2012): 136-43. [CrossRef]

48. Mary Watkins, and Helene Shulman. Towards Psychologies of Liberation. New York: Palgrave MacMillan Publishing, 2008. 
49. Laurence Kirmayer, Cori Simpson, and Margaret Cargo. "Healing traditions: Culture, community and mental health promotion with Canadian Aboriginal peoples." Australasian Psychology 11 (2003): 15-23.

50. Leanne Simpson. Dancing on Our Turtle's Back: Stories of Nishnaabeg Re-Creation, Resurgence, and a New Emergence. Winnipeg: Arbeiter Ring Publishing, 2011.

51. Charles Taylor. "The politics of recognition." In Multiculturalism: Examining the Politics of Recognition. Edited by Amy Gutmann. Princeton: Princeton University Press, 1994.

52. Zitkala-Sa. American Indian Stories, Legends, and Other Writings. New York: Penguin Books, 1901.

53. Sarah Winnemucca. Life among the Piutes: Their Wrongs and Claims. Bishop: Sierra Media Inc., 1969.

54. Combahee River Collective. "A Black Feminist Statement." In Words of Fire: An Anthology of African-American Feminist Thought. Edited by Beverly Guy-Sheftall. New York: New Press, 1995, pp. 210-18.

55. Kimberle Crenshaw. "Demarginalizing the Intersection of Race and Sex: A Black Feminist Critique of Antidiscrimination Doctrine, Feminist Theory and Antiracist Politics." University of Chicago Legal Forum 140 (1989): 139-67.

56. Dorothy Ann Nason. "Red Feminist Literary Analysis: Reading Violence and Criminality in Contemporary Native Women's Writing." Ph.D. Thesis, University of California, Berkeley, CA, USA, 2010.

57. Sandy Grande. Red Pedagogy: Native American Social and Political Thought. Lanham: Rowman \& Littlefield, 2004.

58. Lester-Irabinna Rigney. "A First Perspective of Indigenous Australian Participation in Science: Framing Indigenous Research Towards Indigenous Australian Intellectual Sovereignty." Kaurna Higher Education Journal 7 (2011): 1-13.

59. Eve Tuck, and Wayne Yang. "Decolonization is not a Metaphor." Decolonization: Indigeneity, Education and Society 1 (2012): 1-40.

60. George Manuel, and Michael Polsuns. The Fourth World: An Indian Reality. New York: The Free Press, 1974.

61. Taiaiake Alfred, and John Corntassel. "Being Indigenous: Resurgences against Contemporary Colonialism." Government and Opposition: Politics of Identity 40 (2005): 597-614.

62. Michael Yellow Bird, John Coates, Mel Gray, and Tiani Hetherington. Decolonizing Social Work. Surrey: Ashgate Publishing Limited, 2013.

63. Cynthia Wesley-Esquimaux, and Andrew Snowball. "Viewing Violence, Mental Illness and Addiction Through a Wise Practice Lens." International Journal of Mental Health and Addictions 8 (2010): 390-407. [CrossRef]

64. Cynthia Wesley-Esquimaux, and Brian Calliou. Best Practices in Aboriginal Community Development: A Literature Review and Wise Practices Approach. Alberta: The Banff Center, 2010.

65. Michael Thoms. Leading an Extraordinary Life: Wise Practices for an HIV Prevention Campaign with Two-Spirit Men. Toronto: Two-Spirit People of the First Nations, 2007. 
66. Lewis Williams, and Zubia Mumtaz. "Being Alive Well? Power-knowledge as a Countervailiing Force to the Realization of Mental Well-Being for Canada's Aboriginal Youth.” International Journal of Mental Health Promotion 4 (2008): 21-31.

67. Gregory Brass. "Respecting the Medicines: Narrating an Aboriginal Identity." In Healing Traditions: The Mental Health of Aboriginal Peoples in Canada. Edited by Laurence Kirmayer and Gail Valaskakis. Vancouver: UBC Press, 2009, pp. 355-80.

68. Marlene Brant Castellano. Final Report of the Aboriginal Healing Foundation, Volume I. A Healing Journey: Reclaiming Wellness. Ottawa: Aboriginal Healing Foundation, 2006.

69. James Waldram. Aboriginal Healing in Canada: Studies in Therapeutic Meaning and Practice. Ottawa: Aboriginal Healing Foundation Research Series, 2008.

70. McCreary Centre Society. Raven's Children: Aboriginal Youth Health in BC. Burnaby: McCreary Centre Society, 2000.

71. McCreary Centre Society. Raven's Children II: Aboriginal Youth Health in BC. Burnaby: McCreary Centre Society, 2005.

72. BC Children's Commission. Weighing the Evidence: A Report on BC's Children and Youth; 1999 Annual Report. Victoria: The Children's Commission, 2000.

73. Michael Chandler, and Christopher Lalonde. "Cultural Continuity as a Moderator of Suicide Risk Among Canada's First Nations." In Healing Traditions: The Mental Health of Aboriginal Peoples in Canada. Edited by Laurence Kirmayer and Gail Valaskakis. Vancouver: UBC Press, 2009, pp. 221-48.

74. Rod McCormick. "Aboriginal Approaches to Counselling.” In Healing Traditions: The Mental Health of Aboriginal Peoples in Canada. Edited by Laurence Kirmayer and Gail Valaskakis. Vancouver: UBC Press, 2009, pp. 337-54.

75. Yale Belanger, Liz Barron, Charlene McKay-Turnbull, and Melanie Mills. Urban Aboriginal Youth in Winnipeg: Culture and Identity Formation In Cities. Winnipeg: Canadian Heritage, 2003.

76. Natalie Clark, Patrick Walton, Julie Drolet, Tara Tribute, Georgia Jules, Talicia Main, and Mike Arnouse. "Melq'ilwiye: Coming Together: Intersections of Cultural Identity and Health for Urban Aboriginal Youth." Canadian Journal of Nursing Research (2013): 36-57.

77. Tracy Robinson, and Janie Victoria Ward. "A Belief in Self Far Greater than Anyone's Disbelief: Cultivating Resistance among African American Female Adolescents." Women and Therapy 11 (1991): 87-103.

78. Madeline Dion Stout. "A Survivor Reflects on Resilience." In "Speaking my Truth:" Reflections on Reconciliation and Residential School. Ottawa: Aboriginal Healing Foundation, 2012, pp. 47-53.

79. Gerald Robert Vizenor. Manifest Manners: Postindian Warriors of Survivance. Hanover: Wesleyan University Press, 1994.

80. Mikhail M. Bakhtin, and Michael Holquist. The Dialogic Imagination: Four Essays. Austin: University of Texas Press, 1981.

81. Natalie Clark. "Enter the Hard Place: The Midwifery of Adolescent Women's Stories." MSW Thesis, University of British Columbia, Vancouver, BC, Canada, May 1992. 
82. Trinh T. Minh-Ha. Woman, Native, Other: Writing Postcoloniality and Feminism. Bloomington: Indiana University Press, 1989.

83. Bell Hooks. Feminist Theory from Margin to Center. Boston: South End Press, 1984.

84. Devon A. Mihesuah. Indigenous American Women: Decolonization, Empowerment, Activism. Lincoln: University of Nebraska, 2003.

85. Leslie Marmo Silko. Ceremony. New York: Viking, Penguin Books, 1996.

86. Patricia Hill Collins. "Learning from the Outsider-Within: The Sociological Significance of Black Feminist Thought." In Beyond Methodology: Feminist Scholarship as Lived Research. Edited by Mary Margaret Fonow and Judith Cook. Bloomington: Indiana University Press, 1991, pp. 35-59.

87. Michel Foucault. Language, Counter-Memory, Practice: Selected Essays \& Interviews. Ithaca: Cornell University Press, 1977.

88. Sarah Hunt. "Witnessing the Colonialscape: Lighting the Intimate Fires of Indigenous Legal Pluralism.” Ph.D. Thesis, Simon Fraser University, Burnaby, BC, USA, 2014.

89. Lisa Taylor, Umwali Sollange, and Marie-Jolie Rwigema. "The Ethics of learning from Rwandan survivor communities: The politics of knowledge production and shared authority within community-school collaboration in genocide and critical global citizenship education." In Beyond Testimony and Trauma: Oral History in the Aftermath of Mass Violence. Edited by Steven High. Vancouver: University of British Columbia Press, 2015.

90. Cheryl Bell-Gadsby, Natalie Clark, and Sarah Hunt. It's a Girl Thang: A Manual on Creating Girls Groups. Vancouver: McCreary Youth Foundation, 2006.

91. Natalie Clark, and Sarah Hunt. "Navigating the Crossroads: Exploring Young Women's Experiences of Health Using an Intersectional Framework." In Health Inequities in Canada: Intersectional Frameworks and Practices. Edited by Olena Hankivsky. Vancouver: UBC Press, 2012, pp. 131-46.

92. Eve Tuck. "Suspending Damage: A Letter to Communities." Harvard Educational Review 79 (2009): 409-28.

93. Jo-Ann Archibald. Indigenous Storywork. Educating the Heart, Mind, Body, and Spirit. Vancouver: University of British Columbia Press, 2008. 


\title{
Decolonizing Trauma Studies Round-Table Discussion
}

\section{Stef Craps, Bryan Cheyette, Alan Gibbs, Sonya Andermahr and Larissa Allwork}

\begin{abstract}
This round-table, which featured literary critics Professor Stef Craps, Professor Bryan Cheyette and Dr. Alan Gibbs, was recorded as part of the "Decolonizing Trauma Studies" symposium organized by Dr. Sonya Andermahr and Dr. Larissa Allwork at The School of The Arts, The University of Northampton (15 May 2015). Convened a week after the University of Zaragoza's "Memory Frictions" conference, where Cheyette, Gibbs, Andermahr and Allwork gave papers, the Northampton symposium and round-table was sponsored by The School of The Arts to coincide with Andermahr's guest editorship of this special issue of Humanities. Craps, Cheyette and Gibbs addressed five questions during the round-table. Namely, does trauma studies suffer from a form of psychological universalism? Do you see any signs that trauma studies is becoming more decolonized? What are the challenges of a decolonized trauma studies for disciplinary thinking? How does a decolonized trauma studies relate to pedagogical ethics? Finally, where do you see the future of the field? While this edited transcript retains a certain informality of style, it offers a significant contribution to knowledge by capturing a unique exchange between three key thinkers in contemporary trauma studies, providing a timely analysis of the impact of postcolonial theory on trauma studies, the state of the field and its future possibilities. Issues addressed include the problematic scholarly tendency to universalize a western model of Post-Traumatic Stress Disorder (PTSD); the question of the centrality of the Holocaust in trauma studies and the implications of this for the study of atrocities globally; the vexed issues posed by the representation of perpetrators; as well as how the basic tenets of western cultural trauma theory, until recently so often characterized by a Caruth-inspired focus on belatedness and afterwardness, are being rethought, both in response to developments in the US and in answer to the challenge to 'decolonize' trauma studies.
\end{abstract}

Reprinted from Humanities. Cite as: Craps, S.; Cheyette, B.; Gibbs, A.; Andermahr, S.; Allwork, L. Decolonizing Trauma Studies Round-Table Discussion. Humanities 2015, 4, 905-923.

Larissa Allwork: It has been a fantastic day of papers, and we are going to finish with a very special round-table on the theme of the symposium, which is "Decolonizing Trauma Studies" [1]. Commenting on the questions that we are going to cover are Professor Stef Craps, our keynote speaker, author of Postcolonial Witnessing: Trauma out of Bounds [2] and Director of the Cultural Memory Studies Initiative at Ghent University. Joining him will be Professor Bryan Cheyette, who is Chair in Modern Literature at the University of Reading. He is the editor or author of nine books, most recently Diasporas of the Mind [3] and Volume Seven of the Oxford History of the Novel in English [4], which is forthcoming with Oxford University Press. We are also very happy to welcome Dr. Alan Gibbs, who is Lecturer in American Literature at University College Cork. He has recently written on trauma theory and cultural representations, and in 2014 published Contemporary American Trauma 
Narratives [5]. So, without further ado, I am going to hand over to Dr. Sonya Andermahr, who will ask the questions.

Sonya Andermahr: We are going to start off with an issue that's been bubbling through our discussions all day. It concerns the relationship between individual and collective traumas when we are discussing non-western and minority cultural groups. So the question is, do trauma studies suffer from a form of psychological universalism, in your opinion?

Alan Gibbs: $\quad$ The short answer would be yes. I think that it's well established that this is a problem with the cultural trauma model, and with the model of PTSD widely disseminated through DSM-III [6]. I'm thinking back to Allan Young's book, The Harmony of Illusions, which amazingly was published 20 years ago now [7]. It points out the problem that PTSD is taken to be this kind of timeless, universal way in which we understand trauma, when in fact Young does a very able job of showing how trauma is pieced together from various contemporary discourses and ideologies. I agree with him. I think there are multiple problems of taking this relatively temporally and geographically local phenomenon of PTSD and trying to universalize it.

There are also problems in the treatment of trauma, and Derek Summerfield has pointed this out, that there is a kind of 'neo-colonialism' if you like, of exporting notions of PTSD [8]. I think, Stef, you've talked about this in your work. For example, the problems with western aid workers going into Sri Lanka after the 2004 Tsunami and using their methods to try to treat trauma ([2], pp. 22-23). I think there are also problems in my field, literary studies, of trauma studies-perhaps as part of its attempt to connect disciplines - actually having a colonial mode itself, in trying to dominate other disciplines, across other disciplinary boundaries. These represent problems of trauma theory extending its purview beyond where it operates convincingly. Just to finish, I'll give an example. I remember a paper I heard three or four years ago at a conference on literary representations of trauma. This paper examined ancient Greek literature and the presenter argued that the descriptions of the soldiers post-battle portrayed them as having this "thousand yard stare" and therefore they could be diagnosed as suffering from PTSD. This strikes me as dangerous and presumptuous, to homogenize history in this way, to suggest that humans have always suffered in the same way from trauma. It has a number of implications, but I think that this is something we should further explore.

Stef Craps: I haven't got too much to add, actually, to what Alan has just said. That trauma studies suffers from psychological universalism is one of the key criticisms that I level in my book [2]. I argue that yes, it is important for trauma studies to look beyond the Euro-American context and to pay more attention to the 
traumas associated with colonialism, for example. However, that in itself does not suffice. Because if you're going to impose a western framework on these other histories, you may end up distorting them, so you may be doing more harm than good. In other words, decolonizing trauma studies is not just about expanding the scope, broadening the focus, but also about critically examining and revising dominant conceptions of trauma and recovery.

This is a task not only for cultural trauma theory, but also for psychological trauma research. Among psychologists, concerns have been raised about the PTSD construct, as Alan has already pointed out, and alternative paradigms have been proposed. However, none of this seems to have had much of an impact on the field of cultural trauma research. The impact of different cultural traditions on the way trauma is experienced and on the process of healing is rarely acknowledged. Trauma theory for the most part continues to adhere to the traditional, event-based model of trauma, according to which trauma results from a single, extraordinary, catastrophic event, and recovery takes the form of the talking cure. So, in a sense, the situation in the field of cultural trauma research is even more dire than that in the field of psychological trauma research, because recent insights from the latter field - in which there is a growing awareness, at least, of the need to move beyond psychic universalism - aren't even taken up in the former field. Or, that is, they weren't until very recently.

Bryan Cheyette: For some historical perspective, I would add the figure of Frantz Fanon, who in 1952 in Black Skin, White Masks was already critiquing the Freudian analysis of trauma for being Eurocentric and ignoring Africa [9]. He very much wanted to construct a 'black psychiatry' against dominant modes, which he eventually put into practice in Tunisia and Algeria. The complicating factor is that within Fanon's early critique of Eurocentric psychiatry, there are all kinds of representations that you would not actually want there, such as the mind/body opposition or a disdain for homosexuality and a validation of masculinity. But this was an early critique which shows that, from an anti-colonial perspective, trauma studies has a long history of being thought of as Eurocentric.

Sonya Andermahr: Moving on then to the next major question that we've been exploring in today's symposium: do you see any signs that trauma theory is becoming more decolonized?

Stef Craps: $\quad$ I would say so, yes, judging from the number of publications on colonial trauma and postcolonial trauma theory that have appeared in recent years and the number of conferences and panels that have been devoted to these issues, including this symposium. It struck me, for example, that moving beyond Eurocentrism is the most pronounced trend that can be seen in recent 
collections which try to take stock of the state of the art of research in the field of trauma studies. I'm thinking of The Future of Trauma Theory [10] and Contemporary Approaches in Literary Trauma Theory [11]. Both of these collections contain several essays whose explicit purpose is to decolonize trauma studies.

At the same time, though, my sense is that we're only at the beginning of this process. That's also where I would situate my own work in this area. What I do in my Postcolonial Witnessing book [2] is diagnose a problem but not so much remedy it. That is one of the no doubt many limitations of the book. I don't want to generalize, but to some extent I think this is symptomatic of the phase we're in. I have tended to focus on literary texts that highlight the shortcomings of the dominant trauma discourse, for example Sindiwe Magona's novel Mother to Mother [12] and, more recently, Aminatta Forna's novel The Memory of Love $[13,14]$. These are texts by postcolonial writers who, however, are steeped in western culture, who write in English, and who address a western audience first and foremost. They invest considerable energy in pointing out the inappropriateness and the injustice of applying western frameworks to a colonial or postcolonial situation, but they are less concerned with offering a concrete alternative.

That's the next step, I think: once the critique is out of the way, we can start examining what an alternative to the dominant trauma discourse might look like in practice, on the ground, in particular non-western or minority contexts. It's been very gratifying to see that my work has been taken up by other scholars, especially $\mathrm{PhD}$ students, who are doing just that. I think it's important to study how the cultural production of particular non-western or minority groups bears witness to painful histories. This requires specialized knowledge of these other cultures and languages, of the different media and forms of expression they use, and of local beliefs about suffering and healing. So I think that's where we're headed.

Bryan Cheyette: In my case, a teaching and research interest in Holocaust testimonies came before an interest in trauma theory. I now recognize that the Holocaust has been the dominant trauma discourse, but what Michael Rothberg calls the 'colonial turn' within Holocaust studies has been very important for the decolonizing process which Stef describes [15]. The danger, and maybe I'll talk more about this a little later, is of having a supersessionist model which constructs the Holocaust as the classic expression of trauma that, as a consequence of this model, has to be transcended by newer instances. That model comes up in all kinds of other disciplines; ethnic and racial studies, diaspora studies, even postcolonial studies. Also problematic is the oft-made assumption that the Holocaust is wholly Eurocentric which should be at least 
Stef Craps: Could you elaborate on your point that the assumption that the Holocaust is wholly Eurocentric is problematic? After all, it was a genocide that took place in Europe and was committed by Europeans against other Europeans.

Bryan Cheyette: Obviously, the camps were based in Europe, but, to answer your question in full, I would recommend Mark Mazower's Hitler's Empire, which shows that the Holocaust was a continuation of the colonial project [16]. This argument reinforces the early anti-colonial critiques of Aimé Cesaire [17] and Hannah Arendt, who, reflecting many others in the 1940s and 1950s, saw Nazi atrocities as colonialism brought home to Europe [18]. What Mazower shows is that the Nazis looked to two main colonial projects as a model for their intended colonization of the European continent. Firstly, the growing power and influence of North America was seen to be a consequence of the colonization of the American continent (North and South). The Nazis also saw British colonies in Africa and Asia, which they witnessed first-hand, as a model for their own project of colonizing Europe. There's a wealth of historical detail in Mazower to show that a number of Nazis in Eastern Europe were trained in Africa, especially in West Africa ([16], pp. 581-88). The book also illustrates the tensions between a colonial model of the camps, based on slave labour, and an exterminatory model based on 'race' theory. So there are a large number of connections between the camps and colonialism. Also, of course, the Nazi genocide extended outside of Europe to North Africa especially. So there are all kinds of ways of thinking of the colonial turn historically as well as complicating present-day Eurocentric understandings of the Holocaust.

What I would argue, in terms of my own work on disciplinary thinking, is that up until the 1960s, in relation to an anti-colonial critique, none of these areas were separated out; they were seen as part of the same history: colonialism, fascism, genocide, racism. So it's really only after the 1960s that discussion of these areas began to be 'disciplined'. A figure like Fanon, for example, was influenced enormously in his thinking by issues of anti-Semitism through the work of Jean-Paul Sartre, but also in relation to his own experience as a soldier fighting against fascism. As a result, it seems to me that the assumption that the Holocaust, its causes, history and legacies, are largely Eurocentric needs to be questioned. 
Alan Gibbs: I would just add a couple of things. It is interesting that we are looking at this from different perspectives. Bryan, you're coming at this from the Holocaust studies perspective, and my background is very much in American literature and American studies. What has been really interesting for me has been seeing the impact of postcolonial studies on trauma studies most recently. I think getting back to the original question: yes, I would agree that in the last few years there are many signs that theory is becoming more decolonized. There is much more consciousness of the variety of manifestations of trauma. There is more sensitivity to localized variations in causes and symptomatology and treatment and, especially interesting for me, the representation of trauma.

There is also more sensitivity to phenomena such as insidious trauma, and ideas to do with slow violence. This has had an impact on the way trauma theory and trauma studies are considered in the American context. One of the things that I have been arguing is that this set of cultural trauma theories that have become so dominant are not only inadequate for the postcolonial experience but even for many representations in fairly mainstream American writing as well. What I argue in Contemporary American Trauma Narratives is that these dominant trauma paradigms do not even necessarily work in the contemporary American context [5].

Bryan Cheyette: I agree absolutely with you, Alan. In Diasporas of the Mind, I have a chapter on Philip Roth, and I argue that there's a shift in most of his late fiction, particularly after Sabbath's Theatre [3,19]. After this novel, Roth begins to write from a national perspective (rather than a diasporic perspective), and as a result, locates issues of trauma and suffering within the post-war history of the United States rather than as part of European history as he did in his earlier fiction. As a result, his fiction has become rather earnest. In The Plot Against America, for instance, Roth holds back the more extreme implications of his narrative of American fascism as it only makes sense in a European context [20]. The notion of a traumatized nation, post $9 / 11$, in the US is central to Roth's late fiction, which has been surprisingly well-received given the geopolitical consequences of such national trauma.

Alan Gibbs: $\quad$ Yes, I think so, and I also think that some of the creative and critical writing that has been published since $9 / 11$ has shown the inadequacy of very narrow definitions and narrow prescriptions about the aesthetic representation of trauma. A lot of writers have really strained against that post 9/11.

Stef Craps: I want to briefly come back to Alan's point about insidious trauma in the American context. I think there has indeed been a tendency to map the event-based model of trauma onto western experiences and to assume that insidious trauma is what happens elsewhere. I agree that that's reductive. For example, the Holocaust is often discussed in terms of the event-based model, but 
does it really make sense to think of it as a single catastrophic event? It lasted five years or so and encompassed lots of different kinds of events and experiences; it's hardly a straightforward case of punctual trauma, let alone a textbook example.

Alan Gibbs: Well this is what always surprises me about how dominant that punctual model has become, given that the Holocaust is so much at the root of trauma studies. But yes, absolutely, there are insidious traumas at the heart of American life as well. So again that model does not fit so well there. There is one other thing I would just point out which occurred to me during Sonya Andermahr [21] and Béatriz Perez Zapata's [22] panel today, in terms of getting away from these kinds of dominant models, which I thought was very interesting. Sonya and Béatriz were both talking about how Zadie Smith [23] and Andrea Levy [24] adopt some of this postmodernist trauma aesthetic but were also much more interested in how these authors violate that aesthetic, and how they go beyond it. Now this seems to me quite a significant step forward from a lot of papers and articles that I've encountered over the last few years which frequently perform a fairly formulaic checklist criticism which evaluates the extent to which a particular writer lives up to how trauma should be represented. I thought it was really interesting that you both took a much different approach this afternoon.

Sonya Andermahr: We knew who was going to be listening (Laughter). The next question, suggested by Bryan, concerns disciplinary thinking and the implications and challenge of a decolonized trauma theory for our understanding of our own disciplines and their relations to others. Bryan, would you like to lead on this?

Bryan Cheyette: Yes, this is a key argument in Diasporas of the Mind which goes back to the period of decolonization after the Second World War from the 1940s to the early 1960s. At this time there wasn't the kind of disciplinary thinking which put different national and ethnic histories into separate spheres that we have now. That seems to me to be a period that is well worth exploring as the connections between the history of genocide in Europe and European colonialism are made throughout by anti-colonialists as well as Holocaust survivors, which is why scholars have gone back to Hannah Arendt [18] especially. Disciplinary thinking, on one level, is a way of thinking critically about academic disciplines. My argument is that academic disciplines are constructed increasingly in terms of what they leave out, and defined by what they exclude. Jonathan Boyarin has argued this ([25], p. 172), as has Gayatri Spivak, who talks about "disciplinary fear" [26]. The problem with knowing more and more about less and less is that it can lead to a lack of interconnectedness across disciplines. 
Stef Craps: I think I'm basically on the same page as Bryan in that I also believe in crossing boundaries in full awareness of all the pitfalls this entails. Bryan in his book also talks about what he calls "the anxiety of appropriation" ([3], p. xiv).

Bryan Cheyette: Yes, we seem to have simultaneously come up with a similar term!

Stef Craps: In my book [2] I follow Michael Rothberg [15] in using the concept of metaphor to name a way of looking at history that insists on similarity and in so doing threatens to conflate distinct historical experiences. I oppose it to a metonymical view, which places different histories alongside one another and thus preserves the distance between them. I argue that we need to combine the two logics, that a metonymical view of history needs to supplement a 
metaphorical one. Bryan only mentions metaphor, not metonymy, but I think this is just a question of semantics rather than a fundamental disagreement.

Bryan Cheyette: Yes.

Stef Craps:

What Bryan calls "metaphorical thinking" ([3], pp. xiii-xiv) is not unlike the oscillation between the two logics that I describe ([2], p. 89).

The reason why I tend to dwell on the risks involved in remembering across cultural and national boundaries, as I did in my talk this morning [31], is that many proponents of what Astrid Erll calls the "transcultural turn" in memory studies ([32], pp. 173-74) minimize them or ignore them altogether. Much work in transcultural memory studies, especially by American scholars, articulates a very hopeful vision. I'm thinking particularly of Daniel Levy and Natan Sznaider [33], Alison Landsberg [34] and Jeffrey Alexander [35]. Their work is characterized by a strong belief in the emancipatory potential, the cathartic or healing effects of remembering across cultural and national borders. Personally, I think a healthy dose of scepticism is called for. After all, very often Holocaust comparisons are used in ways that do not lead to greater transcultural understanding and the establishment of a universal human rights culture. I do think the notion that transcultural or transnational remembrance can have beneficial effects - in principle if certainly not always in practice- is worth considering, but not uncritically.

Another issue I want to raise is my growing discomfort with the centrality of the Holocaust in scholarship challenging disciplinary thinking. I wonder if by almost always taking the need to decentre the Holocaust as our starting point, we are not inadvertently reaffirming its centrality. I myself plead guilty in this regard: I also do this in much of my work, including in my talk this morning [31]. In fact, I don't think any individual scholar is to blame exactly, but if we all end up always taking the Holocaust as our point of comparison, it seems to me that our collective efforts to move beyond disciplinary thinking may prove counterproductive. After all, there is something profoundly paradoxical about considering one particular history to be uniquely suited to challenging the uniqueness paradigm. So again, I agree with Bryan about the need for more comparative work in memory and trauma studies, but I would add that it would be salutary and refreshing if a greater variety of histories were brought into contact with one another.

Alan Gibbs: $\quad$ Yes, I would not presume to add very much because it's not something I've given as much thought to. I agree with Stef's dose of healthy scepticism in that as cultural trauma studies emerged there were hopes that it would somehow unite conceptions of memory and different disciplines. I don't think these have been anywhere near achieved, I suppose partly due to differences being 
maintained between disciplines. The areas I am thinking of in particular would be literature, psychology and history in that their perspective on trauma seems to be still very disparate. The example I would cite would be to do with the experience of the perpetrator when it comes to trauma. I might say more about this later, but it is something that, for example, the discipline of history has looked at quite extensively, whereas it seems to me that when you come to literary studies, there is still a strong discomfort with even broaching the notion of the perpetrator.

Sonya Andermahr: Thank you. Now if we can discuss the implications for pedagogy, particularly thinking around the ethics of detachment and identification. Bryan, would you like to say a few words on this?

Bryan Cheyette: This issue came out of the University of Zaragoza conference [29], and I suppose it is a question I could throw open to the panel, who I am assuming teach trauma studies. It seems to me that when one teaches the kind of texts that deal with trauma and attempt to represent trauma, the last thing you want to do is to enable students to turn it into just another academic discipline, where they detach themselves from that trauma. So one of the things that I find very useful, as part of the assessment, is to give students a journal where they can move away from that sense of academic detachment.

There are other ways of critiquing questions of detachment. One form of cosmopolitanism, for instance, has been critiqued as being overly detached [36]. But those who are most self-conscious about their own particular traumas are aware that in some ways they are complicit with those who did the traumatizing when they split themselves by writing about their experiences from an objective or detached perspective. So there is a range of issues around those terms.

Alan Gibbs: I thought it was very interesting when that came up last week at the University of Zaragoza, this idea of actually getting students to admit a kind of emotional response as part of their response to a text.

Bryan Cheyette: Or at least to give them a space where they can engage emotionally with the texts.

Alan Gibbs: $\quad$ Yes, I think that might make me re-think how I teach some of this material. I do tend, and I think this is just coming from a literary studies background, to encourage detachment. I am probably a little averse to emotional responses just because of so many years of training. Again, I suppose we could go back to this idea of a plethora of literary texts that do explore the notion of the perpetrator, or at least the 'grey zone', when it comes to trauma. And it is understandable that this more emotionally invested approach has found it 
distasteful to tackle some of these texts. I think that trauma theory's roots in Holocaust studies and psychology are especially relevant here.

But the fact is, these texts are published, and they are widely read. For example, the plethora of memoirs written by members of the American armed forces following their involvement in various conflicts. As a literary scholar, there is a kind of willful negligence in pretending that texts such as these do not exist. We cannot wish them away. I think what trauma theory and trauma studies can do more usefully is to develop methodologies for understanding these perpetrator trauma texts. For example, how does trauma operate differently for perpetrators? How is it represented differently in terms of narrative and aesthetic forms in these texts? Some work has been started on this. I have done a little bit in my book, and there is Michael Rothberg's, I think potentially very useful, concept of the "implicated subject" [37,38]. This is a figure somewhere between victim or sufferer and perpetrator. Here I believe are the beginnings of some interesting work.

Stef Craps: $\quad$ It seems to me that trauma studies has always been critical of detachment as a stance from which to approach painful histories. It is a basic assumption of much trauma theory that readers or viewers should be affected by trauma testimonies they read or view. There is an important affective or experiential dimension to reading or hearing about histories of suffering; it's not just about assimilating factual knowledge.

Of course, the risk involved in encouraging people to respond affectively to trauma testimonies is that they will over-identify with trauma survivors, appropriating their experience and ignoring its singularity. This is a risk of which trauma theorists have long been aware. People like Cathy Caruth, Dominick LaCapra, Jill Bennett and E. Ann Kaplan have warned against forms of affective involvement that do not respect and recognize alterity. They refer to these kinds of responses as "crude empathy", "facile empathy", or "empty empathy". Desirable empathy, by contrast, is called "empathic unsettlement" ([39], p. 135), "critical empathy" ([40], p. 21), or an "ethics of witnessing" ([41], p. 122). It's a kind of empathy-at-a-distance, which combines affect with critical awareness of the unbridgeable gap between self and other.

This is one trauma-theoretical orthodoxy that I'm quite comfortable with, as long as empathy is indeed checked and combined with a measure of critical distance. In fact, I tend to ask students to prepare for my classes on trauma literature by writing response pieces about the assigned readings, in which they can share their reading experience, if they wish to do so, provided that they also reflect on it. I share Bryan's scepticism about calls for detachment insofar as they devalue the affective, experiential dimension of relating to 
painful histories and embrace the idea of full objectivity, neutrality and aloofness. In Representing the Holocaust, LaCapra argued-and I think this is what you were also getting at, Bryan - that as a historian, one has to come to terms with one's transferential implication in one's object of study, which means: being vigilant not to repeat the problems one is studying ([42], p. 46). He called pure objectification — positioning oneself as a complete outsider - a denial of transference. It actually repeats the kind of thinking that allowed the Nazis to dehumanize the Jews and do what they did in the first place.

I will add, though, that, like Alan, I think there has been too much of an emphasis in trauma studies on identification with victims and too little emphasis on identification with perpetrators. While it's important, of course, to pay attention to the experience of victimhood, it's also important to try to understand the perpetrator's perspective. If we only ever identify with victims - if we only ever place ourselves on the side of the angels, as it werewe effectively deny our own complicity in violent histories and our own capacity for evil. As Rick Crownshaw has argued, the universalization of the victim's identity turns the perpetrator into an unknowable, mysterious figure, who has nothing to do with us, and renders the processes of perpetration incomprehensible ([43], p. 77). So, paradoxically, instead of preventing the repetition of a violent past, trauma studies may actually end up facilitating its recurrence. Again, I don't think any individual trauma theorist is to blame, but if the field as a whole is heavily skewed towards exploring victimhood rather than focusing on perpetration, I do think there is a problem.

The fact that I believe in the value of "empathic unsettlement" ([39], p. 135) also means that I'm very sceptical of the campaign for "trigger warnings" that has swept the US academy over the last year or so [44]. The idea is that professors should give students advance warning if they are planning to confront them with potentially disturbing or upsetting material, and allow them to skip classes that could make them feel uncomfortable. Of course, it's not a black-and-white situation. I do think it's reasonable for a rape survivor, for example, to ask a professor for a heads-up if the reading list includes a text with graphic descriptions of sexual violence. And, of course, students have the right to walk out of a classroom. But generalized trigger warnings are a different matter; there is real harm in utilizing them, it seems to me. I believe that education is basically all about being disturbed, about being made to leave one's comfort zone, about being shaken out of one's habitual assumptions. Discomfort is essential to education; it's what drives it. So you want to be very careful not to tamper with that basic principle. Instead of protecting students, general trigger warnings may prevent them from getting an education. 
Sonya Andermahr: So we move to our final question then, which concerns the future of the field. Alan, if you'd like to predict the future for us?

Alan Gibbs: Obviously, it is a difficult question, and impossible really to answer this without just extrapolating from the present. I can see it going two ways. On the one hand, I think there is a lot more flexibility in the concepts of trauma we have seen emerging in the last 5 to 10 years. There are clear signs now that we are moving beyond the narrower and more prescriptive ways of understanding trauma and conceptualizing how trauma is represented or should be represented. Again thinking back to the Zaragoza "Memory Frictions" conference, Robert Eaglestone's keynote address raised an interesting point. Namely, that the concept of trauma is becoming so wide now, including things like 'slow violence', 'insidious trauma', that the question needs to be raised as to whether we are actually still talking about something that we can label trauma anymore. His feeling seemed to be that perhaps we should come up with new terms [45].

My feeling is more that we can still understand these phenomena according to a concept of trauma. But at the same time, I would admit that as its definition stretches, it begins to become less meaningful as a concept. On the other hand, maybe we are reaching a crisis point in considering the very notion of trauma. I am reflecting on an article that was published towards the end of last year, Joshua Pederson's "Speak Trauma", which came out in the October 2014 issue of Narrative [46]. This presented a serious challenge to some of the most cherished notions of cultural trauma theory. It was very much an attack on some of Cathy Caruth's work and its basis in neurological research that Pederson was very keen to debunk $[47,48]$, connecting with and drawing upon Richard McNally's criticism of Bessel A. Van der Kolk's work [49]. Pederson's essay challenges this dominant idea that belatedness is necessarily part of trauma, that afterwardness is part of traumatic memory. It also presents a challenge to the idea that traumatic memory is necessarily different, that it is registered differently on the brain to regular memory. Now, this is such a foundation of cultural trauma theory that if, as appears to be the case, there is new research challenging even this, then there is an awful lot that is going to have to be re-thought. Pederson's article encourages us to recognize the difference between an inability to remember the traumatic memory and an inability or a refusal to narrate it. I think this is an important distinction, one that I have urged in my own work ([5], p. 75), and which ought to be very influential and important for the future of the field.

As Stef suggests in his work, I think we also need a greater sensitivity towards the context of the text. I have been looking at this in my own field of contemporary American writing and suggesting that there has been the 
emergence of a kind of neo-naturalism for the representation of trauma, partly as a kind of reaction against the traumatic avant-garde. Within this context, it is also important to consider notions of agency which have become increasingly important in contemporary American life. For example, post 9/11, there is a discernible discomfort amongst a large part of the population in accepting responsibility for the government's actions. So this emergence of a new form of naturalism frequently incorporates a kind of determinism that denies characters free will, thus removing responsibility for their actions. This is again a very interesting, quite local manifestation of a particular kind of trauma text that we are going to have to be flexible to account for. So, there are lots of possibilities opening up but also lots of potential problems for the future of the field.

Sonya Andermahr: Great, thank you. Bryan?

Bryan Cheyette: One of my professors taught me that "You can predict everything apart from the future!" The quest for new terms and new ways of thinking is certainly something that characterizes our moment, and I find Alan's use of the term 'crisis-point' in this context very interesting. We are in a kind of crisis, we are post-postmodern, post-theory, post-postcolonialism, I mean we're even post-post! We are looking for new terms and new ways of thinking about our times as well as new vocabularies. So we are, it seems, back to the question of newness, but that does not mean, as I have stressed, that we have to evacuate a historical understanding of the issues which we are discussing. In all of our books, we are looking for new ways of trying to think about our present moment while, it seems to me, aiming for a longer temporal and spatial reach. I agree absolutely with Stef about the question of the centrality of the Holocaust, which was not the case, I hasten to add, when I first started teaching! But the Holocaust has become central to western ways of thinking about history, which is largely because it has been Americanized, an odd phenomenon which complements Alan's work. So new comparative thinking will hopefully move away from that centralization without simply repeating the centralization via de-centralizing it, as Stef has argued. Maybe one example is the panel we had on the Aborigine writers and the issue of The Stolen Generations led by Maram Samman [50] and Justine Seran [51]. I was struck by that whole colonial or neo-colonial model of assimilation, the model of institutionalizing people, which applies across all minority ethnic histories and minorities in general. So you could also look at insane asylums in the United States and look at what the Irish did to young women without families to show that such histories often take place within so-called 'liberal' societies. My approach would be to make these kinds of linkages and comparisons beyond particular disciplines. I do think that 'trauma' and 'trauma studies' is 
pretty exhausted as a term, and I can see why we are getting the kind of critiques from someone like Joshua Pederson [46].

In regards to the future, I agree with Stef that looking at the risks of bringing together different histories and cultures should be at the centre of the comparative thinking enterprise. A lot of the examples that I look at in my own book, by V.S. Naipaul, Anita Desai, Salman Rushdie and others, might be said to have actually reinforced old discourses instead of being a celebratory bringing together of different histories [3]. In terms of a comparative project there are always two ways of looking at the metaphorical or metonymic turn. One approach is to bow to the risk of metaphorical thinking and to stay within particular histories of victimhood, and the second approach, which I champion in Diasporas of the Mind, is to make connections across nations, communities and cultures so as to enlarge our sense of self and include 'other others' in the pantheon of what it is to be human. But we should certainly be self-aware of the tension between risk-taking, which downplays differences, and celebrating inter-connectedness, which is on the side of a new decolonized humanism.

Sonya Andermahr: And finally, Stef, the last word is for you.

Stef Craps: $\quad$ I am quite hopeful about the future of the field, which is something that I probably wouldn't have said 10 years ago. Trauma theory had seemed to me to be stagnating somewhat since its early burst of creative energy in the 1990s. It's not as if nothing was happening, but I saw little evidence of conceptual innovation, of new ideas and theoretical breakthroughs, in the early 2000s. However, in the course of the last few years I've seen various signs of renewal and continuing relevance. It seems to me-and this ties in with what Alan was saying earlier - that the tenets laid down by the founders of trauma studies are increasingly being questioned and that, as a result, the field is becoming more diversified and pluralistic. I think the three of us have each done our bit to help make this happen, along with many others, of course.

Some exciting trends that I see are first of all the tendency to study trauma as a global rather than a European or Western phenomenon, which we've been talking about today. I think it's fair to say that this trend is by now firmly established, though, as I said, it's my sense that we're still only at the beginning of this process.

Secondly, and this has also come up already, attempts are being made to move beyond normative trauma aesthetics. The notion that a modernist aesthetic of fragmentation and aporia is uniquely suited to the task of bearing witness to trauma is losing ground. Trauma studies is confronting its aesthetic elitism problem and becoming more open to and appreciative of alternative modes of representation. This trend was spearheaded by Roger Luckhurst's The Trauma 
Question [52], which discussed the trauma canon alongside popular-cultural engagements with trauma, such as Stephen King novels and popular trauma memoirs. This has been taken further by Anne Rothe in a book called Popular Trauma Culture that looks at misery memoirs and daytime TV shows such as Jerry Springer and Oprah [53]. I myself have recently also supervised a $\mathrm{PhD}$ dissertation on trauma in video games, a medium that had long been neglected by trauma scholars. Alan's scathing critique of the ossified conventions of supposedly unconventional trauma writing is arguably the final nail in the coffin of the narrow trauma aesthetic to which the field has adhered for too long.

A third trend, which I'm particularly excited about and which Alan has also mentioned, is the shift or broadening of focus from victim trauma to perpetrator trauma: the tendency to no longer limit one's enquiry to the experiences of victims but to also take on board those of perpetrators as well as other categories of people implicated in traumatic events or histories. The notion that perpetrators can be trauma sufferers is still controversial, though, mostly because of the persistent tendency to conflate trauma and victimhood. The suspicion is that by claiming that a perpetrator has been traumatized, one is actually claiming victim status for him or her, exculpating him or her, excusing his or her crimes. However, as I see it, engaging with portrayals of perpetrators and various in-between groups is not about exonerating them (or, at least, it doesn't have to be that way) but about counter-acting a questionable tendency in trauma studies to over-identify with innocent victimhood, which, as I was saying earlier, risks blinding us to our own complicity and potential for evil.

A fourth trend, and I'll close with this, is an increasing awareness of the limits of trauma: attempts are being made to save the field from hubristic overreach by recognizing limits to its usefulness and legitimacy. Trauma theory sometimes overestimates its ability to diagnose, and even solve, the world's problems. It's increasingly being recognized - most eloquently, perhaps, by Michael Rothberg in his preface to The Future of Trauma Theory [54] - that trauma is not always the only or best lens for exploring complex global problems; trauma studies doesn't hold the key to understanding them, let alone to fixing them. It is but one possible mode of enquiry among others, valuable but only in consort with other approaches and methodologies, which it cannot and must not displace.

\section{Conflicts of Interest}

The authors declare no conflict of interest. 


\section{References and Notes}

1. For a full contextualization of this round-table discussion and the terms being used see: Sonya Andermahr. "Decolonizing Trauma Studies: Trauma and Postcolonialism-Introduction." Humanities 4 (2015): 500-5.

2. Stef Craps. Postcolonial Witnessing: Trauma Out of Bounds. Basingstoke and New York: Palgrave Macmillan, 2013.

3. Bryan Cheyette. Diasporas of the Mind: Jewish and Postcolonial Writing and the Nightmare of History. New Haven: Yale University Press, 2013.

4. Bryan Cheyette. The Oxford History of the Novel in English, Volume Seven: British and Irish Fiction since 1940. Oxford: Oxford University Press, 2016, forthcoming.

5. Alan Gibbs. Contemporary American Trauma Narratives. Edinburgh: Edinburgh University Press, 2014.

6. Robert L. Spitzer. DSM-III-R Casebook: A Learning Companion to the Diagnostic and Statistical Manual of Mental Disorders, 3rd ed., rev. Washington: American Psychiatric Press, 1989.

7. Allan Young. The Harmony of Illusions: Inventing Post-Traumatic Stress Disorder. Princeton: Princeton University Press, 1995.

8. Derek Summerfield. The Impact of War and Atrocity on Civilian Populations: Basic Principles for NGO Interventions and a Critique of Psychosocial Trauma Projects. London: Overseas Development Institute, 1996.

9. Frantz Fanon. Black Skin, White Masks. New York: Grove Press, 1967.

10. Gert Buelens, Sam Durrant, and Robert Eaglestone, eds. The Future of Trauma Theory: Contemporary Literary and Cultural Criticism. London and New York: Routledge, 2014.

11. Michelle Balaev, ed. Contemporary Approaches in Literary Trauma Theory. New York: Palgrave Macmillan, 2014.

12. Sindiwe Magona. Mother to Mother. Boston: Beacon Press, 1999.

13. Aminatta Forna. The Memory of Love. New York: Atlantic Monthly Press, 2010.

14. Stef Craps. "Beyond Eurocentrism: Trauma Theory in the Global Age." In The Future of Trauma Theory: Contemporary Literary and Cultural Criticism. Edited by Gert Buelens, Samuel Durrant and Robert Eaglestone. New York: Routledge, 2013, pp. 45-61.

15. Michael Rothberg. Multidirectional Memory: Remembering the Holocaust in the Age of Decolonization. Stanford: Stanford University Press, 2009.

16. Mark Mazower. Hitler's Empire: Nazi Rule in Occupied Europe. London: Allen Lane, 2008.

17. Aimé Césaire. Discourse on Colonialism. New York: Monthly Review Press, 2000.

18. Hannah Arendt. The Origins of Totalitarianism. New York: Harcourt Brace, 1951.

19. Philip Roth. Sabbath's Theatre. London: Vintage Books, 2008.

20. Philip Roth. The Plot against America. Boston: Houghton Miffin, 2004.

21. Sonya Andermahr. "Decolonizing Narratives of 1940s Britain in Andrea Levy's Small Island." Paper presented at the Decolonizing Trauma Studies Symposium, The University of Northampton School of The Arts, Northampton, UK, 15 May 2015. 
22. Béatriz Perez-Zapata. "Of Events and Insiduousness: An Analysis of Trauma Theory in the Work of Zadie Smith." Paper presented at the Decolonizing Trauma Studies Symposium, The University of Northampton, School of The Arts, Northampton, UK, 15 May 2015.

23. Zadie Smith. The Embassy of Cambodia. London: Hamish Hamilton, 2013.

24. Andrea Levy. Small Island. New York: Picador, 2005.

25. Jonathan Boyarin. Thinking in Jewish. Chicago: University of Chicago Press, 1996.

26. Gayatri Chakravorty Spivak. Death of a Discipline. New York: Columbia University Press, 2003.

27. "Edward Said/Ari Shavit Interview." Ha'aretz, 18 August 2000. In Power, Politics and Culture: Interviews with Edward W. Said. Edited by Gauri Viswanathan. New York: Pantheon Books, 2001.

28. Edward W. Said. The Question of Palestine. New York: Random House, 1979.

29. Bryan Cheyette. "The Contemporary Novel, Reality Hunger and the Memory Boom." Keynote Lecture at the "Memory Frictions: Conflict-Negotiation-Politics" Conference, The University of Zaragoza, Zaragoza, Spain, 6-8 May 2015.

30. Robin Cohen. Global Diasporas: An Introduction. London: Routledge, 2001.

31. Stef Craps. "The Holocaust and Comparative Genocide in the Poetry of Sherman Alexie." Keynote lecture at the Decolonizing Trauma Studies Symposium, The University of Northampton School of The Arts, Northampton, UK, 15 May 2015.

32. Astrid Erll. Memory in Culture. Basingstoke and New York: Palgrave Macmillan, 2011.

33. Daniel Levy, and Natan Sznaider. The Holocaust and Memory in the Global Age. Philadelphia: Temple University Press, 2006.

34. Alison Landsberg. Prosthetic Memory: The Transformation of American Remembrance in the Age of Mass Culture. New York: Columbia University Press, 2004.

35. Jeffery C. Alexander. "The Social Construction of Moral Universals." European Journal of Social Theory 5 (2002): 5-85.

36. Amanda Anderson. The Powers of Distance: Cosmopolitanism and the Cultivation of Detachment. Princeton: Princeton University Press, 2001.

37. Michael Rothberg. "Trauma Theory: Implicated Subjects and the Question of Israel/Palestine." Profession, 2 May 2014. Available online: https://profession.commons.mla.org/2014/05/02/ trauma-theory-implicated-subjects-and-the-question-of-israelpalestine/ (accessed on 31 July 2015).

38. Michael Rothberg. The Implicated Subject: Beyond Victims and Perpetrators. Stanford: Stanford University Press, 2015 forthcoming.

39. Dominick LaCapra. History in Transit: Experience, Identity, Critical Theory. Ithaca and New York: Cornell University Press, 2004.

40. Jill Bennett. Empathic Vision: Affect, Trauma and Contemporary Art. Stanford: Stanford University Press, 2005.

41. E. Ann Kaplan. Trauma Culture: The Politics of Terror and Loss in Media and Literature. New Brunswick: Rutgers University Press, 2005.

42. Dominick LaCapra. Representing the Holocaust: History, Theory, Trauma. Baltimore and London: Johns Hopkins University Press, 1994. 
43. Richard Crownshaw. "Perpetrator Fictions and Transcultural Memory." Parallax 17 (2011): 75-89.

44. Jennifer Medina. "Warning: The Literary Canon Could Make Students Squirm." The New York Times, 17 May 2014. Available online: http://www.nytimes.com/2014/05/18/us/warningthe-literary-canon-could-make-students-squirm.html?_r=0 (accessed on 31 July 2015).

45. Robert Eaglestone. "Telos and Trauma." Keynote lecture at the "Memory Frictions: Conflict-Negotiation-Politics" Conference, The University of Zaragoza, Zaragoza, Spain, 6-8 May 2015.

46. Joshua Pederson. "Speak Trauma: Towards a Revised Understanding of Literary Trauma Theory." Narrative 22 (2014): 333-53.

47. Cathy Caruth. Trauma: Explorations in Memory. Baltimore and London: John Hopkins University Press, 1995.

48. Cathy Caruth. Unclaimed Experience: Trauma, Narrative and History. Baltimore and London: John Hopkins University Press, 1996.

49. Richard J. McNally. Remembering Trauma. Cambridge and London: Harvard University Press, 2003.

50. Maram Samman. "The Aboriginal Stolen Generations: A Study of (Dis)integration of Identity in Selected Canadian and Australian Plays." Paper presented at the Decolonizing Trauma Studies Symposium, The University of Northampton School of The Arts, Northampton, UK, 15 May 2015.

51. Justine Seran. "'I cannot retract what has been written, it's no longer mine': Stolen Generations Trauma and Collective Memoirs." Paper presented at the Decolonizing Trauma Studies Symposium, The University of Northampton School of The Arts, Northampton, UK, 15 May 2015.

52. Roger Luckhurst. The Trauma Question. Oxford and New York: Routledge, 2008.

53. Anne Rothe. Popular Trauma Culture: Selling the Pain of Others in the Mass Media. New Brunswick: Rutgers University Press, 2011.

54. Michael Rothberg. "Beyond Tancred and Clorinda: Trauma Studies for Implicated Subjects." In The Future of Trauma Theory: Contemporary Literary and Cultural Criticism. Edited by Gert Buelens, Samuel Durrant and Robert Eaglestone. New York: Routledge, 2013, pp. xi-xviii. 

MDPI AG

Klybeckstrasse 64

4057 Basel, Switzerland

Tel. +41616837734

Fax +41613028918

http://www.mdpi.com/

Humanities Editorial Office

E-mail: humanities@mdpi.com

http://www.mdpi.com/journal/humanities 



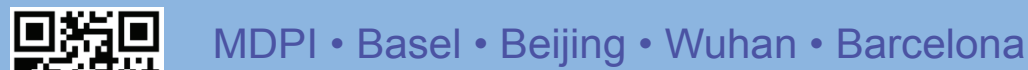
ISBN 978-3-03842-196-2 www.mdpi.com 